\title{
Singing for our supper: Performative advocacy in Canadian art worlds
}

by

\author{
Lowell Gasoi
}

A thesis submitted to the Faculty of Graduate and Postdoctoral Affairs in partial fulfillment of the requirements for the degree of Doctor of Philosophy

in

Communication studies

Carleton University

Ottawa, Ontario

(C) 2020, Lowell Gasoi 


\begin{abstract}
This dissertation examines aspects of artistic production and its relation to cultural policy by focusing on the dynamic performances and dispositions of artists and cultural bureaucrats as they communicate and demonstrate legitimacy through the process of advocacy. I argue for a concept of performative advocacy, a means to consider how, where, and when artists are displaying that legitimacy in relation to governmental agencies, professional and educational organizations, and the larger institution of arts funding and production in some parts of Canada.

Using an institutional ethnographic approach, this study embraces the actions of individual artists and small collectives, particularly those considered in the "emerging" stage of their career, to consider how their actions are coordinated by these institutions and the texts they produce. From students in a suburban theatre training program, to a gathering of artists in Ottawa for Arts Day on the Hill, to program officers at the Canada Council itself, this research reflects on how these artists and arts bureaucrats negotiate their performances as advocates. Performative advocacy helps us to build a better art world through a more grounded understanding of what it is these individuals do as they relate to one another and the larger institution of arts funding supported by the government.

By studying the presence of these actors, we can put cultural policy studies into conversation with our understanding of the work of arts practitioners while enhancing our understanding of the construction of the artistic identity. In this way, I offer a language of theatricality that aids in the understanding of what artists do, on a day-to-day basis, to advocate for their work, allowing policymakers, artists themselves, and the public to better listen and act in the interests of a robust art world.
\end{abstract}




\section{Acknowledgements}

When I made the decision to attend university at 36 years old, my intent was to get my Bachelor's degree and get back to work as quickly as possible. Little did I know that I would absolutely fall in love with the ideas I began to explore, and more importantly, the people with whom I was exploring them. It is to all of them: colleagues, professors, students, and my eversupportive family, that I dedicate this work.

Any dissertation is a collaborative effort, but an ethnography is uniquely indebted to the participants whose working lives are essential to the ideas shared in these pages. And so I thank Zach Fraser, Carolyn Murdoch, the class of 2020, and the entire team at John Abbott College; I thank Guy Rodgers, June Park and the team at ELAN, along with Kate Cornell, Frédéric Julien, and our advocacy team at the Canadian Arts Coalition; and I thank Bryan Croft, Matthew Tiffin, and all those at the Canada Council for the Arts for their time and their honest words.

This is a work that concerns artists, and like an Oscar speech that goes on too long, it would be a fool's errand to try to list all those creators who have made an impression on me. But there are a few that have had a direct impact on this work, and my heart is full, my mind brimming, with their insight. Thank you, Cate, Bridget, Hamal, Farah, Rachael, Lisa, Paul, Jim, and so many more.

I went to Concordia in 2009 to escape from a theatre career that had collapsed around me. I was lost and through my BA and MA at that amazing school, I discovered I was still a theatre maker, and I found new ways to think about it. And so to the amazing Tagny Duff, Matt Soar, Maurice Charland, Ted Little, along with Peter van Wyck, and my MA cohort, particularly the formidable Allison Ferry, my thanks. In research-creation, we never swim alone, and so I offer 
my deepest gratitude to the team that put together our MA show, and especially Luca Paveglio, Aaron George, Alex Goldrich, Paula Jean Hixson, and the force of nature that is Daniel MacIvor. Carleton is a special place, a school that supported me, a department that embraced me. My thanks to everyone, especially Chris Russill, Michael Dorland, Sheryl Hamilton, and to a dream committee: Mary Francoli, Sarah Smith, and the touchstone at the centre of all that I have accomplished in these five years, the incredible Ira Wagman. With their help, I got more help, and so I thank FRQSC, SSHRC, and the Vanier Scholarships.

All doctoral students know that research at this level is hard, and it can be all consuming. A diagnosis of cancer in the midst of preparing this dissertation certainly impacted my work on this project. I could never have imagined getting through this without a wonderful team of doctors, and of course, my family. To my monkeys Eric and Ryan, with love and gratitude. And to my main monkey, Jennifer, thank you for your undying love, support, and generosity. 


\section{Table of contents}

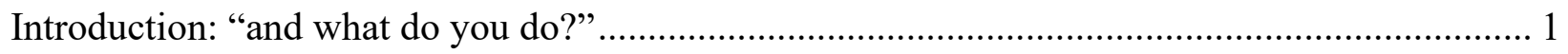

Disposition, presence, performance, and legitimation ......................................................... 2

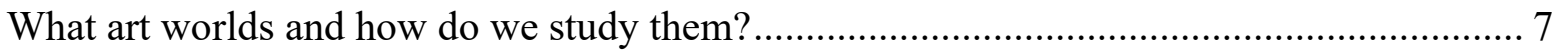

Rethinking the spaces between identity, policy, and production ......................................... 14

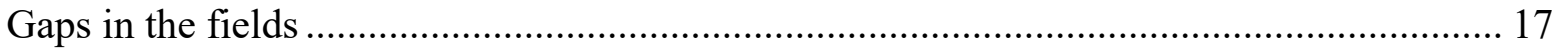

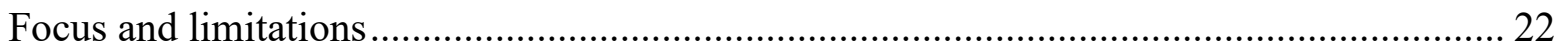

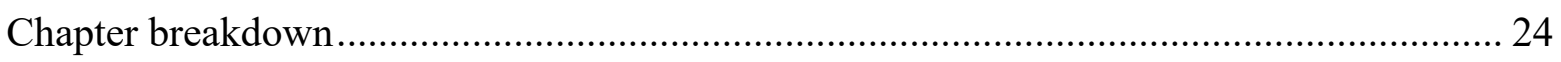

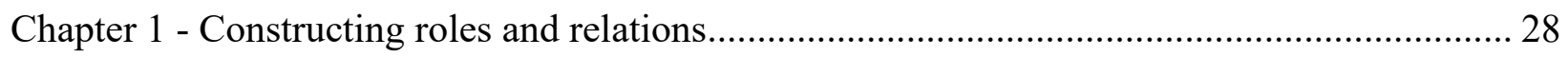

The artist as genius and the Romantic ideal ....................................................................... 30

The artist at work in the "Ministry of Symbols" .................................................................. 35

Disciplining the artist through the lens of governmentality ................................................... 39

Field trips to the museum: policy attachment in the work of art.......................................... 43

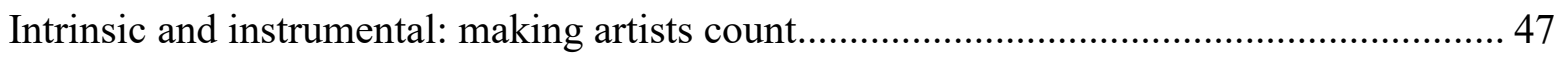

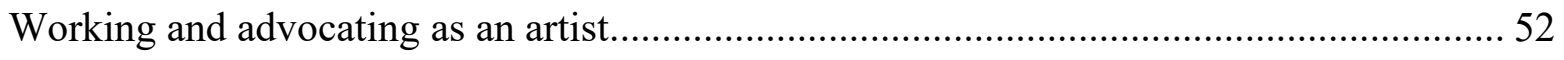

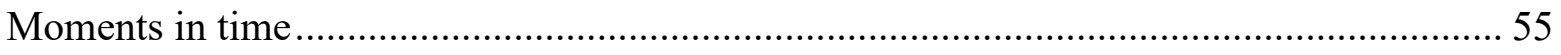

Chapter 2 - The framework of performative advocacy ............................................................ 58

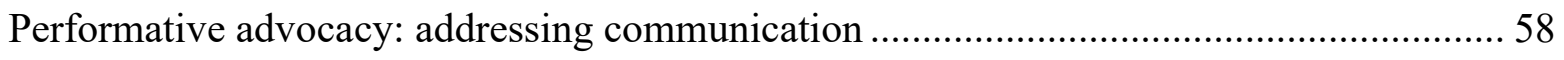

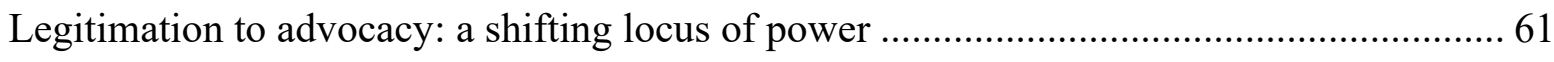

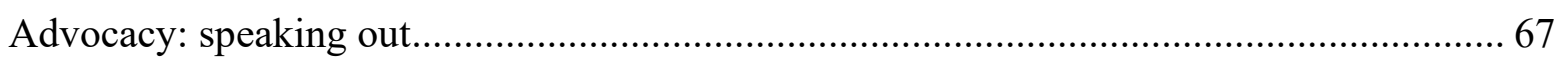

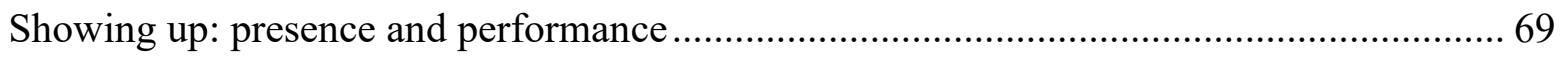

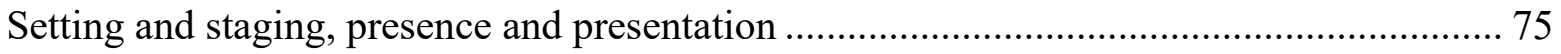

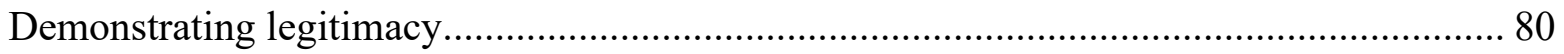

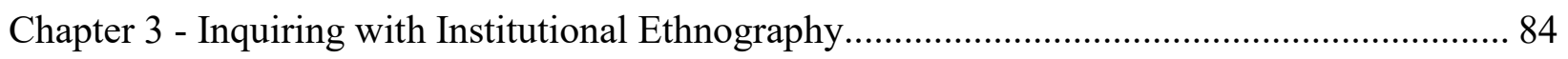

Aligning institutional ethnography and performative advocacy ………………………...... 84

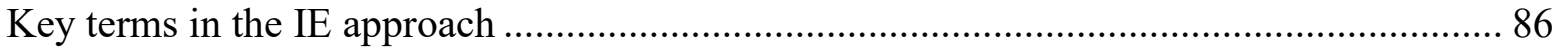

IE and art worlds in Canada ………….............................................................................. 95

People, places, and things: gathering IE data ……………................................................. 99

The artist and the advocate, the individual and the organization ....................................... 103

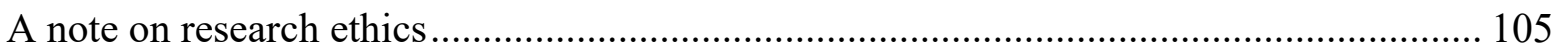


Chapter 4 - Wheres and whens: introducing the research sites 107

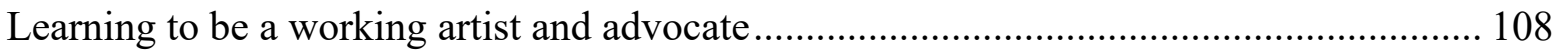

Professional management in the CEGEP ...................................................................... 113

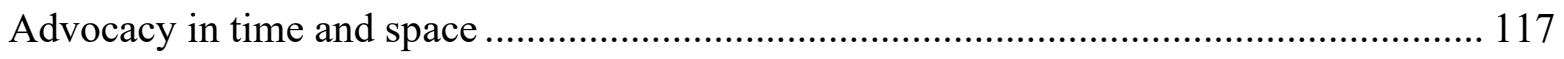

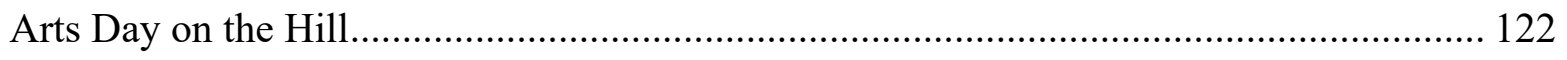

The support system: the Canada Council for the Arts ................................................ 125

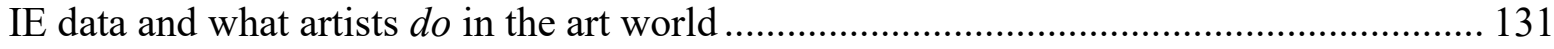

Chapter 5 - Invitation to the disposition of advocacy ........................................................ 134

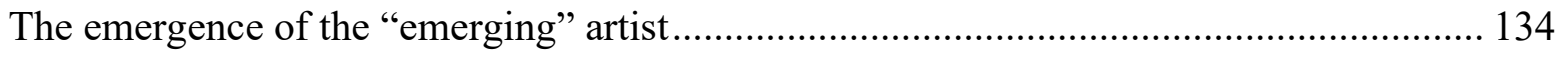

Scaling advocacy in established and emerging organizations ..................................... 135

“Does anyone have a pencil?": teaching professional management .............................. 139

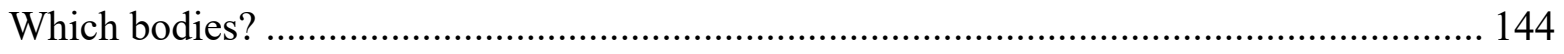

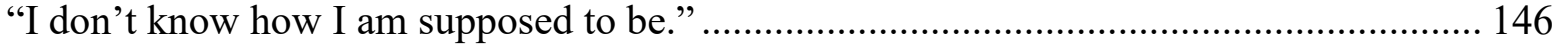

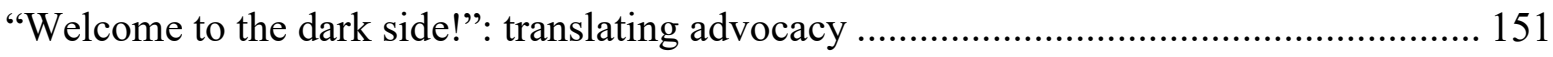

"Make the program officer your friend": workshopping advocacy ................................ 161

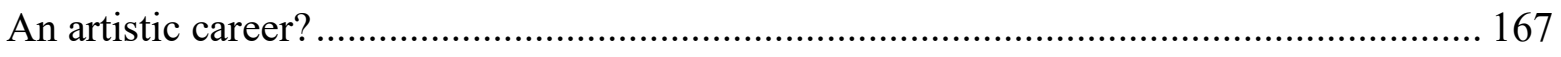

Chapter 6 - Performance, Place, and Presence ................................................................. 172

Gathering bodies in spaces of power ................................................................... 172

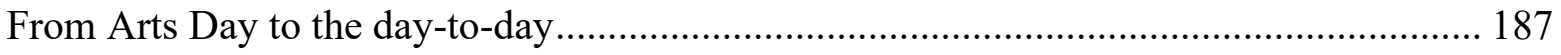

“It's a nice bubble, but it's a bubble": location and presence ........................................ 189

"The outreach piece": Reconfiguring and reconnecting at the Canada Council ................ 196

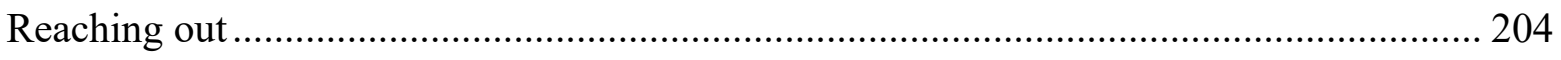

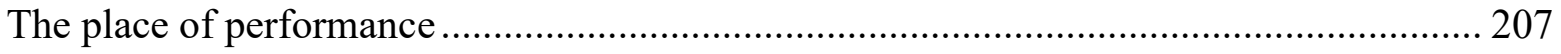

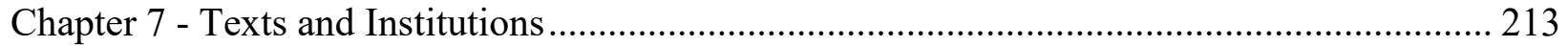

"And the artists show up": activating the script ...................................................... 215

"It has to look like you": CVs, headshots, codes and templates .................................... 220

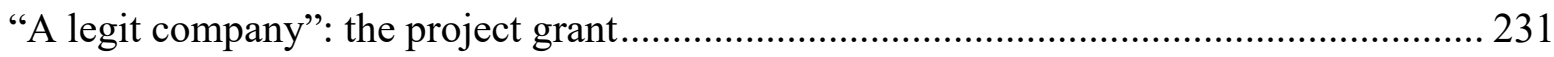

"I read the applications": validating the artist at the Canada Council .............................. 238

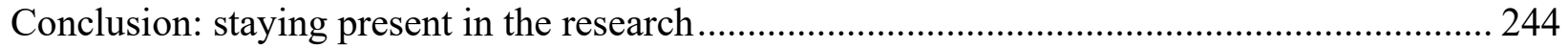

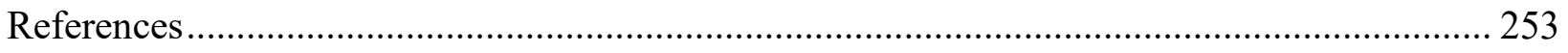




\section{Introduction: "and what do you do?"}

Most polite introductions among new members of my social circle have proceeded roughly along these lines:

"Hello, Lowell, my name is John. Nice to meet you. And what do you do?"

"Hi, John. Yes, well, I am an artist."

This dissertation explores how my response is not an answer to John's question. As someone who has spent the majority of my working life making theatre, I have also spent countless hours in advocacy efforts. I have worked at building up the funding, the relationships, and the legitimacy that enables the making of artworks. This work differs from core artistic activity, the creation and execution of artistic objects and performances. How can we begin to theorize that difference and build a deeper knowledge of how artistic work happens?

This dissertation examines the introduction of performative and communicative actions that characterize certain aspects of the art world (Becker, 1982). I will look at emerging performing artists as they begin to negotiate the advocacy relationships that are a vital part of the work of artmaking and constructing an artistic career. I understand advocacy as representing acts that demonstrate professional legitimacy. These typically occur when artists encounter different support systems that play a key role in the production of their creative work. To illustrate, I focus my dissertation on certain relations with political representatives, educational structures, and fellow artists, along with Canada's national arts council.

Legitimation occurs on various levels and with a wide array of institutions and structures. Arts funding as a legitimating institution exists on national, provincial, and municipal levels. Legitimation processes also encompass private sector donors, professional organizations and unions, training institutions (which are also touched on here), as well as the art market itself. It is 
through an engagement with these structures that artists demonstrate the legitimacy of their work and that of their colleagues. I further acknowledge the importance of the processes of legitimation undertaken by the nation itself, and the institution of arts funding, in demonstrating the value of art work.

How does advocacy shape the dispositions of both these artists and those with whom they form advocacy relationships, such as arts bureaucrats, politicians, and policymakers? This question opens lines of inquiry around concepts such as disposition, performance, and presence. How are art world members negotiating their performances and their presence as advocates? How are they invited into the process of advocacy, with its own special language, taking place in its own spaces and times? How do artists and arts bureaucrats engage with the texts emerging from these institutions of legitimation? These questions are vital to building a better understanding of the art world. They offer artists, policymakers, academics, and the public more grounded and practical knowledge of what these individuals do and how their activities are coordinated by the institutions of legitimation. This research explores these questions of communication and does not promote certain policy positions. It helps members of the art world become more aware of how they engage with one another.

\section{Disposition, presence, performance, and legitimation}

This research argues for new avenues to think about some familiar concepts in the study of artistic production. It bridges gaps in our understanding of cultural policy, cultural labour, and the sociology of the arts. The concepts of performance and presence inform the study of advocacy actions and the dispositions of art world members as they demonstrate legitimacy.

Artists in the early stages of their practice and cultural policy bureaucrats working in places like the Canada Council for the Arts embody certain dispositions. These behaviours are 
expected of them in order to demonstrate their legitimacy as they gather and distribute the resources and funding to make artworks and build sustainable careers. Disposition is a concept most associated with Pierre Bourdieu and the idea of habitus (Bourdieu, 1992). Habitus is the set of embodied behaviours and performances that are developed in relation to class, education, and social position (Bourdieu, 1984). Artists, like the authors Mallarmé and Zola that concern Bourdieu in Distinction, can exhibit a high art disposition. This marks their artworks as legitimate and noble both for them as artists and for those audiences that demonstrate an appreciation of the works (Bourdieu, 1984, p. 20).

French sociologist Bernard Lahire points out a problem with habitus. He argues that Bourdieu offers very little analysis of how we are to recognize and apply the idea (Lahire, 2003, pp. 333-334). I focus less on habitus as a socially constructed identity understood through class position and educational systems and more on Lahire's argument that the idea is useful on the level of the individual and their actions. As Lahire states, disposition is best analyzed through "empirical research" that "should test such rhetorical concepts in order to give them the status of useful scientific concepts" (2003, p. 333). A focus on the actions of individuals as they relate to institutions helps us to see how dispositions are "actualized" (2003, p. 338). My cases examine artists as well as arts bureaucrats and political staff as they relate to the present situation, demonstrating their behaviours in relation to legitimating structures.

I take a more immediate perspective on studying these dispositions, pushing beyond the development of aesthetic traditions and taste in the understanding of artistic identity. Immediacy here is about being in the room, in the moment. Locality and temporality imply a concept of presence. I employ presence in its most theatrical sense: the idea of "being there" when the performer is actively engaged in the moment, attentive to the situation and their fellow actors and 
taking up their own space within the relationship and the scene. Presence speaks to a sense of openness and improvisation, being available to seize opportunities for new relationships and communication to develop in a moment of encounter.

As geographer and cultural scholar Alison Bain writes, presence in the art world is often thought of in terms of the artists' identity. It is the impact of their reputation as associated with their work circulating in places like galleries and museums. It is also evident in their relations with funding agencies and professional organizations (2004, p. 421). I see presence as a means to examine the live and mediated encounters among artists and these legitimating structures as they occur in specific moments like advocacy events, grant applications, workshops, and art school classes that teach artists how to perform their professional work. I look beyond artistic identity and the fuzzy notion of inculcation into long-standing traditions to build an experiential, immediate understanding of how artists are performing and demonstrating their legitimacy.

Maintaining the theatrical metaphor, performance is a set of actions or tactics used to reach the goal of legitimation. These include the deployment of language and gesture, interactions with individuals and technologies, and movement through certain spaces and moments: workshops, classes, gatherings, and protests. Relying on the dramaturgical framework of Burke and Goffman $(1969 ; 1959)$, performance is located and immediate. Performing artists understand this idea as central to their artistic work and yet it is also vital to their professional presentation and demonstration of legitimacy in relation to government structures and institutions. It is also central to the work of government structures that support the arts for various instrumental purposes. 
Performance is connected to the idea of performativity, a means to investigate the discursive constraints that coordinate the activities of individuals like artists and the ability of these individuals to speak back to and resist those constraints.

Legitimation is being performed and demonstrated in these present moments and encounters. This is the complex process where creative practices, traditions, and artistic value move from the margins of public attention and government interest into the mainstream. Legitimation is performed by artists, by advocates, and by institutions and professional organizations. It occurs across specific times and spaces, shaping the contours of what is discursively permitted. It helps to define what is "in" and what is "out" in terms of public interest and government priority.

We see this process of legitimation in the advent of "peak television". In their book Legitimating Television, Michael Newman and Elana Levine discuss legitimation as an exercise heavily inspired by Bourdieusian notions of taste distinction, class, and education. Using the current golden age of TV as their case study, Newman and Levine argue legitimation occurs through a linking of art objects (TV shows) to already established paradigms of high art, such as literature and film (2011, pp. 4-5). Art is made acceptable by appealing to a socially constructed and "inscribed" (2011, p. 6) set of aesthetic principles. A television program like The Sopranos shares aesthetic and narrative forms long classified as legitimate in the film world and thus gains its own legitimacy by association with that tradition.

In the performing art world that is of primary concern to this dissertation, legitimation can be seen through the acceptance or rejection of certain disciplines and artistic traditions within art schools and funding priorities at arts councils. A contentious example is presently being negotiated after recent changes in the funding model at the Canada Council for the Arts that were 
implemented in 2015. Some artists and advocates are questioning the relevance of what is often termed socially engaged, or community-engaged arts practices ${ }^{1}$. This tradition refers to artworks (plays, cabarets, parades are good examples) that are not designed primarily to gather a paying audience, but rather to reflect and narrate particular social issues within a community. For instance, Jumblies Theatre creates plays by and for marginalized, racialized, and economically disadvantaged people in and around Scarborough, Ontario. They have been working hard to legitimate their practice and build resources and funding while the Canada Council has removed all explicit mention of socially engaged artworks from their policy framework, documents, and website. The issue is whether such practices and the artists that work in this area can maintain their legitimacy and the government support that makes their work sustainable and valued, despite the long-standing history of such work in Canada.

These four key concepts: legitimation, presence, performance, and disposition, work together to build an understanding of communication in the art world. Understanding this relationship is vital since much of the performing arts made in this country, and especially artwork coming from smaller and emerging artists and collectives, is made with the support of public funds disbursed through arts councils.

While there does not appear to be specific statistics that account for the percentage of public performances by performing artists that are funded by government monies (a gap that should be addressed), we can infer the importance of public money from economics research. According to data from Canadian arts research organization Hill Strategies in a 2007 survey of 216 performing arts organizations, revenue from various levels of government accounted for

\footnotetext{
${ }^{1}$ For a good overview of these concerns, refer to the work of the International Centre of Art for Social Change ("International Centre of Art for Social Change", n.d.)
} 
more than one-quarter (27\%) of total annual revenue ("Finances of Performing Arts Organizations", 2007). Indicating the importance of a focus on smaller organizations, the report further states that, "[g]overnment revenues are a smaller portion of the total revenues of larger organizations than smaller organizations $(25 \%$ of revenues for the largest organizations compared with $43 \%$ for the smallest organizations)" ("Finances of Performing Arts Organizations", 2007). Across disciplines, theatre tends toward the lowest levels of government support (19\%), while music and dance companies were highest with $31 \%$ of total revenue from the public purse ("Finances of Performing Arts Organizations", 2007). These numbers, while now nearly 15 years old, still suggest that public funds are vital to the creation of artworks here in Canada.

We must examine what artists are doing, alongside their artistic activity, to relate to these structures of support, to advocate for themselves and their colleagues in the art world, and to build sustainable artistic careers. This research does not advocate for more or less money in the art world, nor does it question whether one is an artist or not. It seeks to ensure that all members of these art worlds can have an impact through robust communication and persuasive argument. We must strive to move beyond questions of what an artist is and toward a more subtle and substantive examination of what they do. How do the art world members that I have studied here pursue their professional activities and negotiate their performances between core creative work and advocacy?

\section{What art worlds and how do we study them?}

Sociologist Howard Becker defines the art world as a realm of collective activity where people are doing things to make artworks. The concept seeks "an understanding of the complexity of the cooperative networks through which art happens" (1982, p. 1). Becker helps us 
to understand that art work requires not just the vision, inspiration, and effort of the artist, but a host of "support personnel" (1982, p. 4) that surround them and enable artistic production, distribution, and consumption. This world includes artists, technical personnel, administrators, and managers. It also includes government agencies, schools, and professional organizations that fund, educate, and ultimately legitimate the work of art. Becker reminds us that art worlds are constructed through discourse and convention, allowing for some practices to become legitimate while others remain on the fringes or disallowed entirely (1982). The ethnographic aspects of Becker's work are instructive in maintaining the importance of human activity, alongside political economic considerations, in the formation and function of these worlds.

My research embraces this key focus on human activity and its presence in time and space. One cannot truly study the whole of the art world, it is a concept that must be localized. Ethnographer and cultural sociologist Sarah Thornton's Seven Days in the Art World (2012) situates the art world as a series of spaces and moments: the art school classroom, the gallery, the art auction, the studio, giving both a temporal and spatial focus to this world of production, distribution, and consumption. My study deals with pockets of the art world in Canada at this particular time (2018 - 2020), touching on some of the same discourses as Thornton: the education of artists, the production of art and its legitimation, the relationships with governmental bodies in the building of an artistic career that allows for a sustainable practice.

Data from Statistics Canada's Cultural Satellite Account $(\mathrm{CSA})^{2}$ can provide a global view and context for the cultural sector and its economic impact in this country. The CSA defines culture broadly (and includes sport as well) as "the images, sounds and stories that we

\footnotetext{
${ }^{2}$ According to McCaughey et al., the Cultural Satellite Account (CSA) was developed in 2012 to track the economic impact of the cultural sector, including data from provincial and territorial governments. The CSA mirrors similar frameworks in countries like Finland and Spain (2014).
} 
see, hear and read every day" (Government of Canada, 2019). Numbers from 2017, the latest available on the CSA website, state that culture is $2.7 \%$ of Canada's gross domestic product (GDP), representing “\$59.7 billion, supporting 784,500 jobs” (Government of Canada, 2019). Regionally, the most populous provinces, Ontario, Quebec, and British Columbia, have much larger cultural sectors by GDP than Saskatchewan or PEI. The significance of cultural production to the country's economic output is larger than that of agriculture, thought to be one of Canada's driving economic indicators.

To focus on the people and organizations that are of interest to this research, I turn to the breakdown of the various sectors of cultural production the CSA counts. Far and away the largest contributor to GDP and jobs in Canada is the audio-visual and interactive sector, defined as "activities related to video game publishing, film, television and video production, as well as motion picture exhibition" (Government of Canada, 2019). This sector, which is often referred to as the cultural industries, is separated from traditional artistic production areas like visual art, literary art, and live performance. The relative GDP and job impacts are represented in this graph from Statistics Canada.

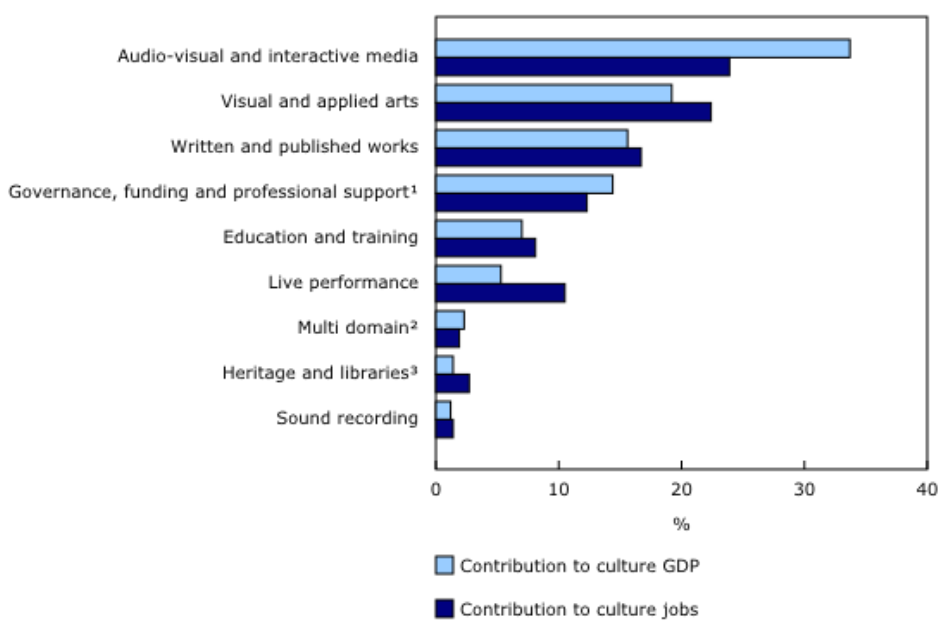

Table 1 - Categories of cultural activity according to the CSA (Government of Canada, 2019) 
While these numbers are important to political economic analysis, it is the border between these cultural industries and the traditionally defined art world that is key to my focus. More and more attention in scholarship is given to the cultural industries sector, likely driven by their growing economic importance. This can crowd out meaningful discussion of arts policies and their impact on the working artist. It can be forgotten that the very performers that appear on screen are often trained, experienced, and continue to work on smaller stages and studios across the country.

By combining these sectors into a poorly delineated realm of cultural production cultural policy and cultural labour studies can fall prey to what scholars Sarah Baker and David Hesmondhalgh have decried as a failure to "engage with the complexity of actual networks of cultural production" (2008, p. 100). For instance, the field may be interested in the number of actors working in film and television production but it will miss the intersection of those performers with live theatre, dance, and operatic production, practices that feed into the pool of workers who take on these evolving jobs. Performers very often move back and forth between "industry" work and live theatrical work, and the kinds of advocacy they engage in is entirely different, as is the control they have over their own creative pursuits simply due to the scale of these varying production processes. In another example, research may examine the efforts of musicians who are committed to their craft while shifting their practices to respond to the digital media landscape and yet miss the relationship between these artists and multimedia and video designers who help to enhance, package, and distribute these works through evolving digital networks, along with the shifting skillset required of these individuals as they negotiate these new media for their work. 
Rapid technological advances since the late 1970s and on into today's streaming wars and digital media landscape have an impact on these discussions. In Canada, this focus also comes from a perspective on cultural production that aligns with technological and infrastructural arguments made so forcefully by communications scholar Maurice Charland in his well-read treatise "Technological Nationalism" (1986). This tends to direct scholarship toward the symbols and messages that run through these technologically mediated channels, along with considerations of the channels themselves, and away from art objects that engage more immediately and co-presently with audiences like theatre and dance (1986, pp. 215-216).

As Ira Wagman observed in his call for more reflexivity in communication studies there are constructions of artistic careers amid these infrastructure focused policy processes in Canada to which we pay little heed (2010, p. 626). My research seeks to re-engage with these artists, and with early career artists $^{3}$ especially, to illuminate their efforts to introduce and maintain legitimacy even as this shift toward cultural industry discourses challenges the attention they are paid by governments and the academy. A focus on early career artists allows us to examine these dispositions as they are being formed and focuses on the individuals that most often negotiate the artistic disposition and that of the advocate.

With my experience and knowledge of the theatre community, I admit to a strong bias toward theatre artists and administrators in that discipline. The theories and methods I advance are applicable to performing artists in dance, circus, and music, along with visual and literary artists. The crossover between certain aspects of artistic production in live and recorded or

\footnotetext{
${ }^{3}$ An early career artist as defined by the Canada Council is one who is seeking their first grant and has not received support in the past. While this is a helpful definition, I suggest a wider understanding of these artists as those who are working to attain a stable and sustainable artistic practice, and those who are newly emerging from training institutions and building their relationship with the arts funding institution on the national, provincial, and municipal levels.
} 
broadcast media is relevant and I argue that much of the evidence gathered from the participants in this research can be useful in the study of community television, art films, and other smaller scale media producers. Keeping my focus on arts policy allows for a clearer picture of this pocket of the art world. We can then expand these theories to encompass other aspects of cultural production and wider areas of public and cultural policy like taxation, copyright, and broadcast regulation.

Following on from the reflection argued for by Wagman, it is the self-reflexivity made possible by my own experiences as a working artist and my integration in certain sectors of the art world that brings a unique perspective to this research. As a performer and director, I see the actions of my fellow artists in light of performance. As an arts administrator and advocate, I am concerned with policy and its implications as I continue to relate to government and its arts support apparatus. This dissertation is therefore as much an autoethnography as an ethnography of the art world, particularly as it is connected to the methodological approach of institutional ethnography (Smith 2005, p. 6; Taber 2010, p. 13). To acknowledge my standpoint, and to use my own experiences to both inform my research and to demonstrate connections and links between experiences and theory, autoethnographic details are an integral part of illuminating the practices and the questions I am exploring here. My scholarly foundation in communication studies, with its strong links to sociology and performative understandings of discourse, language, and social relations, informs this research and my relations with my participants.

This rich intersection of experiences implies a theoretical and methodological commitment to embrace actions and behaviours, suggesting an ethnographic approach. Canadian sociologist Dorothy Smith's institutional ethnography, or IE (2005), with its ties to the dramatism of Kenneth Burke (1969) and presentational concepts of Erving Goffman (1959) and 
its close attention to the enactment and embodiment of texts, employs a language and a standpoint that maintains this focus on the experiences of individuals. It is the approach that best embraces that self-reflexivity and immediacy of presence that I feel is crucial to a better understanding of art world relations. In line with the argument made by cultural sociologist Kevin Walby, I closely align my theoretical investment in performance and presence with this methodological approach, allowing for a focused "attention to the aspects of the real that we deem worthy" (2007, p. 1023).

The technical aspects of data gathering in an IE study like this one align with ethnographic approaches from disciplines like anthropology and sociology. My study involved observations and the recording of fieldnotes at the various sites which are elaborated in chapter 4. These observations would be followed up with what Smith calls "text work" (1990, p. 216), examining the texts that impact on the work being observed and providing a framework with which to approach questions that can then be asked of subjects in an interview situation. This process of weaving observations, text work, and interviews resulted in a rich pool of data. Interviews were recorded with a smartphone (unless participants chose not to be recorded, as in the case of two members of the staff at the Canada Council) and were transcribed verbatim by me. Two interviews with another participant were conducted over Skype and recorded and transcribed by me. A total of 16 interviews took place over the course of the research, totaling approximately 20 hours of recordings. The observational research amounted to approximately 45 hours spent at the various sites over the course of five months from September 2019 to January 2020.

Reflecting on these experiences, I consider the research to be the kind of "deep hanging out" practiced by Clifford Geertz (1998). In my case, the hanging out was more in line with the 
approach of Ben Walmsley in his discussion of anthropological approaches to discovering artistic value (2013, p. 277). While I discovered slightly different questions related not so much to artistic value as to the representation and demonstration of legitimacy through advocacy, the phenomenological and qualitative approach was appropriate and productive in providing this rich data that not only informed the questions and theorizations, but also centred the experiences of these human beings as they related to the institutions of artistic support and production. As with Walmsley's approach, I sought out thematic and narrative associations in the data rather than strictly coding keywords. While my initial theoretical framework did inform my approach, it was from this thematic investigation that I discovered the particular focus on presence and locality that grounded and differentiated my research from similar work in the field.

\section{Rethinking the spaces between identity, policy, and production}

Like many artists who also work as administrators, arts bureaucrats, marketers, ticket sellers, even teachers, and academics, I have long struggled with questions of self-identification. This dissertation engages in a critique of the idea of identity as a framework for understanding artistic production and those who work to make art. To understand the making of art, I argue for a need to move beyond questions of who is and who is not an artist. We must critically examine the individual not as an isolated, Romantic genius figure but as an active agent in the network of institutions, texts, and technologies that legitimate and facilitate (or not) their work.

A focus on individual experiences is key to understanding the working lives and performances of artists. It is useful to have some sense of the statistics that define those workers. According to 2016 data from Hill Strategies, artists (defined as those whose work is primarily core creative activity) represent 158,000 jobs or more than $1 \%$ of the Canadian labour force (Hill, 2019). When Hill's research expands the definition to "cultural worker", adding in what 
Becker would term "support personnel” (1982) and Negus calls "cultural intermediaries” (2002), the sector jumps to 726,000 workers at $4 \%$ of the total workforce. Demographically, individuals in the age range of 25 - 34 years represent the largest percentage of both artists and cultural workers, indicating a worthy focus on early career artists (Hill, 2019).

Data from the Canada Council for the Arts also suggests the importance of early career artists. Their Explore and Create program, which is the instrument most likely to support the work of emerging artists, is the largest program at $\$ 68$ million, and almost half the individual artists supported by the program are first-time recipients of funding (707 out of 1,549 individual grants according to the 2018-2019 grant year) ("2018-19 Explore and Create Funding Overview", n.d.). The activity pursued by the individuals that mediate between artists and the state, the program officers that are often artists themselves, is absent from much of the literature despite the importance of these funding processes. For that reason, I focus some much-needed attention on program officers and their dispositions in this research.

The problem is that we have a field of research in artistic production and we have a field of policy studies that explores the regulations, texts, and institutions under which artists labour, but we have paid scant attention to the intersection of these inquiries. We need a more robust understanding of the communicative work involved in building the conditions and relationships that help art to be made. In this way, we open up new avenues and languages to understand the work of art and the work of artists. We can critique notions of artistic identification, refocusing on what artists do and where they do it in interaction with legitimating structures.

The individuals and structures that exist alongside these artists that work to legitimate their work are sometimes referred to as cultural intermediaries and there is literature that identifies and examines their role in the art world (Hracs, 2015; Maguire \& Matthews, 2012; 
Negus, 2002). This dissertation suggests that there is another way to think about this intermediating work. That is to suggest, particularly in the case of artists at the early stages of their careers, that support personnel and those advocating for artists are very often the artists themselves. Maguire and Matthews write that the intermediary has become "a descriptive catchall for seemingly any creative or cultural occupation or institution" (2012, p. 1). What I offer in this dissertation is what these scholars call for: "greater empirical attention to the stratification and differentiation of cultural intermediaries with regard to their devices, dispositions, locations within regimes of mediation, and impacts" $(2012$, p. 2). It is the active negotiation of these varied dispositions, their shifting performance, that will help us to understand these art worlds more completely.

These individuals take on roles that place them in a constant state of performative flux. They are working not just to make art but to build an environment where art work is possible and sustainable. Performative advocacy is a concept that foregrounds these artists' demonstrations of legitimacy in time and space, mediated by texts and technologies in relation to the institutional structures that enable their work. It allows us to understand the fluid negotiation of professional rhythms and activities as individuals communicate the value of their work. This advocacy also speaks to the relationship artists and these institutions build together as they co-create and develop policies and work together to communicate and evaluate the impact of these policies on the art world.

In cultural policy discourses, it is these "big moments" that tend to be used to illustrate how artists and government relate. We encounter a focus on policy documents, institutions, and processes relating to large-scale transformations and milestones in cultural policy (such as Royal Commissions like the Massey Commission, or UK "new public management" practices, or even 
national, cultural events like Canada150). Performative advocacy helps to fill in the more quotidian practices that art world members engage with every day.

Cultural labour studies offer some sense of how artistic work is negotiated but does not speak of the importance of demonstrating legitimacy as an advocate. Instead, the focus is on emancipatory projects that seek to empower artists in a struggle against exploitation. Along with the battle for artistic freedom, which I define as efforts to build an environment for artistic creation that is free of censorship and unencumbered by capital and overriding concerns around marketability, must come the daily work to maintain the relevance of art. The value of art and artists must be communicated not just among artists and their audiences but to the structures of government that facilitate the work.

\section{Gaps in the fields}

Scholarship in the fields of cultural policy, sociology of the arts, and cultural labour, does an excellent job of paying attention to the practices of members of the art world. It helps to explain how these art world members relate to the aesthetic production, dissemination, and consumption of art objects in social, political economic, and art historical contexts. The work of Howard Becker (1982), Janet Wolff (1993), Richard Peterson (2007), and Pierre Bourdieu (1983, 1984) are most often cited in this "production of culture" perspective (Peterson \& Anand, 2004).

More recently, scholars like Georgina Born (2010), Alison Gerber (2017), and Eduardo de la Fuente (2007) have offered useful formulations of artistic production studies. An artist and anthropologist, Born comes from that disciplinary perspective. Despite her problematic suggestion that we "broaden conceptually by shifting the terms from 'art' to 'cultural production"” (2010, p. 172), she suggests that the sociology of art has lost its link to the aesthetic and to the temporality of conventions that inform the making of artworks (2010). Gerber's work 
claims to be "interested primarily in practices, not products, and in a plurality of artists who define goals and success in divergent ways" (2017, p. 13). However, she remains decidedly focused on how the value of art is produced while paying little attention to advocacy. Attention must also be paid to the building of resources and relationships that allow for sustainable art worlds, populated by a variety of artists and supported, quite often, by government funding and policy. As de la Fuente argues in Art From Start to Finish, "[t]he 'grubby', mundane details of artistic production are important" (2007, p. 421). One of those details is the advocacy process that leads not directly to the art object but rather to the environment where artistic work and careers are viable and sustainable.

Cultural policy studies is the subfield that attempts to theorize these processes in light of Foucauldian governmentality discourses. It is epitomized in the Australian tradition represented by the scholarship of Tony Bennett (2002). Canadian scholars including Michael Dorland (1998; 2000), Zoë Druick (2007a), and Ira Wagman (2007), along with others in Europe, mostly in the UK, like Clive Gray (2002; 2007), Justin Lewis and Toby Miller (2002), and Jim McGuigan (2004) each offer perspectives on what can be a totalizing and abstract theory of the regulation of the artist through discourse. Governmentality suggests no means to "get outside" the text.

As Jonathan Sterne writes, "[t]he focus on logics of power in Foucault's work limits its applicability in terms of accounting for one's own implication as an agent (or as part of an agent) in fields of power relations" (2002, p. 64). In other words, it is all well and good to know one is subject to the administrative bureaucracy of government institutions. What one can do with that knowledge is not a strong feature of governmentality conceptualization. It leaves aside the agency of individuals and collectives, like artists and their advocacy organizations, in their 
relationship with a nebulous concept of the state. This is precisely the actions that more ethnographic and performance-based research can address.

In terms of how we understand the work of the artist, scholars like Mark Banks (2007), Nicole Cohen (2015), David Throsby (1999), and Greig de Peuter (2014b), find their perspective in Marxist critiques of cultural labour. For these critical voices, the articulation of the artist with neoliberal shifts in creative work tend to highlight the exploitation of the artist and the precarity of their working conditions in what has become known as the "gig economy". Banks, Gill, and Taylor discuss the relatively recent scholarly interest in cultural workers. They point out the immaterial nature of this work and the difficulties in theorizing an industry that does not build widgets but rather builds the symbolic reality of our social and political lives (2013, p. 3). Scholarship on the creative economy often focuses on this transition from the traditional production discourses of Fordism to the new world of digital products, and in particular the attendant exploitation of workers. Taylor and Littleton argue the studies in this area approach production from "narrative and critical discursive psychology", whereas what is called for is a "fine-grained analysis", embracing on-the-ground observation and interviews (2008, p. 276).

Taylor and Littleton suggest that exploitation narrative is often linked to the creative identity (2008, p. 277). Despite the rhetoric that would present this work, and the people that get to do it, as cool and innovative, there is a growing body of evidence that shows it to be an “oppressively standardized, 'computerized', and a homogenized labour process" (Mark Banks et al., 2013, p. 3). Nicole Cohen describes the exploitation of cultural workers as a site of struggle where workers like freelance writers must organize to resist falling prey to capitalist processes that devalue their creative efforts in the name of the fantasy of self-directed and cool, creative work (2015). 
Such a framework is vital to the political project for artists to live a sustainable and economically viable life. However, it can fail to specifically address the processes of advocacy and the agency of certain artists, especially early-career performing artists, whose relationships tend to focus directly on government sponsored arts councils and funders. Critiques that come from a Marxist perspective may suggest a role for government in creating and enforcing policies that protect artists from exploitation, but they fail to address the immediate relationship between artists and those government structures in the performance of advocacy. They do not pay sufficient attention to the demonstrations of legitimacy that attempt to build sustained funding and acceptance into the discourses of government priority. What my research with certain artists has demonstrated is that they are not looking for a comfortable and less precarious role within a larger artistic organization. Nor do they want others to fight for their rights. Rather they seek a substantive role in building up their own ability to fulfill a creative vision and establish a career. They seek control over their own place in these art worlds and a recognition that it is the government itself that will fund much of their art work. That is the relationship that should be well understood and enhanced through better communication.

In all these debates, there is a failure to centralize the artists' performance, along with that of the government and its agents, institutions, and structures. The arts funding apparatus in Canada is complex. It works on various levels both inside and outside government support. The Canadian constitution does not define the jurisdiction of arts policy. We see a constant tension where the federal government sees the symbols of national identity created by artists to be in its mandate, whereas the provinces and territories make claims about art's inherent educational value to take it under their own policy portfolio. 
Even within federal funding structures, there are overlaps between arts funding programs administered by the Department of Canadian Heritage (DCH) and those under the Canada Council for the Arts. DCH generally supports art that celebrates and commemorates local community and national events through events, public monuments, and built heritage. The Council is mandated to support work based primarily on artistic merit. Even more complex is the increasing involvement of municipal arts councils that have emerged from historical constructions of city responsibility for "recreation" and have conflated that to amount to a "municipal role in culture" alongside "the municipal role in recreation" (Dick et al., 2019, p. 2). Funding may also come from the private sector including corporations, foundations, and individual donors or patrons, along with earned revenue from the box office and artists' fees. The focus of my research remains on certain interactions with government sponsored funding agencies and political representatives. This complexity acknowledges that the funding environment requires a variety of dispositions and performances geared toward a wide array of values and goals for funders and the artists themselves. In short, communicating to funders as an advocate, as a means to establish legitimacy and build a career, means speaking a variety of languages in a dizzying array of situations and relationships.

A communication studies perspective, informed by a performance framework and an acknowledgement of the vital importance of language and texts, will bridge a gap in our understanding by directly exploring the performance of advocacy. Scholarship that focuses on the artist and their working conditions can often be relegated to advocacy-first research that seeks to gather new and better resources for the arts sector. My study seeks to offer a critical understanding of the relationship itself, giving all parties the knowledge to make relevant policy decisions expressed through persuasive arguments. 


\section{Focus and limitations}

Advocacy in Canadian art worlds is the subject of this dissertation and I use the plural to highlight both the multi-faceted nature of artists and their work and the diversity of practices and relations within the cultural production sector. The broad strokes of this sector suggest the huge impact cultural work has on our economy and the policy environment. A tighter focus on artistic production activities in specific parts of the art world, particularly emerging artists as they are introduced into the performances of advocacy, can provide clarity that informs the study of many pockets of artistic work.

The term cultural production, a catch-all that can include anything from a local community dance recital to the production of a massive Hollywood film, lacks a specificity that is important to the close observation of artistic activities. The art world can be a broad concept that is focused by careful examination of the actions of individuals. Within the constraints of a doctoral dissertation, I have both practical and theoretical reasons to zoom in on certain aspects of these worlds even more tightly.

I am an artist and researcher who has spent 30 years working in the English-language theatre community in Montreal, Quebec, its outlying suburbs, and in Ottawa and Kingston, Ontario. I am aware that the study of artists working in these environments shares certain limitations. A geographic focus, particularly one that somewhat surrounds the city of Ottawa, offers an opportunity to study artists who have the ability to be present at one centre of political power. These individuals can interact more directly with structures like the Canada Council even though I acknowledge the limitations concerning the experiences of practitioners from further afield. 
The same may be said of my focus on artists whose primary language is English. This focus allows for a strong sense of the actions and language of certain pockets of the art world while being aware that language is an important feature of cultural policy in this country. The importance of art work in the struggle for Quebec's linguistic and cultural distinctness in Canadian society has translated into a stronger support system in that province than in most other jurisdictions in the country. As Kevin Mulcahy writes, "public support for the arts in Quebec has more political significance than it does for other North American governments, because cultural policy debates have been intertwined with both Canadian nationalism and the character of the Canadian federal system" (1995, p. 226). As a linguistic minority, francophone Quebec artists are often more reliant on public subsidy as they face a considerably smaller market and reduced opportunities for export of art objects like theatre and literature that rely on language. Mulcahy suggests (in his 1995 paper) that Quebec artists are "between 30 and 45 percent" reliant on public money to pursue their work, and the administrative machine of the Ministry of Culture and the Conseil des arts et des lettres de Quebec that grew from it is a vital interface for these individuals and organizations (1995, p. 229).

Opening the door to questions of difference between French and English language artists and their relations with federal and provincial bodies would invite avenues of inquiry that could quickly engulf this project. It would further direct my attention toward the provincial level (at least in Quebec, but also in eastern Ontario, New Brunswick, and Manitoba). Rather, I have decided to focus my attention on these relations at the level of the Canada Council for the Arts, Canada's federal, arm's-length funding body, and to restrict the organizations with which I interact to those operating primarily in English. 
The immediacy of ethnographic research and the notion of presence and performance can better address the temporality of ongoing engagement and legacies of these "moments" in the everyday work on the ground. By placing a narrow focus on what art world members are doing, I suggest we avoid some of the abstracted and totalizing discourses that have dominated cultural policy studies, sociological understandings of cultural production, and cultural and creative labour.

\section{Chapter breakdown}

This dissertation begins with a chapter that surveys some of the relevant literature in the study of artistic production, artists themselves, and the intervention of the state through cultural policy and arts support. This review details some of the historical and current constructions of artists and their interactions with governmental structures and institutions like arts councils and professional organizations. These relations create artists as figures in our scholarship, policy, and public understanding. The literature demonstrates the tendency to present artists as a series of oppositions: as Romantic geniuses, and as participants in the collective action of an art world; as economic drivers, and as victims of economic exploitation; as figures wielding a national voice, and as critics of the power of the state; as creatives, and as creatures under the thumb of the bureaucracy. I argue that much of this literature glosses over a missing moment in these art world interactions, that of the performance of advocacy, the process of demonstrating legitimacy, and the things artists do to pursue that goal. I reiterate a need to focus not on who or what artists are (and are not) but rather on what they do to become visible to the apparatus that enables their work.

The following chapter offers a theoretical framework to address this gap that I call performative advocacy. This concept inserts itself into the moments of interaction that are often 
skipped in the discussion of policy results and aesthetic objects in the realm of artistic production. My theory draws on the concepts of performativity in language and discourse along with dramatic metaphors and the key idea of presence. Performative advocacy offers a critique that puts the everyday actions of artists and government representatives into conversation with cultural policies. The theory suggests productive ways to approach these actors' unique activation of texts, policy documents and regulations, and political scripts and advocacy texts, within the institutional spaces and moments that current studies tend to overlook.

Closely linked to this performance framework is a methodological approach to inquiry that is aligned with the foregrounding of individual actions and experiences across many different sites and with respect to particular texts: institutional ethnography (IE). IE is an approach that links together human activity on the local level and the texts and institutions that coordinate and constrain that activity, often coming from a centralized bureaucracy. This approach allows for ethnographic data gathered from observations and interviews, along with texts. In the art world, these texts consist of objects like grant applications, artistic CVs, headshots, policy briefs, and advocacy scripts. These texts are not the objects of study in and of themselves as we often encounter in cultural policy studies. They are the coordinating or ruling instruments that are activated and negotiated by advocates and art world members like arts program officers. The performative back and forth between these texts and the institutional structures of artistic funding and legitimation is best explored through observation and interviews informed by these texts. This offers a window on how the work of advocacy is pursued and how the communication among artists and these structures takes place.

The next chapter introduces and contextualizes my research sites, establishing them as both physical and temporal elements of the advocacy process. The first site considers the 
formation and introduction of the advocative disposition. This process is exemplified by observations I made at a CEGEP course in "professional management" for actors. The second site is an advocacy event in Ottawa where I consider the wider history of arts advocacy and open considerations of location, movement, and presence in performative advocacy. The third site is the program office at the Canada Council for the Arts, the government-sponsored corporation that offers artists legitimacy through financial support. The Council demonstrates a constantly evolving understanding of what the role of government should be in the art world. I situate these sites within their historical and transformative context and explain their value as loci for my inquiry.

The following three chapters then delve deeper into the data from these sites to explore the themes of formation, presence and performance, and texts and institutions, and how those themes are evident in each of the sites. This demonstrates the coordination of activities across different spaces and times as suggested by IE. Rather than attempting to align each site with only one specific concept or theme, I show how these ideas weave themselves through each of these moments, locations, and interactions. I uncover a complex network of performance that artists, arts professionals, and arts bureaucrats need to negotiate.

The final chapter concludes with a summation and a call for further research that maintains a focus on "presence" as a key to understand these interactions from an on-the-ground perspective. This dissertation is a response to the many scholars, like Eleanora Belfiore, who have called for more ethnographic and immediate research on the working lives of artists (2016). Cultural policy may be, as Belfiore suggests, replete with "bullshit" that obscures the reality of those who interact with such policies, ignoring "how things really are". If the study of such policies suffers from the "temptation to articulate research questions in policy- or advocacy- 
friendly terms" (2009, p. 353), then paying attention to the performance of advocacy shifts the object from promoting a political position to understanding the process and communication of advocacy itself.

Alison Bain suggests we need to "attend to the spaces in which these artists operate, and to emphasise their perceptions and subjective experiences in the complex process of occupational identity construction" $(2004$, p. 424). I agree though I warn against the idea of identity itself as a way to mark out the artist as unique. Professional activity that parallels the core artistic work does not alter nor construct identity so much as it alters performance and requires presence in those spaces that Bain recognizes as important. The tendency to construct the artist as various identities can be seen throughout the literature to which I will now attend. By paying attention to these performances as roles, theatricalizing what is clearly a series of demonstrations of legitimacy in relation to government support for the arts, I offer a new and immediate perspective on art worlds in Canada. 


\section{Chapter 1 - Constructing roles and relations}

This project engages with the figure of the working artist and the roles they take up in advocacy within certain pockets of the art world. It needs to examine the various moments and relations through which artists are constituted relative to each other and to the institutions of legitimation in that world. I employ the terms constitution and construction as these relations and the way we think about them are not natural nor objective. They are deliberate and in a constant state of growth, maintenance and repair. They shift and reconnect over time, space, and political reality. Artists and arts bureaucrats are part of a network that includes institutions, technologies, and traditions that legitimate art work. As scholars who study this work, we must constantly reevaluate our own role, as well as the artists' roles in the cycle of artistic production.

It is also worth noting that the concepts of artworks and art objects that are being treated in this dissertation come from a decidedly Western context. The traditions and context that I deal with here, the institution of globally Western artwork, tends to background ideas about art work that comes from non-White, and Indigenous perspectives. This is a limitation that further research does and should continue to address and it should be acknowledged that certain biases are evident in the work I present here.

This chapter will review some of the literature that considers how these moments and connections come to be understood and identified. This will include engagement with the sociology of the arts, cultural policy (in western liberal democratic contexts, and in Canada more specifically), and cultural labour, providing a grounding in some of these visions of the artist. The chapter will also identify and critique our picture of artistic production and cultural policy that is often taken through a wide-angle lens. I will demonstrate that our awareness of the artist and their work leans heavily on bureaucratic processes that place pressures on core creative and 
critical work. These pressures recommend particular performances and dispositions for artists that can be in tension with their pursuit of a career as a creative producer.

To map out these constructions I will begin with a discussion of the Romantic artist. This mad, genial, prophetic figure might appear to be relegated to the dusty past of early $19^{\text {th }}$ century poets and yet it continues to exhibit an enormous hold on formations of the artist in sociological terms as well as in the public imagination. I will follow the expansion of this isolated artist into the collective activity of the art world, where artistic work begins to become enmeshed with bureaucratic and policy processes as its sustainability comes to rely on institutions such as government-sponsored funding and legitimation of artistic work.

The literature then suggests we question the ways that such governmental and institutional processes prescribe roles for artists. They are constructed as national spokespersons wielding the power of symbols to reify, unify, and protect the nation; as educators and as salves for human suffering, implicating the artist into health and social welfare discourses; and as the economic engine for new creative and cultural industries, subject to the evolving pressures of neoliberal political economies. The discourses of precarity and exploitation that accompany such pressures move us into relatively recent critiques of artistic work concerned with relations of production and the ethics of labour.

I will show that the frameworks used to examine the work of art and of artists expose a gap in their professional activities as they negotiate their roles and behaviours, their language and performances in relation to structures of legitimation. The everyday moments and interactions can be ignored in focusing on the art object, on policy analysis, instrumentalization, and labour conditions. These gaps are addressed by a movement toward a performative theory of this work as it proceeds through advocacy toward the goal of legitimation. 


\section{The artist as genius and the Romantic ideal}

When we imagine the artist as a figure it can be difficult to get away from the vision of an isolated, creative force of nature. As pointed out by Hesmondhalgh and Pratt, cultural policy can be guilty of constructing the artist as the insular figure "who works for the love of art, typically suffering poverty in a garret room" $(2005$, p. 7$)$. However, the moment we begin to trace this Romantic ideal back through time the vision quickly disconnects from the everyday practice of art-making as a much more social and collective process. Exploring this dissonance and its evolution can help us to understand how artists, along with those that develop and deploy policy that interacts with artists, can recognize the work of advocacy as a part of art work.

Literary and language scholar Henry Staten argues that manifestations of the Romantic artist are rooted in confused understandings of classical Greek concepts like techne as interpreted by Heidegger (2012, pp. 43-44). Drawing on the "Origin of the Work of Art", Staten suggests that Heidegger offers a critique of Romantic notions of the creative genius that contrast "art" as a kind of natural emergence, a poesis that imagines the artist as a vessel for inspiration, and physis or "craft", the view that places the artist-agent as the primary creative force (2012, p. 44). Staten argues that Heidegger's work "purports to show the ontological ground of unity that underlies the split between modernism and Romanticism" (2012, p. 44). Staten suggests that a further examination of poesis and physis is necessary to understand art-making as a process of bringing Truth to light (2012, p. 45).

According to Heidegger, this imagined discoverer of Truth remains a unique human person. Staten suggests that Lukacs, drawing on the work of Aristotle and bringing Marxist notions of labour and production into the conversation, opens the work of art to a collective and social reality. For Aristotle, "the techne that empowers the individual is itself a socially 
accumulated and instituted knowledge" (Staten, 2012, p. 55). This duality in understanding the creative producer as isolated individual or as socially and institutionally embedded artist lies at the heart of the Romantic myth and its critique.

If the artist is possessed of some unique creative vision they alone can see and interpret, and their contribution to our symbolic lives is necessary, then it can be argued that they must be freed from economic and material want in order to bring that vision to light. One of the ways those material needs can be taken up is by mechanisms of government support and funding. However, constructing the artist as supplicant to the nation immediately belies the individuality of the prophetic artist, acknowledging the social nature of art work in its relation to legitimating structures (government departments and arts councils) that enable the resources for it to exist. Once the existence of these social bonds become evident, we see a dynamic where artists are constantly negotiating their presentation to each other and these government institutions as intermediaries. How can we study that dynamic to better understand communication and enhance these relationships?

Sociologists of the arts see the challenges with this duality between the artist and the intermediary. As Janet Wolff argues in her work on the social production of art, this figure of the lone artist as separated from his or her (though often his) community and "starving in a garret" (1993, p. 11) draws from $19^{\text {th }}$-century notions of creators that emerge under particular social circumstances. These conditions include the dawn of industrialization and generally recognized processes of modernity, urbanization, and the movement toward capitalist economic models. Wolff suggests that this has little relation to the role artists played up to that point (1993, pp. 1112). Histories of artists suggest socially integrated, collegial workers, grouped into academies 
and guilds, exhibiting their works together and generally fulfilling commissions offered by the Church or the aristocracy (1993, p. 12).

Howard Becker argues that the artist has been accorded special status only in a small number of societies, notably Western European formations that have come to influence North American ideals (1982, pp. 14-15). Becker shows the correlation between the special gifts of the artist and the creation of what we call a work of art. He also argues that the status of "artist" is often arbitrary and challenged by the art market, professional organizations, and other artists. As he considers his various categorizations of artists (the "integrated professional", the "maverick", the "folk artist" and the "naïve artist") along with his overarching theory of the artist and their surrounding "support personnel" (the stretchers of canvas, the makers of pigment, the stagehands and publishers, and the administrators that enable the creation and dissemination of works even when they are not themselves considered directly to be "artists"), Becker demonstrates that the Romantic artist as isolated genius is a construction that cannot truly relate to the practices of the art world even though its core activities may be pursued by specific individuals (1982).

In Becker's formulation, the expansion and contraction of the art world and the reification of certain practitioners or practices demonstrates a process that is not only made possible by collective effort but culturally placed in communities and nations, moments in space and in time. In other words, the inclusion of an artist or practice in the art world is a process of legitimation that defines that world. Performing that legitimation is part of what we understand as the work of the artist as intermediary and so we must examine both what that performance looks and sounds like as well as when, where, and with whom such performances take place.

Performances of legitimation also occur within the art market. Gary Alan Fine offers a more market-oriented perspective on the authenticity of artists and their tenuous relationship to 
the art world (2003). Writing about this sought-after authenticity that affects the market for work by the self-taught artist, Fine suggests that the market enshrines the creation of the individual as the ultimate in value. Citing the work of sociologist Ralph Turner, Fine concludes: "[a]lthough these claims downplay the importance of the artist's community, institutional affiliations, and nation, they resonate in a culture that wishes to believe that persons can impulsively create a meaningful world without relying upon others" (2003, p. 60). Fine is concerned with what this might say about the artist as an identity but we must also be concerned with what these individuals might do, or not, to enhance that reputation, and with whom they do it.

Writing in his book, Why Are Artists Poor? The exceptional economy of the arts, Dutch artist and sociologist Hans Abbing employs language that recalls the relationship between the artist and the Church, giving art itself status as a "sacred" offering (2002, pp. 24-25). Abbing, like Wolff and Becker, notes that pre-Renaissance work in the arts had an industrial and collective nature. He states, "[p]rior to the Renaissance, works people now call art were basically multiples usually made by trained artisans" (2002, p. 26). He suggests that during the Renaissance, and into the Romantic period, the artist as a gifted figure "'entered' the work of art" (2002, p. 26), tying its authenticity and value to the creative vision of a single individual. This vision of the Romantic artist has created a perversion in the economy of the arts where artists routinely accept substandard payment and working conditions in part due to a laundry list of perceptions of the work as sacred, humanistic, made possible due to divine inspiration or natural talent, uniquely suited to the individual, and expressive of their freedom from base matters. Abbing states that these "myths or persistent beliefs about art and artists make the economy of the arts exceptional" (2002, p. 31 original emphasis). 
Abbing suggests that authenticity and the conflation of the artist and the art object (mostly painting and sculpture in his examples) are features of this sacred act, an idea prevalent in much discourse around art historical and sociological constructions of the artist. For instance, Catherine Soussloff, in framing the "artist" as a historiographic, Foucauldian discursive concept, suggests they are "locked into the work of art". Their genius is displayed not through the individual persona or a set of character traits but inherent in the objects and texts created (1997, p. 8). Soussloff suggests that the construction of the mythical, heroic artist also has a longer and more complex history than we generally imagine. This figure is tied up with early examples of biographical texts, life stories of artists that embed them in the culture of their time and place, and also, according to Soussloff's reading of the work of Kris and Kurz, "heroize" them (1997, p. 96). This genre text, the biography of the heroic artist, did much to set a cultural norm for the Romantic artist as we come to know them throughout the $19^{\text {th }}$ and $20^{\text {th }}$ centuries and on into today. We need only take note of the explosion of biographies on famous artists that have become popular reading, translated into mass-market films and television series.

Much of the literature I have included here poses challenges to the Romantic ideal of the artist as isolated genius engaged with work that is perceived to be removed from the everyday, inspired by some transcendent, individual spark. Artists build their legitimacy through processes facilitated by the art world and its advocates. These advocates interact with public and statesupported processes and mediations such as radio play on the $\mathrm{CBC}$ or exhibitions at the National Gallery. These processes are fundamental to making the artist a household name and allowing the artist to have a career in the arts. A communications studies perspective is useful in revealing these processes which include the efforts of artists and advocates to get the powerful institutions of legitimation to pay attention to the work. It is useful to analytically separate the making of 
artworks and the work of artists as advocates, even though the individuals who perform this work are often the same, to better understand how these individuals negotiate their dispositions of the moment and communicate with the structures of government that support the arts.

How do we explore those relationships and articulations of the artist to the social and political environment? One place to begin is by looking at the artist as they become articulated with the "nation" and cast in the role of the national voice.

\section{The artist at work in the "Ministry of Symbols"}

When former Minister of Canadian Heritage Melanie Joly was appointed to her post in Justin Trudeau's first majority, Liberal government in 2015, she gave an interview to journalist Robert Everett-Green of the National Post identifying her new government portfolio as the "Ministry of Symbols" (Joly as cited in Everett-Green, 2017). Everett-Green writes that when asked what kind of symbols Joly was referring to, the main points were that they were not Harper-era Conservative ones, but rather "symbols of progressiveness" (Joly as cited in EverettGreen, 2017). Joly's vague statement seemed to reference government priorities like feminist ideals, reinvestment in the arts sector more broadly, and support for bilingualism and multiculturalism. Joly offered no specifics about her symbols, and perhaps more tellingly for this research, who exactly would be tasked to create, circulate, and interpret them here at home, or abroad. The programs and structures that fall under the purview of her Ministry: the CBC, the Canada Council, the NFB and Telefilm, the broadcast industry, along with programs like the Cultural Spaces Fund, the Canadian Arts Presenters Fund, and the Canadian Arts Training Fund, draw a conclusion that the cultural industries and working artists are the expected crafters of these national icons. 
In reading some of the literature on the arts as a means for national pride, unity, and protection, there is a clear if problematic construction of the artist as national spokesperson. They are imagined as the creators, keepers, and distributors of these symbols. This not only occurs at the national level but also on the provincial and municipal levels. This is especially true in Quebec where the "nation" is symbolically the province itself and the artists' interface is much more likely to lie with those legitimating structures such as the provincial funder, the Conseil des arts et lettres du Quebec (CALQ) and the various disciplinary arts organizations that exist within the province than with federal corporations like the Canada Council.

If this is the case, then the ways that artists relate to the structures that legitimate and support the creation of these symbols are relevant to the idea of the nation. This requires a certain understanding of the nation's instrumental vision of symbolic production. That vision can conflict with the artist's responsibility to speak with a critical voice on governmental power and to reflect a diverse society including many marginalized populations and ideologies that are not always represented in dominant government discourses.

Ryan Edwardson writes about a specific example that well encapsulates this articulation of the artist and the nation. Captain Canuck is a Canadian superhero (though notably without any actual superpowers) that first appeared in comic book form in 1975, created by Richard Comely (2003, p. 184). As Edwardson argues, the character, festooned in red and white and emblazoned with the maple leaf, is "a cultural artifact, a key item in the construction of modern Canadian cultural identity and consciousness" (2003, p. 184). Captain Canuck was eventually appropriated by the government in the form of exhibitions, a postage stamp, and other national symbols. Despite this tendency for the nation to co-opt the work of the artist, I suggest that it is in part the work of the artist to imagine and reflect the nation back to itself, as embodied in narrative and 
image. The artist does not do this alone, creating from some epiphany about their origins and their connection to some idealized version of Benedict Anderson's "imagined community", the concept of a far-flung population bound together through media and symbol (2006, p. 6). The work is culturally situated, informed by history, and quite often, especially in Canada, directly supported financially by the nation itself.

There are two important implications of intervention by governments in acquiring and deploying the creative work of an artist, or group of artists, into things like stamps, exhibits at National Galleries, and so on. The first is that governments use artworks to establish a sense of unity and pride in the population. The second is that such unity and pride is necessary, particularly in a case like Canada. There is a perceived threat that outside cultural influences, most often envisioned in our case by a dominating American creative industry, will swallow up our own voice and render us culturally indistinct from other nations.

Canadian literature on the arts and cultural policy is often concerned with art as a means to unify the nation through questions of infrastructure and distribution. With a vast landmass and a comparatively tiny population, this is not a surprise. Studies from Canadian scholars like Harold Innis guide the way. Charles Acland, whose writing has engaged with the intersection of Innis' materialism and cultural policy, suggests that in culture Innis "saw the struggle for humanist values shaped or stifled by material conditions, especially cultural artifacts and their technologies of production and circulation" (Acland, 2006, p. 180). Those conditions were partly determined by the nature of Canadian geography, both internal to the nation, and in proximity to our culturally megalithic neighbour. Acland cites Innis' advocacy for the supportive recommendations of the Massey Report (2006, p. 181), though even if the Canadian state were to consider not directly supporting the arts, they would still be very interested in moving messages 
around through communication technologies that could bind small and disparate pockets of citizens. Those channels of communication must be filled with something and as Maurice Charland suggests, if the Canadian state was not going to back its own creative voices those pipes would quickly fill with American cultural products (1986, p. 214).

The importance that is placed on Charland's work in the context of communications studies scholarship in this country demonstrates that infrastructure can quickly become enmeshed with a protectionist discourse in cultural policy. As Jody Berland writes, "[Canadian] cultural policy was founded on the assumption that building national, publicly owned cultural and media infrastructures dedicated to presenting alternatives to American mass media would guarantee an expansion of a creative, commercially unimpeded cultural space and public sphere" (1995, p. 516). Surely this vibrant, national scene for artistic expression is something government could wish for. But what exactly does such a forum mean for artists as they try to reflect their communities and speak to their country? The focus on infrastructure, distribution, and regulation can ignore the working lives of artists themselves and their interactions with these policies on the local level.

What we see here is that policies themselves are worthy of study but the making and activation of policy as a set of practices performed by artists, arts bureaucrats, and political staffers, some of whom are embodied in the same individuals, is a key aspect of the art world that cannot be overlooked. What individuals do is governed by these frameworks that connect the artistic vision and the idea of the nation, creating an environment where advocacy has very particular demonstrations. Governance of the self and understanding the symbolic political dimension of creative work and the performance of compliance to national needs takes us into a key concept in cultural policy studies, that of governmentality. 


\section{Disciplining the artist through the lens of governmentality}

Michel Foucault's governmentality has weaved its way through cultural policy studies in Canada and other Commonwealth countries since the late 1980s. Foucault introduced his notion of this "art of governing", where the state turns its attention from concerns over land and foreign relations and toward the disciplining and education of its own population (Foucault as cited in Burchell et al., 1991, pp. 2-3) in a speech at the College de France in 1978 (Fougère \& Solitander, 2007, p. 2). It has been applied by several scholars in cultural policy, notably in Australia by Tony Bennett (2013), to examine how governments employ culture and artworks to prescribe codes of conduct for citizens and to direct their tastes and education (Ahearne, 2009; McGuigan, 2004, p. 15; Mulcahy, 2006, p. 320). As Miller and Yúdice state, governmentality is operational in the art world when "the dominant culture uses education, philosophy, religion, aesthetics, and art to make its dominance appear normal and natural to the heterogeneous groups that constitute society" (Miller and Yúdice as cited in Mulcahy, 2006, p. 320). Some also suggest it can be a means to manage and to repress dissent and protest (Carroll, 1987, p. 31; Léger, 2010, p. 563). Clive Robertson makes this argument in his examination of arts policy in Canada as it relates to artist-run centres. Robertson likens this art world to a social movement that has been “managed" by government funding processes (2006, pp. 61-63).

In Bennett's Birth of the Museum, the strict conduct expected of the public as they move through a museum space is envisioned as a mirror to the kinds of panoptical surveillance and ensuing self-discipline in Foucault's prisons and hospitals (2013, pp. 59-60). The objects placed in these spaces are further demonstrated to be of value to the governmental structures that create museums as representations of the national narrative. Zoë Druick similarly suggests that the early films of the National Film Board, supported and influenced by government institutions almost as 
propaganda, exemplify Foucault's concept as a means to construct cultural citizens (2007a, pp. 24-25).

While these governmentality formulations suggest the strong influence of national symbols to discipline a population, the creation of policy can also be subject to these same pressures. There is the possibility of resistance, however, as Wagman suggests. He argues that applying governmentality to the processes of policymaking is "unable to account for the agonistic relations between interested parties both within and outside of government that impact upon the formation and direction of policy initiatives" (2007, p. 19). Those relations, the specific actions of word and body, are precisely the ones this dissertation begins to uncover.

These critiques of governmentality are aligned with the focus of my research on the practices and experiences of particular artists and cultural bureaucrats. Governmentality tells us something about policy and the art world as a "site for the production of cultural citizens" as suggested by Lewis and Miller (2002, p. 1). However, more attention can be paid to the relationship between political power and the work of the researcher (Scullion \& García, 2005, p. 115). As noted by Jonathan Sterne, even in Australia where the focus on the governmentality concept appeared greatest, research in cultural policy is embracing ethnographic techniques that are engaging with implementation and grounded realities of artists as they relate to government (2002, p. 84). My research focuses not on the nebulous conglomeration of "cultural citizens" but on some defined communities of artists and cultural workers as they are formed, at least in part, through governmental intervention in the art world. We must engage closely with those who work under the auspices of government support, negotiating the daily tension between aligning with national goals and rationales for artworks and their desire for self-expression, critique, and unconstrained creativity. 
Governmentality and the technologies of administration that require compliance with increasingly complex reporting mechanisms illustrate one of the more pervasive policy constructions of the artist in the past several decades. Identified by UK scholars as "new public management" (Bell \& Oakley, 2015, p. 54; Born, 2010, p. 189; Clive Gray, 2007, p. 208; McGuigan, 2004, p. 46), the policies recast artists as administrators, or even accountants, facing an eroding of state trust and pressure to justify their use of public funds through extensive audits and reports (Banks \& Hesmondhalgh, 2009, p. 428). New public management is, in fact, a much wider phenomenon in the governance of nations and institutions such as health care and social services. Andrew Gamble describes it as "a set of ideas for managing all institutions in the public sector and involving devices such as internal markets, contracting out, tendering and financial incentives" (1994, p. 135). This shift of public responsibility from governments to private organizations comes with its "managing" discourses that include all manner of reporting and justification that Belfiore calls "Value for Money" (2004, p. 191). Public monies are seen as investments strongly controlled by centralized institutions that exercise power through the deployment of performance-related instruments such as extensive auditing and reporting procedures.

This shift toward a "culture of audit" lies at the heart of Georgina Born's examination of the Birt era at the British Broadcasting Corporation detailed in her book, Uncertain Vision (2005). My research is closely aligned with the work of Born who engages in her own institutional ethnography of cultural institutions and individuals working within them. Along with her first book, Rationalizing Culture (1995), which delves into the Paris-based Institute for Research and Coordination in Acoustics/Music, the two volumes detail years-long periods of participant observation in key cultural institutions in media and the performing arts. 
Born's methodological rigour is evident in the reams of interview data and observations she shares in these books. Uncertain Vision is also replete with examples of texts: policy briefs, memoranda, operational hierarchies, and the all-important charter that funds the $\mathrm{BBC}$ through a tax on UK households. She takes particular note of how these texts are "activated", how they are embodied, resisted, and negotiated by people like television producers, Board members, and financial personnel. Born's illumination of these new public management principles mirrors some of the challenges facing artists in Canada and illustrates the idea of governmentality at work in the art world.

In Canada, this new public management ideal is discussed but in slightly different, often Bourdieusian, terms. Linking the artist and the accountant can prove reductionist at best and according to both Brigit Knecht and Marisol D'Andrea, symbolically violent at worst. Knecht employs Bourdieu's notion of symbolic violence to describe the pressure placed by government reporting mechanisms in the province of Alberta, on artists and arts organizations that are illequipped to handle the bureaucratic performances such a system requires (2011, pp. 251-252). Likewise, Marisol D'Andrea looks at the governmental relationships to its arts councils, primarily on the federal level, as increasingly framed "through symbolic power". This is where "the government entrenches a reality that defines the basis of legitimacy in the arts within economic logic" (2017, p. 247). Both scholars employ interview data to allow for the experiences of artists to inform their discussions, relating reflections from arts council jurors, artists, and advocates. My work is in conversation with both these scholars but I take a more humanist approach as recommended by Becker as opposed to the agonistic framework of Bourdieu. 


\section{Field trips to the museum: policy attachment in the work of art}

As detailed in the work of Tony Bennett on museums and governmentality in Australia, along with Edwardson's example of Captain Canuck, a museum can be a central institution for the display of national identity. Carol Duncan and Allan Wallach argue that the museum is a national and social construct. "In common with ancient ceremonial monuments, museums embody and make visible the idea of the state" (1980, p. 449). The museum is also a space invested with goals like public education and social inclusion, acting as a nexus for various articulations of artists and their works. Since this project has a focus on the performing arts, museums and galleries do not play as large a role in my analysis. They are nevertheless spaces where the arts, often visual but also including performance and other time-based works (film and video, sound installation, etc.), including the design and architecture of the space itself (Duncan \& Wallach, 1980), are framed in a manner that is decidedly instrumentalist.

A CBC News story in October 2018 touted a pilot project initiated by the Montreal Museum of Fine Arts and Médecins francophone du Canada. In the program, doctors in Quebec would write prescriptions for their patients that consisted not of pharmaceuticals or diagnostic tests, nor even physiotherapy, but a trip to the museum for "a day of paintings, sculpture and relaxation" (CBC News, 2018). Patients being treated for conditions as wide-ranging as diabetes, eating disorders, and high blood pressure are given free access to the works in the gallery, to an onsite art therapist, and to the Michel de la Chenelière International Atelier for Education and Art Therapy, touted on the museum's website as the "largest educational complex in a North American art museum, welcoming over 300,000 participants to its activities every year" ("Michel de La Chenelière International Atelier for Education and Art Therapy | MMFA", n.d.). According to Nathalie Bondil, the director-general and chief curator at the museum, her space 
can help alleviate stress and promote healing. "When you enter the museum, you escape from the speed of our daily life. It's a kind of modern cathedral" (Bondil as cited in CBC News, 2018).

Here is an explicit articulation of an artistic space, a hospital, and a church as spaces of physical and spiritual healing. Doctors suggest that looking at beautiful art can stimulate the secretion of hormones and increase brain activity that will promote good health. Art therapy has a long history and yet in this news story, the idea is framed as "treading on uncharted ground" (CBC News, 2018). This example offers the museum as a place where the work of the artist is displayed and celebrated but also put to work in highly instrumental ways. In this case, it is in the realm of healthcare. What are some of the other ways that the work of art and the space of the museum can be used? How then is a case made for state support in an instrumental fashion?

What is meant by the term "instrumental" in cultural policy? Surely all public policies, including those in the cultural realm, seek to address particular issues deemed important by governments based on their reading of the political and social situation in their constituencies? A 2008 volume of the journal Cultural Trends presents a debate among many of the major scholars researching in this field. In his commentary, Stuart Davies tries to define instrumentality while noting that the volume's authors' "assumptions reveal a lack of overall clarity as well as a lack of agreement about the language of instrumentality or instrumentalism" (2008, p. 259).

Davies offers three terms to help think through instrumentality: policy, purpose, and strategy (2008, p. 260). Policy, for Davies, is a "vehicle for accountability", a means for government to tie investment in the arts to outcomes for people (2008, p. 259). Policy demands specifics but the "purpose" of artworks is opposed to that idea. It is open-ended and noncontingent (Davies, 2008, p. 260) and instrumentalism, according to Davies' reading of Clive Gray, can adversely influence the function of a space like a museum. Davies argues that arts 
spaces like museums also employ instrumentalism in their own "strategy" to link their values to those of supporting institutions. He writes, "[i]n applying for a grant from the Heritage Lottery Fund, for example, a museum manager is making a conscious strategic choice to sign up to the HLF's objectives and values in return for hard cash" (2008, p. 260). Instrumentalism is presented as a contested and complicated term, and not the terrain of government only. Davies' argument acknowledges the instrumentality of advocacy efforts by artists and arts administrators as they are expected to align with state interests.

Clive Gray argues that instrumentalization occurs when supporters of the arts expect artworks to perform societal functions beyond the aesthetic and intrinsic ennoblement of the human spirit (2007, p. 203). For Gray, the push to "commodify" the arts in this manner is problematic and leads to "a burden of expectation that cultural policies should provide a host of solutions to problems that are originally economic, social, political or ideological" (2007, p. 207). Marxian conceptions of commodification suggest that the use-value of art is being transformed in the discourses of public funding justification, for exchange-value, a kind of cultural capital that governments can accumulate and disburse for political gain (Vestheim, 1994, pp. 58-59; Volkerling, 1996, p. 189).

Lisanne Gibson offers a more nuanced and historically embedded argument, suggesting that practitioners and institutions, like museums, have always seen their presence in the community and in the nation, as more than an aesthetic service to elites (2008, pp. 249-250). Gibson's argument seeks to "reject simplistic dichotomies such as 'instrumentalism' and 'intrinsic' as concepts $[\ldots]$, and therefore enable critical engagement with the specificities of a cultural institution's or programme's operation" (2008, p. 255). My research fully endorses this notion of breaking down binary opposition in such concepts by trying to understand how they are 
communicated and acted upon by those who relate with and those who make up the institutions themselves. This reveals the impact of policy on the choices made within these institutions. It further suggests an agential role for individuals to better communicate their perspectives and experiences.

Arts advocates recognize that government involves itself with the arts. This can lead to an approach to advocacy that Clive Gray calls "policy attachment". Closer in practice to Davies' idea of strategy, advocates link outcomes in arts and culture to other more "important" policy areas (2002, pp. 80-81). When Canada Council for the Arts CEO Simon Brault was VicePresident of the arts funder's Board of Directors, he offered a statement exemplifying the work of those actors as having "proposed imaginative and promising links between education and culture, between health and culture, between citizenship and culture, between economic development and culture, and so on and so forth" (Brault, n.d. par. 21).

The link between arts and education is perhaps one of the more obvious in the realm of policy attachments. In her discussion of the conceptual underpinnings of the Massey Commission, Zoë Druick suggests that the report authors "were bound up in a set of problems that connected culture to media and education" (2007b, p. 160). Cultural policy discussions in post-WWII Canada were as concerned with the advent of mass media technologies as their use in the circulation of knowledge and education of the public (2007b, p. 172). This example points toward a more diffuse understanding of cultural policies by the state, with its potential misunderstanding by artists acting as advocates.

The question of how art can contribute to a healthier society continues to be an issue not simply for education and medicine, but for the wider notion of social well-being. How do we, as a society, understand and enumerate that value without the input of the artists that create the 
works? McCaughey et. al note the importance of research initiated among coalitions of NGOs, governments, and academics, even while decrying the ongoing disintegration of those networks. An example is the defunding and disbanding of the Canadian Conference on the Arts in October of 2012, a lobbying and research organization that has existed in one form or another since 1946. This dissolution is an example of how "these connections have weakened and dispersed as government support for research has diminished" (2014, p. 117). The authors go on to suggest that future examinations of these values as they relate to health, a greying population, and even environmental sustainability, will necessitate "designing an adequate constellation of information sources to inform and evaluate policy" (2014, p. 117). Including the voices of artists in that gathering of data and understanding their specific language and experiences will be crucial.

\section{Intrinsic and instrumental: making artists count}

Widely regarded as one of the foundational documents in Canadian cultural policy, the Massey Report states that "if the cultural life of Canada is anaemic, it must be nourished, and this will cost money" (as cited in Dewing, 2010, p. 8). As Klamer and Petrova demonstrate, policy considerations very often come down to questions of funding (2007, p. 245). We must pay attention to issues such as regulations and protections for cultural works and workers. Copyright and status of the artist laws are significant, along with what Becker calls "conditions of civic order" (1982, p. 5) that allow artists to create freely and fairly and without undue constraint based on things like obscenity regulations or even the dangers of war. Still, much of the policy discussion in many areas, not just the arts, comes down to a basic equation: money in, results out. Questions must be asked regarding the economic benefits of arts funding and the constitution of the artist as an economic driver. What results are being sought and how are they 
to be measured? What are the implications that an economic framework places on working artists?

Trying to understand the economy of the art world, Hans Abbing identifies a tension between two economic structures that underpin artistic creation: the "gift sphere", money coming from subsidies and donations from wealthy patrons and government institutions, and the "market sphere", money coming from the sale of artworks in a marketplace, or from more instrumental expectations of financial investment (2002, p. 39). Artists depend on both of these sources of income to live and pursue their work. In Canada, as in many other western liberal democracies outside the United States which is more reliant on private investment, art worlds tend to lean heavily toward gifts and subsidies. Abbing suggests that the value and legitimation of artworks are increased by their reliance on gifts. These are seen as decisions based not on instrumental notions of what the art can do. They are not valued as investments in a market, nor as a boon to the cultural capital of the investor. The value of the gift is derived from what they intrinsically add to the community (2002, pp. 41-42). This creates what Abbing identifies as a "denial" of the economy, requiring many artists to ignore economic considerations (such as secure and sustainable employment) in order to maintain their status as driven by purer, aesthetically minded goals, attracting more gifts and subsidies. Abbing does note that there are exceptions to this rule, artists like Andy Warhol, who “openly displayed their interest in money and market values". However, they are mostly seen as acting ironically, the exception that proves the rule (2002, pp. 49-50).

We do not need to look very far to see the operation of these spheres and their implications for working artists in Canadian funding discourses. The purpose of grants from the Canada Council for the Arts is explicitly laid out in its founding legislation. The Council's 
purpose is to "foster and promote the study and enjoyment of, and the production of works in, the arts", and it does so by making "awards to persons in Canada for outstanding accomplishment in the arts", making "grants, scholarships or loans to persons in Canada for study or research in the arts", and acting to "sponsor exhibitions, performances and publications of works in the arts" (Canada Council for the Arts Act, 2001). This has generally been interpreted by program officers, peer-review juries, and the administration of the Council, along with the artists that the Council supports, to mean that the Council makes its contributions to creators in the art world without regard to instrumental considerations. In other words: cash in, the best art out.

According to the Council's granting policies on its website, it "awards funding to those applications that demonstrate the highest artistic excellence and meet all the assessment criteria" ("Funding Principles", n.d.). Those criteria differ depending on the objectives of various funding programs. The Explore and Create program, which serves emerging artists and smaller arts organizations, has criteria that fall into three main categories: artistic merit or the quality of the project as described, impact on the advancement of artistic practice in the field, and the feasibility of the project, including its budget and distribution and marketing plans. There are no explicit references in the granting guidelines to policy attachment in areas like healthcare, education, or social inclusion. Implicitly, certain criteria do exist, like the support for official languages minority creation in Canada, strategic funds that respond to "different intended outcomes" ("Funding Principles", n.d.), and recent moves toward ensuring harassment-free workplaces in the art world, along with those that prioritize digital works. These are generally not communicated front and centre, and the Council's peer assessment principle and arm'slength model maintains its focus on art for art's sake. 
On the other side of the federal funding environment in Canada, funding programs available from the Department of Canadian Heritage (DCH) are overtly tied to a number of policy priorities. These include cultural preservation and infrastructure through the Cultural Spaces Fund; education through the Canadian Arts Training Fund; national unity and identity through programs on the local (Building Communities through the Arts Fund) and national (Commemorate Canada and Celebrate Canada) levels; and direct employment of artists and cultural workers through programs like Young Canada Works. The implication of these programs is that the aesthetic value of the work is in constant tension with its instrumental value in the social and economic world. This has an impact on the practices of artists, challenging them to decide how to frame their work, whether focused on the subsidies awarded primarily for aesthetic considerations, or leaning toward the investments and market incentives that instrumentalize their art within the context of community building.

There is a link here to Noël Carroll's essay, strongly critical of theoretical justifications for state funding of the arts. Carroll suggests a number of potential justifications for such economic expenditures noting the contrast between ideas of cultural preservation and cultural creation (1987, p. 22). Protecting the heritage of a community or nation is a legitimate reason for state intervention and Carroll reiterates several points about national defense, unification, and identity formation, all elements of the DCH programs. The creation of new works, he argues, is more problematic. Carroll states, "[i]t is often difficult to imagine the way in which grants to individual artists for new works - as opposed to city art centers - can engineer economic wellbeing" (1987, p. 30), unless, as he goes on to argue, a case can be made for the economic benefits brought on by tourism or as a balm for unemployment. He argues there is no evidence suggesting art is the best avenue to meet those goals, nor is the state beholden to offer citizens 
employment in jobs that are irrelevant (1987, p. 30). Carroll concludes that the only proper functions for art in society are "those concerning the aesthetic environment and the moralizing effects" of these works and since that requires that only certain arts be supported, it might be better to simply abandon the whole exercise (1987, p. 34).

For arts management scholars Jonathan Paquette and Eleonora Redaelli, policy evaluation would appear to be the obvious conclusion of any governmental intervention. However, the arts are not amenable to this kind of instrumental relationship. They are "often associated with abstract objectives and made difficult to evaluate" $(2015$, p. 68). Paquette and Redaelli point out that evaluation is carried out not only by the funder, and the artists but by the population at large, including the academic community $(2015$, p. 69). These broader evaluations make their impacts known in places like the ballot box. Arts funding decisions do not usually play an enormous role in voting intentions but neither can they be entirely discounted, particularly on smaller scales like in provincial and municipal elections. These kinds of evaluations are not usually characterized by positivist, hard data but rather by narrative and conversation about the things that we value as a community.

Danish scholars Bille et. al suggest that cultural policymakers "justify their attitudes and decisions on economic themes such as growth, employment, and branding value instead of traditional cultural themes such as education, empowerment, and enlightenment" (2016, p. 238). Based on the work of Skot-Hansen, their choice of categorizations is interesting, particularly in labeling cultural themes as "traditional". This suggests that the economic rationale for cultural policy is more recent or less institutionalized in the discourse as the more Romantic or humanistic notions which I have been illustrating in the last several sections of this review. While Abbing, Becker, Wolff, Bourdieu, and many other sociologists of the arts have argued that 
money and art have always been strange but close bedfellows, the Danish essay is important to this research because its focus is not on the actual political economy of artistic production but rather on the ways policy decisions are communicated and legitimated (Bille et al., 2016, pp. 248-249). Bille et al. make specific reference to the terms "investment" and "support", words used by funding bodies that implicate different codes or systems of communication, akin in many respects to the binaries of "market" and "gift" or "instrumental" and "intrinsic". They argue these codes mean that "cultural institutions' communications are linked to the cultural policy communication" even when there is a disjuncture between how the institution sees itself and how they advocate for resources (2016, p. 253).

I close with this argument because it suggests that if art world members are more cognizant of the language of economics that governments employ to justify how and why they intervene in cultural matters, they might choose to align their own performances to those codes, or they may attempt to shift or subvert them. This has an impact on the language of arts advocacy where, as Australian Jo Caust argues, many art world members "shift towards using a language that described the arts as an industry and developed the economic/cultural industry model" (2003, p. 54). We can use these codes of communication to think about how artists are seen to negotiate this Scylla and Charybdis of legitimation for their work.

\section{Working and advocating as an artist}

A working artist can be many things. As Becker notes in his division of artistic labour, most artists have worn more than one hat in the art world, and many maintain parallel careers as support personnel (1982). At the very least they create and consume art. The nature of the work, particularly as an emerging artist, is predicated on the flexibility to take on and excel at various tasks that straddle the line between the creative and the administrative. 
Lindsay Stephens explores some of these questions of cultural labour from an ethnographic perspective. Her work on circus performers in Canada is of methodological significance to my research and of conceptual interest through employing theorizations of practice and legitimation. For Stephens, the decision by the Canada Council in 2009 to recognize circus arts as a separate and unique artistic discipline created new relationships between these performers and the evolving creative industries in Canada (2015, pp. 243-244). While the designation by the Council legitimated the practice, it also shed light on the tension between what circus artists perceive as artistic work and the more corporate or administrative work of finding gigs and executing them, including "relatively well-paid gigs for private and corporate clients at a range of venues such as nightclubs, private homes, convention centres, and public spaces" that are necessary for financial survival for many artists (2015, p. 249).

Stephens' embodied research of these performers is useful in thinking through complex questions of agency and alienation in circus arts from an experiential viewpoint. When she shares the frustrations of performers constrained by both technical requirements of equipment and space for creating and presenting their work, and by the expectations of clients and the increasing corporatization of circus under the guise of innovation and artistic excellence in cases like Cirque du Soleil, she illustrates that "content and satisfaction of creating within structures of art production was preferable to the experience of performance created under more typical labour relations" (2015, p. 253). It has become increasingly difficult to tell these structures apart as those labour relations become part of "informal and affective relations of production" that Stephens sees as vital to the study of working artists (2015, p. 255). These relations are characterized by precarity, instability, and a potentially problematic redefinition of our understanding of what the term "art work" does in our social reality $(2015$, p. 255$)$. 
Precarity is one of the dominant themes in discussions of artistic work. Defined by Greig de Peuter as "existential, financial, and social insecurity exacerbated by the flexiblization of labour associated with post-Fordism" (2014b, p. 267), precarity is associated with contract and freelance work, what has become known as the gig economy. This construction of artistic work puts the responsibility on the worker to provide services, replacing the traditional notion of an employer who looks after the needs of a defined group of employees (2014a, p. 32). The examinations de Peuter offers demonstrate how culture industry workers, mainly artists, production personnel, and administrators, are confronting precarity through collective advocacy across disciplines and modes of working, through critiquing unpaid labour, and through "involvement in wider social movement politics, in particular, the politics of occupation" (2014a, p. 32). As de Peuter notes in his conclusion to his essay 'Beyond the Model Worker', continuing research "must grapple with a fundamental tension between accommodative and antagonistic responses" (2014b, p. 267). This invites questions around the ways in which artists present themselves as advocates in the halls of power.

Alison Bain is a geographer who writes about artists and identity as well as creative work in varied physical locations, including outside traditional city centres. Along with her colleague Heather McLean, Bain draws on interviews from artists' collectives in the Toronto area as they negotiate precarious work and space issues amid the rash of funding cuts to the arts under the Harper government. Their discussion of "Do-It-Ourselves" mentality (2013, p. 99), focusing on the collective nature of this work has important links to my research. The active conception they suggest is a solid foundation for my examination of the communicative actions in the advocacy that attended this moment of history. 
This literature that discusses some of the challenges to precarity and alienation on the part of artists often portrays the artist as protestor, or in de Peuter's conception, antagonist (2014b). But what of his question regarding more accommodative responses to such struggles? While the term accommodative seems to suggest a giving up of power or agency on one side of the debate, I would rather take de Peuter's suggestion as a means to shift the conversation to advocacy, a process that I see as somewhere between notions of dissent and those of acceptance and resignation to exploitation.

\section{Moments in time}

This literature and the series of constructions of the artist that it presents demonstrate that relations between the artist and our public imagination of their roles in the social world are temporary, built on shifting sands. Yet only certain moments of inflection are held up for inquiry. This dissertation inquires into the moments in the work of art-making when artists become aware and engaged in the communication and demonstration of their legitimacy. The legitimation of art work is a complex process involving many institutional actors in the art world. It is a critical and under-represented aspect of cultural policy studies. It is productive to ask not only what we study in the production of art, but when we study: when are these moments to which we pay the most attention.

Looking at the research in the sociology of art, the temporal concerns vacillate between historical constructions of the artist from the medieval period, through the renaissance, and into the modern era, and the production/consumption period. The shifting conception of what an artist does, and with whom they do it, is certainly important to this research, but what of the when? Becker's division of labour in the art world (1982, p. 13) helps to identify some of the activities engaged in by art world participants, and Bourdieu's work is very much concerned with the 
processes of creation and consumption circumscribed by notions of habitus and class/taste constructions, situated historically. There is very little discussion of the moment when communication with government helps to create the environment where the work of artists is legitimated and supported. For Becker, the state is underdeveloped and limited to abstract discussions of regulation, copyright, and censorship. Becker touches upon advocacy by artists themselves in writing about the situation when government support becomes the primary path for artistic production and "artists must take into account as a constraint what the government will and won't support" (1982, p. 185). As with much of his conception of government in Art Worlds, this is treated as a kind of state censorship more than a performative relationship between artists, acting as advocates, and a state structure and bureaucracy.

Conceptions of cultural policy are understood as a Foucauldian governmentality project designed to produce "cultural citizens" that are amenable to state-sponsored symbolic constructions of nationhood and proper civic behaviour. Perhaps they are imagined as institutions and structures that are the result of consultations and commissions but whose ongoing effects on the artists that create and advocate under their auspices are undertheorized. Either way, the everyday impact of these policies is often glossed over in a bid for a teleological summation of the policy itself, even going so far as to background the important contributions of artists themselves as they inform and co-develop cultural policies.

It would seem that issues around cultural labour would be amenable to a better understanding of this uneasy relationship between artists and legitimating institutions. Nonetheless, as Matthew Rowe points out, sociologists have done a fine job investigating the larger structures of creative labour, "but provide little insight into the micro-level experience of career navigation" $(2019$, p. 71$)$. My research shows that a part of that navigation is in the 
disjunctive moment when artists shift their dispositions into advocate. Rowe's "boundary work" conception is a productive way of thinking through the dispositions required by such transitions. Rowe, along with Banks, Fine, Cohen, and many others considering creative labour, makes no mention of the "employer" of many (if not most) emerging Canadian artists, the government itself. Banks provides some detail on this relationship in his Politics of Cultural Work (2007, pp. 53-54), and my research pushes that discussion forward beyond governmentality and into a more performative theorization of advocacy. By not lagging behind in historical and governmental discourses, nor jumping ahead into the production and consumption processes, this study steps into the middle moment. I inquire into the demonstration of artists' legitimacy with governmental structures that constructs the metaphorical theatre set on which art work is to be understood and valued. 
Gasoi - 58

\section{Chapter 2 - The framework of performative advocacy}

\section{Performative advocacy: addressing communication}

The call for more empirical and practice-oriented research is a theme running through the literature detailing various constructions of the artist and their connection to policies and practices in the collective action of the art world. While it may be obvious to suggest more closely observed, ethnographic data from the art world can provide insight into the practices of artists, it is vital to consider just what that data is supposed to tell us. How can we offer new insights and not a retreading of familiar arguments? Ethnographic research does not simply offer what Jeremy Shtern suggests can be "a rigorous framework of discourse and knowledge" that brings the researchers' own experiences and positionality to bear on the documents that comprise much of the corpus of studies in cultural production (2012, p. 181). It must also ask new questions within renewed approaches to understanding that help to shake us out of established patterns of engagement with the complex relationships between artists and those that make artwork possible in this country.

In this chapter, I will advance performative advocacy as a conceptual framework through which to examine the work of art world members as they relate to each other and to the powerful institutions in these worlds. Performative advocacy understands the process of demonstrating legitimacy through speech acts and live encounters as well as through contact with the texts that circumscribe these relations.

Performative cultural policy research is less common because of the kinds of questions being asked through the approaches detailed above. Studies have been guided into two streams: those that probe the aesthetic and creative value of the art object and the conventions and disciplines that circumscribe its production, and those that consider the social, political, and 
economic value of these works and their articulation with societal needs. These I have identified as intrinsic and instrumental values. We must also acknowledge that the ways that we study art work, or what is more commonly referred to as cultural production concerns itself with the art objects produced and the processes that lead to their distribution and encounter with an audience. Even the term cultural production undermines a clear focus on the arts sector as it becomes entangled with the larger creative industries or sport, or built heritage. This is a teleological approach that can gloss over a key step in that process, namely the communication among artists and their funders (and as is the case primarily in Canada, governments at all levels and their attendant funding apparatus such as arm's-length arts councils) toward producing the means and environment to make artwork. Strictly intrinsic or instrumental conceptions fail to address a nuanced and empirical discussion of the efforts and experiences of creators and practitioners to advocate for their ability to produce art. By missing out on this step, we have a web of disciplines and fields that have historically ignored the performative dimension of interactions with the institutional structures that legitimate the work. To repair this absence we must put communication back into a central place in the professional processes of artists and those who work to support them.

Cultural management scholar Robert Cluley suggests the "division of labor" between creatives and their "support personnel" (Becker as cited in Cluley, 2012, p. 204) is a defining aspect of the study of artistic production and especially its language. In the world of emerging performing artists discussed in this dissertation, I recognize that the creative work and that of their support and mediation can very often be embodied in a single individual. The division is illustrative not of identity then, but of dispositions and language use that, "is a resource which conditions social actions yet is, in turn, a resource out of which social structures are built" 
(Cluley, 2012, p. 214). Art world members rely on language to pursue advocacy. To study that language and its mediation through the body of the advocate and the texts with which they interact is a way to pierce through some of the more abstract conceptions of the cultural worker and the state that exist within scholarship in cultural policy and production. It brings focus to the practices of artists, arts professionals, and arts advocates, again, often embodied in one individual, who are constantly negotiating those performances as required. In short, this study draws attention to what art world members do beyond core artistic activity.

This approach addresses the call for more closely observed, experiential data, a challenge recognized by Oliver Bennett. Bennett is concerned over the "torn halves" of pure humanistic research and advocative work designed to influence policy and emancipate artists (2004, p. 246). To navigate this tension, the focus must be on those moments of encounter and interaction that build the enabling environment of art work and not on the binary between artistic freedom and institutional or national concerns. Illuminating the work of communication, the presence of artists interacting with the legitimating apparatus of funders and political support, and the demonstrations required by all does not recommend policy. Nor does it advance one agenda over another. It creates a more robust and transparent network of communication that aids all actors in the art world to be better advocates.

I offer a path to navigate what Eleonora Belfiore has called "a third route", bridging the gaps between Bennett's call for advocacy and an approach to research that takes a critical yet disconnected stance (2016, p. 205). This is what can be gained by this more ethnographic approach. By engaging with cultural policy and the study of artistic production through direct examination of the communicative practices of artists and government officials, I conceptualize the processes of legitimation in the art world as a problem of performance and construction of 
the artistic career. I do not seek a means to pursue policy change, nor do I engage in an art historical project that discovers the artist and their identity within the object of their creation. I illuminate the experiences of working artists as they perform the role of advocate, both within and outside of the cultural bureaucracy. Disposition and performance offer immediate and active theorizations of what art world members do in relation to the institutions of legitimation while avoiding the dangers of treating the "artist" as a solid identity. Proximity and place are key considerations in the theatrical metaphor of presence that illustrates how artists move through situations and spaces to encounter texts, technologies, and individuals that enable their creation.

I will begin my exploration of performative advocacy by elaborating on two key terms: legitimation and advocacy. I will employ these concepts to consider how power can reside in different bodies, structures, and places in the art world. This leads me to consider more deeply the notion of place, movement, and presence in the work of advocacy. Artists appear before each other and in relation to power, whether during a face-to-face meeting or as they navigate the texts and platforms that govern their advocacy.

\section{Legitimation to advocacy: a shifting locus of power}

How does legitimation differ from, and relate to, advocacy? The words can sometimes be used interchangeably in cultural policy and the relations to power structures in the art world and yet they are not synonymous, they have different investments and perspectives to offer. University of Toronto sociologist Shyon Baumann considers the work of legitimation as a collective process. Baumann builds a connection between art worlds and social movements (2007, p. 48), where legitimation is understood as a process that arises "when the unaccepted is made accepted through consensus" (2007, p. 49). This notion of consensus suggests a process that shares power across government and civil society and this is the case across the various 
members of the art world as well. Social movements gain support and resources through a collective repositioning of their value to society $(2007$, p. 51$)$. How then does this repositioning occur as artists begin to build their professional careers and the resources to make their work? How do they relate to and influence the structures and institutions, the rules, texts, regulations, and technologies that legitimate their choices?

The etymology of legitimation can help to understand it as a process in policymaking. To legitimate, as a verb, is to make or declare something to be lawful. The root is from lex, Latin for law or legal. The suggestion is that the process of legitimation is pursued by those who have the power to make laws. It occurs in Parliaments, committee rooms, and other agencies of government. In the case of arts policies, it is handed down to artists through documents and texts. We can use this notion of legitimation to consider the concerns of cultural policy scholars like Jane Woddis who argue that the field is more interested in governmental machinations than in the influence of practitioners and other interest groups $(2014$, p. 496). In characterizing the debates and theories in the literature, with some notable exceptions, Woddis writes, "policymaking is seen primarily as the terrain of government and funders and there is a scarcity of sustained or in-depth discussion of arts organisations and artists as participants in the policy process" (2014, p. 496).

Woddis suggests that the process of policymaking and of the legitimation of certain policy priorities like artistic creation can better be understood by thinking in terms of "invited" and "uninvited" interventions by practitioners in governmental procedures. In the case of art worlds, government can reach out and seek consultation with arts service organizations or collectives of artists to both legitimate decisions regarding cultural policy and appear to be responsive to the sector in the eyes of the public and of other policymakers in areas such as 
education, health, social welfare, etc. (2014, p. 499). On the other hand, the more traditional understanding of artists lobbying, protesting, even harassing governments and their officials are uninvited attempts to influence policy, happening through unofficial channels (2014, p. 500). My observations and discussions demonstrate this process unfolding in the case of the Quebec English-Language Network (ELAN) and the Canadian Arts Coalition (CAC) whose work has moved from more traditionally uninvited intervention in the policy process to now being a sought-after source of information and legitimacy for policymakers.

Woddis further makes the point that such uninvited efforts are not always targeted directly at government. They are just as often directed at the public or at other practitioners and organizations such as the example of playwrights talking to theatres to suggest better compensation for their work. As Woddis states, "all arts organisations have their own policies embedded in mission statements, business plans and other strategy documents. The playwrights' organisations have therefore seen the policies of theatres as an equally important target for their activities" (2014, p. 503). This is most decidedly the case with ELAN and with the actions of CAC that are detailed in my fieldwork. Theirs is not a simple case of talking to the state, but a more nuanced placement of themselves as representatives, legitimating both artists' practices and those of government and its agencies.

When a practice is legitimated, this acceptance is demonstrated by official and unofficial regulations and policies, and it is legitimated institutionally and discursively. Legislation includes the texts that codify those regulations. For instance, the Status of the Artist $\mathrm{Act}^{4}$ and the

\footnotetext{
${ }^{4}$ This is the act that defines certain rights and responsibilities of artists as a unique class of workers that "express the diverse nature of the Canadian way of life and the individual and collective aspirations of Canadians" (Status of the Artist Act/Loi Sur Le Statut de l'artiste, 1992). It pays particular attention to the rights of artists to collectively bargain with producers.
} 
Canada Council for the Arts Act ${ }^{5}$ in Canada are two results of legitimation processes that moved practices of art work out of grey zones governed by unofficial sets of convention and tradition and into government-sanctioned areas of public policy supported by public monies. Policies range from those officially formed into legislation to those created and pursued through less official conventions of practice, literature, and alterations in the recognition of art work and of artists. This is to say that these practices are legitimated by, and result in, actions such as discussion in the art world, the shifting of public funding, and acceptance into places like art schools, studios, and galleries. The art work, its resulting performances and art objects, and its creators become lawful.

It is worth taking a moment to elaborate on the historical creation of the arts support apparatus in Canada, including the Canada Council and its many provincial, territorial, and municipal counterparts. As examined by scholars like Jeffrey Brison (2005) and Anna Rosser Upchurch (2016), Canadian arts funding, as a concept, came from our close relations to both the United States and the United Kingdom. As Brison points out, the 1941 Kingston Conference, recognized as one of the foundational moments in the creation of a system of arts advocacy and the resultant institutionalization of arts funding that emerged from the Massey Report, was funded and organized in large part by the American Carnegie Corporation (2005, p. 70). Visits to Canada's various regions by members of both the Carnegie Corporation and the Rockefeller Foundation enhanced the move toward expressing regional identity through cultural narrative

\footnotetext{
${ }^{5}$ This act established the arm's-length, federal funding body to support artists and their work. It's objects are to "foster and promote the study and enjoyment of, and the production of works in, the arts" which the corporation does by awarding grants and prizes to artists and arts organizations. The act also defines the structure and basic operations of the Council, and its Board of Directors, appointed by the government through the Minister of Canadian Heritage (Canada Council for the Arts Act, 2009). that defines certain rights and responsibilities of artists as a unique class of workers that "express the diverse nature of the Canadian way of life and the individual and collective aspirations of Canadians" (Status of the Artist Act/Loi Sur Le Statut de l'artiste, 1992).
} 
across all of North America. Brison states, "Rockefeller money and expertise proved invaluable to Canadians seeking to define local and regional traditions and cultures" $(2005$, p. 119) and their ideas influenced those, like Vincent Massey and Brooke Claxton, who would become leaders in the cultural funding movement in Canada (2005, p. 120).

While the work of these philanthropic institutions had a decidedly economic and corporate hierarchy that came from fundamental American values, a contrasting spirit of cultural funding and its centralization came from across the Atlantic. Upchurch points to the strong influence on the development of Canadian arts and cultural policy through the exporting of the Arts Council of Great Britain (ACGB) model and what she identifies as the "clerisy", a group of cultural and intellectual elites that sparked these conversations (2016). Upchurch points out that "Canada did not simply duplicate the administrative structure of the ACGB; indeed, there were significant differences between the two institutions in their earliest years" (2016, p. 131), including the ACGB focus on arts organizations over the Canada Council's more diverse support of individual artists along with scholars in the humanities. They did share the arm's-length approach to limiting political and corporate interests in making funding decisions. They both emerged from the impact of this clerisy, "a secular priesthood, setting standards of value and behaviour" (2016, p. 51) as embodied by people like John Maynard Keynes, the leading British promoter of arts support.

What both influences demonstrate is that a cultural and a corporate elitism was at the foundation of arts policy in Canada. The tug-of-war between popular culture and regional autonomy and the centralized decisions about what constitutes "high art" (Upchurch, 2016, pp. 164-165) continues to influence how art is legitimated in this country and the performances necessitated by art world members as they seek that legitimation. 
The complex influences on the institution of arts funding also demonstrate that legitimation is not a one-way street where artists are constantly turning to institutions and structures of the state to beg for the gift of legitimacy in the form of grants or recognition in legislation or policy. Rather, the nation itself can be seen as seeking legitimation through the work of artists. I have discussed this in the literature around instrumentality and policy attachments and particularly notions of national display through artworks. Vincent Dubois, in his essay on the cultural policy implications of the work of Bourdieu, notes that in France a desire for cultural equality and democratization appeared "as a central political issue in the legitimation strategies of the Ministry of Culture" (2011, p. 497). Michael Volkerling suggests that nationstates can use things like anthems, flags, and national narratives in literature and plays to legitimate their very existence, further requiring the state to make these high artworks accessible to the widest possible swath of the population $(1996, \mathrm{p} .196)$. This requirement would most often be met with the use of subsidies by the state to create and disseminate the works, making it possible for the public to see them despite market conditions (referred to often as "market failures") that would traditionally make it impossible for artists to sustain such works. Legitimation is a complex and networked process involving political economic relations as well as the slow and steady work of institutional change.

We see here that legitimation is not a process that is exclusive of influence from both inside and outside the nation, nor does all the power reside in governmental structures. If Woddis is calling for more attention to the influence of artists on the policy process, then my theorization responds, and it does so by taking an approach that links the idea of legitimation to one of advocacy. 


\section{Advocacy: speaking out}

I define the process of demonstrating legitimation by deploying the concept of advocacy. To return to etymology, advocacy has linguistic ties that place the human voice at the fore: it is to (Latin $-a d$ ) call to speak (Latin - vocare). This suggests that it is through the intervention of actors, speaking and acting on their own behalf and that of their colleagues, that changes in the social reality are realized. It is those acts of demonstration, those calls and their attendant textually mediated communications that I want to consider closely in this study. In a legal context, an advocate in a court of law is one who represents and "defends" a litigant. In this sense, the advocate "pleads", introduces "evidence", and argues for a course of action that will benefit their "client", whether that be an individual, organization, or the state itself. In this sense, advocacy is more rhetorical and active than legitimation. It is the demonstration and display of that legitimation, the call for it to occur.

Lisa Young and Joanna Everitt in their book Advocacy Groups, define advocacy in relation to the political process (2005). Advocates seek change in policies and laws but with the important caveat that they have no interest in becoming a governing body $(2005, \mathrm{p}$. 5). These advocacy groups are doing something that they want to make easier or more sustainable through alterations to governmental rules and regulations, including the disbursement of resources. In terms of artistic work, they are attempting to move their activity into an accepted space worthy of support from public monies controlled by government and by arm's-length funding bodies. This notion of doing something together is a further strengthening of the active theorization, as of Becker's art world itself, and is a key to thinking about advocacy as a socially performative or demonstrative practice whose speech acts illustrate relations of power. 
For Raúl Acosta, advocacy is "political work", an effort to influence the policy and projects of government "outside legal frameworks but with claims to moral authority" (2012, p. 159). To think about advocacy as work, as work that has a moral imperative, has important implications for the place of artistic creation and creators in public policy. Can art work be understood as a moral necessity? Furthermore, how does the idea of art as a moral necessity begin to shift the work of artists from creators and distributors of intrinsically valued objects to champions for the place of art as a reflection of society?

Advocacy in other areas of public policy is often framed as having an inherent or natural correctness. Of course we should try to lessen wait times at hospitals. Of course raising the minimum wage will help poor people. Certainly we need a robust infrastructure to protect our national sovereignty. If it is to have moral authority, arts advocacy conceptualizes art work as a public good. It ennobles the human spirit and therefore must be supported. The work of advocacy is not simply a matter of targeting the proper messages, backed by this moral authority, at governmental structures, but it is demonstrative of a wider communications challenge implicating the entire art world and impacting the behaviours of artists, arts professionals, and arts bureaucrats.

Oliver Bennett and Eleanora Belfiore propose that advocacy in the arts throughout its evolution from the 1960s through the 1980s in the UK has increasingly recognized the relationship between arts funding and its impact or value to society (2007). Despite the strong shift toward audit culture and quantitative measurement, the impact of such funding remains difficult to define: is it economic? spiritual? aesthetic? the elusive idea of quality of life? democratic renewal? This also calls into question those processes by which artists choose to 
present their works as beneficial to societal needs while creating tension with the notion of art being an intrinsic good valued for its own sake.

As suggested in a 2018 editorial by Bonnie Green of the Stratford Festival, on the occasion of her stepping down as advocacy chair for the Professional Association of Canadian Theatres, "[t]he thing is, if one works in theatre, one is an advocate for theatre" (2018). Green's pronouncement suggests that advocacy is fundamental to our understanding of the work of art. We require an examination of advocacy as interventions by artists into the institutions and places of power in the art world, both from within and outside those very institutions. This study advances our understanding of social and power relations in the art world. It moves us toward addressing how experiences, speech, texts, and bodies are activated in this work.

Bennett and Belfiore engage in a quest for evaluative measures that challenge new public management and audit discourses in the arts. Jane Woddis is seeking to recentre the practitioner in the processes of cultural policy. These scholars leave an opening for research that is focused on the performance of advocacy. My theory helps to illuminate how that performance is understood through evolving platforms and practices of textual mediation and the live encounter between artists and government representatives. It pays attention to when and where these encounters happen in time and space and considers questions of presence and performance that are less well recognized in the literature.

\section{Showing up: presence and performance}

If we are to thread the needle and find the promised third route offered by close observation and analysis of moments of encounter in advocacy, of speaking back to policy as human voices but also through textually mediated interactions, we need to consider two related concepts: presence and performance. Advocacy is more than uninvited or invited interventions 
by artists acting as advocates into the field of government policymaking. It is more than grant applications, electronic portals, and new funding models and priorities. Advocacy is a presentational act. It is a display of body, of voice, in time and space, as much as it is a textually mediated relationship defined by forms, CVs, project descriptions, and artists' statements. To consider these aspects of performative advocacy, it is useful to embrace both the dramaturgical work of Kenneth Burke and Erving Goffman, along with notions of performativity from both J. L. Austin and Judith Butler. In this manner my concept considers the how, the when, and the where of advocacy.

Performance is a productive way to think about how art world members negotiate these moments of demonstration and display. Performativity questions the actions themselves (in body and in text) that construct ideas of the artistic career and give artists the agency to form their social selves in relation to these powerful structures. Presence opens the path to the live and immediate interaction of people in the spaces that constitute centres of power and influence in the formation and implementation of policies around artistic creation. This can be held in tension with issues of textual mediation which I recognize as one of the primary ways that the practices of artists are prescribed by the institution of arts funding.

Kenneth Burke introduced the notion of dramatism to think about social interaction and rhetoric (1969, p. xv). In A Grammar of Motives, Burke suggests that “[m]en seek for vocabularies that will be faithful reflections of reality. To this end, they must develop vocabularies that are selections of reality" $(1969$, p. 59, original emphasis). What Burke is saying is that there are many ways to frame the action of a given set of social relations and what we choose to illuminate, to stage if we are to use theatrical terms, is a directorial decision that guides our attention toward certain elements of those interactions and away from others. By placing the 
actions of art world members in their role as advocates, on a stage that reveals the motivations and artifices involved in those relations, we might better understand the use of bodies, voices, and appearance in the political world of arts advocacy. We might offer both advocates and their audiences in governmental structures and in the wider arena of the public better tools through which to understand each other. Finally, we might use these insights to inform other aspects of advocacy in sectors unrelated to the arts but equally concerned with public policy pursued by individuals negotiating a slippery sense of what they are doing in relation to government institutions.

As a metaphor for advocative action, the stage is a productive representation (or, as Burke suggests, a useful selection) as actors (and their collaborators, like directors, playwrights and so forth, along with the expanded notion of "performer" which would include dancers, musicians, circus artists, etc.) are always interested in motivations: the necessity of proceeding in one direction or another, the necessity of speaking certain words, moving in a particular way, striking the right note, or performing certain actions to achieve the goals of the scene or the score, and to overcome obstacles.

The presentational concepts examined by Erving Goffman are valuable for illuminating the advocacy work of performing artists that are the primary focus of this study. Artists are experts at presenting themselves and observing the behaviours and dispositions in our social life. Goffman, in his seminal work The Presentation of Self in Everyday Life (1959), offers up a vision of social interaction as theatrical performance. Goffman's suggestion that the scene, while it can be a tool for the actor to employ to maintain, enhance, or legitimate his performance, is also a constraint that produces certain kinds of performances. "When an actor takes on an 
established social role, usually he finds that a particular front has already been established for it" (1959, p. 17).

There is a further utility to acknowledging the staged actions of advocacy as performance and it is connected to speech acts and their conventionalized, ritualistic nature. Speech act theory posits the construction and deployment of language as an active practice that does something (Austin, 1975). One way to theorize advocacy acknowledges actors that are doing something that they believe would be easier with the support of government resources, though they may have no desire to shift from doing that thing to the more abstract idea of governing. As human performers, or what Burke refers to as "agents", we use all of the tools at our disposal: speech acts, body language, and placement in the Burkean "scene". These are very powerful instruments to help understand the work of advocacy because we should be interested in every action taken by artists as they perform the role of advocate.

Speech acts and performative utterances (Austin, 1975, pp. 5-6; Searle, 1965) demonstrate that language has concrete effects in the social reality. According to J. L. Austin, performatives are utterances that accomplish real actions in the world as in his example of the words "I do" spoken at a wedding (1975, pp. 5-6). The act of speaking those words constitutes the marriage, a social institution that has legal and moral effects on the people being married and on the wider community. Scholars of language like Jeremy Searle (1965) and James Benjamin (1976) expand on this idea noting that this active language performs these actions in specific circumstances. When one makes a statement, argues Searle, "[m]eaning is more than a matter of intention, it is also a matter of convention" (1965, p. 8). People may say "I do" many times throughout the day but the context in which it is spoken at a marriage, surrounded by other 
rituals, and spoken by the appropriate agent before an officiate and the community, creates the social action.

Dancing in the street and using specific words (like pas de bourree, for instance) may be enough to give oneself the ability to be called a "dancer", one does not need to display a certificate from Les Grands Ballets. Legitimacy in the art world is an ongoing process throughout the artistic career. It is enabled by the act of declaring oneself an artist as much as by training or membership in a union or professional organization. Ongoing advocacy and justification are requirements for maintaining the artistic career in ways that are quite different than other professions that do not continually have to justify their very existence.

Austinian conceptions of performativity are neatly balanced by the critique of Austin's work that comes from feminist scholar Judith Butler (1997). Austin's speech acts presume the speaker as the "actor" that creates the change in social reality through their act of speaking. By declaring my work as artistic, I gain access to the art world. While it may reject me, I nonetheless qualify for certain interactions with the structures of legitimation through that naming. Butler foregrounds the ways in which the social reality "speaks" the actor, hailing them into particular roles and practices in a discursive sense (Cabantous et al., 2016). Where the artist who refers to themselves as a dancer may embody that role and perform its practices, there are other non-artistic behaviours expected of them. When they encounter the institutions of government and seek legitimation through the performance of advocacy, they will be required to engage in certain practices with certain texts in certain places, all of which have almost nothing to do with the art of dancing. In one instance the artist would appear to have the ability to name their career as "dancer", while in the other their legitimacy is a product of interaction with a powerful and discursive structure that names them. 
That interaction becomes even more complex when we incorporate the notion of advocacy in relation to things like funding or service to an arts service organization. Here the dancer is using other, perhaps less developed skills and dispositions, to represent a group of people in the same artistic discipline, or even outside that discipline, specifically to make the environment in which their work happens more sustainable and amenable. This is a key consideration that helps us to complicate the actions of advocacy not as a purely agential choice on the part of the artist but rather a disposition that artists can be required to perform.

Some scholars have attempted to align notions of performance and intervention in policy and their work influences my own. Rosie Anderson examines the advocative work of activists as they attempt to influence policymaking decisions using a dramaturgical framework. Anderson deploys the theatrical concept of the Fool, a character uniquely able to speak truth to power through comedy and pathos $(2014$, p. 16). Anderson works to "explain how I arrived at a way of representing - or perhaps represencing - the activist" (2014, p. 18, original emphasis) through ethnographic methods within the NGOs she observed.

Anderson is interested in the ways activists perform theatrically before various constituencies, including government. She is also inquiring into the influence that dramaturgical concepts like action, speech, appearance, and mise-en-scene, have on the emotional work of policy creation (2014, p. 18). As with my study, Anderson employs an institutional ethnographic (IE) method but acknowledges the limitation of policymaking as a messy process that does not always foreground the recorded texts and documents that are of such keen interest to IE research. I appreciate Anderson's attention to the physical and the scenic elements of performance as it relates to policy. 


\section{Setting and staging, presence and presentation}

Dramaturgical concepts of setting and staging are the central metaphors used by Maarten Hajer in his essay on participatory politics in the Netherlands (2005). Hajer suggests that we need to pay more attention to the elements of setting as they help to produce subjects relating to institutions of power and their manipulation can help to inform advocative and democratic practices $(2005$, p. 626). For instance, large donations to charitable causes are often announced either in a well-appointed conference room, able to accommodate cameras and microphones that will capture or broadcast the important moment, or in the location in which the charity operates, like a hospital or community centre. These announcements are further staged using props like oversized novelty cheques or members of the population addressed by the charity's work. In this case, even people, often posed, smiling and grateful yet silent, can be used as props to complete the performative transaction.

Artists who understand these constraints and who know how to fit within them tend to be more successful in triggering the release of resources for their own work. Just as politicians who understand the particular conventions of speaking or answering questions without actually saying very much at all, or used car salesmen who respond to a low offer on their car by "checking with the manager" so that they can come back and report that they would have given the client the discount but the boss said no, these games are a part of many different kinds of interactions. The knowledges learned through convention, through media representations, through social networks, all help to prescribe these particular kinds of performances.

These codes exist at multiple levels and they are not restricted to the textual mediation of application forms and online portals but also extend to physical, bodily performance, and issues of social position, ethnicity, etc. Nor are they restricted to communications between artists and 
government but also exist within the arts community itself, particularly in moments where artists are negotiating the divided labour of administration and artistic creation as discussed in the work of advocacy groups of working artists. This often requires certain groups of artists, particularly those with difficult or fraught relations with the government (artists of colour, Indigenous artists, deaf and disabled artists, and other marginalized groups) to perform advocacy on very specific levels.

For instance, the creation of the Indigenous Creating, Knowing, and Sharing grant section at the Canada Council is welcome recognition that the traditional practices of Indigenous artists have been underserved in the past. However, these artists are now streamlined into very specific kinds of performances with the Council. They may choose to continue to apply to less targeted sections of funding but this may raise the question for a program officer if an artist does not engage with the granting program launched specifically for them. Is more advocacy expected of some artists over others? Do some members of the art world, possessing knowledge and experience gained perhaps from family connections and history with funding bodies, have to become advocates? Is Bonnie Green correct in stating that simply being a part of the theatre community requires this advocative performance?

The performance of legitimacy as artist and as advocate must comprise an understanding of the tension between the art maker and the cultural worker, hearkening back to, and troubling, the Romantic ideal. As Alison Bain writes of visual artists in the current art world (2005, p. 29):

[A]rtists are required to be experimental and innovative, and to push the frontiers of art while capitalizing upon the development of a distinctive and marketable individuality. In this market-savvy entrepreneurial role, artists are encouraged to exaggerate and exploit their individuality and to feed into popular myths to reinforce their occupational authenticity. 
There is an interesting disjuncture in language and performance that is revealed in blurring the lines between artist and advocate and that is evident in much of the fieldwork observations I offer here. The ways that artists negotiate and demonstrate their value to the community and their work for the art world are of interest when I consider how many arts administrators and advocates trained and maintain a practice as artists. The same may be said in the context of artists working as educators who train emerging artists to embrace the administrative work of art-making while trying to establish a career as a creator. How slippery is that distinction and the divisions of activity within the person we call (or who calls themselves) artist? How are these questions further complicated by the fact that some government agents (including all of the Canada Council program officers I interviewed for this study and those with whom I have a personal connection and knowledge of their history) also self-identify as artists, sometimes actively practicing, though often lapsed? It would seem to be a given that program officers will have some prior knowledge of the arts sector but is that knowledge necessarily based on artistic creative practice? How many program officers come from the world of arts administration and what kinds of knowledge do they bring to their work? The constraints of time and resources did not allow this research to delve too deeply into these questions but this is an area worthy of further research. For this study, the dynamic performances of the moment are of primary interest.

Goffman's notion of presentation is very much concerned with the settings of work as evidenced by his deployment of specific examples like offices, restaurants, and his contention in the preface to Presentation of Self that he is looking at "the kind of social life that is organised within the physical confines of a building or plant" (1959, preface). Imagining the confines of these spaces helps us to understand the quotidian nature of the everyday that Goffman is trying to 
investigate and the importance of face-to-face interaction as a fundamental mode of social organization. While writing in the 1950s he obviously could not countenance the world of digital communication and telepresence that currently exists and yet his theories continue to influence our thinking about social interaction and the ways that digital advocacy relates to the physical encounter of human agents. Performative advocacy embraces the significance of co-presence both as an element of the bodily nature of advocacy and the understanding that interacting with structures of power in the art world often means moving toward them, gathering in their physical spaces, and making presentations at specific spaces and times.

Parliament Hill in Ottawa is such a space of assembly as are many national capitals, economic centres, and even community hubs, including churches, schools, etc. Ottawa is significant as the seat of government and the home of Crown Corporations like the Canada Council that relate to the work of artists. The gathering of arts advocates for face-to-face meetings with targeted MPs, Ministers, and political staffers, and with each other in the private spaces of offices as well as in the public spaces of reception rooms, local pubs, and even on the streets of the national capital, is an opportunity to consider how the physical movement of these individuals is understood.

A showcase advocacy event like Arts Day on the Hill begins with a conglomeration of online messages, email exchanges, videoconferences, and it will result in exchanges of policy documents and recommendations. The day itself, part of the tactical advantage of the event is a focused gathering of human bodies at one space and at one time. The significance of such an assembly on the work of artists, acting as advocates, is in the demonstration and display of coming together to make a statement of solidarity, demanding physical recognition of the artist as a body in time and space. The presence of these artists meeting with people in spaces that are 
usually only mediated through interactions with policy documents, funding portals, and well managed and choreographed speeches is an opportunity to think more deeply about both liveness as a feature of advocative action and the performance of both artists and government agents as influenced by the materiality of these institutional spaces. Studying the gathering of these individuals is a way to consider who gets to perform in these spaces, how certain artists are invited, or even coerced, into becoming advocates. The work of advocacy also requires that certain other work, like core creative activity, be paused or backgrounded for the demonstration of legitimacy to take place.

The body, and particularly numerous assembled bodies, are imagined as instantiations of political speech and action, often by entering and occupying public spaces, or spaces that are traditionally and even legally prohibited. We see this in the work of Judith Butler, drawing on the biopolitics of Foucault among other concepts, to explore the idea of assembly and presence as political action. In her Notes Toward a Performative Theory of Assembly, she suggests "[s]howing up, standing, breathing, moving, standing still, speech, and silence" $(2015$, p. 18) are all elements of political action that expand traditional notions of Parliamentary processes and challenge us to consider speech acts as embodied $(2015$, p. 19). Well documented examples include the actions of Occupy activists (Butler, 2015, p. 1; Hardt \& Negri, 2017, p. 68) and the various occupations that made up the Arab Spring.

In theatre and performance studies, Jaana Parviainen describes this kind of direct political action as "resisting choreographies" (2010, p. 311), suggesting the organized movement of individuals. As she states, her interest is not restricted to the delivery of speech acts but rather "how involvement in different choreographies directs us to deliver speech acts as agents in these 
constellations" (2010, p. 315). As with the work of Benjamin, speech acts are closely linked to their context, in this case, the physical, bodily context, of where they occur.

If the bodily assembly of artists is understood primarily as protest action we run up against the problem identified by de Peuter where research addressing the relationship between artists and the state must try to reconcile the divide between a rhetoric of dissent and resistance and a politically valuable agonism (2014b, p. 278) that recognizes fundamental differences and seeks negotiated solutions. It is here where the notion of advocacy and its performative dimension can be valuable as it seeks answers about communication and not simple solutions to policy problems.

These ideas of assembly, embodied speech, and political action are important but they do not address some aspects of movement that performative advocacy can seek to answer. When artists appear before each other as advocates amid the institutions of power in the art world and in spaces traditionally controlled by those structures that govern their art work, what are the movements, and the transformations of practice and performance that help them to get there?

\section{Demonstrating legitimacy}

Performative advocacy is a means to think about the activities pursued by artists in the course of their everyday lives both in the studio and in the realm of advocacy. It recognizes humans as they are required to speak, ad vocare, to perform actions, to demonstrate the legitimacy of their art in a world of work and in the construction of a career. This is never a oneway transaction that travels from the structures of power to the artists. It is a performative web of associations, actions, and performances. This activity is performed through encounters, both live and textually mediated, necessitating different demonstrations of legitimation. 
Performative advocacy works to re-centre the artist as advocate in discussions around artistic production and funding, probing the value discourses of the arts in Canada and shedding light on the language and texts that circumscribe this important work. It moves us away from the totalizing and overwhelming influence of governmentality and administration in the study of art work. It helps to identify the specific practices performed by these artists and by the government agents with whom they engage in advocacy. This is a theorization that is aligned with the work of Becker: humanistic, collective, ethnographic, and practice-oriented. It embraces the immediacy and intimacy of individual experiences and expressions and the manner in which agents appear before each other and in the spaces of power, moving toward and away from them while being aware of what is being left behind. It invites a reflexive position for the researcher while resisting the demand to be activist or advocative. As in the words of James Reid, "the researcher is 'present' in the research, as the main research instrument, and has 'presence', as an embodied being in the present" $(2017$, p. 2). The work of art and its performative relationship to the work of advocacy helps us to understand how creative practices are repositioned from the margins into the mainstream of policy and public funding discourses with a particular focus on how national programs are implemented on the ground and in the community.

The conversations and observations along with the linkages made to texts and institutionalized policies discussed in this ethnography begin to answer how advocacy work cannot really be “divided”. Becker's terminology suggests this work is allocated among artists acting as advocates, arts bureaucrats, professional lobbyists, and even educators who instill that sense of collective action and the importance of advocating for the entire art world during training. All these functions, or what Bourdieu might call "posts" (1993, p. 98), can be embodied in one individual and certainly within the same organization and their division can be 
analytically useful as long as we recognize the shifting performances required. As noted by Catherine Goetze in her discussion of Bourdeiusian concepts, there is a connection between disposition and performance, with Bourdieu reformulating the work of Goffman to understand the effects of symbolic capital on social relations and practices (Goetze, 2017, p. 24). Performative advocacy highlights that connection and understands that dispositions are embodied performances that are staged in relation to legitimating institutions including schools, arts organizations, government bodies, and funders at various levels.

I further engage with the spaces in which this work takes place, both in the physical sense (studios, classrooms, workshops, offices, the halls of Parliament) and in what Arendt calls the "space of appearance" (1998, p. 204), that philosophically constructed network of relationships and artifice where humans perform and negotiate power. These engagements inform the major sites I have chosen for my research: a theatre school, an advocacy event on Parliament Hill, and the program office of the Canada Council. I am interested in how artists, acting as advocates, and governmental bodies co-create the conditions under which artists create artworks through their use of texts (grant proposals, evaluative forms, service agreements, etc.) and through live negotiations and interactions. I am interested in the spatial movement of these agents and their performance, both bodily and through speech acts and shifting dispositions, as they put these texts into practice.

These investments necessitate an approach to the generation and analysis of data that expressly acknowledges the power that texts have in the coordination of these activities. This approach must acknowledge the importance of place and an engagement with practices and human experiences as a central mode of producing and expressing knowledge. The methodological approach must acknowledge the position of the artist and their connection to the 
researcher both as research object but also as sympathetic members that recognize their own standpoint. This standpoint is the socially constructed "world" that engages in this work from within highly mediated institutional constructions like "the nation of Canada", our "heritage" and our "national identity", or even "our art" as these exist in relation to policies and priorities like social welfare, national unity, or protection from cultural domination from outside our borders. The approach to inquiry that best responds to the immediacy of these practices, the focus on lived experience, and the embracing of language and text, is institutional ethnography. 


\section{Chapter 3 - Inquiring with Institutional Ethnography}

\section{Aligning institutional ethnography and performative advocacy}

A performative approach to inquiry in art world advocacy suggests certain methodological commitments that consider the practices of individuals and their interactions with institutions and structures that legitimate their work. In this case, performance must be understood not simply as a staged event but rather in the sense of a performative action, often speech and gesture, but also relations with structures and technologies that call forth a social reality and build environments where art work is enabled. In this chapter, I will suggest a connection between this framework of performative advocacy and the approach to inquiry known as institutional ethnography (IE). To contextualize the approach and demonstrate its appropriateness I will offer a brief history of IE and a critical summation of some of the central tenets underpinning the methodological approach. As suggested by Anderson, IE helps us understand that "the practices of policy work are an enactment of a wider system of knowledge that understands rationality and emotion to be two essential but irreconcilable ways of knowing and being in the world" $(2014$, p. 18).

IE is ideally placed as an approach to inquiry that foregrounds the lived experiences of research participants in conjunction with an investment in texts as performances. I will offer my understanding of how I interpret and implement IE in revealing the communication of the working artist with governmental structures. This includes establishing a sense of the how and where of the performing artists' advocacy work: their training and formation as advocates, their presence and practices of advocacy, their interactions and entanglements with creative and administrative activities, and their implication in the institutions that legitimate their efforts. 
IE was developed in the 1980s by Canadian sociologist and feminist researcher Dorothy E. Smith. Smith was in search of a critical response to traditional ethnographic methods in sociology that, she argued, do not adequately explicate the embodied experiences of marginalized communities, particularly women (2005, pp. 9-10). Smith explains that the impetus for her method came from seeking a feminist stance in contrast to those traditional methods that privileged the production of knowledge from "the Archimedean point, the position outside the world, from which it could be grasped objectively" (2005, pp. 28-29). Smith offers IE as a means to approach social phenomena through uncovering "how things work, how they are actually put together" (1987, p. 147). This active approach is indicated for a project that proposes to explain what we do rather than who we are.

Coming as it does from a feminist perspective, IE has been used extensively to study aspects of work situations that are often heavily gendered: nursing, primary education, and social work being some of the main objects of inquiry. The impetus for IE's development came from Smith's own experience along with her friend and collaborator Alison Griffith as single mothers within a school system (or "institution") that viewed them as outside the mainstream. Despite years of slow recognition that many familial arrangements exist, the normative nuclear family maintains a strong hold on the policies and ideologies of many school systems. Those falling outside that ideal are often singled out with students' behaviour attributed to challenges "at home" implicating parents as a source of "difference". These two women sought a new way to understand the nature of their relationship to the "school", its administrative structures and norms, and the social relations that attended "motherhood" as it was prescribed by the school system (2005, pp. 32-33). Smith recognized similar institutionalization in the academy that suppressed certain knowledge and experiences, particularly those coming from women. 
IE proposes a way to gather and to analyze data that maintains the primacy of lived human experience. It is meant to confront overarching theoretical assumptions about the world and draw both questions and answers from the everyday practices of individuals as they relate to institutions and texts that coordinate their activities. As Campbell and Gregor argue, the focus of the approach is on "concepts of social organization, social relations, ruling relations, texts, textmediation and objective knowing, experience, discourse, and discursive organization" (2004, p. 27). Those are a lot of concepts and this points to one of the central critiques of IE, that it misunderstands or obfuscates its theoretical investments. My research weaves together performative advocacy and IE, acknowledging that the approach to inquiry foregrounds the actions, the performances of individuals as they are coordinated by texts and institutions. In so doing, this research makes a clear link between the methodological approach and a theoretical framework, each supporting the other. Smith's $\mathrm{PhD}$ advisor was none other than Erving Goffman himself, suggesting a clear influence of performance frameworks on the founder of the IE approach.

\section{Key terms in the IE approach}

Undertaking an institutional ethnography involves coming to grips with a few key terms that Smith and her adherents invoke in their work. Primary among these is the idea of the institution itself. A fresh examination of arts advocacy is enabled by expanding the notion of arts funding to embrace its institutional nature. Rather than focus on the specific organizations and corporations that function to support creation: arts councils, government ministries, professional organizations, the IE approach looks at the wider implications of practices, texts, and relationships that surround the idea of government intervention in the art world. It is this dynamic movement between the embedded coordination of activity and the individual actions 
and performances of those in these pockets of the art world that makes this approach productive in illuminating performative advocacy.

In the first of several books written on the approach, Smith provides a glossary which defines institutions as "complexes embedded in the 'ruling relations' that are organized around a distinctive function such as education, health care, and so on" (2005, p. 225). This explanation helps us to understand that we are not constrained by talking about specific organizations or structures, even if institutions tend to manifest physically in places like welfare offices, hospitals, nursing homes, etc. What Smith is proposing is that institutions are social constructs that are in flux but that work to "generalize" the actions of individuals across different spaces $(2005, \mathrm{p}$. 225). In art world advocacy this tends to force a constant re-evaluation of what work artists must do in order to create a sustainable environment where they can produce and circulate artworks. It requires knowledge well beyond traditional understandings of artistic production: what they will do in rehearsal rooms, studios, and performance venues. Rather, we invite other avenues and stages of performance: in boardrooms, workshops, and in front of computers connected to complex webs of interaction with grant application portals and pre-budget briefs.

IE imagines the institution of health care as a network of laws, policies, ethical imperatives, spaces, workers, patients, technologies, behaviours, and so on, all of which serve to coordinate the activities of the various individuals that engage with the institution. This kind of theorizing is one of the reasons that Thompson and Pinsent-Johnson can make the argument that IE and actor-network-theory share some methodological links (2011, p. 695). Both approaches suggest that there is much more to interactions that build social and political realities. Special attention should be paid to objects and processes like texts and documents, technologies, and mediations, as well as physical spaces and the presence of actors within them. Rather than 
studying these as separate elements of an institution like arts funding and support, the network itself, its active construction of actors as they work to relate to these other parts, is analyzed through individual experiences.

That link is particularly helpful when it comes to considering performative advocacy as the institutions, the practices, and the materiality and presence of the individuals in relation with one another lies at the centre of the inquiry. This means that the kinds of data produced and analyzed with IE include the impact of the material texts and documents that coordinate the activities, the performances of individuals in the art world. The data includes cultural policies, grant applications, artistic CVs, headshots and so on. Most importantly, the actions themselves must be considered: the talk, the filling out of these applications, the interactions with spaces and technologies of cultural policy, and the experiences and actions of individuals that are ideally observed as they go about their professional lives and pursue advocacy. These data speak to the administrative functions that many artists and arts bureaucrats must perform, where they perform them and what materials and technologies they use.

As I have suggested in my discussion of the artist as implicated in instrumental state priorities, constructs like "Canadian heritage" or "Canadian identity" or even "arts funding" more generally, act as institutions in the art world. The network of instrumental and intrinsic arguments for public policy to support artistic production and the structures, organizations, and technologies that have emerged and continue to emerge and shift toward that end are an institution in this country. They maintain organizing constructs and prescribe certain behaviours (applying for grants, meeting with political leaders, lobbying the Canada Council, legitimating artistic work through online profiles, training in a CEGEP, etc.) that artists must perform in order to demonstrate their legitimacy through advocacy. 
Smith is also explicit in tying together institutions with the power to organize and coordinate language. Both the language used by the institution to define its purposes and the language it requires from those that interact with it are coordinated from a central location and impact on language at the local level. In her essay on texts in institutions, Smith argues that these constructs serve to suppress the language and practices of individuals on a local level and require adherence to "extra-local" codes (2001, pp. 159-160). For instance, artists who hope to present themselves as legitimate and worthy of support from government are required to present the purposefulness of their creative work in the form of program descriptions, history of production, an artists' statement, or a CV. These texts have specific forms and coded words, for instance, how they define their "discipline", or more recently, their "interdisciplinarity", their "impact" in the art world and on audiences, or making explicit an artists' past granting history or their history of prizes, exhibitions, or performances (Klostermann, 2016, p. 55).

This leads us necessarily into a discussion of texts as a foundational IE concept. According to Smith, texts are the product of these institutions and do the work of coordinating activities of individuals across space (2001, p. 160). The significant qualities of these texts are their materiality, their replicability, and their ability to expand the ethnographic frame beyond basic observation. Smith and Turner insist that texts are "material objects that carry messages" (2014, p. 5): actual documents, like funding agreements, program guidelines, CVs, artist profiles, and grant applications.

What differentiates the approach is the attempt to bridge semiotic or critical discourse types of textual analysis that focus on the making of meaning and a sociological or practical orientation that seeks an understanding of how texts are activated by individuals as they relate to the institutional structures that often produce these texts (Smith \& Turner, 2014, pp. 6-7). There 
is a significant strain of policy research that relies on critical discourse analysis (Schon \& Rein, 1995; Timofeeva, 2008) along with linguistic and semiotic analyses as methods (Shtern, 2012). Exploring how policies and their languages come to mean what they mean and how they impact all members in the art world in various ways is a productive method. IE takes the opposite yet complementary approach, approaching policy from the actions and experiences of those practitioners and policymakers that work within the institutions and activate the texts that circumscribe their working lives. This reversed focus leads ultimately to a more humanistic understanding, a practice-based knowledge of the art world and its members.

The fact that these documents are repeated is what coordinates activity, despite varied readings of the texts, across different local situations. While not always precisely the same, repeated words, numbers, and schema in these texts are "key devices in hooking people's activities in particular local settings and at particular times into the transcending organization of the ruling relations" (Smith, 2001, p. 164). The specific line items in a theatrical production budget are a good example. Despite vast differences in production styles and artistic orientation, the format of a budget remains remarkably similar and the knowledge to complete these forms must be learned, shared, and activated in order to have success in obtaining support.

A third key term for IE inquiry is ruling relations (Smith, 2005, p. 227). These are understood as the established relations that exert power and influence over the practices of individuals across a range of local contexts that are discovered to be ubiquitous and "implicated in the governing of society" (Dobson, 2001, p. 154). Campbell and Gregor offer a useful example of students riding the bus in a Canadian town. The actions of lining up and waiting for the bus, showing an ID card when stepping on, the verification of the driver, along with all the preceding activities that involved getting the bus pass in the first place (picture-taking, proof of 
student status, fee payment, etc.) are all governed by an extra-local set of relations that determine how the activity of getting from home to school will take place (2004, pp. 29-30). The authors note that much of this interaction occurs without the need for speech. The process, like many bureaucratic exchanges, is almost entirely textually mediated. As long as everyone displays the proper texts, the practice of riding the bus is smooth and easy. It is when a new text is introduced, such as recent moves in some jurisdictions to require a different transit pass depending on your age, that we note the importance of these texts and relations in our everyday lives (Campbell \& Gregor, 2004, p. 30).

We see the same processes at work in the art world and particularly in the relations between artists and the institution of arts support and funding. Grant application forms are texts that are created and administered from a central location and they require the application of particular languages and forms (project descriptions, budget forms, marketing plans, along with personal justifications like CVs and production histories). They also require the investment of time and money (to hire a consultant for example), even the same "lining up" (if we extend the metaphor to include the interruption of core artistic activities and family life to spend hours in front of a computer to write and submit the grant application). In many cases, the process is entirely textually mediated even if speaking to a program officer is recommended. Displaying the "proper" responses means you get to "ride the bus" or make your artwork with the support of public funds.

When policy requirements and texts are altered this has a direct impact on the practices of artists. A recent example is the requirement by the Canada Council that grant recipients demonstrate their commitment to respectful workplaces, a new "box to tick" that many artists are struggling to negotiate due to a lack of knowledge in human relations as well as a simple lack of 
resources, time, and funds to implement various policies, such as hiring an intimacy coach to deal with scenes of a sexual nature in a play.

Texts appearing and being activated across various moments and places in the art world coordinate the actions of individual art world members. As Teghtsoonian argues, there is a clear link between this idea of ruling relations and the concept of governmentality. Both governmentality and ruling relations bring together an "interest in understanding the particular mechanisms through which the goals and ambitions of those who rule/govern are taken up by individuals in diverse local sites as their own" (Teghtsoonian, 2016, p. 2). Policies, texts, and the language of government funding bodies, along with the kinds of application and advocacy processes that circumscribe how artists interface with the state (through practices and representations like online profiles in the application portal of the Canada Council for instance), instantiate ruling relations in the art world. They work to stage the performances of artists as advocates. The ambition to create art as freely as possible is held in tension with the texts required to be activated to ensure the resources for the pursuit of that creation.

The ethnographic aspect of an IE inquiry focuses on the close observation of everyday practices and experiences of individuals as they negotiate these ruling relations and activate texts that help to produce and enact them. This helps us to get beyond the logics of power as described by Jonathan Sterne (2002, p. 64) and into some of the actual practices governed by these relations. Smith's convictions seek to challenge and force an evolution of sociological methods that do not take enough stock of individuals" "local particularities of bodily existence" (2005, p. 227). This is what Smith refers to as standpoint. According to Dobson's take on the idea, the research must meet these people "where we are" (2001, p. 148), the "we" being a social position that accounts for both the researcher and the object of inquiry. Standpoint, explains Smith, is "a 
point of entry into discovering the social that does not subordinate the knowing subject to objectified forms of knowledge or political economy" (2005, p. 10).

There are two significant aspects of standpoint that help to connect this research to the art world. The first is identified by Tummons (2017, p. 153) and it concerns the value of reflexivity on the part of the researcher when they closely identify with the experiences of the group under study. How can I do this unbiased work when I declare myself so clearly as an artist and use that very fact to secure access to the people and spaces that make this research possible? If there is a consistent refrain in the responses of my research participants upon explaining the basic nature of my study, it is how important it is for the arts sector. What does this mean? I have read that refrain in the same way that Scullion and Garcia have, in that "what the cultural sector really wants from research is the killer evidence that will release dizzying amounts of money into the sector" (2005, p. 120). As Sterne notes, cultural policy researchers are bound to ethically consider their relationship to the power structures they are examining, forcing an answer to "the question of political representation: for whom does cultural policy studies take its stand in the policy field?" (2002, p. 82). The implication here is that if the researcher stands for the artist, they are likely to take on an advocative role that seeks out that killer data point that will open the financial floodgates. However, if the researcher tends toward a view from an administrative or governmental position, there is an inclination toward abstraction and a positivist agenda focused on quantifiable results of arts programs and holding artists and their practices accountable for public expenditure. What we see is the need for governments to realize the hard numbers and clear results that can be directly justified by their policies.

My history as a theatre maker gives me both important avenues of access to, and understanding of, the practices and experiences of artists. That history also forces me to be 
critical of my own positionality as an advocate. I am an artist and arts administrator. I acknowledge that individuals engaged in art work and advocacy are a "standpoint" group within the institutional order of Canadian art and cultural policy as I seek to study it. As Smith suggests, standpoint can be a way into an institutional discourse that embraces the experiences and knowledges of the study object without objectifying or attempting to stand outside their experience (2005, pp. 10-11). It is not to suggest that a researcher who is not an artist could not engage in such research. Rather, it is that the position of the researcher and the identification with the standpoint group is an integral part of the approach to inquiry. It informs choices of language, the implementation of methods, even theoretical leanings. In my case, it recommends the use of a performance framework as that is my standpoint and the primary group I am attempting to research.

These methodological investments: institutions, texts, ruling relations, and standpoint, make IE a unique and productive means of exploring aspects of the art world. They also represent the reasoning behind my personal connection and appropriateness for this work. Many researchers have taken a close look at the art world. Many come from that world and seek to advocate an activist agenda. Georgina Born, for instance, as a classically trained musician and a member of several musical outfits in the United Kingdom, can use that social position to enter the world of IRCAM (1995). As Teghtsoonian points out, IE researchers are often concerned with the emancipation of the standpoint group (2016). George Smith's action research in the LGBTQ+ community, to which Teghtsoonian points, is a clear example of the tension that exists between academic and emancipatory research. As George Smith states, "I think of investigating a politico-administrative regime as an ordinary part of the day-to-day work of challenging and transforming a ruling apparatus" (1990, p. 646). He then goes on to remind us that these studies 
are designed to be published, read, and debated both by academics and by those that would derive potential benefit from the findings (1990, p. 647). In the art world then, IE is ideally placed to help the researcher and participants to navigate Belfiore's "third route" (2016, p. 205) through ethnography.

\section{IE and art worlds in Canada}

My research has uncovered that IE has been used in only two significant studies of artistic work in Canada and both are grounded in the visual arts. Artist and researcher Janna Klostermann, in seeking to explicate the relations between visual artists and the gallery system, notes the use of texts such as artists' statements, CVs, and grant applications, as examples of ruling mechanisms for artists who are trying to break into the Canadian visual art network (2016, p. 46). While Klostermann has little to say about relations with government, I suggest that the same is true of the vast majority of those relations in that they are circumscribed by textual mediation, ruling relations, and coordination of activities constrained by expectations of language and performance.

Klostermann made observations at a number of galleries, events, and in artists' studios. She examined institutional texts and performed interviews. All these are hallmarks of IE and of ethnography more generally and guided her efforts to "make visible how visual artists participate discursively in public galleries and in the art world" (2016, p. 45). While making the argument that artists represent a marginalized (or even deviant) community can be problematic (as they can also represent members of the economic and cultural elite), it cannot be ignored that, in Canada in particular, many artists and arts organizations rely on forms of governmental support available at the federal, provincial, and municipal level. These supports can make them subject to the practices of grant writing, marketing, and performative advocacy that can be studied through IE. 
My research goes further than Klostermann to examine not just the artist in the market but also the importance of this government and para-government relationship to politicians and arts councils. Using a similar set of methods, I am also more cognizant of my own artistic processes and reflexivity, using those memories and experiences to inform my interviews and my observations of this key relationship within the art world.

Brian Rusted's study of "cowboy art" is well connected to my approach through its methodological combination of IE and performance studies (2006, pp. 118-119). The understanding of texts as performative is foundational to the field of performance studies, and Rusted offers Della Polock's argument as a link between the field and IE. Performativity offers "a dynamic re-conception of texts as inseparable from the processes by which they are made, understood, and deployed" (Polock as cited in Rusted, 2006, p. 117). In this way, argues Rusted, performance comes into conversation with fields like communication studies and visual epistemologies that focus on that same bridge of semiotics and practice provided by IE (2006, pp. 117). This helps to explain the practices of curation, the evaluation, and the legitimation of certain genres of art, including "cowboy art" (2006, pp. 120-121). Rusted offers "an attempt to identify some of the ways these lived practices associated with the production, collection, and exhibition of painting are performed and experienced from a curatorial standpoint" (2006, pp. 118). Like Klostermann, his interest lies more in the ruling relations imposed by the market and the gallery system rather than governmental funding and support, but his deployment of the method demonstrates its viability and appropriateness to examining artistic production and the advocacy thereof through a performative lens.

Rusted's IE study of visual artworks embraces the performativity of texts in art world practices. The communication of advocacy approached through ethnography and a close 
attention to how texts are activated would therefore invite a similar approach. The kinds of institutions that Rusted is considering (museums and galleries) can exhibit many of the same processes of legitimation engaged in by the government and its funding bodies like the Canada Council or training institutions like John Abbott College that I will discuss in the forthcoming chapters. Like Rusted, I believe that examining these processes from the standpoint of artists and their embodied practices in advocacy can help us to bridge gaps in the understanding of public support for artworks and the "ruling relations" inherent in making that case for support, without falling into the trap of becoming advocates ourselves (2006, pp. 134).

What would an IE inquiry of artistic advocacy in Canada look like? As Klostermann suggests, we need to pay attention to elements like grant applications, the Status of the Artist legislation, CVs and artist statements as well as the texts created by arts councils that circumscribe the values we are attributing to art work (2016). We need to explore how artists are activating these texts, how they are doing the work of creating an environment where their art can be made in relation to the ruling structures of the Canada Council and the Department of Canadian Heritage. Texts and technologies are required to legitimate artistic work and provide for its funding and distribution. It is not the texts themselves that we must study but what artists are doing with them. We must understand how their disposition and professional rhythms need to change to perform this advocacy. We need to consider their communication and the other individuals and institutions with whom they interact. We need to do this at the ground level, informed by ethnographic methods like participant observation and interviews. In this way, we get a better sense of the performance of artists and governmental agents in the development and implementation of policy directions and funding priorities without falling back on grand and abstracted reports and narratives nor on theoretical commitments like governmentality. 
I have suggested that advocacy can be considered in terms of the performance and demonstration of legitimacy by artists in their interactions with governmental bodies. I am inquiring into a moment of communication that takes place amid the process of art work. This is how I tackle the problem of temporality that I identify in the literature. It is not the moment of conception, of creation, nor is it the moment of reception, of encounter with the audience. Nor is it the moment when the artist comes to embody the object they have conceived or the recognition that such creative actions involve a larger collective than the individual artist. Nor is it in the development and evaluation of cultural policies that take up so much space in both governmental and academic discourse around art-making in Canada. All of these are significant but they miss the moment of advocacy, that parallel action that occurs when artists demonstrate their legitimacy.

The present-ness of these moments of encounter can be glossed over by policy studies oriented toward political economy and governmentality, by production studies oriented toward sociological and art historical constructions of the artist and their creative objects, and finally by studies of creative labour that consider the results of such policies and discourses like neoliberalism as they impact artists. Investigating the middle-space of these communicative moments is how IE helps to address these relations, explicating what Smith calls "disjunctures" (2005) or the moments where individual experiences are understood to be disconnected from institutional and textually mediated practices. Revealing these disjunctures as performative encounters where particular demonstrations of legitimacy are being enacted offers a unique look at these relations, one that IE can help illuminate.

A theoretical, as well as a methodological framework of performativity, helps to bridge many of the bifurcations that exist in current understandings of the working artist and their 
practices of legitimation. If the artist creates for intrinsic and aesthetic value, for "art's sake", they might perform that discourse and embody that disposition as they attempt to advocate for the resources to make their work. However, they may also recognize the existing discourse that legitimates art work for the nation, one that is primarily instrumental and based on economic, social, or educational values, and perform that disposition in the course of their interactions with the structures of funding and support. This kind of shifting of language and disposition is an example of Smith's coordinated activities and it suggests the existence of "ruling relations" impacting the art world.

Artists may embody a position as an advocate that attempts to influence that discourse to shift from one end of this continuum to the other: from extrinsic or instrumental concerns to more intrinsic commitments. All of these actions can be understood as performances that activate cultural policies, technologies, texts, and documents within the art world. All pursued through the kinds of actions that performativity thinks about: speech acts, gesture, presence, institutional authority, and so on.

\section{People, places, and things: gathering IE data}

How does an IE inquiry actually work? What are the kinds of data that are sought and how does an analysis proceed? As a practical approach, Smith's colleagues and students offer a number of texts that help to explain the process. I will summarize these here and then offer an example from my own artistic and administrative work of how such an approach might illuminate practices. This will situate my research sites and expectations explained in the following chapter.

Since part of the agenda for the development of IE was to offer a critique to the traditional sociological methods of ethnography, IE must begin with the basic ethnographic 
tenets of participant observation, interviews, and other qualitative data gathering and analysis techniques. As Kevin Walby points out, the difference in how IE treats individuals as opposed to more traditional ethnomethodologies is that they are not the object of study but rather "an entry point into understanding organisational processes" (2013, pp. 142-143). Listening, observing, and asking questions is informed by "text work", the coordinated activation of texts across local situations in relation to the ruling structures that govern everyday practices (2013, p. 143).

Jean Louis Deveau draws on Marxist historical materialism in the IE approach to data gathering and analysis, suggesting that it allows researchers to keep what people are doing and the stuff they are doing it with at the centre of the inquiry $(2009$, p. 3). Deveau offers a series of examples including police interventions and issues within his own university administration to demonstrate the ways that IE can provide new avenues for understanding. He explains the process of constructing and exploring the "problematic", or area of inquiry, by first identifying the experiences of individuals, then the ruling relations that are governing those experiences, and finally proceeding to examine those relations through interviewing participants who are "experts in their own lives" (2009, pp. 14-15). The interview process, along with participant observation and the analysis of relevant texts, is always informed by the standpoint of the researchers themselves. For many, including Deveau, this seems to lend itself to activist research, though I would argue that uncovering ruling relations and how they manifest communicatively does not necessarily lead only to "emancipatory" scholarship (2009, p. 16).

An art world related example is offered by Leanne Warren in her discussion of the organization and coordination of an orchestra, mediated by the musical score. For Warren, "the score is a link between the macro level of musical discourse embodied in other texts, such as books of musicology, musical ethnography, and performance practice" (2001, p. 327). Warren 
often uses language reminiscent of Becker in describing the collective action of the musicians in the orchestra, informed by history and rituals of performance, supported by their art world, and coordinated by the score. The score is a text embedded with "the instrumentation specified and continuing through notes to phrasing, dynamics, and other interpretative marking" (Warren, 2001, p. 331) and is understood through institutional training, history, and ideologies around classical music. The text here is literally activated, in the sense that it is the core of the performative act of playing the symphony as a harmonized group of musicians. Since the composer of classical music is most often unavailable, the score acts as a link back to the absent author, a figure that exerts extra-local power over the musicians by virtue of their institutional ethos and the history of past performances of the same works.

To help clarify the process and approach IE can offer to the study of advocacy and the art world, I offer a recent example from my own work as an arts administrator. This example acknowledges my relations to the standpoint group of artists impacted by the problematic under examination here as well as demonstrating the approach to inquiry. In 2014, I was appointed general manager of SALON Theatre, a mid-sized non-profit arts company in Kingston, Ontario. The program I shepherded, a series of artistic activities centred around Sir John A. Macdonald's $200^{\text {th }}$ birthday, was supported by over $\$ 800,000$ of federal funds from the Department of Canadian Heritage (DCH), under the aptly named DCH initiative "Commemoration and Celebration". Under the funding agreement, a document signed by the company's board of directors and representatives from DCH, SALON was to provide activities and entertainments to "increase national public awareness of Macdonald and his accomplishments". The language of the funding agreement delineates the conditions for the production of art under which the artists in the company will work, going so far as to suggest something of its content. The agreement 
demanded specific activities including the creation of a website and educational materials, an online database or library of Macdonald related materials, performances by members of SALON Theatre aboard VIA Rail trains and in walking tours in Kingston, and a mandate to engage or even perhaps to do a little proselytizing by "enlist(ing) Canadian artists in communities to create artwork and entertainments based on Macdonald's life and achievements".

This agreement, negotiated once SALON had been selected as a partner in the program, demonstrates the power of a textual document, ostensibly created by the interaction of an arts organization and a state agency, in that it placed clear expectations on the ways in which SALON was to present its "activities". That the values expressed, and the expectations held, were agreed upon by the two parties does not deny the impact of the funder on coordinating the activities of these artists. Here was a Canadian "institution", one with a complex and often controversial history, that was managing the creative activities of a group of artists, each with their own complicated relationship to the subject matter and to the ethical responsibility of spending such a large amount of public funds.

Examining this case study from an IE approach would involve pushing beyond the institutional understanding of discourses like "founding fathers" to focus on the experiences and processes of individuals like arts administrators, artists, and government officials who have found themselves involved in the development and circulation of these symbols and the impact of these policies and their implementation. In the case of SALON, the artists of the company might be interviewed as to their own understanding of the funding agreement. DCH officials might be questioned about their interactions (or lack thereof) with the artists working on the SirJohnA2015 project. Certainly, the texts would be analyzed along with the actual performances and "entertainments" created by the company under the agreement. 
Gathering this data and performing an analysis would allow us to understand the advocacy relationships created through these policy positions. We begin to explore the diverse understandings of what an institution like "Canada's founding" might mean to a group of artists, and how institutions can be rethought, in my SALON example, as objects like the "founding father, Sir John A. Macdonald" and its relationship to the amorphous notion of "Canadian Heritage".

Like the performing artworks that are the practice and product of the worlds I am researching here, I consider advocacy a performative act. Just as the institutional discourses of "John A. Macdonald" or "Canadian heritage" might speak the subject in particular acts of body and voice. To study this advocacy, I need to consider notions of text not only as written document but as performed in the moment. IE and a performative framework of understanding help us to consider the where of performance, its temporal when, and its where, considering ideas of presence, the live and immediate interaction of people in the spaces that constitute centres of power and influence in the formation and implementation of policies around artistic creation.

\section{The artist and the advocate, the individual and the organization}

Bernard Lahire points to a tension that exists in sociological research between the social group and the individual. In calling for what he terms a "sociology at the level of the individual", Lahire suggests that an understanding of habitus as embodied in the individual can help to understand the formation of larger more socially constructed dispositions (2003, p. 335). That formation, the process by which dispositions come to be introduced, is important as it demonstrates the beginnings of the kinds of performances advocates will pursue and the ritualization of such performances in the art world. Young and Everitt acknowledge that there is precious little research on the formation of advocacy groups in Canada (2005, p. 29). The authors 
do pay some attention to the demographic tendencies in some groups but this information does not tell us how advocates become advocates. This is a key question to consider if we are to examine the negotiation of performances by artists who are also advocates for their work and that of their practices in the art world.

The individual advocate that is invited into the larger network of arts advocacy is at the centre of Julie Hawkins' discussion of the process in the United States. She argues that "[i]ndividuals have always been at the core of arts advocacy strategy. Recruited and organized by professional arts advocacy organizations, individuals are enlisted as 'arts advocates' and asked to demonstrate their support of the arts" (2012, p. 130). Hawkins' argument suggests that we must pay attention to how advocates become implicated in the processes of advocacy. What kinds of performances are expected of them as they encounter state structures and other artists and organizations with whom they will interact and demonstrate their own legitimacy and that of the work and individuals they might represent. This can be understood as a performative process that makes advocates visible and also teaches them the language and pathways, textually mediated and co-present, that will bring them into the realm of the advocate.

Observations from research sites will offer insight into these processes of introduction and recruitment: at the level of artist training in a theatre acting program at John Abbott College, and also through the formal and informal coalitions of advocacy actions that occur both online and in co-present gatherings like Arts Day. I will illuminate this process of introduction and the kinds of performances we begin to see as artists consider their roles as advocates. These cases will also serve to consider the question of these groups as gatherings of individual emerging artists, becoming familiar with the collective negotiations of performative advocacy. 
Gasoi - 105

\section{A note on research ethics}

As with any research in Canada that deals with human subjects, this project was undertaken in adherence to the Tri-Council Policy Statement: Ethical Conduct for Research Involving Humans (TCPS-2). My work was reviewed and approved by the Research Ethics Board at Carleton University. The risks foreseen to my research participants were considered very minor and included damage to job prospects and reputation particularly for participants working at the Canada Council for the Arts. All participants reviewed an information letter regarding the research and since no deception was required they were informed of the nature and goals of the project. Consent for interviews was obtained and participants were permitted to withdraw their participation at any time. Most participants permitted their names to be used in identifying them. When any member of a segment of participants did not consent to being identified, I made all participants in that segment anonymous. This was the case for program officers and managers at the Canada Council (with the exception of my initial contact, Bryan Croft), as well as the students in the JAC professional management course. Interviews were collected by voice recording, unless the participant did not consent to be recorded (which was the case for only two participants total), in which case written notes were taken. The interviews were transcribed personally by me and all data was kept secure in accordance with the procedures required by the ethics board.

It is worth noting that the process of interfacing with the ethics board is one that demonstrates many of the processes IE itself seeks to explicate. The strict adherence to application forms, the production of documents, and their "activation" through specific practices such as keeping data safe and reproducing exact verbal forms to obtain consent when written 
consent is not appropriate, all these are actions coordinated by ruling relations and the institution of the academy. 
Gasoi - 107

\section{Chapter 4 - Wheres and whens: introducing the research sites}

Performative advocacy and an IE approach to communication within the art world demands an encounter with particular places and moments. Rather than seek a recipe for the successful legitimation of artistic practices, this research inquires into the moment-to-moment presence of art world members as they relate to one another and to these structures of legitimation. This chapter will introduce my research sites and participants and discuss the kinds of data and analysis that such an approach brings to the discussion. For the purposes of this study, my use of the term site is meant to include both physical locations (like classrooms and offices) but also those temporal moments of interaction and events that are under consideration. Acknowledging the importance of both time and space in the performance of advocacy is vital to this research. Introducing these sites will also offer an opportunity to contextualize the important histories of these institutions and events within the larger context of the construction of the artist and arts advocacy in Canada.

The qualities of a research site must reflect the theoretical and methodological investments being made. The three main sites I have chosen are demonstrative of particular wheres and whens of performative advocacy. They exemplify institutions where dispositions are exhibited and texts coordinate the activities of artists and arts bureaucrats. A CEGEP class in professional management for emerging theatre actors implicates the formation of dispositions at the very emergence of an artistic career as well as the introduction of the careful and confusing negotiations of the artist and the advocate. An advocacy event, Arts Day on the Hill, brings artists into the presence of political leaders and their staff to enact texts and perform in various ways both for these powerful figures and for one another. In their Ottawa offices and at outreach 
events in Montreal and Kingston, program officers at the Canada Council for the Arts offer a perspective seldom seen in this research, that of the bureaucrats working with artists as part of the state-sponsored funding apparatus that legitimates the artist in this country. Their performance, their interaction with texts that circumscribe their activities, and current outreach efforts are productive examples of the ways such advocacy circulates.

\section{Learning to be a working artist and advocate}

To understand the processes that introduce individuals into the roles that are required of them in the art world, we must begin by exploring the institutions where artists receive their formal training. It is well established that formal training is not the only way that artists pursue their journey as creators. Many will simply make the decision to pursue a career in the arts and then learn their craft "on-the-job" or in informal workshops and collectives. Data from Hill Strategies in 2016 indicates that of the approximately 158,000 artists in Canada, 6\% have no official training at all, while $69 \%$ have been trained in a University of CEGEP program of some kind (Hill, 2019). A quarter of all artists (25\%) list high-school diplomas and apprenticeships as their highest level of education (Hill, 2019).

As Becker states, tradition also plays an important role in training artists in their practices. This happens in the home, in the studio, and in the community, as much as in any formal training institution (1982). In fact, even the criteria for a "professional" artist as established by arts councils like the Canada Council for the Arts acknowledges that artists receive training but not always in formally recognized institutions.

The important gap that is identified by these various training opportunities is that these career paths tend to put much less emphasis on processes of legitimation and advocacy with the government and rather more on the individual artist seeking legitimation from other artists and 
the art market. It is through the formalization of training in art schools that many individuals are taught to more fully embrace the structures of government support that underpin much artistic production. Becker and many other scholars of artistic production address the processes of introduction to the making of art and it may be useful to think about how artists come to be creators in the art world. What I am seeking here is a further step in that process that explores the fluid negotiations of disposition and activities of some artists when the move between creating and interfacing with legitimating funding and educational institutions.

It would be natural to look to arts education for more on this moment in the formation of artistic dispositions. For instance, consider the process as examined by Daniel Ashton in his essay on cultural workers in UK cultural industries (2013). As noted, there is a difference in the discourses of cultural work as applied to the media "industries" that are of concern to Ashton, rather than the traditionally defined arts sector. Nonetheless, some of Ashton's observations apply. Ashton suggests that the classroom or studio is a space that begins to engender the performances of the artist required by the industry. The training of these individuals, in part, is an introduction to the modes of work and the emergence of "professional identity" (2013, p. 484), the movement between the artist-as-student and the artist-as-worker in an industry. Ashton focuses on the working conditions of artists by suggesting that the classroom could be a place to prepare for precarity and challenging working conditions, where artists are prepared for the harsh realities of piecework and the need for "permanent education" (2013, p. 483). This is a disposition that performing artists are often encouraged to embrace in the character of neverending workshops, skills training, and unpaid or poorly paid opportunities for "exposure" in the art world that is framed as leading to more substantial career avenues. In this study, no mention is made of advocacy as a feature of art work, meaning that one key avenue of career formation, 
that of funding art work through programs and funds administered by the government and its arts councils, is not being introduced to these students. We must consider how often this is the case in the training of artists in conservatory type institutions, and even if there is an acknowledgement of the relationship, when and how that introduction is offered.

A study more specifically addressing the fine arts sector is Sarah Thornton's ethnography, Seven Days in the Art World (2012). One of her "days" is spent deconstructing parts of the Romantic myth in the classroom at the California Institute of the Arts with artist and teacher Michael Asher. Thornton offers an evocative, thick description of the institutional imperatives and conventions constraining the work and critique of the group of visual artists she is examining. Thornton notes that the MFA, the institutional degree, has long been the foremost legitimating criteria for visual artists (2012, pp. 45-46). Thornton quotes art historian Howard Singerman in arguing that the most important thing that students learn at art school is 'how to be an artist, how to occupy that name, how to embody that occupation"” (2012, p. 56).

In Thornton's arguments, one can find hints at the wider world of work that awaits these students outside of the class cocoon. From the student who insists they will create work to respond directly to the commodification of artworks and it will "fly off the shelves" (Thornton, 2012, p. 58), to the whole notion that art schools, like CalArts, "turn their back" to the market for art work (Thornton, 2012, p. 59), the classroom is demonstrative of the historic and ongoing tensions between the instrumental and the intrinsic. Moreover, it is not only the market but as Ashton suggests, the entire system of career management and practice that constructs artists' sense of the necessary performances they learn as they develop their careers (2013). It is significant that both Thornton and Ashton identify the market and the industry model as problematics that challenge notions of authenticity and creative control but neither touch on the 
fact that art school is also one of the places where students first become engaged in relations with the legitimating power of the arts funding institution.

An argument could be made that I am simply misreading the identity of the art worker that should be the subject of study here. Arts administrators are not absolutely required to be artists. They are often the support personnel that work to create the conditions under which artists are freed to create. There are many educational sites and programs that I may have chosen to consider the emerging roles of artist, administrator, and advocate. Arts administration programs are housed in various faculties across the spectrum of higher education: management and MBA streams at Carleton University's Sprott School of Management and the Schulich School of Business at York; certificate programs within communications at Centennial College, and attached to performing arts faculties at the University of Windsor and Humber College; along with a general BA program in arts administration at Bishops University in Quebec, while the Dan School of Drama and Music at Queen's University in Kingston offers programs in Entrepreneurship, Innovation \& Creativity.

All of these programs offer a similar type of training, consisting primarily of marketing and communications, some manner of non-profit governance and general administration, basic economics and budgeting courses, and courses that are designed to familiarize students with the art world into which they intend to enter. The language of experiential learning and transferable skills is as present in these program descriptions as in many places in the academic world. The description at the Sprott School at Carleton ("Arts Management", n.d.) is illustrative of the kind of language present across the board, suggesting that arts management is a specific subset of other managerial situations:

Managers in arts organizations large and small are faced with decisions that parallel those of their colleagues in the for-profit sector and government, but 
these are overlaid with specific considerations concerning aesthetic and cultural judgements that bring into play a number of additional factors.

The importance of situating my observations in a conservatory-style acting training institution is to clearly investigate the negotiation of dispositions between the "actor" and the "working artist". I observe these individuals as they begin to grapple with the reality of advocating for their work and grasping the importance of relations with the state in the pursuit of their careers. There is value in investigating emerging arts administrators in this context as they are trained to interact with government. What I seek to understand is not the education and performances of arts administrators as their own subset of management and administrative personnel but rather how many artists, particularly those who begin their career in producing their own work with limited support, become implicated in these kinds of performances. How are they streamed into dispositions of advocacy, not as a replacement for their core artistic activity, but as a vital adjunct to it? This requires observation of artists in training and with performance at the heart of this research, emerging performing artists best demonstrate that process.

The training of arts professionals is complex. There are a multitude of approaches and pathways, many of which reflect our continued adherence to the Romantic myth of the artist. As Born argues in Rationalizing Culture, the myth of solitary authorship is a problem for the postmodern musical creation that interests her. That problem is in part a question of "what extent composers are aware of the relation between their aesthetic and the likely fate of their music in terms of public reception and economic subsidy" (1995, p. 15). We cannot separate questions of aesthetics and training from how artworks interact with the public and the government and its policies. For Born, there will always be "some kind of cultural sphere defined not by the market but by judgments of legitimacy fueling cultural policy and subsidy" (1995, p. 11). The training of 
artists must therefore reckon with how they will embody the dispositions of that sphere, and how that will continue to influence cultural policy.

At the same time, artist training has been influenced as much as other social and humanities fields by neoliberal discourses of innovation, entrepreneurship, and marketization. While a larger study of the evolving field of arts management training is a worthy pursuit ${ }^{6}$, this research is focused on how the training of the artist, the traditional core creative individual, is held in tension with the introduction of dispositions, texts, and performances required to interface with advocacy processes.

\section{Professional management in the CEGEP}

The case study most closely related to this process is the professional management course offered to third-year acting students at John Abbott College, a CEGEP in the Quebec suburb of Ste-Anne-de-Bellevue on the western tip of the island of Montreal. The CEGEP is Quebec's answer to grades twelve and thirteen in most of the rest of Canada, though its structure and history are unique and require some brief explanation.

The CEGEP is an interesting example itself as an institution born of a Commission-based policy process, much like the Canada Council for the Arts. On the heels of the Quiet Revolution, as the province of Quebec emerged as a secular province from under the thumb of the Catholic Church, the Royal Commission of Inquiry on Education in the Province of Quebec, known as the Parent Commission, attempted to address the lack of universal access to higher education that was seemingly required as economic models and technologies emerged and transformed the workforce (Donald, 1997, p. 166). To harmonize the Quebec system with the rest of Canada, the

\footnotetext{
${ }^{6}$ And one that has been treated by Paquette and Redaelli in their book, Arts Management and Cultural Policy Research
} 
Colleges d'enseignment generale et professionel (CEGEPs) were created. As Janet Donald writes in her chapter in Glen Jones' book on higher education in Canada, the CEGEP network also sought to "encompass the role of both the classical colleges and the existing technical schools and institutes" (1997, p. 166). As suggested by the name, the CEGEP would offer both traditional pre-university training, giving students in Quebec the extra year or two of classes typical of other provinces before entering university, but also three-year vocational programs designed to lead directly to the working world. The CEGEP was also a public institution, providing its services free to students, encouraging the democratization of education sought by the Parent Commission.

The technical education offered by the CEGEP system includes training in fields as diverse as aircraft maintenance, nursing, architectural technology, and dental hygiene. Many of the fine arts programs, including extensive offerings in illustration, animation, and visual arts at Montreal's Dawson College, are of this three-year vocational variety, and the training provided tends toward a conservatory model that focuses heavily on creative training and less on general education. Dawson College was the first English-language institution to open under the CEGEP model in 1969, two years after the original twelve French-language schools were incorporated (Donald, 1997, p. 169). Vanier College and John Abbott College both followed in 1970. Dawson College instituted a theatre program in 1973, making the decision to incorporate both acting and the technical aspects of theatrical production into a single three-year vocational program. The theatre program at John Abbott College was formed out of the English Department and began modestly with a "theatre workshop" class for English majors, evolving over the following years into a fully realized vocational program with streams for actors, designers, and production personnel. 
$\mathrm{JAC}$ is one of four major institutions for the training of theatre professionals in English in Quebec. Training is also offered at Concordia University, the National Theatre School of Canada (NTS), and Dawson College. The CEGEP level programs are key to this study as they offer access to the youngest set of emerging artists, and thereby the possibility to witness the initial stages of how artists begin to see themselves as advocates. Dawson is located in downtown Montreal, while JAC's suburban location has a certain geographic isolation that is analytically useful in considerations of presence and movement that will be explored further. Students at NTS and Concordia tend to have already spent at least some time in the profession or in preliminary training institutions and may have already made certain choices and developed interactions with governmental structures, applied for grants, and participated in advocacy actions, or joined professional organizations.

The program at JAC offers students their professional management course in the fifth semester of a six-semester program of study. Dawson College also offers a "Career Management" course in the fifth semester. Both courses have a very similar curriculum, promising discussions of "photos, resumes, agents, unions (CAEA, ACTRA, UDA), the business of auditioning, theatre vs. film industry, employment research, self-producing, grant writing, taxes/finances, working in other markets (i.e. TO, Vancouver, LA, NY) and other career options in the arts" ("Course List | Professional Theatre", n.d.).

What does situating the training of English-language actors in the CEGEP system mean in relation to this particular part of the art world? Since the CEGEP system is publicly funded and offers free tuition, it is certainly possible that students might choose to pursue an education in the fine arts with less consideration of financial security and long-term sustainability in a career. We must also be aware of the demographic work on CEGEP attendance, which notes that 
despite the lack of tuition payments required to attend CEGEPs, they have traditionally attracted primarily middle and upper-class students (Denis, 1975, p. 50; Denis \& Lipkin, 1972, p. 128).

It is also significant that CEGEP is the standard path toward higher education in the province of Quebec. This creates a potentially legitimating discourse around the fine arts training offered by these institutions simply by virtue of their status as a required post-secondary step. The CEGEP system requires that students attending three-year, professional programs also complete required "general education" courses in English, French, the humanities, and physical education.

What we see in the CEGEP is a legitimate path toward an artistic career, with access to the introductory discourses that form the artist as a professional in relation to the institutions, traditions, and policies that make up the art world. The three-year "career" program offered by institutions like JAC promise the artist the requisite training to enter the workforce. Therefore, it is productive to observe the introduction of advocacy performances as a part of that promise. Since this training is geared not toward creating arts administrators, or even business professionals with some understanding of symbolic production, it demonstrates the uneasy negotiation of communication that invites the artist to embrace the work of creating a sustainable career, including with government support structures.

The access I was granted to observe all aspects of the "professional management" class, to interview the instructor, Zach Fraser, and to interview students, offered a large amount of data. In addition, there were a number of important texts, from the course syllabus to the various assignments including a mock grant application, acting $\mathrm{CVs}$, and headshots, which served to illustrate the coordination of activities and the dispositions expected from these students as they begin to interact with the world outside their training. As "actors", these students displayed 
productive performances in relation to ruling relations not only within the classroom environment itself but with the larger structures of legitimation as "working artists", ideal for analysis through IE methodologies.

\section{Advocacy in time and space}

The classroom is not the only place where artists are introduced to advocacy relationships with government and the institution of arts support. Where and when advocacy actions take place is an important aspect of how we research the coordinated performances of advocacy. Advocacy is an ongoing process designed to impact policy decisions. It is pursued by collectives and by individuals, a host of competing interests. This makes it nearly impossible to study it holistically. The IE approach again aids us in this regard as there is no intention to uncover a clear historical lineage of advocacy. There is no attempt to implement some grand unified theory that will link together the many strains of advocacy work throughout the art world and beyond. I see IE as using this received history as a text itself, a coordinating aspect of the institutions that govern artists' activity in time and space. We must acknowledge that history but it is not finally the object of study. Rather it is something activated by the artist, acting as advocate, in the demonstration of their legitimacy.

The fractured nature of advocacy as identified by Acosta in his thinking about advocacy networks (2012), and by Sabatier in his notion of the advocacy coalition framework (1988) remains a problem worthy of study. The plethora of loose and often competing organizational structures that perform the advocacy role in the art world is hard to pin down. Nonetheless, one of the few moments and places that can help to see how these individuals and their actions coalesce is the second site of research I have chosen for this study, Arts Day on the Hill. 
Arts Day can be considered an advocacy event. Advocacy events are often closely tied to theorizations of dissent and protest and they can be centred around specific moments in time. Thomas Birkland argues for the relevance of "focusing events" to crystallize policy action and the force of argument by advocates (1998). Birkland offers examples of natural and industrial disasters like hurricanes and nuclear accidents where "immediately obvious harms done by focusing events highlight problems to which government or other institutions might respond" (1998, p. 54).

It is challenging to imagine an analog in the art world but there is a moment that fits the pattern well: the allegations of sexual misconduct at Soulpepper Theatre. This event, while it is purported to have taken place over the course of several years, crystallized at a particular moment and prompted a flurry of advocacy actions on the part of a coalition of advocacy groups and individuals leading to a significant and ongoing policy change. The funding of initiatives like the Not in Our Space campaign at Canadian Actors' Equity and the Cultural Human Resources Council's Respectful Workplaces in the Arts project are examples of issues that this event has moved from what Birkland calls the "systemic agenda" or a consideration of policy options, to the "institutional agenda" where actual policy action becomes manifest in the structures and spaces where activity occurs (1998, p. 55),

These focusing events can allow for the instantiation of advocacy relationships. Thinking solely in terms of such symbolically pregnant moments can be a detriment to a more quotidian discussion of presence and performance in the examination of interactions between artists and these institutions. This is evident in Gregory Klages' dissertation on arts advocacy in Canada (2008), one of the only examples I have discovered that focuses specifically on the topic. For Klages, the received narrative is that the lobbying around the Massey Commission that led to the 
creation of the Canada Council for the Arts in 1957 and the growing public financial support for art work in the 1960s and 70s represented the zenith of arts advocacy in this country. Klages suggests that we would do well to rethink this story as the processes of advocacy are better understood in fits and starts, even as waves, rather than a linear progression centred around particular events (2008, pp. 7-8). Klages presents the work of the Canadian Conference for the Arts, along with its predecessors like the Canadian Arts Council, that existed in some form or other from the end of the second world war, as implicated in some of the most significant moments of arts advocacy in Canadian history (2008, pp. 118-119). However, these moments, including the 1941 Kingston Conference and the 1944 "March on Ottawa" are moments that are routinely mentioned as crystallizations of arts advocacy.

The Canadian Conference for the Arts (CCA) had been the largest and most engaged advocacy group in the arts since its founding in the mid-1940s. In large part, their advocacy work has been textually mediated, including the production of reports and budget briefs to governmental structures. They also have a history of conferences and gatherings of artists "every few years" ("History", 2011), leading to significant changes in cultural policies like taxation regulations for artists, copyright reform, and funding. Despite the success of their work, the CCA officially ceased operating in 2012 due in part to significant cuts to their funding by the Harper Conservative government ("The Canadian Conference of the Arts to Close Doors after 67 Years", 2012).

In the ever-shifting reorganization of these groups, the CCAs charitable number has been recently taken over by a new coalition of artists and researchers dubbed Mass Culture. While this group seeks to carry on some of the work of the CCA, their mandate is decidedly nonadvocative, rather intending to "form a network of stakeholders, which, through research, will 
address cultural research issues at organizational, sectoral, and governmental levels" ("Mass Culture $\bullet$ Mobilisation Culturelle", n.d.). According to their website, the organization was founded by artists and quickly expanded to include more than 700 "public service employees, sector service organization/network employees, or arts organization staff members" ("Mass Culture • Mobilisation Culturelle", n.d.). The fact that the vast majority of these individuals have experience interfacing with government may create interesting opportunities for the circulation of advocacy knowledge within the organization's research mandate. It will be worth further study to investigate how this change in mandate will impact the art world going forward and whether Mass Culture can maintain its distance from advocacy. In the interests of transparency, I will state that I am a member of Mass Culture and I have written for their online blog and worked with some of their committees.

While the CCA had operated as an umbrella organization of artists working in numerous disciplines, other advocacy groups often have a disciplinary focus, both diversifying and fracturing arts advocacy efforts. Some of these organizations, like the visual arts association Canadian Artists' Representation/Front des artistes Canadien (CARFAC), act more like unions for artists working toward broader representation and focused on working conditions and proper compensation.

Both the Professional Association of Canadian Theatres (PACT) and the Canadian Dance Assembly (CDA) are good examples of disciplinary organizations with a strong advocacy focus. Both feature advocacy committees as part of their organizational structure, reflected in the communication on their websites with pages specifically dedicated to advocacy efforts. The CDA expressly states that part of their work is to participate "actively in Government and Government Agency consultation processes, and intervene[s] on policy and investment issues 
that impact the dance sector" ("Briefs and Reports | Canadian Dance Assembly", n.d.). The CDA lists several advocacy partnerships, both internal committees, and external organizations like the Canadian Arts Coalition. Individuals who sit on these committees, including CDAs executive director Kate Cornell, are often leaders in larger advocacy organizations, a fact that points to the concentration of responsibility on certain individual artists whose career trajectory is weighted toward advocacy and administration even while they seek to retain a practice as a working creative artist. Kate Cornell's biography, listed on the CDA website, demonstrates this negotiation of disposition and the ongoing struggle with precarity in the art world: "In the gig economy, Kate has had many titles [...]" ("Staff Directory - About Us | Canadian Dance Assembly", n.d. $)^{7}$.

This network of organizations must also include the advocacy efforts carried out by individuals and artistic companies themselves, who often work independently of coalitions both official and informal. This is one of the reasons I chose a methodological approach that does not treat these organizations and their histories as the object of study but instead seeks to understand how the structures that have existed, and more importantly, those that exist now, impact on the actions of these artists. To do that effectively actions must be identified in time and space. The quotidian activities can be balanced with attention to a yearly event like Arts Day, offering an advocacy action to examine. Rather than seek out a "disaster" as a focusing event, this study looks at an annual gathering of artists and government officials. It highlights a moment in space and time when these interactions can be examined not in terms of fixing immediate and dire

\footnotetext{
${ }^{7}$ In fact, since April 2020, Cornell has moved on from the CAC and the CDA and, according to her LinkedIn profile, now works as a freelance arts advocate, currently on contract with the organization AfterMeToo.
} 
policy problems but in inching forward a long-term agenda and building relationships through presence.

\section{Arts Day on the Hill}

The second site of research therefore responds to both the questions of presence and of temporality that are problematics to explore through IE. Arts Day on the Hill is an annual lobby day organized by various arts service organizations and artistic companies since its inception in 2002. Arts Day 2018 featured more than 100 artists, arts administrators, and other advocates, gathering on Parliament Hill in Ottawa. The goal was to meet with Members of Parliament, Ministers, Senators, and other political leaders, including officials in the Prime Minister's Office, to keep the arts sector visible to the Canadian government. I was granted access as an observer to the 2018 version of Arts Day, led by the Canadian Arts Coalition (CAC), a national umbrella group representing the interests of the arts sector at the national level. According to the CAC website, Arts Day is designed to "encourage continued investment to our vibrant and creative sector".

The CAC itself was formed in 2007 amidst another specific cultural context, the celebration of the 50th anniversary of the founding of the Canada Council. It is a coalition in the sense that it draws its membership not from individual artists but from arts service organizations, governed "with a volunteer Steering Committee comprised of artists and arts administrators" (“About Us | Canadian Arts Coalition”, n.d.). In addition to the organization of several Arts Days, the CAC has engaged in further advocacy campaigns at the national level including a 2013-2014 campaign they called Arts308, a multi-year effort to increase the capacity of artists within each federal riding to acquire knowledge and resources to push an arts agenda with their local MPs. This campaign can be seen as the corollary to the gathering of advocates in Ottawa 
for Arts Day. Instead of bringing artists together en masse in Ottawa, this campaign successfully spread the power of advocacy across the country. However, it is worth noting that the messaging, resources, texts, and training remained centralized within the steering committee at the CAC.

The CAC claims their advocacy efforts have led the Trudeau government to double the budget for the Canada Council for the Arts in 2016, along with a host of other investments within the Council and the Department of Canadian Heritage ("History - Canadian Arts Coalition", n.d.). They most recently took credit for a $\$ 16$ million increase in the budget of the Canadian Arts Presentation Fund, a central advocacy effort at Arts Day 2018. The success of these initiatives can be attributed largely to a regular and sustained effort to maintain presence and visibility of artists through advocacy events like Arts Day. With the action of artists, acting as advocates, relating directly to the structure, texts, and location of political power on Parliament Hill, this event is an ideal case study for demonstrating performative advocacy.

In addition to the CAC and its co-chairs, Kate Cornell and Frédéric Julien, with whom I spent time observing and interviewing before, during, and after Arts Day, I also interviewed Guy Rodgers, the executive director of Quebec based arts advocacy organization, the Quebec English Language Arts Network (ELAN). Like the CAC, ELAN is an umbrella arts service organization, comprising a coalition of individual artists, companies, and other organizations. ELAN was created as a result of an advocacy event itself, the 2004 Quebec Arts Summit. This gathering of artists and cultural workers sought to address the long history of perceived oppression of English-language culture and the resulting emigration of English speakers from the province. The group drew representatives from several existing advocacy organizations like the Quebec Drama Federation and the Quebec Writers Federation to build a coalition of artists from all disciplines to support one another and build bridges between Quebec's famed "two solitudes". 
Drawing initial funding from both the Canada Council for the Arts and Canadian Heritage, ELAN produced a newsletter, networking events, and relationships with various organizations in the art world. In addition to its role as a cultural hub, ELAN became involved in direct advocacy with governmental structures, pushing for funds and programs to build capacity within the art world through workshops and conferences that target artists and arts organizations. ELAN is not a member of the CAC and did not participate directly in Arts Day.

Both ELAN and the CAC are clearly branded in their own organizational and professional identity as advocacy organizations. ELAN's mission statement describes the organization as advocating for its individual and organizational members. The CAC is even more specific in their language, listing their first two guiding principles as: "We advocate on federallevel issues within Canada" and "We advocate for the betterment of the arts and culture sector, on behalf of artists and arts organizations". These organizations are almost exclusively staffed by artists with training, experience, and practices in making artworks. As advocates, these individuals have chosen, or more often they have been coaxed and implored by colleagues in the art world, to divide their time and develop skills in administration and government relations in order to facilitate the support for the making of art. In the case of the CAC, the group is entirely volunteer-driven, with arts leaders from constituent organizations filling the committee roles and administrative tasks required to pursue their advocacy. ELAN has six paid staff members (as of 2019) and a fluctuating number of contracted project managers for their various programs. Even though experience in the arts is not always explicit in their job descriptions, they still tend to source those individuals from within the art world. Their staff is comprised of practitioners and does not come from the realms of political science, nor general non-profit management. It is the 
negotiation of these artists' professional activities as advocates that demonstrates performative advocacy.

Though some artists move between the civil society and political realms, in general, these artists have no desire to govern. They are simply doing something that they wish to put on the government radar to facilitate the making of their art objects and performances. These artists are invited into a different career formation, a different mode of working, that can be confusing and frustrating for their artistic practice, and for their place in relation to their colleagues. This performative disjuncture is how we approach the study of artistic production through performative advocacy, paying attention to the middle-step, the formation and performance of the artistic dispositions required to encounter the apparatus of the state and advocate for the legitimacy of their practices.

\section{The support system: the Canada Council for the Arts}

The third site of research is the office of the Canada Council for the Arts in Ottawa, along with a number of outreach events, workshops, and information sessions related to programs and funding administered by the Council. While it is clear that IE takes a broad interpretation of "institutions", if ruling relations in the Canadian art world can be considered to be coordinated from any particular position, it might well be the policies that are enacted in the offices of the Council.

The Canada Council for the Arts is the nation's arm's-length funding body. It was established by statute in 1957, six years after the Massey Commission report. Similar in principle to the Arts Council of Great Britain, which later fragmented into separate entities for England, Scotland, and Wales, the Canada Council is a crown corporation that operates at arm's-length from the government, reporting to Parliament through the Department of Canadian Heritage. The 
arm's-length relationship is designed to mitigate the possibility of political interference in the awarding of public funds to artistic work, a principle that has received much critical concern from artists and academics over the 60-odd years of its existence (D'Andrea, 2017, p. 246; Gattinger \& Saint-Pierre, 2008, p. 170; McCormack, 1984, p. 268). The Canada Council for the Arts Act mandates the corporation "to foster and promote the study and enjoyment of, and the production of works in, the arts", and it does so by awarding grants, sponsoring artworks, and promoting Canadian artwork at home and abroad (Canada Council for the Arts Act, 2001).

In 2017, the Council engaged in a complete re-organization of its funding model, streamlining its funding programs and operations to better respond to a rapidly changing art world. Many saw these actions as a result or response to the Trudeau Liberal government's reinvestment in the Council, whose budget they promised to double over the course of five years starting in 2016.

While scholars like Monica Gattinger (2017) and Jack Granatstein (1984) have written about the early development of the Canada Council, and Anna Rosser Upchurch (2016) and Jeffrey Brison (2005) have touched on some key comparisons with British and American funding institutions and their impacts on the Canadian model, it is worth considering the wider theoretical context of institutions of public funding for the arts in the western liberal democratic context. Michael Volkerling (1996) does an excellent job identifying the historical chapters of state intervention in the arts. Volkerling is primarily interested in the policies of British Commonwealth countries like Canada, New Zealand, and Australia. In his analysis, he notes four phases that appear across these various contexts.

Volkerling begins with the foundational period (from 1945 - 1965), where arts councils were first established to rebuild and repair a national symbology badly shaken by the second 
world war. Following this was a period of professionalization (1965 - 1985) where the centralized and mostly urban artworks that were dominant in funding discourses were challenged by more local and non-traditional practices, including socially engaged artistic work aligned with the radical social change of the late sixties and early seventies.

The late 1980s then saw a reactionary impulse, linked together with Thatcher and Reagan-style neoliberalism where arts funding moved from material support of the artist to an argument for shifting artists toward self-supporting market strategies like audience development and connections to private capital. This reaction phase was followed by an incorporation phase which once more shifted attention back onto government regulation thanks to the enormous impact of media and communication technologies like broadcast and the internet.

Volkerling argues that the state would require a more global vision when cultural products began to move rapidly through the air and through fibre-optic cables, erasing borders and re-invigorating the debates over the dangers of losing the national voice. In turn, this incorporation linked together the discourses of economic growth and prosperity, and the creation and distribution of cultural products as an export strategy, as diplomacy and soft power in a troubled world, and as a means of asserting national sovereignty (Volkerling, 1996).

What all of these historical transformations demonstrate is that the government's interests, informed by political and social contexts both within and outside national borders, are impossible to separate quite so easily from the operation of an arts council. As Volkerling states, "the beneficiaries of these policies are the business and professional interests whose support is essential to the maintenance of political power" (1996, p. 208).

This framework provided by Volkerling is useful to understand some of the changes the political and social reality of the moment has wrought upon the Canada Council and particularly 
the expansion and contraction of its budget allotment as reflected in the economic priorities of the government at various moments in time. The initial investment that founded the Council came from estate taxes (known in Canada as death duties) from two powerful individuals, Sir James Dunn and Izaak Walton Killam. Since that time, government has funded the Council in rough accordance with Volkerling's timeline, increasing budgets in the 1960s and 1970s, slashing them in the 1980s and 1990s, and increasing them again most recently in the later 2010s, responding to technological and global movements of cultural products. The takeaway is that arts councils, while they purport to be independent of government influence, have their operations embedded in the political economy of the patron state.

Michael Rushton points out that pure economics is only a part of the complex relationship between arts councils like the Canada Council and the nation-state (2002). His argument notes the differences inherent in the public funding of arts within a Parliamentary system like Canada and a Presidential system like the US with their National Endowment for the Arts. The political organization will necessarily have an impact on the real and perceived independence of arts councils. The issue that might be considered is not whether arts councils can ever be truly independent of the state but whether they should be (2002). Very few political leaders will be experts in artistic production. Rushton argues that there are always areas of public policy that require experience and special knowledge to be properly evaluated, offering medicine and scientific research as examples (2002, p. 155). The symbolic power of the arts, however, challenges easily quantifiable evaluative measures (such as whether a medical treatment keeps more people alive), and it takes time and focus to measure these impacts, both of which are often missing in the day-to-day work of legislators and policy decision-makers. Can the culturecrats in these arts councils be counted on to understand the government's agenda and can politicians 
allow for arts councils to exhibit "the faith they and the public are willing to place in the judgment of experts in the field" (2002, p. 164)?

The political context, organizational systems, and political economic history of arts councils are all significant background for the study of arts advocacy. The foundation of arts councils is often attributed to advocacy efforts by artists and culturecrats, and the fluctuations in budget allotments, along with the independence of artistic creativity so prized by artists is sustained by ongoing efforts to build relationships with both politicians and Council staff.

In the context of this research, the Council represents one of the core sites of institutionalized artistic support. However, as Clive Robertson points out in his dissertation on arts funding and artist-run centres in Canada, it is not always helpful to imagine an entity like the Canada Council as one entity at all (2004, p. 194). Instead, Robertson refers to the Canada Council as a "policy accretion", a distributed network of funding administrators who work to ensure that funding decisions are based on artistic merit over political economic pressures. As Klamer and Petrova suggest, artists who face the constant shift between market forces and public funding must rely on cultural intermediaries to help them navigate these different "spheres" (2007). Rather than seeing the Council simply as a function of the government sphere, it is more useful to imagine the people within its walls taking on an intermediary role themselves.

To understand how ruling relations operate in the art world, an examination of the regulatory texts, internal policies, and artist-facing digital interactions (like the Council's funding portal), along with their implementation by program officers as they relate to artists, is fundamental to the research. However, I would again point out that an IE approach to these questions does not take these texts and technological mediations as the objects of study themselves but rather tries to understand their activation in the work of artists and program 
officers. We can better understand how art world members advocate and seek to demonstrate their legitimacy through their interaction with these texts and with online profiles rather than studying the texts themselves. This shifts the discussion and methodological commitments away from issues like critical discourse analysis and into more present methods like interviews and observation informed by these texts.

My history as an artist and arts administrator has provided me with my own experience and standpoint with regard to interactions with the Council. This research is concerned primarily with the performance of artists in these interactions, both textual (through funding applications, creation of profiles, etc.) and co-present (in situations like info sessions and workshops). It is productive to have the perspective of program officers, those who directly interact with artists on a daily basis, as the other side of this communication.

After considerable negotiation and making my presence and research interests known to several program officers at various public events presented by the Council, I was given access to the Council offices in Ottawa for a day of observation and a series of interviews with four program officers and three managers. Although several program officers are personal friends from my time in the theatre community, the individuals with whom I interacted in this study do not have any personal connection to me.

Having these interviews take place in the Council offices was ideal, as Janet Rankin suggests that an IE approach must "focus on the materiality of people's doings in locations that have substance and matter" (2017, p. 2). The substance of these interviews, as suggested by an IE approach, was to "find traces of ruling relations within the descriptions of everyday work" (Rankin, 2017, p. 3) and to confirm that these relations do not constitute a one-way pressure on 
artists from government institutions, but rather impact on all members of these art worlds, including those that act as conduits to the legitimacy that arts council funding brings to art work. As Norman Denzin reminds us, the kinds of postmodern and postpositivist methods I am talking about employing with these sites are messy. He writes, these "messy approaches embrace experimental critical works that are always incomplete, personal, self-reflexive, and resistant to totalizing theories" (1995, p. 183). The themes of formation and disposition, presence and performance, and the attention to texts and institutions do not neatly fit into prescribed sites of inquiry, even though there are definite affinities between formation at JAC, presence at Arts Day, and institutions at the Canada Council. More important than this, however, is a focus on the individuals and their coordinated actions as they perform as advocates in these various spaces.

\section{IE data and what artists $d o$ in the art world}

What I have been able to gather from these disparate sites is a collection of data from observation, discussion, and texts that offer a map to the social relations between artist advocates and state structures. Campbell and Gregor (2004), in their primer on IE methods, call for the map as a metaphor to help understand how the activities of individuals on the local level are coordinated by distant structures of ruling relations. The art world acts in precisely this way, and moreover, I have found that physical presence and moving from the local to the centres of power in the art world can explicate those relations on a visceral and bodily level. Howard Becker seems to ask for precisely this kind of research in his critique of Bourdieu's "field" concept (2006, p. 277):

The metaphor of world - which does not seem to be at all true of the metaphor of field - contains people, all sorts of people, who are in the middle of doing something that requires them to pay attention to each other. 
Becker, a few sentences later in the same text, rejects the spatiality of the world, suggesting rather that a world is defined by practice (Becker \& Pessin, 2006, p. 278). I think Becker is too quick to put aside an awareness of location and movement. IE's interest in practice as related to the mapping of moving and performing bodies in space and time is productive in art world research.

Denzin reminds us that we cannot hope to "study experience directly", but rather we build our understanding through the performances of individuals in relation to their social, political, and cultural circumstances (2003, p. 191). Artists and government, both creators and wielders of symbols in interaction with one another, represent a challenging subject through which to consider the co-performance of ethnography (Conquergood as cited in Denzin, 2003, p. 191). Rather than imagining the artist as a subjugated victim of Goffman's total institution (1968, p. 4), an IE approach embraces the performativity of the actor, in a local situation, negotiating the texts and institutions that coordinate their activity from outside. As Susie Scott claims, "identity performances entail the individual actively doing rather than passively being or having a self: authorship is an ongoing, agentic process" (2010, p. 222). IE helps to trouble the notion of the artistic identity as something stable: not what we are, but what we do.

The following chapters will present data from these disparate sites through observations and interviews and the activation of texts that individuals within these sites must negotiate. Rather than present these sites themselves as substantive chapters, I have chosen to break these chapters down by different themes. I begin by exploring how artists are introduced into the disposition of advocacy, followed by a discussion of performance, presence, and locality, and concluding with a look at texts and institutions. Evident in this structure is the fact that these themes are present at each of these sites, coordinating activities across them all and 
demonstrating the connections sought by the IE approach. While some sites tend toward certain themes more than others, the key takeaway is that studying these artists and cultural bureaucrats across these spaces and moments of performative advocacy keeps us from assumptions about how, where, and when these individuals are demonstrating their legitimacy. The performance of advocacy is an ongoing process that engages across time and space, and tracing these themes is more productive than attempting to create specific associations that ultimately shift and rearticulate depending on circumstances. 
Gasoi - 134

\section{Chapter 5 - Invitation to the disposition of advocacy}

\section{The emergence of the "emerging" artist}

The dissertation examines how art world members are acting as advocates for their work in relation to the institutions of funding and legitimation. It is important to understand how these relations are constructed from their beginnings, and how they are pursued in everyday activities. In making use of an IE approach, I understand an institution as a set of discourses that coordinate the activities of individuals on the local level, and not simply as particular organizations or locations. For instance, we might often think of a hospital as an institution, yet it is only one aspect of the "institution" that is health care, with all its attendant discourses, bureaucracies, texts, and ruling relations that coordinate the activities of patients, nurses, doctors, orderlies, etc. As Smith states, "[s]tate agencies are tied with professional forms of organization, and both are interpenetrated by relations of discourse" (2005, p. 225). So, the Canada Council for the Arts is itself an institution, but in this research, it is only part of the institutional ensemble that legitimates artists and their work through government intervention and funding of art-making.

Engaging with this larger institution of arts support and legitimation requires certain performances and dispositions in time and space that I characterize as performative advocacy. From this position, I can consider a key question: how are artists invited into the language and practices of advocacy? When are these kinds of dispositions introduced into the working lives of artists and what performances are activated as they begin to transition from training to thinking about building sustainable careers? Perhaps even further, we can begin to ask whether there is such a thing as an "advocative disposition" in the art world, and if so, what are its communicative elements and performances? 
This chapter approaches these questions by detailing observations and the results of interviews from all my sites of research. The chapter situates some practices and histories of arts advocacy that I have identified. I also consider some of the other ways artists are implicated in the work of advocacy, including advocacy events, workshops, and info sessions that prescribe the kinds of language and behaviours that artists will adopt to interact with government agents and funding structures. This chapter concludes by describing how young theatre performers are introduced to what an artistic career might actually look like.

Can we consider the intellectual and the material things that make up a "career" as a means to probe practices and communication of advocacy designed to demonstrate the legitimacy of artistic work? By focusing on structures that tend to serve the interests of "emerging" artists, like many arts advocacy groups and service organizations, as well as on JAC as a training institution, I can approach these questions within the context of art world members with the vital consideration of emergence and formation of these dispositions. Individuals demonstrate these dispositions through their engagement with the texts and technologies of the administrative machine of arts funding: grant application forms, artistic CVs, etc., as well as opening up relationships with professional organizations that perform advocacy in relation to these institutions. These artists further become introduced to particular language use and presentation of their bodies in certain spaces. They begin to understand how to negotiate entry into these relationships. That entry is more or less difficult depending on factors as disparate as race and gender, experience, historical relationships, and past knowledge.

\section{Scaling advocacy in established and emerging organizations}

The arts sector, what I define as the traditionally "fine" arts such as music, dance, theatre, visual art, and literature, feature actors working at many different phases in their development as 
individual artists and as arts organizations. This includes established performing arts companies, nationally recognized musicians, long-running visual arts collectives and organizations, and some interdisciplinary artists with considerable history and connection to the state and its legitimating apparatus. These larger, more integrated, and more politically connected companies have a history of legitimation and most have reached a sometimes uneasy but essentially status quo relationship with government and its arts funding bodies. This is not to suggest that companies like The National Arts Centre, The Banff Centre, PEI's Confederation Centre for the Arts, The National Ballet, and others do not engage in advocacy. They can be some of the most effective advocates as they can call upon their history, instrumental effects on their communities and on the country as a whole, their international reputations, along with considerable audience numbers, diverse and well-connected boards of directors, even fully staffed government relations departments, all in an effort to make the case for their own legitimation as key players in the art world.

This kind of advocacy maintains features of performativity but such interactions with governmental structures are often pursued in a routine and professionalized manner. This is a project that seeks to maintain a status quo relationship of legitimacy and funding support rather than expand the field in any significant way. The managers and cultural professionals that engage in such work with these large organizations may even be former arts bureaucrats with long-standing relations to cultural policy and funding structures at the national, provincial, and municipal levels. Consider the brief summary of biographical information of a selection of senior board members at the NAC and the Banff Centre (acquired from the company websites in 2019) and note the prevalence of directors with governmental and "cultural industry" connections. 


\begin{tabular}{|c|c|}
\hline \multicolumn{2}{|c|}{ National Arts Centre } \\
\hline Director & Affiliations \\
\hline Adrian Burns & $\begin{array}{l}\text { SHAW Communications; Copyright Board of Canada, CanWest Global; } \\
\text { CRTC }\end{array}$ \\
\hline Angela Birdsell & $\begin{array}{l}\text { Canada Council for the Arts; Saskatchewan Arts Board; Orchestras } \\
\text { Canada }\end{array}$ \\
\hline Sanjay Shahani & $\begin{array}{l}\text { Ontario Trillium Foundation; Ontario Arts Council; Canada Council for } \\
\text { the Arts }\end{array}$ \\
\hline Jim Watson & Mayor of Ottawa; Canadian Tourism Commission; Ontario MPP \\
\hline \multicolumn{2}{|l|}{ Banff Centre } \\
\hline Director & Affiliations \\
\hline Carolyn Campbell & $\begin{array}{l}\text { Mayor's Think Tank for Arts and Culture Edmonton; Travel Alberta; } \\
\text { Alberta Chamber of Commerce }\end{array}$ \\
\hline Larry Fichtner & $\begin{array}{l}\text { Board of the National Arts Centre; Boards of oil and gas industry } \\
\text { corporations }\end{array}$ \\
\hline Gay Mitchell & Toronto Board of Trade; Royal Bank of Canada \\
\hline Judith LaRocque & $\begin{array}{l}\text { Deputy Minister of Canadian Heritage; Secretary to the Governor } \\
\text { General of Canada; CRTC }\end{array}$ \\
\hline
\end{tabular}

Table 2 - Relations of Board members from NAC and Banff centre as per websites, 2019

In addition to these connections, larger companies will employ lobbyists and professionals in government relations whose primary function is to engage in this advocacy. While the question of where and how these arts advocates operate in the field is of interest, it is out of the scope of this research because in the case of these individuals and lobbying organizations, the division of labour between advocate and artist can be more clearly delineated and the negotiations of artistic disposition and performance are better defined. This dedicated mode of advocacy has been studied by scholars like Jason Hall (2005), Guillaume Sirois (2018), and particularly Sarah Jennings who has investigated the historic and ongoing influence of the National Arts Centre on cultural policy (2009, pp. 106-107). 
The interests of this dissertation are situated in bridging the gap in research that can gloss over the moment-to-moment development and negotiation of the dispositions of artists who are constantly navigating the messy tensions of artistic work and demonstrations of legitimacy. The “emerging" artist, and by association, the "emerging" advocate, is an important figure that has received scant attention. They are the ideal locus for demonstrating the processes of performative advocacy. Artists and groups who are newly emerging into these kinds of relationships exemplify the power imbalances that exist in relationships with state institutions and they are specifically streamed into relationships by virtue of institutional practices.

Woong Jo Chang considers the idea of "small" in the art world in his 2010 essay, "How Small are Small Arts Organizations?" (2010). While Chang offers a US perspective, he notes the difficulty in categorizing these organizations based simply on budgets or audience participation numbers (2010, p. 221). Chang recommends that we go beyond such quantitative variables to look at the impact arts organizations have on their community and their connectivity on that local level. In addition to the generally agreed-upon category of "emerging" or recently formed organizations, Chang wonders about those who choose to remain "self-subsidizing" (2010, p. 232), using their own resources to pursue the work they want and eschewing government involvement. I have met arts managers in the theatre community in Montreal who proudly claim their independence from government subsidy. As Chang concludes, grouping organizations into “emerging" or "small", misrepresents both the forms of such collectives and their potential choices regarding relations with legitimating structures (2010, p. 232).

Many of the groups of artists and arts organizations I am focused on in this research can be considered small or emerging, but my definition is slightly different than that of Chang. It is the very fact that they are new to the structures of legitimation and relations with government 
that make them useful to this study because their professional rhythms and performances are still in flux. How arts funding might interact with these newly formed and forming artists and companies is a key question. The Canada Council, in an effort to reach out to new prospective clients, created a specific profile for the "new and early career artist" in 2019. According to the Council website, the profile's intent is in "making it easier for artists to apply for their first grant". There is, however, very little difference in the application process, and these artists are seemingly only differentiated by the fact that they have not been funded by the Council in the past. We must simply imagine that the program officers tasked with interacting with these artists are meant to guide them along the way more carefully than with other artists who have established some relationship with the Council or with other arts funding organizations. Nonetheless, even if it is more of a marketing term than a true shift in policy, it is clear that recent reinvestments in the arts funding institution have recommended the opening up of the process to "emerging" artists. How those artists are being introduced into the dispositions they must inhabit to access these new funds may well begin in training institutions like John Abbott College.

\section{"Does anyone have a pencil?": teaching professional management}

JAC's three-year program generally has an intake of about 25-30 students in each of its three streams of instruction: acting, technical production (which encompasses set-building, lighting and rigging, costume construction, etc.) and design (which includes set and costume design, lighting and sound design, and related work). Due to attrition among students, the thirdyear acting class tends to hover around 15 students. As the shift toward a more entrepreneurial art world began to take hold in the late 1990s and early 2000s, the school recognized that holding on to its conservatory-style training of performers for the stage only needed to change. The 
school began to introduce courses that touched on television production and general camera acting courses that aligned with increased attention to the cultural industries. As well, actors were encouraged to think beyond the "starving artist", Romantic model and embrace their own agency in building their career paths. The professional management course was introduced in 2006 and has been a part of the curriculum since that time.

Acting students in the mandatory third-year Professional Management course at JAC are very much in the formative stage with little to no knowledge of the structures they are about to encounter as they move from "student" to "professional". Their instructor, actor, director, playwright, and puppeteer Zach Fraser guides them along that journey. Fraser joined the faculty at JAC in 2008 and has taught the professional management course since 2013. Fraser exemplifies how one experienced artist begins to help the next generation to envision and embody the dispositions that will make them both artists and advocates.

In our first interview together Fraser expressed his strong desire to engage with students in this way, to introduce them to this parallel work of art. It was also a kind of teaching that many of his colleagues at the school were eager to hand over to him. Other teachers, many of whom do not maintain an ongoing professional practice outside the school, have become somewhat disconnected from the work of making theatre outside the CEGEP. As a working professional deeply embedded in the community, Fraser felt he could offer students an in-thetrenches perspective on the working life of a theatre actor. Fraser has also self-produced some successful puppet-theatre performances, including works funded by the Canada Council. Fraser also teaches acting courses at JAC and courses in acting and puppeteering at the National Theatre School (Fraser, personal communication, September 27, 2018). 
In their 2014 issue of Canadian Theatre Review focusing on acting training, Belshaw and Fancy invited a host of stakeholders, including practitioners, academics, and administrators to share thoughts on the state of training institutions and acting practices in Canada. Their research noted the challenges in understanding the language and performance of emerging actors and their teachers as they begin to engage with various constructions of work: the artist, the administrator, the student or the teacher, along with those not mentioned in their interviews, the policymaker and the state-sponsored granting machinery (2014, p. 7). All these stakeholders, with their various understandings of art work, play a role in defining what kind of career the emerging actor might enjoy as they cross the threshold between student and professional. JAC's course offers an opportunity to observe that transitional movement and to begin to understand some of the language, texts, and performances in this movement toward the profession of art-making and its implication for the parallel work of advocacy.

Showing respect for the access that I have been given to the class, I arrive early for my first day of observation. Zach warns me that he hasn't had a chance to inform the students that there will be a researcher present in the class. We'll take care of that in the first few minutes, he says. I follow him up a set of stairs and down a long hall into the Visual Arts Department. It turns out that this studio, a wide-open space bordered on one side with windows covered by heavy black curtains and on the other by what appears to be a small washing area, probably for paints, brushes and such, has been appropriated by the Theatre Department to accommodate the need for some extra space. This location strikes me immediately as odd as I assumed a course in professional management would meet in a standard "classroom" setting with desks and chairs, perhaps a chalkboard and projector for PowerPoint presentations. Instead, we find ourselves in a 
"creative" space. The confusion of where and how this course is to proceed is heightened as I listen to the murmurs of students as they begin to filter into the room.

"Do we wear shoes?" "Do we need journals?" "Does anyone have a pencil?"

While some of this is standard student fare on the first day of a new course, I observe that they are not entirely sure how they are meant to present themselves in this class. There's a lot of milling about by the door, unsure whether they should stride in and take the space as they might be expected to do in an "acting" course, or if they should quietly enter and take a seat, as they might do in one of their academically oriented general education classes in English or Humanities. Throughout the observation period, this tension between the presentational identity of the "actor" and that of the "student, learning to work in the industry" will be reproduced. This is reflected in this space that, while clearly a studio where "acting work" is meant to happen, will masquerade as a "classroom", in these sessions from 6:00pm to 9:00pm on Monday evenings.

I ask Zach about this disconnect during an interview and he tells me that he appreciates not being stuck in a room with desks. His reasons seem personal to his own pedagogical style and not particularly art-focused. He explains that "[y]ou have the same three kids in the front row that are the whole conversation... you have a large back row where they're half with you, half asleep and on their cellphones and just distant. You feel like you're the one talking all the time" (Fraser, personal communication, September 27, 2018). Without that structure, a circle of chairs can be more of the conversation that Zach seems to want from this course. Nonetheless, I note the discomfort the students seem to feel with the space even through the entirely practical matter of having to write in notebooks without desk surfaces on which to write.

Back on our first day, the students begin to settle into chairs in a rough circle. Zach informs them that they should have a journal, and a pencil or pen, and I watch as they rummage 
through bags and amongst each other, shifting themselves from "actor" to "student". Some have shoes, most do not.

Zach has expressed to me that the course often proceeds as a conversation, prompted by questions, but designed to give the students a space to explore what a working life as an actor might be (Fraser, personal communication, September 27, 2018). Zach proceeds through his introduction to the course, offering a comment on the tension between the "actor" and the "working actor" as he tells the students that this class is what " $50 \%$ of your work is going to be about" once they leave the comfortable confines of the school. He tells them they need to begin to think of themselves as a business. If you want to get to do the work, he tells us, you need to think about the "discipline" of the business. Hands shoot up and a frisson stirs the room. The students are animated: whether they are scared or just hungry for information that appears to have been denied to them up to this point in their training, I'm not yet sure. Zach does not want to take questions yet but one student is insistent enough to get her unexpected concern addressed.

"In some of our other classes, our teachers are OK if we need to move, that we stand up quietly... Could we - would that be all right here?" she asks. While this might seem like a nonsequitur, it is difficult to ignore the explicit link between the discipline of "the business" and the discipline of the body that is present in this moment. While still negotiating what this space is going to be for the next eight weeks, this student seems to be internalizing a fear of the discipline required to get to make her art, by ensuring she has permission in this space to move her body. Still not quite understanding how to be in this class is an echo of the limited understanding of how these artists are going to move through the art world and gain a sense of their own agency through constructing a legitimate artistic career path. 


\section{Which bodies?}

The physical embodiment of this discipline is well connected not only to notions of governmentality as a feature of cultural (and by extension, education in the arts) policy, but also allows us a moment to consider which bodies are in the room in the first place. There have been long-standing questions and concerns emerging from the \#metoo movement about gendered work in the art world. An IE approach allows us to acknowledge feminist critique as it is threaded through the kinds of advocacy relations that suggest themselves in the links between artists and the state.

There are 13 women and 4 men in the class, a statistic that seems to contrast with the analysis of theatre sector workers as presented by Coles and her colleagues in a report for the Ontario Arts Council. In their 2018 meta-survey, they note $46 \%$ of performers in the theatre sector are female, while $22 \%$ of leadership roles (such as directors, choreographers, and producers) are occupied by women. In the same report, the authors cite statistics from the National Theatre School in 2014-2015, that 58\% of students at the school were women, and 59\% of graduates so identified (2018). This skewed representation may well represent one of the underlying concerns of Smith's feminist framework, the need for a more robust analysis of the particular relations that women need to embody as advocates in relation to institutions like the role of the artist and their performance as advocate.

In May of 2018, the Standing Committee on Canadian Heritage, chaired by MP Julie Dabrusin $^{8}$, heard testimony from members of the cultural sector. In January of 2019, they

\footnotetext{
${ }^{8}$ According to her bio, Ms. Dabrusin, Liberal MP for Toronto-Danforth, was born in Montreal and moved to Toronto in the mid-2000s. She has been active in grassroots organizations like Park People, which advocate for public use of greenspaces. In addition to her role as Chair of the Heritage committee, she is Parliamentary Secretary to the Heritage Minister. Her connection to Heritage comes through her work in public spaces rather than any specific knowledge or experience of the art world.
} 
produced a report entitled Gender Parity In Canadian Artistic And Cultural Organizations (Dabrusin, 2019). A part of that testimony from the Canadian Arts Coalition detailed a "power imbalance", with a large number of women involved in the arts but very few rising to senior levels of management and artistic direction (Dabrusin, 2019, p. 5). One of the potential issues identified is the lack of female representation on the volunteer boards of directors of arts organizations. Since these are the bodies that ultimately make hiring decisions, these gender biases become a barrier to women without advocates that identify with them on these boards. It is worth noting this power dynamic exists in arts organizations and non-profits in general, where power flows from a group of unpaid workers, some of whom also exhibit few skills or knowledge of arts and charity management. Since women are generally paid less than men, in addition to occupying more traditional roles in the family, their time is limited, and sitting on a board is often seen as a luxury. According to Julia Oullette of the Museum of Contemporary Art in Toronto, training is a key. Despite their desires, "small and mid-sized organizations lack the funds to support this kind of talent incubation. Government support would go a long way" (Ouellette as cited in Dabrusin, 2019, p. 16).

The report further states that, "some witnesses suggested that the federal government urge all organizations that receive federal funding to set a goal of gender parity in key leadership roles" (Dabrusin, 2019, p. 21). As with the example of the controversy at Soulpepper Theatre, while encouraging a necessary movement towards gender parity, this recommendation represents a direct disciplining of artists and artistic organizations through the levers of funding which is a concern across the art world.

What is significant in this discussion is that an approach that incorporates IE can be used to acknowledge these power imbalances and suggest ways to include such insights into 
scholarship through a focus on the actions of individuals and their interactions with state and organizational structures. In short, the bodies and their movement matter as much as the policies, conventions, and texts that move them.

\section{"I don't know how I am supposed to be."}

Back in the classroom at JAC, Zach is presenting the syllabus which lists several assignments that introduce students to various artistic and advocative dispositions. In my observations throughout the course, Zach never expressly uses the term advocacy. When I would bring it up with the students he seemed to feel the term fit well with what he was trying to do. For Zach, the idea of the course is to start a dialogue with the students that introduces them to the world outside the college. By requiring them to engage with the art world as an institution that requires processes of legitimation in the form of relations with artistic companies, funding bodies, tax programs, and professional organizations, students begin to embody new dispositions outside of those expected in the conservatory-based school. Zach is very aware from his own experience as a performer, and from his knowledge of the art world in and around Montreal, that the students will be required to take on multiple posts, many jobs, many professional activities that are not directly related to stage acting. He tells me that "success is to be able to make some portion of a living in some way linked to the arts" (Fraser, personal communication, September 27, 2018). When I question him a little further on that success and the economic language he uses, he clarifies: "The intent of it [the course] is to be able to teach the skills of how artists are brought into the business side. People to know, how to find their place in the market, and like using words like market perhaps" (Fraser, personal communication, September 27, 2018). At least a part of the job of the course is to introduce new language that these emerging artists have yet to truly encounter. 
The syllabus lists eight different evaluation measures along with participation in class discussions where presence will be assessed. These assignments expect students to produce texts: they are required to submit journals in which they are to gather lists of resources available (rehearsal studios and performance venues, production companies with whom they might work, and advocacy groups) to emerging artists in and around Montreal; they are to prepare a professional $\mathrm{CV}$, and a headshot; they are to complete a tax receipt assignment wherein they begin to explore how artists claim taxes and expenses involved in the work of making art; and they are to create a mock production grant, based on the criteria of the Canada Council for the Arts, including a basic project description, budget, and marketing plan.

While the production of the $\mathrm{CV}$ and headshot will be discussed later in terms of their strict institutional and textual forms, and the project grant assignment is the most direct relation to the government's funding apparatus, I will now spend some time relating observations from some of the other discussions in the classroom, particularly as they introduce dispositions of advocacy to these emerging artists.

Coming as it does in the first semester of the final year, Zach asks the students if, over their summer break, they experienced any revelations about their training and their place in the art world. Several students describe moments of anxiety around how they are expected to work as actors. In one student's words, "I don't know how I'm supposed to be in the world". Another student responds by suggesting that while some will discover that the lifestyle of the artist is "not for them", others will "give up on themselves". Zach tries to reframe these concerns by reminding the students that they do not need to subscribe to the Romantic vision of "the poor starving artist". There are all kinds of pathways to a career in the art world and many of them, while administrative in nature, maintain features of creativity. 
This establishes a fundamental argument that I observe through the entirety of my time in the course. There are many paths to success and fulfilment as an artist and an important one is to understand the artists' role as advocate. For students whose experience of being an actor up to this stage has been entirely focused on the learning and execution of acting techniques, the acknowledgement that the work of art-making is, as Zach states, "at least 50\%" advocacy, is shaking their sense of identity. It is bringing about the shift that is often seen by scholars like Childress and Gerber, who argue in line with Shyon Baumann, that "artists are workers with occupational identities who sometimes create or embed themselves within organizations in order to better legitimate and disperse their ideational claims" (2007, p. 237). As they seek to find their place in the art world, these students are being asked to consider the role of advocate and the relationships with legitimation that such a role will entail.

The claim "I am an artist", is a speech act that is only "happy" (Austin, 1975, p. 14) if the individual is properly placed within the institutional context, legitimated by structures including government funding bodies and professional advocacy organizations. That we often concern ourselves with whether an artist is an artist or not, or whether they are a professional or not, is an indication that we are not paying enough attention to the performativity of this language and perhaps too much to the notion of identity, the constative claims of these names. These claims are not true or false since they are not descriptive of the individual but rather performative, building a social reality through speech action.

This process of embedding into legitimating organizations begins with the fact that these students are training in a CEGEP program but it does not end there. The assignments Zach has given them involve exploring the organizational contours of their art world by researching and reporting on rehearsal spaces, artistic companies and their directors, arts service organizations, 
and funding bodies. Zach suggests that students must "imagine that you're already a professional, right now" which means they need to start to become visible to the people and structures that will legitimate their work. In the following weeks, as I observe the students offer up their brief presentations on professional organizations and funders like the Quebec Drama Federation, Montreal Arts Interculturel, and the Conseil des arts de Montreal, it is not that they are becoming industry professionals by dint of some shift in identity. They are being encouraged to engage with these organizations from the relatively safe space of students learning about their part of the art world. They are recognizing that their creative work will likely only be possible once they establish their presence within a network of legitimating institutional support, an advocacy network of which they must demonstrate that they are a part.

Zach's teaching style and engagement with his students is a further indication of how individuals can be invited into the dispositions of advocacy. In a nod to the Socratic, Zach plies his students with questions that encourage them to consider what advocacy work is expected of them. For instance, by asking students whether they had some kind of "aha" moment over the course of their summer break, Zach is teasing out a discussion about who sees themselves continuing in the acting profession and who might be wavering in their commitment. Those that saw a show or something that inspired them are further encouraged to think about what it took to create the environment where that kind of performance was possible.

Zach draws a lot on his personal experiences as a performer and producer to inform his students about some of the performances expected of them as advocates. Introducing the grant application assignment at the end of our first class together, Zach informs the students of his own success in legitimating his work, while also opening the wider discussion about theatre as a "money-making gesture". Most theatre would not exist without government support, Zach tells 
them, and since arts improve our quality of life they are deserving of government support. The question is what kind of work needs to happen in order to tap into that stream of support and to encourage that support to further circulate in the art world.

Much of his work is in trying to get students to reach out beyond the school environment. For instance, when a student presents a short report on a rehearsal space that is missing some vital information, Zach asks if the student actually called them up to request the information rather than simply checking a website. This exchange leads to a fulsome discussion on the importance of making actual contact with the individuals that control resources in their pocket of the art world. This advice, to reach out and make contact, is a theme that is repeated by workshop leaders and advocates throughout my observations, particularly when it comes to making contact with program officers at arts councils.

A tangible example of the institutional performance Zach is trying to help these students embody is the tax assignment. As professional artists, the students must be made aware that many of their daily expenses can be used for tax purposes. For one month, students are to gather receipts that they feel are appropriate to the pursuit of their professional lives. This leads to a number of interesting discussions and questions about what constitutes a professional activity and the ways in which mundane, quotidian activities are in fact, embedded in the institutional reality of the artist. For example, Zach informs the students that many independent and small companies in and around Montreal are run out of people's homes. While this surprises some students, the implications are clear that some expenses many would not think of, like portions of rent, utilities, internet access costs, etc., may be "business" expenses that are eligible for tax purposes. As a one-person independent contractor, or as a member of a small company, the 
location and body of the artist is implicated in professional dispositions that have material and economic impacts.

A meeting at a cafe, hair and skin products, photoshoots, office expenses for the home, all of these expenses and their categorization as work receipts confuse the reality of daily life with the role of the artist. They are also markers of the fluid negotiation of action and disposition that considers how artists are supposed to be in the world.

\section{"Welcome to the dark side!": translating advocacy}

Over the course of my career as a theatre artist, I have seen the transformations in communication wrought by social media, offering me the ability to observe the art world in a more quotidian manner than was possible when the community was only able to share its activities with each other at meetings and events, perhaps over newsletters and websites. I have seen companies founded, produce work, and dissolve on my Facebook timelines. Just as significantly, I have marvelled at the informal networks of commiseration and self-help that have manifest during the processes of grant-writing in the arts community. The following posts, presented unedited, floated through my own personal Facebook feed during the course of this research:

"Love that stage of the flu where you cough every minute and get like no sleep (even taking cough suppressant) and then have to keep writing grant applications."

"A perfect day for Grant-writing!" with the comment: "its never a perfect day for that"

"Is grant writing season over yet? Please???" with the comment: "You'll find an empathetic ear here!"

"Today is budget day for grant writing. But to keep it all balanced it is also spa day." with the comment: "Happy grant time!" 
While I recognize that my own Facebook feed is a narrow set of examples of particular performances of the digital self on social media, these posts are powerful examples that demonstrate two important functions in performative advocacy. First, they demonstrate the legitimacy of the artist as one who understands and engages in the processes of grant-getting. There are artists who, by choice or by circumstance, do not interact with the processes of government support. Community or amateur theatre practitioners are a good example. Their lack of status as "professional" artists in the classification of granting agencies puts them outside this kind of disposition. It is worth investigating what kinds of alternative dispositions exist for these kinds of practitioners, where they go, and how they seek the support necessary to pursue their art work, but at the moment this falls outside the scope of this research.

Doing this grant work is understood as a necessary hardship and a diversion from the "real work" of art-making. However, it is also an implicit call to members of the art world that may be questioning whether they are capable or deserving of this kind of engagement, that this is the time to be pursuing these interactions. "A perfect day for Grant-writing!" suggests that this is what all professional artists need to be doing today. The comment, "its never a perfect day for that", while very likely meant sarcastically, also shows that the commenter recognizes that this process is one that all professional artists must endure despite its onerous nature.

But what about the post that seeks the "balance" of a day of grant writing (and budgets, no less) and a day at the spa? Along with the "empathetic ear" offered to the plaintive cry for the process to be over, this communication speaks to the second aspect of performative advocacy suggested by these posts, a shared disposition. These comments recognize that this process is not the preferred activity of the artist. While the spa may not be a core artistic activity, it can be seen as a bodily process that both washes away the unwelcome feeling of interacting with the 
government funding apparatus, and a moment to recharge the creative batteries after their exhaustion in the service of advocacy.

Another post is demonstrative of this call to community and the transformation of artists into advocates: "Thanks to all in my community who let me pick their brains re: production, budget, grant writing, professional advice, etc. If I have the knowledge and can ever help anyone else out, ask." Here the identification of advocacy as a community activity is linked to special knowledges, textual forms, and languages that circulate among those "brains" that have experience and insight into the processes of advocacy. Once one is inculcated into the forms and dispositions required of the advocate, it is a responsibility to share that knowledge, to pass it on in order to build more advocates and create a situation where rising water can float all artistic boats.

As Guy Rodgers, executive director of the Quebec English-Language Arts Network (ELAN), tells me (Rodgers, personal communication, September 11, 2018):

There are companies that have the resources and capacity who can write complicated grant applications, and there are those that don't. You've got to keep things simple for them, and provide them with the information, how to write a grant.

ELAN has suggested that creating something like a physical hub, a "centre of excellence" for the pursuit of advocacy in the arts sector, would help to build the capacity for artists to interact with funding agencies and demonstrate their legitimacy in accordance with the texts and forms government requires. The notion of transforming the virtual network of collective advocacy into co-presence in a physical location speaks to the value of presence and proximity in the performance of advocacy and the introduction of the advocative disposition which could be practiced in this particular space with the support of those with more experience embodying such 
a disposition. Such a "hub" would demonstrate that spaces where art gets made are not confined to the studios, rehearsal halls, and performance venues that we often imagine, but extend to the creation of dispositions and interactions of advocacy. Building this capacity in the community requires both experience, performance, and a "stage" on which to display legitimacy.

Those with the required skills are expected to introduce advocative processes and communication tactics to the art world. The students at JAC are introduced to the specific texts, knowledges, and performances expected of them as they are introduced into the professional art world. A similar process is ongoing when advocacy groups like ELAN and the Canadian Arts Coalition (CAC) attempt to form new advocates from the ranks of artists that make up the sector.

The CAC is an advocacy group comprised of arts service organizations and some artistic producing companies. As it does not accept memberships from individual artists, it is through delegates from these organizations that the CAC draws its advocates. A key understanding here is that these are artists whose interests lie primarily in the creation of art. How do they become advocates? How do they begin to understand the performances of legitimacy that will not only help to facilitate their own creations but the work of their peers?

In an interview with Kate Cornell, co-chair of the Canadian Arts Coalition, I was curious about the formation of arts advocates. How does someone like Kate, who has devoted much of her career to advocacy, persuade other artists and arts professionals of the importance of this work? In introducing the idea of advocacy to an artist, she explained her approach to me this way (Cornell, personal communication, January 18, 2019):

I ask them, first and foremost, do you get Canada Council money? Do you think that the doubling of the Canada Council budget just happened because fairies came along, you know. No! That was 10 years of advocacy and I can't tell you how many times I see that artists are completely floored by that. 
Kate went on to tell me that:

It's much harder to convince an artist to come and be an advocate, it's much easier to convince a manager to become an advocate. You've got to meet them where they're at, and what their issue is going to be to motivate them to become advocates.

These two statements demonstrate the disjuncture that exists between the work of art and the work of advocacy and management, between core artistic activity, and the administrative disposition that haunts the identity discussions around artists. What we call ourselves is a performative act, creating a social reality that can constrain our actions and our perception in the community, and with those state representatives with whom we pursue advocacy.

One of the most pervasive of these categorizations of art workers is the requirement by the Canada Council to create online profiles that delineate the individual as either "artist" or "arts professional'" These profiles are then employed by individuals depending on the nature of the project for which they are applying. In other words, these are fluid roles and dispositions, not solid identities. The Council website defines the artist as a professional creator who has specialized training, is recognized by their peers, has a history of public presentation, and is committed to devoting more time to artistic activity, if they can afford it. The arts professional is not defined as clearly, but is referred to as "those who play non-artistic roles such as administrators, technicians, etc.”. One ostensibly works as creator, pursuing that core artistic activity, while the other is the intermediary: the administrator, agent, curator, or advocate whose work is in the creation of the environment where art can be made. Kate's insights would seem to suggest that the border between these "profiles" is quite porous, and more a question of the moment than anything like an identity.

Kate explains that a manager, the arts professional that is concerned with the gathering and disbursement of resources, physical, human, etc., required to enable the production of the art, 
its distribution, and consumption, moves more easily into the advocacy role. But so many of these smaller, emerging arts organizations and individual artists that populate the emerging art world fold these activities into a single individual. Furthermore, the artists themselves, as Kate's first quote reveals, must be made to understand the significance of advocacy work.

When and how do these kinds of transformations take place? As Jane Woddis suggests, advocacy is not simply a matter of applying political arguments to governmental structures. There is a whole world of communication that happens within the arts community itself (2014, p. 503). While Woddis' argument concerns tensions between artistic disciplines and labour conditions within organizations themselves, we should not ignore the process of promoting the dispositions of advocacy. Advocates, Kate reminds me, are often formed by being "volun-told" to engage in this work, essentially dragooned into the role of advocate. This is not to suggest that artists do not want to make their situation better for their own work and that of their peers, but that to interact with governmental structures is not something with which all feel comfortable. It is an unfamiliar script, a dramatic situation that is alien and therefore frightening. Artists in general, Kate tells me, “don't get that Ottawa level. They don't understand how it refers to them and how it's relevant to them" (Cornell, personal communication, January 18, 2019).

To bridge that gap in understanding and to make a new advocate, Kate suggests that concrete examples, presence, and language must be employed. People are not "born arts champions" (Cornell, personal communication, January 18, 2019) and often they need to see the results of advocacy efforts to be convinced. Those examples need to impact directly on the bottom line for arts administrators. Kate mentions that most larger organizations have a history and understanding of advocacy relationships with the state but smaller companies and individuals need something more tangible to them. 
"I try in my tactics to assess who I'm talking to and pick the success story from my little cabinet, and share that, as a way of enticing them in," Kate tells me (Cornell, personal communication, January 18, 2019). For instance, in Kate's testimony before a Commons standing committee on dance where she represented the Canadian Dance Assembly in efforts to get a tax exemption for foreign workers in the arts sector, she tells me: "I made the comparison between the hockey player and the ballet dancer." She argued that if there were exemptions available for one kind of cultural activity then it must follow that dance, as another cultural activity, would be appropriate. That parallel not only convinced policymakers but also helped arts administrators to understand how tax policy could affect their budgets. "Whoa, you saved me like $\$ 10,000$ dollars off my budget because I'm not paying that $\$ 1000$ fee (per worker) and now I'm paying \$230.” From there, Kate suggests, administrators are much more amenable when she asks them to come to an advocacy event (Cornell, personal communication, January 18, 2019).

Presence at an advocacy event is the goal, explains Kate, for recruiting new advocates. These are the "baby steps," as she calls them. "Do you want to come to this meeting? Do you want to come and see what Arts Day at City Hall is like?" (Cornell, personal communication, January 18, 2019). Starting at a more local level allows artists and emerging advocates to better see the connection to their immediate circumstances. In one example, Kate is able to engage with an artist simply by virtue of their sharing an office space together. This began "a two-year process of... oh, where are you going to now? who are you talking to now?" which she expects will culminate in a protest event at Queen's Park in Toronto. An advocate is born, Kate seems to say: "Right! Welcome to the dark side! So, I said you can have all my speeches, I will walk you through this, we can have coffee!" 
She sums it up this way (Cornell, personal communication, January 18, 2019):

You can talk until you're blue in the face, but I know [...] that once we get them to come out to an Arts Day, the magic happens, and they see the importance of those face-to-face conversations, they see the change that is potentially there.

That change is also a matter of altering the way one speaks about interactions with government bodies. As in the example of the grant-writing networks I saw formed on Facebook, sharing and translating the language of artists to the kinds of economic discourses that concern governments is a key to introducing artists to the demonstration of legitimacy in relation to these funding structures. Guy Rodgers tells me that "advocacy is a form of mediation" (Rodgers, personal communication, December 19, 2018). This suggests there are codes present in the language of advocacy and despite the wealth of research on the semiotic understanding of this language, the langue of advocacy, the important point is that these codes are activated, as paroles, in the practices of artists demonstrating their legitimacy, shared among networks of advocates, and crystallized into specific forms and texts, including cultural policies (Volkerling, 1996, p. 191). As Robert Higham argues, in the vein of Abbing and others, "cultural policy warriors should make their arguments in the language of economics" (2002, p. 364).

Economics may not be the only language advocates need to adopt. For instance, when ELAN was forming as an organization Guy explains that a consultant worked with the members to distill the needs identified within the English-language art world in Quebec into the simplest language. Two words emerged from that process: "visibility and access". Guy explains, "that was the beginning of our understanding of the power of words and connecting needs with government policy" (Rodgers, personal communication, December 19, 2018) Not only are those words powerful but they are significant theoretical connections to performative advocacy. Artists 
acting as advocates must be present and visible (Butler, 2015; Goffman, 1959; Klostermann, 2016, p. 45; Tummons, 2017), which allows them access, physical and social access, to the institutions that legitimate the work of art. Guy explains that every grant application, every program description, every evaluation and report centred around those words. As ELAN moved from uninvited advocate to a partnership role with the Department of Canadian Heritage, these words codified that relationship and the goals of their efforts. Though they have economic implications, these are words that speak of presence and of connection to the institutions that legitimate the work.

The significance of these words and the place of ELAN as an advocacy organization for English-language artists in Quebec warrants some further mention here. ELAN began to emerge as an idea in connection to initiatives from the Quebec Community Groups Network (QCGN), an advocacy coalition that has been working for English-language rights and recognition since 1994. The QCGN comprised groups that received support from Canadian Heritage under the auspices of the Official Language Minority program, a pocket of funds devoted to Englishlanguage groups in Quebec, as well as Francophone groups outside the province. With advocacy from cultural groups within the QCGN, money was redistributed to English-language artists in Quebec through Canada Council programs.

ELAN was formed as a further response to these funding inequities as identified by the artists that gathered for the 2004 Quebec Arts Summit. After its incorporation in 2005, the following years saw ELAN gain significance as a strong voice for advocacy and an invited consultant for a number of key programs at all three levels of government. Even more significant to this research are programs that ELAN initiated and funded that were focused around the ideas of visibility and access. Their "schmoozer" events brought artists and community members 
together in the same time and space for networking and demonstrations of solidarity. Schmoozers quickly moved from taking place primarily in the urban centre of Montreal to suburban and even rural spaces like the Eastern Townships. ELAN established partnerships with organizations like Youth Employment Services, making themselves visible to artists that might be seeking services not specifically aesthetic in nature but rather economic. Conferences and other gatherings followed including the State of the Arts conference in 2010 with a recent follow-up in 2018. In continuing efforts to bridge the divide between English and French artistic communities, ELAN initiated the Enfins Visibles (Finally Visible) program, a virtual video showcase of artists from both linguistic communities, expressly designed to highlight their work online and increase recognition by audiences and funders alike.

Evident in ELAN's programs is a diversity of mediations along with a strong focus on presence. Guy told me that ELAN emerged not from concerns over the retention of the English language but of English-language speakers, the people themselves, and their representation in artistic forms would be a key support for that goal (Rodgers, personal communication, December 19, 2018). Kate Cornell of the CAC also suggests that different media forms could provide the ability to perform advocacy work in significant ways. As she communicates both with members of the art world and with politicians and their representatives, she tries to go beyond newsletters, speeches, and Twitter (some of her preferred mediations). Kate suggests to me, "Maybe I should start vlogging or something, do more of the video stuff because when I talk that seems to engage people a little more effectively" (Cornell, personal communication, January 18, 2019). As a dancer, the visual presence of the body in space, even over video, seems to have a currency in advocacy efforts. 
This question of translation and of education in the performances of advocacy and the ways that state representatives might receive those performances comes up over and over throughout my work in the field. These actions comprise the more general efforts of Arts Day organizers to keep artistic production on the government radar, to the education and introduction of advocative dispositions to artists who are newly engaging, sometimes unwillingly, in the processes of advocacy. This adoption of specific performances is further evident in the ways that artists, acting as advocates, are taught to encounter state institutions on a human level.

\section{"Make the program officer your friend": workshopping advocacy}

If there is one thing that appears more often on my Facebook feed than complaints over grant-writing, it is the advertisements and invitations to workshops and information sessions on that very process. Often presented with tongue-in-cheek images like the one below, these workshops are the physical manifestation of the social media network of information exchange that begins the process of advocacy.

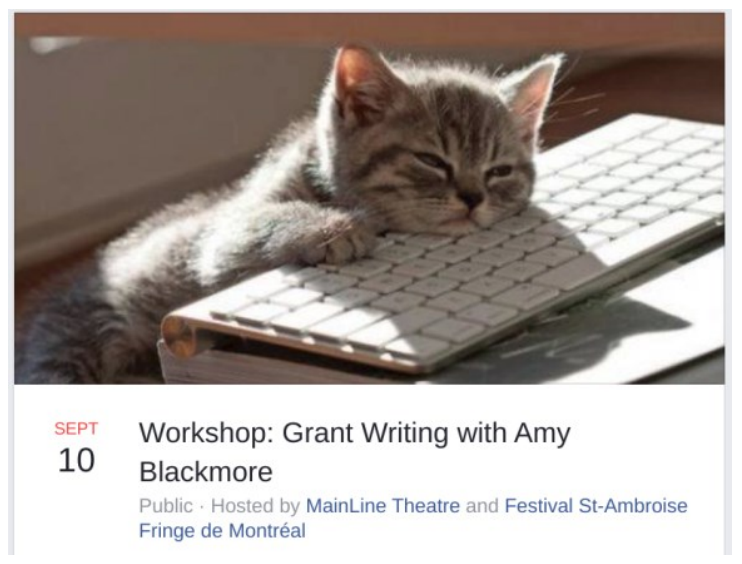

Figure 1 - Facebook ad for grant workshop from MainLine Theatre ${ }^{9}$

\footnotetext{
${ }^{9}$ MainLine Theatre is a performance venue and an arts organization in downtown Montreal formed in 1991. The organization is a hub of independent theatre and dance production, as well as the home of the Montreal Fringe Festival, a yearly event present in many major cities across North America and Europe ("About MainLine Theatre| Théâtre MainLine Theatre", n.d.).
} 
These workshops are also a moment where the dispositions required for advocacy are introduced and reinforced. I will discuss this aspect of formation through observations from two encounters: a workshop on grant-writing delivered by a consultant from ELAN in Chelsea, Quebec on November 12, 2018, and an information session presented by staff from the Canada Council in Kingston, Ontario on November 20 of that same year.

Throughout 2018 ELAN delivered a series of workshops they called the Savvy Sessions, with support from the Canada Council. The sessions comprised a number of different skills and practical areas of instruction such as marketing, touring, self-producing, music recording, and grant-writing. These workshop sessions, many taking place in the regions of Quebec outside of Montreal, were primarily designed to build the administrative capacity of Quebec's Englishlanguage art world. I attended a session on grant-writing in Chelsea, Quebec, a town just north of Ottawa. The session was held in a small gallery and was led by June Park ${ }^{10}$, a Montreal-based arts consultant and "cultural connector" who had been charged with delivering the Savvy Sessions program overall. It was attended by eight artists, from different disciplines including visual arts, fine craft, and performance. There were seven women and one man present at this session.

The small number of participants and the lo-fi setting made for a general sense of intimacy with the material. According to ELAN's website, the idea of these sessions was to understand the new Canada Council funding model and to gain "insights into making CALQ (Quebec provincial funding) and CAM (Montreal municipal funding) applications”.

\footnotetext{
${ }^{10}$ Ms. Park has extensive experience as an arts advocate, administrator and writer. She studied arts administration at the University of Waterloo, and has sat on a number of Boards, including the Quebec Drama Federation. She has worked in marketing and finance for the Royal Ontario Museum and Opera Ontario. She is also a freelance grant writer herself and works with culturally diverse companies to increase their access to funding and support.
} 
Furthermore, participants in the workshops would "focus on using appropriate 'grant' language" leading to a "polished submission". In my observation, what happened was that we spent a good amount of time talking about how to engage with the technologies of the funding apparatus and build a relationship with program officers.

June Park delivered a slideshow filled with practical tips and tricks on how to proceed through the grant-writing process, but her language was decidedly more personal. Building a relationship with the program officer to which your application is assigned was presented as an absolutely essential part of a successful grant application. "Call them," June instructed, "make them your friend". These program officers, she intimated, would be in the jury room presenting your work to the assessors, and the more they remember and think of you, the better their pitch for your work would be. By forming a bond with the program officer they become your advocate in that space to which you are physically denied but in which you must appear as visible as possible. As Marisol D'Andrea suggests in her work on jury processes, there is a fundamental tension between the arts community (as represented by the peer assessors in the jury) and the arts council bureaucracy (represented by the program officer) that is linked closely to the tension between intrinsic and instrumental policy considerations for art work (2017, p. 254). Artists are expected to perform a relationship with the program officer to establish a symbolic presence in the room and to help to resolve that tension.

The application process itself, with its online portals and word-limited forms and boxes, was a major concern for these artists, all of whom appeared older, probably in their fifties to sixties. June warned that the complexity of the forms can easily have artists "filling out info in the wrong boxes", leading to an almost certain refusal of the application. I felt the tension in the room rise as these discussions focused on the importance of "following the instructions 
precisely". This precise technical disposition was in contrast with June's advice to the participants to "tell your story with heart, with meaning". In forming a project description, participants were told it was important to imagine art work as more than "just writing a song, or painting a painting... it is why this, why now?" The artist must precisely follow the proper textual mediations but do so with language that is more than instrumental. And yet, June warns, the Council "does not expect you to change the world". I watched as the participants' eyes began to glaze over at this point from what I felt was an overload of information but also a disjuncture in the proposed dispositions which were being presented as the keys to success in this relationship with these funding bodies.

During a break I observed participants discussing how they felt their own practices were falling somehow between the cracks of the funding system. Many were socially engaged artists whose work was decidedly local, meant for local consumption, and connected with local issues in their town and in rural Quebec in general. Many wondered how they were meant to translate the language of social practices in the arts into something they felt the Council and other granting bodies would understand. For instance, one artist whose work crosses disciplines of visual and spoken word practices was pitching an idea about telling the stories of racialized people within his community and their experiences of discrimination through a "visual score". As a white artist he was concerned about finding appropriate partners in the Black community and moreover, how to express the value of such a partnership within the specific questions of "artistic rationale" demanded by a Council grant application. Ms. Park suggested that he frame the issue around "impact" and how his work would influence not the social world of the community itself but the art world and its practices in representing racialized people. 
The work of art can become explicitly tied to ideals of social progress and human emancipation. Nevertheless, this work must always grapple with a tension between the desire to create without constraint, to share an artistic vision free of instrumental concerns and attachments to specific policy ideals, and the recognition that creation can be supported and legitimated by links to public health, social inclusion, and education. In these competing visions, we see the struggle between art as a public good based on its intrinsic ability to elevate and celebrate the human spirit and art as an instrument of social change, a tool to address inequities and alleviate human suffering caused by issues as wide-ranging as colonialism, racism, ableism, and countless other isms plaguing the community and the nation.

When the session resumed there were some writing exercises that asked participants to create a project description for a potential application. Some of the critiques that were shared by June align with this confusion over disposition and language. June observed that many artists were "selling" their work rather than pointing to its artistic value for these funding bodies. Most used "too many adjectives, too much "purple prose"" instead of simply relaying the facts of the project and forming an impression that makes the program officer and jury, "believe they are going to do this". The session closed with two stark reminders: the Council funds artists who are committed to being artists, an identification that was linked to the idea of the "professional"; and that Chelsea is close enough to Ottawa that these artists, "can go see the program officers", a further prompting toward the importance of presence and relationship.

What this close observation suggests is that there are specific dispositions that experienced arts consultants who have interfaced with the government funding apparatus believe to be appropriate, even required, to build a legitimate artistic career. Those dispositions are founded on appropriate language choices, presence, and proper adherence to the technical and 
textual interfaces that have been put in place. Those dispositions are not at all innate to these artists, many of whom see their work as somehow out of sync with the priorities that they imagine funders promote. Overcoming this disjuncture requires more than a workshop or two, it is an ongoing process of advocacy, that must proceed not only from consultants and groups like ELAN, but also from the government and its arts councils themselves.

This leads me to a rainy afternoon just a few days after the Chelsea session where I found myself in the lobby of the Agnes Etherington Art Centre on the campus of Queen's University in the town of Kingston, Ontario. As part of their outreach efforts, two program officers from the Canada Council were here to talk about the programs they deliver and to make themselves available for one-on-one consultations with artists seeking to better connect to the funding process. The rain has me arriving a little late and as I slide into a seat at the back of the 40 or so artists and administrators that fill the room one of the program officers, coffee in hand, is offering up some comments on a slide about the application process. As the assembled crowd pull out smartphones to snap photos of the slide, a woman asks, "Is this stuff on your website?". The officer responds, "no," and the woman is then joined by a chorus of people: "then you're going too fast, hold on!”

Evident in this brief intervention is the belief that there is something in this presentation that will unlock the key to a successful grant application or offer some palpable connection to the Council process. If this is information that is not available on the Council's website, then those present sense that they are getting something, some connection, some language, some knowledge that is hidden from other artists, and that has value to them. They are learning a performance, a script perhaps, that they will need to become successful advocates. 
My observations of the presentation pointed to some of the themes that have already emerged in this research. In discussing the rather extensive budget forms required in their applications, one of the Council presenters shares with us that, "the first time I opened this [Excel] sheet, I'll admit, I shut it down right away!" The form scared her, she admits, and the nods and uncomfortable giggles around the room attest to a shared sense that the textual performances that circumscribe this relationship are imbalanced. Many artists tend not to think in terms of economic value and yet there is a requirement to be precise about the numbers. They must accurately forecast the cost of their work, and even more problematic, its potential monetary value to an audience. Contrast this moment with a discussion toward the end of the session where the presenters suggest that it is up to the artist to tell the program officer, and through them, the jury, how their project is significant. Furthermore, it is the applicant who must, “tell us, we need to know who you are!" Artists are expected not only to demonstrate their economic value, but to legitimate their identity as artists, to explain who they are.

More than once the word "demonstration" was used to suggest a disposition for the artist to advocate for their work. All the materials, supporting documents, history, and even the numbers, are demonstrations of the seriousness, viability, and value of the artist and their project. Part of that demonstration includes the adherence to the proper forms and language that these officers and the institution of arts funding will use to legitimate the practice and offer the beginnings of a relationship with these that may lead to an artistic career.

\section{An artistic career?}

Back at John Abbott College, it is the final meeting of the professional management class and time to wrap up some of the conversations that have been floating around during these past eight weeks. Zach digs through some chairs and detritus in an alcove of our studio/classroom and 
brings out a mobile chalkboard. Searching around for a piece of chalk, he informs us that he is going to "be a teacher" for a few minutes. "We're going to do an exercise that I often do in this course". He turns to me with a grin and says, "Lowell, you'll appreciate this one." My curiosity is piqued. With chalk poised, he asks the room, "We're talking about being a professional actor in this course, so... How can you make money at this?"

The students begin to pepper Zach with suggestions ranging from voice actor for cartoons to motion capture for video games to the more obscure but decidedly performance-oriented gigs like "border services or medical simulation performer". Zach is writing furiously and also gently guiding them toward a more expanded set of possibilities than the various takes on "performer" they are currently imagining. Slowly and inevitably, students begin to explore the work of art not as strictly related to acting, but in a wider sense as box office ticket taker, usher, grant writer, arts administrator, teacher, and agent/manager. The students seem to oscillate between the excitement of imagining all these possibilities and the cynicism of their generation, recognizing the chances of them having a single, defined career trajectory as an increasingly unattainable dream.

I know where Zach is going with this and so when he turns to me and asks the inevitable question I am prepared for my answer: "How many of these have you done, Lowell?" All of them, of course. As Belshaw and Fancy identified, artists who want a career do not remain artists only, they must articulate with all the people, the structures, the texts, and the spaces where art is made (2014, pp. 5-6). To begin to think beyond the question of being an actor for hire and into one of controlling and building one's own career as an artist, one must let go of the Romantic myth and even let go of the idea that an artist will spend the majority of their time making art. It is just as likely that they will do almost every other function, hopefully in the art world itself, but 
even outside of it, to create an environment for themselves where they can do the work of making art.

In Canada, much of the art we consider professional and legitimate is made hand-in-hand with the funding and bureaucratic apparatus of the nation, the province, the city. When interviewing a student after class one week, I ask her about how she sees her career moving forward. This is a student who is known in the class as someone who has produced a Fringe Festival play in Montreal and has plans to do more. She tells me that she expects to work hard, to make "a legit company" meaning that she wants to pay her artists and pay herself. She understands full well that this means she will need to apply for grants, a process that she feels is obscure, intimidating, and laborious. That Zach's perception of professional management includes an introduction to interactions with the funding apparatus is both an acknowledgement that the career of an artist, beyond being "for hire", is fundamentally linked to advocacy, albeit on a localized level, with the government and its arts councils.

There is a moment in my interviews with Zach when it is clear that things are getting very personal. Zach is well aware that he has landed in a privileged place, as a working professional and a teacher, with a career that is more stable than most performers can ever hope for. Sharing some of his own early experiences trying to navigate a precarious professional life with the pressures of starting a family, there are some tears as he expresses hope that these students will be able to find the balance that eludes so many artists (Fraser, personal communication, November 13, 2018).

For me, the thing is I want these kids to find happy lives. So for some of them, they're going to find their happy lives in a professional theatre context. Some are going to continue to be active theatre-makers in a nonprofessional way. Some are going to take all of their acting skills and be more confident people that work in politics and communications firms or who knows what. Some of them are just going to be better. 
To build an artistic career these students will learn how to move into the professional art world, both physically and performatively. They will think about how much space they will take up, and where. They will adhere to forms, to codes and conventions, textual and photographic, that are circumscribed by institutions that form the art world within which they may work. Or some will not. Instead, they will discover that the skills and experiences of their artistic training and these coordinated dispositions will serve other masters, both within the art world and outside of it. Some will be actors for hire, while still others will seek to "go legit", almost certainly articulating with the state and its funding apparatus to do so.

Lingo and Tepper suggest the need for "more research on what sustains creative identity as artists move across diverse contexts and increasingly find themselves working in non-arts jobs" (2013, p. 352). Alison Bain makes a similar argument, suggesting that to be called a professional artist "involves successful claim and defence of professional status through the construction and maintenance of an artistic identity" (2005, p. 34). I don't believe that questions of identity are useful in the discussion of advocacy because the process is in fact, performative, not prescriptive. It is not a process of reframing the whole self but rather one of particular behaviours, specific performances on stages and in backstage spaces that concentrate and demonstrate power relations. It both speaks the advocate and enables the advocate to speak into existence (Austin, 1975; Butler, 1997; Cabantous et al., 2016) the ways in which they will encounter the state to advocate and demonstrate their legitimacy in the art world.

Artists are introduced to these performances as advocates through disparate moments and places: classrooms, workshop spaces, meeting rooms. Dispositions are prescribed that demand certain "ways of being" that shift the rhythms and activities of the artist from their core artistic 
activity to often confusing demonstrations: the stillness of a body in a "classroom"; the production of texts meeting exacting requirements; the formation of new networks, both online and offline, where collective knowledge is built; the absorbing of information and language that is hidden from others and that may open the door to a legitimate artistic career with the support of public funding. Artists are often introduced to these dispositions by a mentor like a teacher, workshop leader, experienced arts advocate, even program officers who work within the arts funding institution.

These encounters are performative in that they speak into existence a new relationship with the institution. To imagine an artistic career in Canada, particularly one for an emerging artist or "small" arts organization, without the support and legitimation of the institution of arts funding, is to choose a hard road indeed, perhaps even an impossible one. The identity of the artist is not in flux here but the ways that they move through the art world are. They will be required to enter new spaces, to embody new actions, to speak new languages. The hope for many advocates will be to embed these dispositions deeply enough that the artist becomes capable of making that shift and encouraging it in others. They will build the advocacy network throughout their part of the art world. The next chapter will consider those spaces and performances more completely by suggesting the importance of presence as a key aspect of performative advocacy. 
Gasoi - 172

\section{Chapter 6 - Performance, Place, and Presence}

\section{Gathering bodies in spaces of power}

The formation of these dispositions and behaviours of the artist helps to situate some of their actions as advocacy, inscribing the kinds of performance they will be expected to pursue in specific places and in relationships with the structures that legitimate their art work. To avoid the abstract inquiry into cultural policy and artistic production that we often see, presence and place can be productive heuristics, linked to the IE approach, in studying the delicate dance of these dispositions in the performance of advocacy. How do advocates move, and how are they moved, among the spaces they navigate as part of their demonstrations of legitimacy? How does the notion of presence help us to think through the material and the performative interactions among art world members, including representatives of arts funding agencies and of the government? It is from this formation of disposition that we can witness the everyday embodiment of advocacy in time and space. Performative advocacy is interested in the present, and the presence, of advocates. The temporal moments and the specific locations where the demonstrations of legitimacy are practiced and located are held up for analysis.

This chapter situates the performance of advocacy with a close focus on observations of a specific day of action, Arts Day on the Hill 2018 (which took place on October 2, 2018, and is hereafter referred to simply as Arts Day), led by the Canadian Arts Coalition (CAC). Arts Day is one of many interventions by artists acting as advocates and a key moment for observation as a specific day of action, or what one of the organizers described to me as a "showcase event". Arts Day offers a case study for the presence and performance of advocacy. The event is one of the few that is entirely focused on the physical encounter, co-present in time and space, between artists acting as advocates and political leaders and officials. 
There are many other instances where these interactions take place. They include hearings at various levels of Parliament, consultations that increasingly occur online through text-based surveys, advisory panels, and informal or "uninvited" discussions. For example, in the fall of 2016, then Minister of Canadian Heritage Melanie Joly launched a large public consultation to develop the Creative Canada policy framework, and more specifically to address the future of digital creativity in light of changing consumption practices that include things like streaming services (Canadian Heritage, 2017). According to the final report, the consultation received more than 30,000 submissions, "including a wide range of creators and cultural entrepreneurs, [who] took part in the discussion in a variety of ways, from in-person events to online discussions" (Canadian Heritage, 2017). Despite this apparently democratic process, Marianne Bourcheix-Laporte has noted that "upon investigation, the \#DigiCanCon consultations appear to be in line with what Mark Andrejevic has termed the "pacification of interactivity", a means for government to appear to be interactive and responsive but also managing dissent (Bourcheix-Laporte, 2019, p. 2). A closer examination of the process of these consultations should include questions over presence and the mediation of interaction, as well as an appreciation for the kinds of texts and performances that are being enacted and embodied.

Through observations during the Arts Day event and meetings between artist advocates and state representatives, place, presence, and performance are examined. This chapter considers notions of movement and location on a more geographic level in the JAC professional management class, using the suburban location of the school and the movement of students to further inquire into their performances as they become advocates, reorienting themselves with relation to the structures that will legitimate their work. Finally, I will discuss the "place" of the Canada Council's program officers as the institution works to restore links to the arts community 
after a period of radical internal change. I will examine how the presence (and absence) of the Council in communities is linked to the textually and technologically mediated advocacy actions of artists in their day-to-day interactions with this structure of arts funding.

I will begin this exploration with Arts Day, an event and demonstration that instantiates the artist as advocate, as an individual making proactive and reactive performative choices in language and presence. Arts Day is also useful to understand the gathering together of individuals in the same physical space, embodying the dispositions to which they have been introduced and inculcated. In my observations of various interactions among artists, and in a particular meeting with a political staffer, I will explore questions of presence and performance of advocacy. I will discuss the ways that advocates remain open and available to opportunities to present themselves outside the strict adherence to a textually-mediated plan for such encounters.

As discussed in my presentation of Arts Day as a site of research, this yearly advocacy event gathers artists and arts professionals from across the country to Ottawa in the fall in an attempt to maintain the visibility of the arts sector in the eyes of MPs, Senators, Cabinet Ministers, and even the Prime Minister's Office. As such, I suggested it is an ideal site for demonstrations of legitimacy, the processes of advocacy that can be facilitated by professional lobbyists but that are pursued here primarily by these artists themselves.

Performances of advocacy, and the spaces in which they occur, do not necessarily have to be as formalized as imagined by government relations firms, lobbying registries, and presentations to standing committees in the House of Commons. They do not happen exclusively in articulation with the apparatus of the state. Nevertheless, there are moments, and the entering of certain spaces, that demonstrate advocacy as understood in the more traditional sense of relating to governing structures in an attempt to influence policy, grow appropriate resources, 
and otherwise increase the recognition of certain sectors of activity by those with the power to facilitate the work. Howard Becker reminds us that the state is an integral part of the art world, just as artists and those citizens that support their efforts, are just that, citizens, who vote, protest, lobby, and otherwise interact with the power of the state as it develops and implements cultural policies (1982, p. 165).

And so I find myself on October 2, 2018, standing at a bar table in a reception room in the Wellington Building on Ottawa's famed Sparks Street, just steps from Parliament. I, along with over 100 of my fellow arts advocates, have gathered to celebrate the conclusion of the $9^{\text {th }}$ annual Arts Day on the Hill. We have all been through airport-style security to get here. The room is abuzz with artists enjoying the hospitality, including free food and wine, offered by MP Julie Dabrusin, Chair of the House Standing Committee on Canadian Heritage and the host of this event. The assembled crowd of artists and administrators, dotted through with MPs and lobbyists, is awaiting remarks by Pablo Rodriguez, the Minister of Canadian Heritage, who is not yet present. Certainly present and holding a highly visible position just to the left of the central podium, is invited speaker Kevin Loring, and some members of his staff. Mr. Loring, a highly respected indigenous playwright and director from the Lytton First Nation in British Columbia, has recently been appointed the first Artistic Director of Indigenous Theatre at the National Arts Centre (NAC). A Crown Corporation dedicated to presenting Canadian art in the nation's capital city, the NAC touts their Indigenous Theatre company as the first in the world, emerging from "the rise of Indigenous activism beginning in the 1960s" ("About | NAC Indigenous Theatre", n.d.). The timing of this emergence must be seen in light of the Truth and Reconciliation Commission and their recommendations to address a chronic under-representation, and underfunding, of Indigenous stories in the Canadian art world. This is an excellent example of the 
government performing its own version of cultural diversity and representation, advocating its own responsiveness through a policy choice to promote an Indigenous artist. Loring himself has become an advocate thanks to recent controversies including the government's refusal to fund the Indigenous theatre department to the levels they are seeking (Friend, 2019).

Loring's presence here, his pride of place, is an explicit acknowledgement of this troubled relationship between the government and certain pockets of this country's varied art worlds. The simple fact of his appearance in this space speaks volumes about the ways that government can potentially instrumentalize the work of Indigenous artists to attempt to demonstrate a movement toward reconciliation, and more importantly, the ways that artists use their bodies and voices to resist and re-appropriate that process. Loring's presence says both, "you put me here" and "I am here now, deal with me and the issues and people that I represent" without actually speaking a word of the speech he has been invited to deliver.

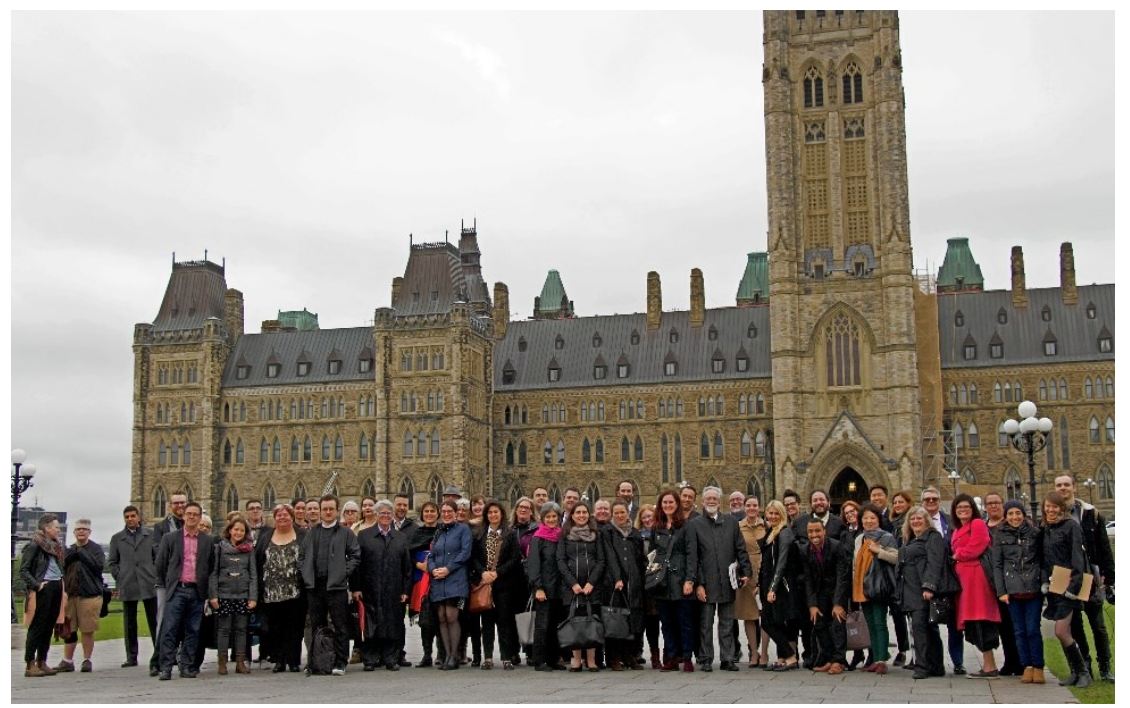

Figure 2 - Advocates gathered on Parliament Hill for Arts Day 2018 - Photo courtesy of Canadian Arts Coalition 
This idea of presence can be thought of as the taking of public space (Bain, 2004; Butler, 2015; Puwar, 2004). Like the photo seen above, Arts Day acts as a material affirmation of the existence of artists across the country and a gathering to demonstrate their legitimacy. It is not the first nor only time that artists have gathered to be present in Ottawa or in other spaces. While such actions are significant in terms of arts advocacy, it is also worth noting that artistic and theatrical forms are a long-standing feature of advocacy at many levels and as a part of many political and social movements. Canadian theatre scholar and practitioner Alan Filewood reminds us that we can trace onstage performances from the overtly political of Brecht's epic theatre to more recent examples like the work of Theatre du Soleil on French refugees (Filewood, 2011). In their 2003 theatrical production, Le Dernier Caravanserail, the company explored the shifting discourses around embracing refugees in a post-911 Europe (Stevens, 2016). However, those performances do not always occur on stages. Traditions from Indian street theatre to the South American traditions of Augusto Boal use performance as a means to probe political repression and empower or emancipate individuals.

Performing arts unions have taken their advocacy to Parliament Hill on occasion. In 2011, on the heels of the Harper Conservative government's majority win and in light of increasing rhetoric from the government on the importance of digital content creation and distribution, the Globe and Mail newspaper cited members of the actors' union ACTRA as they “took the train from Toronto [...] for their regular lobbying pilgrimage to Parliament Hill" to meet with Heritage Minister James Moore (Taber, 2011). While ACTRA president Ferne Downey expressed disappointment and skepticism in light of historic Conservative government bias against the arts and the refusal of Moore to meet with the group directly, "when she meets individually with Conservative MPs and 'lifts the veil' about who they are, how they struggle 
and how important culture is to the economy, she gets a good reception" (Taber, 2011). Advocacy would seem to work more effectively on the local level where relationships are formed with MPs and their staff rather than with the Heritage Minister directly.

The visual and literary art world is involved with such advocacy somewhat more often as a factor of its reliance on government not for direct financial support (though they do seek that) but rather for policies and enforcement of copyright provisions that protect their work and changes to compensation via resale rights. The ephemerality of performing arts like dance and theatre often means these artists do not often involve themselves in copyright negotiations unless we venture into broadcast and the wider cultural industries. Canadian Artists Representation/Front des artistes canadiens (CARFAC), the trade organization that represents visual artists, has been involved in successful advocacy campaigns for protections and proper compensation for visual art, including that purchased and displayed by government institutions like the National Gallery. In fact, CARFAC took their case all the way to the Supreme Court of Canada (Canadian Artists' Representation v. National Gallery of Canada, 2014), and received a judgement in their favour in 2014 which paved the way for a more equitable compensation agreement. In these cases, we must consider a more diffuse concept of presence, more akin to Bain's taking of space in the media and in the public imaginary (2004).

What is often missing from these discussions is that immediate sense of physical encounter and how this might impact upon the advocacy process. As Kate Cornell discusses during our interviews, Arts Days also take place on a provincial and municipal level (Cornell, personal communication, January 18,2019$)$. This suggests that there is a value and an interaction that is only reached through the physical gathering together of artists, acting as advocates, and 
the structures of legitimation represented by government officials and political leaders on multiple levels.

Much of the advocacy that actually takes place during an event like Arts Day occurs in the private spaces of meeting rooms, MP's offices, coffee shops, and corridors. The notion of public and private spaces and advocates' ability to move through those spaces inhabited by state representatives and their staff, is an important aspect of Arts Day. A lobbyist involved in the planning and execution of Arts Day (Mazurk, personal communication, October 12, 2018) explained it to me this way:

These [private] meetings are often opportunities to better understand a government process (like how a grant is administered), the current dynamics as seen from the MP/bureaucrat themselves, go deeper into messaging, build understanding on what you/your-sector does, come up against potential oppositional messaging, and test messaging that resonates. New insights are often gleaned, relationships built. I believe it is so important to do both engage one-on-one with government stakeholders plus participation in the more open, public studies and processes.

This explanation helps appreciate the processes that might be involved in these meetings and the kinds of outcomes that can be expected. What is less well articulated here, and what observation brings to the inquiry, is that the activity taking place in these spaces involves particular settings, props, costumes, and language. These are the theatrical tools we can use to demonstrate the importance of an experiential framework for considering this relationship between artists and the state as it is enacted in these moments.

Entering these spaces requires submission to security protocols and the acquiring and producing of various texts, from simple identity checks to airport-style scans and bodily searches. One requires a chaperone, staffer or security agent, to accompany the advocate as they access these spaces. How do these experiences help to shed light on the authorized entry to 
spaces in this moment? What are these buildings, with their secure entries and their centripetal power to draw advocates to them while screening them out? They are, at least in the most basic sense, some of the key places where politics is transacted. As such, they are spaces of appearance (Arendt, 1998, pp. 198-199). For Hannah Arendt, this is the world in which political action and speech take place, where human beings appear before one another for purposes of persuasion and the seeking of common ground (1998, pp. 198-199).

Judith Butler's Notes Toward a Theory of Performative Assembly offers a critique of Hannah Arendt, suggesting that one of the problems with Arendt's concept of the "space of appearance" is that it is just that, conceptual, even philosophical. It ignores the materiality of the space itself, its structures and platforms, that can both constrain and amplify the message of a group of assembled bodies (2015, pp. 71-73). Paying close attention to the materiality of the spaces in which artists and the state interact can help to illuminate how artist advocates are constructed and their legitimacy is enacted. In her book Space Invaders, Nirmal Puwar writes "bodies do not simply move through spaces, but constitute and are constituted by them" (2004, p. 32). Like Butler, Puwar offers a critical examination of racialized and gendered bodies within unauthorized spaces. While that is an important critical reflection, Puwar also touches on the notion of workspaces, making a connection to advocacy. Puwar suggests that women and racialized minorities are in need of advocates to speak for them, to make them visible, in these spaces where they are disauthorized (2004, pp. 121-122).

As Arendt suggests with her metaphor of appearance, visibility is a prerequisite for action and speech. Invoking the art world, Puwar cites curators who choose to exhibit artists based on their visibility, often facilitated by mentors and other advocates. These artists, challenged by race, gender, socio-economic class, differing levels of talent, and the structure of their field, 
cannot hope to advance in their chosen path without being visible, being seen among the networks and apparatuses that make their work possible. I argue that the grand curator in Canada is the state itself, authorizing and legitimating works of art and of artists through their recognition, their cultural policies and protections, and through programs of direct financial support. Arts councils like the Canada Council do employ peer juries to evaluate and rank applications for support, yet it is the disbursement of public monies, with final decisions made by arts bureaucrats, that are a key element of the legitimation process. Advocates, including these juries, can make artists visible to the state, and they do so in part by being present, assembling in places of concentrated state power and institutions, like Ottawa.

By considering the materiality of spaces of appearance and the access to those spaces for the purposes of advocacy, we can imagine the advocate as facilitating, through one's own authorized appearance, the visibility of bodies that might otherwise be barred, in a space and a place that concentrates power. What are the processes of this kind of advocacy, and in what ways are artists engaging with these procedures, entering and working within these spaces? For juries, they can be "invited" advocates, making their contribution to the policy implementation process, however, there are moments of intervention that are outside of the institutionalized procedures of evaluation.

I have already touched on one important aspect, the choreography of security protocols that George McHendry describes as "an accomplishment of communication, resulting from everyday cultural performances" (2016, p. 549). The security dance, and the performance that it requires of advocates seeking to interact with government officials, creates an immediate power dynamic that I have observed colouring the relationship once the parties move into the space of the office. As in Robert Hariman's description of the courtly style of political communication 
(1995, pp. 60-62), the performance of anxiety (through the security dance and the follow-theleader movement through the halls, anterooms and sanctums of these offices) and the power derived from physical proximity to the body of the "sovereign" (whether the MP him or herself or a representative who is understood to stand for them) are rhetorical performances that reproduce Foucauldian micro-power as it circulates in these spaces.

While gaining entry to these private spaces is an important prerequisite for the interactions of a performative advocacy, once in the room there are further dynamics at play. This is particularly true when the interaction is framed in advance as adversarial. As Abbing has argued, artist advocates are often imagined as a group demanding more money without accompanying accountability for outcomes, and this can create a framework for interaction that is inherently confrontational (2002). On Arts Day 2018, I was attached to a small team of advocates who were set to meet with Conservative MP Kellie Leitch. A training webinar delivered several days before the event made it clear that the approach to Conservative politicians would be more problematic, not simply because of the perceived Conservative bias against the arts, but because the opposition party would have less stake in the policy process at the time.

The Harper Conservative government was perceived as entirely antagonistic to the art world. While the actual numbers in terms of investment and support for art work have been questioned $^{11}$, arts advocates pointed to the cancellation of several key programs offered by the Department of Canadian Heritage that impacted Telefilm, the National Film Board, and the Arts Abroad program for cultural diplomacy. There was also consternation around comments the

\footnotetext{
${ }^{11}$ The Globe and Mail reported in 2008, when Harper held only a minority in Parliament, that the cuts amounted to $\$ 44.8$ million, where government officials disputed that total arts funding actually increased (Bradshaw, 2008).
} 
Prime Minister himself made, such as those suggesting that "ordinary people" did not care about the arts (Benzie et al., 2008).

In a brief coffee and chat with the advocacy team before this meeting, this antagonism was discussed and it was suggested that our presence would be a true invasion of "enemy" territory. Prepared for resistance, it was decided to "stick to the script", and once again we passed through security and into the lobby of a building where we would wait for an appointed staffer to descend from the offices above and ferry us into the presence of the MP. As is often the case, and often discovered at the last minute, the politician is unavailable, and we are met by a policy advisor.

In an interview several days after this meeting, Kate Cornell told me that she often understands these staffer meetings to be "private" (Cornell, personal communication, October 16, 2018). It is tacitly agreed that a certain informality is possible, despite the official surroundings, though this was not necessarily clear to the artists in my team who were performing very much as official advocates. According to Kate, this experience can be markedly different from meeting the MP themselves, where a performative publicness will generally be enacted, both on the artists' side, and on the politicians'. The obligatory selfie, the round of handshakes, the exchange of documents and business cards, all these are performances that are often more comfortable for artists to understand, roles that are easier to clarify, scripts that are plain to be enacted.

At this Arts Day meeting, this informality, the sense of the private space was physically evident. We gathered in an outer office, sitting in a rough circle of chairs, no desks or other adornments of officialdom were present. The staffer took no notes. We were in a situation where some of the material expectations of the encounter were absent. This was in contrast to the 
performance required to gain access, imbued with physical barriers and document production, what McHendry calls "a performative repertoire of security policies" (2016, p. 548). The tone and language of the meeting began with the formal pleasantries but quite quickly moved into a very colloquial discussion that featured profanity-laced characterizations of artists as whining, Toronto-centric, elites, unable to understand the realities of working-class Canadians. "If I have to hear about Toronto artists again, well... that just doesn't fly with me. You need to talk about how the arts are going to fill up my hotels, educate my kids."

It appeared that we somehow found ourselves not in the expected Goffman-esque front, but rather in a backstage space (1959) where the formal relations established between constituents and their political representatives lose coherence, and where control is established through the express use of colloquial, even vulgar, performance. Even the anticipated props were missing: no desk, no meeting table, not even a visible Canadian flag. The characters were more extreme than imagined.

In Goffman's restaurant example, the waitress shifts her disposition and expectations of behaviour as she moves from the rough and informal space of the kitchens to the well-rehearsed, polite, and genteel interactions with the diners in the front-of-house dining room (1959). Similarly, the artist on stage or in the studio or rehearsal space embodies a different disposition, a different performance, to the artist in the boardroom, the town hall, the Minister's office, or in front of the computer maneuvering through the Canada Council funding portal.

What roles are artists adopting when they pursue the various activities of advocacy? Who are their audiences in these circumstances and how is the artist presenting reality? The ways in which these performances reflect the values ascribed to the artist by the art world and the community at large are of interest. As Goffman writes, "When the individual presents himself 
before others, his performance will tend to incorporate and exemplify officially accredited values of the society, more so, in fact, than does his behaviour as a whole" (Goffman, 1959, p. 23). This behaviour can be addressed by observing the communications and the work of these artists in the context of their practice as creative producers and in their relationships and performances of advocacy.

We were expected to meet this staffer in this space, and I observed some of the members of the advocacy group quickly shift their own approach from one that focused on the Coalition approved messaging and documents for this Arts Day and into a mode of performance that might be described as submissive. Being behind enemy lines, as it were, the change in language and attitude from the team went from delivering a pre-determined and documented message to seeking advice from this man; from reaching out, to becoming drawn toward. This was a marked contrast to later meetings I had observed, including one with a Ministerial policy advisor, where the team was present to deliver a certain message, the advisors were expected, and did, listen, take notes, and receive documents. At this first meeting, I noted leave-behind documents, props that were at the ready, were quietly moved back into portfolios. Some tried to stick to the prescribed and scripted performance, to recreate something they experienced in a more conducive or "normal" meeting. However, as any trained actor will tell you, trying to reconstruct the exact performance of the show before can lead to a stilted character, a missed opportunity for true connection and communication.

I do not want to oversimplify or even mischaracterize this meeting as negative or somehow "less than" what was anticipated. In fact, the shift from front to backstage, from a formalized encounter that was expected to feature a certain public-oriented performance, to something more private, created a connection with this staffer that provided important insight 
into how Conservative politicians and operatives appear to understand the arts. But at the risk of invoking one more theatrical metaphor, being present is the key. Allowing the scene to shift and following the other actors, what in acting terms is literally termed being present, offered the advocates a unique opportunity to be heard and reflected as they are perceived in certain political and social communities. When a member of the team asked how this staffer might approach his boss to make a pitch for the arts, he provided a clear avenue of approach: make it about kids, about health (given that Leitch is a doctor) and about the local economy; utter not the word Toronto!

I am back now in the reception hall in the Wellington Building. I look around the room to see artists from across the country congregating, laughing and enjoying each others' company, performing that public identity that demands a certain attention, a call to recognize the significance of one's presence. In my post-event interview, I asked Kate Cornell what she sees when looking at the artists and the MPs, dotted about such a reception room: "There were six other receptions happening that night, and they were at ours. They just wanted to be in that room and that speaks a lot to the love, the sense of pride, the collegial spirit that was there" (Cornell, personal communication, October 16, 2018). For her, Arts Day is more than an opportunity to demonstrate that politicians and their staff can be accessible and open to advocacy. It shows that even within the non-stop, go-go, demands of an artistic career, there is time to come together with fellow practitioners and take a moment to rediscover the power of assembly and presence in one space at one time. While there are challenges to getting the traction and buy-in from staffers in private offices where very little accountability is offered, Cornell tells me "I also recognize that those public spaces are super-charged with the opportunity to challenge people in power" (Cornell, personal communication, October 16, 2018). There is a significance to a meeting in 
Ottawa that simply cannot be matched by discussions in riding offices and local town halls. These kinds of follow-ups are vital, but as lobbyists I have interviewed told me, Arts Day is a "showcase event", the kind of gathering in the space of appearance that concentrates and constitutes power.

\section{From Arts Day to the day-to-day}

While I understand Arts Day as a unique temporal and spatial instance of advocacy, I also want to point to the existence of less fixed and more diffuse demonstrations of presence. In an interview conducted at the offices of the Quebec English-Language Arts Network (ELAN) in Montreal, I discussed this aspect of performative advocacy with Guy Rodgers, the non-profit organization's executive director. ELAN, while it is well connected and funded by Canadian Heritage and the Canada Council, did not participate in Arts Day and is not a current (as of November 2019) member of the CAC.

If Arts Day is a showcase, a coordinated and focused display of presence on the Hill, Guy sees his relationship to Ottawa as something less concentrated and more of an ongoing exchange of information. In Guy's conception, Ottawa does not so much draw him for a singular, targeted purpose, as it presents the opportunity to improvise. In contrast to many of his colleagues within similar arts service organizations, Guy makes a point of traveling to Ottawa to sign funding agreements in person. His base in Montreal, a mere two-hour drive from Ottawa, facilitates this movement. Even so, he could easily choose to mail in these documents and communicate with these organizations via email and telephone. While visiting these offices, he explains (Rodgers, personal communication, September 11, 2018):

Well, I can check in with them, see what their impressions are, how do they feel about ELAN, hear the scuttlebutt. Is there some organization that's having a problem? Do they need my input on something? 
Guy likens these kinds of informal relations to the networking events or "schmoozers" that ELAN puts on every few months for its membership. The informality of these events invites unplanned linkages to be made. A musician meets a filmmaker, and a music video is born. An author meets a visual artist, and a new picture book might be the result. Artists go into these spaces open to possibilities, but they do not necessarily expect particular outcomes. This is not to suggest that Guy simply wanders into the offices of Canadian Heritage and pokes around for a new funding program, "schmoozing" program officers or political staffers. Simply being there to sign documents, or to consult on an issue, or to participate in the development of a policy would fall under the umbrella of invited advocacy (Woddis, 2014, p. 500). Yet the consequences of being in the room can be unexpectedly useful for advancing the relationship if the advocate is both physically and performatively present.

What emerges from these observations is that presence is a key element to effective advocacy. While the question of assembly can be couched in terms of dissent, of the breaching and invasion of unauthorized spaces, the data from these meetings and discussions illustrate how bodies in proximity to each other can influence and impact on the creation and the enactment of policy. As I have discussed in my review of the literature, there can be a tendency in our examination of cultural policy, especially in Canada, to focus on texts, reports, statistics, governmental measures, media concentration, and the impacts of these on abstracted audiences. My research works to shift this conversation toward an awareness of the intimate practices of producers and creators, of artists and advocates, and of governmental agents, working within powerful structures. Presence is a powerful means by which to frame that exploration. This draws us toward questions of how arts advocates not only speak, write, and engage in digital 
advocacy, but also how they are moved around by the work of advocacy, just as they may be by the work of art itself.

\section{"It's a nice bubble, but it's a bubble": location and presence}

While I employ an IE approach to suggest that structures existing in the extra-local context coordinate the activities of individuals in their local situation, the above observations show that these extra-local structures also draw individuals physically to them in order to present themselves as advocates. This fact can have consequences for the understanding of advocacy and the work of advocates in their own communities.

For instance, Kate Cornell is both Co-Chair of the CAC, an arts advocacy organization that works across disciplines and at the national level, and Executive Director of the Canadian Dance Assembly, also a national organization, but discipline-specific to dance, that has a membership and activities focused on Toronto. In our interviews, Kate expressed how she can feel pressure from her Board of Directors and membership at the Dance Assembly when they feel she is spending too much time in Ottawa. "It can be difficult for them to see the relevance of the work when I am away,” she says (Cornell, personal communication, October 16, 2018). This invokes the importance of presence, not just in terms of connecting with the places of state power in Ottawa, but in the potential disconnection to the local concerns of artists who do not feel they can access the processes of advocacy taking place far from home.

Guy Rodgers at ELAN expresses his own concerns about how his actions, his presence and his absence, can be misperceived by ELAN's membership (Rodgers, personal communication, December 19, 2018):

If we're doing a workshop on grant writing, that's not hard to explain. But if I'm in Ottawa talking to a bunch of people, with other ASOs [arts service organizations], talking about all the problems, what's the payoff, what's the benefit. If I'm at OLMC [Official Language Minority Commission] 
meetings in Ottawa... why are we wasting our time and energy on that? We're trying harder and harder to explain what we're doing, why, what's the payoff.

With this in mind, I can examine the more macro or geographical location, and the movement of individual artist advocates, to consider where they are coming from and where they are going. My fieldwork showed artists moving from spaces of art-making to spaces of advocacy, in both a physical sense and in terms of their manner and performance. What are the spaces and situations these artists are leaving in order to be present as advocates? What kinds of repercussions might they face by leaving those physical and performative spaces for a time? How will they return, and what might have changed for them and for those situations? Similar questions might be asked of the government agents, politicians and staffers that attend meetings, both public and private, where they will encounter these advocates. In this way, we address not only the moment of assembly for advocacy, but also the ways it draws individuals toward it, and how this impacts their presence in their own constituencies.

Ottawa may be the centre of political power in Canada. There are other locations, cities like Vancouver, Toronto, and Montréal, that are understood as the centres of artistic legitimation in the art world itself. This can be a source of tension as major cultural hubs, as imagined by Florida (2002), also tend to attract the vast majority of the arts funding. This creates an equity problem for organizations like the Canada Council and potentially discourages the development of artistic production in rural or suburban areas. As Alison Bain writes in her work on suburban cultural production, legitimacy is more difficult to pursue from the suburban space, despite strong claims to artistic excellence (2013).

JAC is located on the western tip of Montreal, a significant distance from the downtown core. In an interview with Zach after the first few weeks of the course, I ask him how the 
location of the school might affect the kind of art and the kind of artists that emerge from it. "I live downtown Montréal. So I come out here every day... I am aware of the fact that I'm coming into what is actually a pretty nice bubble, but it is a bubble" (Fraser, personal communication, September 27, 2018). The consequences of training in that bubble are complex. As Bain suggests in her geographically informed work on creative identity formation, the "clustering" of artists in physical proximity, usually in city centres, is imagined as conducive to creative work. Yet in practice, this is often less evident as artists jealously guard their private space in which they can explore their creative process without social interruption (2005, p. 36). Despite this observation, Bain also notes the importance of less structured groupings of artists that can "develop from connections formed during undergraduate or graduate fine art programmes" (2005, p. 37), and that such formations can play an important role in the development of an artistic identity. Setting aside the fraught question of identity, we can see how a certain kind of artistic career can be imagined from this particular suburban space. JAC's isolation may be both a blessing and a curse in that artists are forced into close interaction within their "bubble" and yet they can be distant from where one locates the power centres of artistic creation and the places where career artists are supposed to live and work.

In our interviews, Zach identifies the distance in this case as more of a symbolic one. There isn't a serious bar to a 30-minute drive or even a 45-minute public transit ride, and yet one of the challenges identified by both Zach and the students I spoke with is that the artistic directors, casting agents, managers, and other artists that make up the Montréal theatre community will not make the trip to Ste-Anne-de-Bellevue to see the work put on by these students. The other English language CEGEP-level training institution, Dawson College, located in the western portion of the city and accessible by Metro or even a reasonable walk, does not 
suffer from this same challenge. Their location within the downtown core makes it physically and symbolically easier to see the work done by students there as legitimate. The National Theatre School is also located in the downtown core. This "symbolic distance" as Zach identifies it, becomes a barrier that makes interaction with the art world, and presence in its places of power and influence, more difficult. Imagining the artistic career and performing the necessary advocacy is impacted by this removal from the centre.

In the case of these acting students, it may be early in their careers as artists to think about those places of power as related to government arts agencies and funding bodies, just as it might be difficult to imagine themselves as advocates. However, there is an understanding that the work of being an artist is one that demands a presence. This notion of presence is spoken of in theatrical terms as being emotionally available and open to the impulses in a given scene or situation, an availability to one's acting partner in a scene. In this classroom, that word is reframed in terms of physical and professional presentation. It is also about proximity, an issue of accessing the right people in the right places to open the possibilities of an artistic career path. Zach explains this to me during one of our interviews when he implicitly links the presence of these emerging artists with their future in the industry (Fraser, personal communication, November 13, 2018):

If the ultimate goal is to raise your profile within the theatre network, there is no denying that downtown Montréal you'll hit more... you'll catch more of the people... the other theatre-makers.

While not government representatives, these other theatre-makers will nonetheless open the initial pathways to advocacy with these structures that can facilitate the building an artistic career. Zach emphasizes this point when he notes that these other theatre-makers are both advocates and judges of their efforts, as many will sit on juries and adjudication committees for 
various funders. Others might have the administrative skills and facility with language to access monies and other resources that help artistic careers get launched and sustained. He explains "I think if they're looking to get work as an actor or to be surrounded by actors and theatre directors, classes and stuff, then they're making their life easier by going to a larger centre" (Fraser, personal communication, November 13, 2018).

Their interactions begin by trying to obtain the kinds of representation, agents and managers, that will advocate with these structures on their behalf. They work toward establishing a presence in the minds of those in the art world that make funding decisions. This suggests that a movement out of the bubble, into the larger centre, seems to be required. It can be useful to think about this in terms of concentric circles of interaction, and these occur both in the different communities of people with whom these artists are engaging, and the increasingly larger distances, symbolic and geographic, that these interactions might require.

Back in the classroom, Zach is asking students to present some of the information they have found on Montréal-based rehearsal spaces, theatre companies, and arts service organizations, in what he has termed their "emerging artists' toolkit". A student presentation on Montréal-based casting agency Andrea Kenyon and Associates leads to an exchange about agents and how these actors might find their first representation.

Student: What is the school's role in trying to get agents to come see our work?

Zach: Carolyn [the departmental administrator] will usually send out some invitations, but there's no policy that requires us to bring them. That's on you! I can tell you, [and there is some hesitation here as Zach is clearly weighing whether this comment will discourage or harden their resolve] the only time I have seen the artistic directors and agents come out to our shows is when I drive them, personally. 
Both the student's question and Zach's answer drive home the physical and symbolic gulfs that face these artists as they try to move toward professionalization from a suburban location, and from the kinds of performances that these emerging artists have demonstrated up to this point in their evolution. As Bain and McLean suggest, legitimacy is a process that can be connected to the suburban space, but it is often tied up in questions of the "fine line that divides amateurs and professionals" $(2013$, p. 183). Knowing they are nearing the end of their journey as students, and finally being given the space in this classroom to begin exploring what the art world outside JAC's "bubble" looks like, these kinds of questions speak to the movement from "student" to "professional", a movement that is complicated by JAC's physical isolation from the centre of the Montréal performing arts world.

If physical location and the isolation of a suburban campus is a factor in building relationships with the art world, then how do these students, many of whom live, work, and play all in their suburban communities, understand the wider question of where the art world is located? During the second week of class, Zach asks the students where they might see themselves in five years. He has informed me that this is often a useful conversation for them as they can begin to see both the length of the journey that still lies before them and also how their classmates may have very different visions of what a working artistic career might be. Their responses are telling, particularly in terms of movement through space. Eight of the students see their future in Toronto, acknowledged as the theatre centre of Canada. There is a noticeable focus on dreams of musical theatre success, something that is seen by the students as happening in Toronto, perhaps in New York. A number of students understand that further schooling would be necessary or desirable, whether it be in training institutions in Montréal, Toronto, or New York, all major urban centres. 
"Everyone says you need to be in LA [Los Angeles], or at least Toronto," says one student. There are many nodding heads. I take the opportunity to ask who "everyone" might be more specifically. The responses range from friends or television personalities to parents. Other students discuss the possibilities of staying in Montréal and even one or two are invested in building capacity in their suburban communities. "There's some good stuff being done here," one explains, almost challenging her classmates to defy her observation. I take the opportunity to share my own experiences with trying to move my own theatre company from Montréal to the western suburb of Beaconsfield in the early 2000s. My move was unsuccessful I explained, but not necessarily because of the suburban location, it was simply due to the need to have time and resources to build a following. In fact, I argued, the support I received from municipal structures in several West Island towns was unmatched by anything that Montréal provided to me during my five years of work there.

One student, noticeably uncomfortable during much of this conversation, is prompted by Zach for her response. "I have a boyfriend and I think we're going to get married, so I'll go where he goes." She looks embarrassed by this admission, and yet she is clear in her conviction. “I think you can make it work wherever and I don't know if I'll keep doing this". This students' response is significant in terms of IE's commitment to a feminist framework. Her struggle to find her place in the art world is a reminder that many institutions impact on the artist and their career. Questions of interaction with the government are not the only pressures facing these artists, particularly women. The institution of marriage and that of the traditional couple, or even the place of women in the working world, remain significant issues in the lives of artists. Location is not simply geographic, but social, and gendered. 
Kate Cornell discussed being a female advocate in the halls of power, an insight that sheds light on this aspect of performance. Kate told me that she is often able to reach female staffers and politicians more easily by identifying with issues like the \#metoo movement and the general "lack of female representation in leadership in the arts". Kate mentions that these kinds of conversations tend to be restricted to private spaces like MP offices. In the more public spaces of lobbies, boardrooms, and town hall type meetings, the power dynamics can be quite different. A public display makes it challenging to engage with these kinds of institutional critiques. Performative advocacy can therefore suggest a strong connection between social position and the physical stage on which these advocacy moments take place. Just to recognize that numerous institutions help to locate the artist as advocate is a stark reminder that whatever their imagination of their location and relationship to the art world, artists, and particularly female artists and advocates, first need to consider whether they will in fact be a part of that art world going forward. Will they find ways to move through the expectations of a gendered political and artistic community to demonstrate their own legitimacy, and what kind of insight does that offer them to communicate on behalf of fellow artists?

\section{"The outreach piece": Reconfiguring and reconnecting at the Canada}

\section{Council}

Judith Butler's critiques of Arendt's philosophical space of appearance ultimately link together the material and the symbolic sense of space. This link helps us to think through the ties between presence and performance of advocacy, the "being" in a physical place and the activities and dispositions that are expected or subverted while there. These are distinct aspects of advocacy, trying to reach out from JAC's “bubble”, and Ottawa's power to gather advocates to itself, happen at the level of physical presence. They also happen in the hearts and minds of 
students concerned about leaving the comfort of a known and safe environment, and arts advocates who must justify their absence even when they are doing precisely the kind of work they are expected to do for their community. I turn now to the "presence" of the Crown Corporation at the centre of my research, Canada's national arm's-length funding body, the Canada Council for the Arts ${ }^{12}$.

The offices of the Canada Council are on Elgin St., in the heart of Ottawa. The building itself is called Performance Court, a modern office tower though with a heritage façade, a stone's throw from Parliament Hill. There is a gallery space on the ground floor along with cafes, private corporations, and a few other government offices, including the corporate headquarters of Shopify. Once again I am buzzed into a protected space, security and access restrictions remaining a constant in dealing with any government institution. There is a tension between the notions of openness and transparency for the use of public funds and the passcards and buzzers that protect these spaces.

As I wait for the smiling woman at the reception desk to arrange for my security pass, another gentleman is buzzed through. He is a tall man, wearing a large top hat. On his nose sit tiny round spectacles, not glasses, spectacles, perhaps even "pince-nez", the kind you might imagine a Dickens' character to wear. I am struck by the presence of this gentleman, his aura that so clearly speaks of an "artist". I'm not able to approach or question why this person chose to dress this way, but I note that he does not get the same security pass as me, indicating the likelihood that he is Council staff. Demonstrations of legitimacy come in all forms, including presentational choices of clothing and personal style.

\footnotetext{
${ }^{12}$ I spent one day, January 25, 2019, at the Canada Council offices, observing the work of program officers and interviewing officers and managers. Preparatory and follow-up emails and phone conversations took place for several months before and several weeks after this date. All quoted interview data was from this date. As per our agreement, program officers are not specifically identified.
} 
When I am joined by my guide, Bryan Croft, a program manager who oversees the work of the program officers I will be interviewing and observing, I note he is dressed very casually. Without prompting, he offers: "You're going to see all kinds of clothing today, it's 'sweatpant' day". I wonder how various artists and arts professionals, along with these arts bureaucrats, interpret the idea of casual dress in a professional context where costumes are an important element of the performance of legitimacy.

I am being led through a dizzying array of cubicles and hallways, dotted through with communication pods that look like something out of Kubrick's 2001: A Space Odyssey. Bryan tells me that these pods are useful for private conversations that are less amenable to the open office plan that the Council has adopted. I am trying to treat this tour as an "observational walkabout" (Van den Bulck et al., 2019, p. 221), a technique that helps to build a sense of the "fabric" of an organization and inform further data gathered through interviews. Walking through the space of the Council offices provides "supporting contextual environmental and rich ethnographic data" that can inform the understanding of texts and interview data (Van den Bulck et al., 2019, p. 221). Bryan explains that the organization of the Council space, reconfigured entirely within the last several years, reflects the interdisciplinary nature of the new funding model. Program officers, many of whom are still closely linked to particular disciplines through their experiences and past or current practice, are encouraged to interact across those disciplinary lines simply by being placed in an open office configuration. My research participants recognized this new configuration as an advantage in that they were able to draw on each other's knowledge quickly and in a more personal manner. There was also the disadvantage of an open plan that encouraged distraction and could reduce their productivity. 
Since the Council moved from a disciplinary practice-based model where grants were categorized by the kinds of practices in which artists are engaged (ie. theatre grants, visual arts grants, music grants), to the new model that focuses on the artists' level of practice and where their work is meant to impact on society (ie. explore and create grants for emerging artists, arts abroad grants for international touring), the space itself has been reorganized to reflect the organizational and policy reality. In their statement announcing the new funding model, the Council suggested that this reorganization would "offer artists a simpler, more artist-centred application process, to respond proactively and constructively to current trends and issues in the arts and to maximize the social, creative and economic impact of the arts in Canada" "Canada Council Unveils New Funding Model”, n.d.). Writing for Canadian Art, one of the country's foremost visual arts magazines, Caoimhe Morgan-Feir (2016) noted the following:

Despite the expansive nature of the restructuring, the information sessions have been punctuated by an insistence that much would stay the same, particularly through assurances that individuals and activities who received funding before the restructuring would continue to be eligible for funding under the new model.

Morgan-Feir's concern was that changes to the model would result in a loss of funding or a radical change in priorities. In 2016, the journal Canadian Theatre Review (CTR) devoted an issue to the subject of arts funding. The reorganization of the federal funder's granting programs was clearly top of mind in the editors' push for scholarship on the issue. Nicholas Hanson (2016, p. 5) wrote this of cultural policy in Canada:

[A]lthough discussions often emphasize governmental policies, organizational structures, and economic principles, the effect of these sometimes abstract notions impacts individual people in deeply personal ways. Arts funding is not just a system of circulating resources; arts funding is an ecosystem that shapes if, how, and when people can engage with the arts. 
How has the sea change in that ecosystem impacted the arts sector? Many in the arts community were encouraged by the move to simplify the 147 different funding streams into 6 . Some expressed concern that a change in the language of disciplinarity would confuse artists who understand themselves in terms of their artistic practice, and not in terms of whether they are Exploring and Creating, or Engaging and Sustaining, two of the names given to the new streams. Even interdisciplinary artists understood their work as fitting into the Inter-Arts practice. The complete change from a practice-orientation to a temporal, or level of engagement one, was confusing at best.

In that same issue of $C T R$, playwright Darrah Teitel interviewed two Council staff members about the new funding model in a piece entitled "New Pie and More Pie". The reassurance they tried to offer in the piece is telling (Normandin as cited in Teitel, 2016, p. 15):

One of the messages that is clear is that this new funding model is not there to destabilize or to jeopardize the artistic eco-system. We haven't restructured our funding model after budget cuts like other organizations have.

What we see in this quote is a move to both downplay the changes going on, and to appeal in economic terms, promising more pie for all the artists in the country. The idea is that new monies need to be distributed in new ways, rather than cutting programs in light of financial hardship.

What I discovered in my observations and interviews with Council officers is that while the physical organization of the space encourages an interdisciplinary cross-pollination of ideas and practices, there are issues that continue to linger in that assessment of proposals. They remain primarily within artistic disciplines, creating a challenge for these program officers trying to construct juries with the knowledge and legitimacy to evaluate diverse applications. That transition is reflected in the physical space as noted by a program officer: 
We went through a kind of a funny transition where we all we left our old programs and then came in on a Monday basically, and were introduced to our new programs. We all moved our offices.

The tension is not only found in the locative but is further characterized by shifting language, as mentioned by a number of my research participants:

We call them fields of practice now not disciplines, which we used to call them. And so this is a kind of a shifting target.

[...] honestly to define a multidisciplinary practice, I know a lot of people talk about how the Council... disciplines are not supposed to matter anymore.

[...] the mandate of the Canada Council is to support "professional artists". And by that I mean this in visual arts, this in music, this in dance [...]

In history we all were disciplinary section directors, and I was director of dance, and of the dance section. And so we had teams which were disciplinary, but we all with our teams, we all worked towards the reshuffling of all the activities that the Council supports into those six programs that would respond to the needs of all the disciplines.

There is also a clear connection between the ways that program officers work to guide artists into these new pathways toward funding and legitimation, and the language and dispositions they are expected to adopt as discussed earlier in the formation and communication of the emerging artist. One officer explained it to me this way:

So, with the new funding model, the intent has been to open things up and do less gatekeeping. However, gates still exist in the way that the profiles are written and in the guidelines that are written, and who has access to what. So there are still barriers and while our intentions are to kind of open things up very widely, sometimes the reality is very different. 
This officer's internal advocacy efforts are not only related to questions of legitimacy, they are also concerned with which pathways that artists can take to advocate for their own work and to build a profile worthy of support. A belief in the importance of the program officers' human judgement, above and beyond the policies and texts that "automate" the granting process, is evident:

I think there has to be a little more leeway for the officers to say, yeah I think this needs to be in. I think this could come to the competition instead of having it be like closed off.

In the end, it is not the program officer that assesses the application for support, but a jury composed of peers. As my tour with Bryan continues we pass jury rooms that are empty now but are periodically filled with these assessors from across the country who are transported to Ottawa to evaluate applications from other artists and make recommendations for funding to Council staff. Like Parliament Hill, the Council draws artists to Ottawa in order for the processes of advocacy to occur. When I ask about the possibility for the Council to be more physically diffuse, perhaps creating satellite offices across the country to be more present in the smaller communities outside of Ottawa, Montréal or Toronto, Bryan responds with an argument about resources and logistics. It is simply too expensive for the institution to spread itself physically in this manner, and those resources are better spent in providing as much money as possible to the artists the Council is meant to support ${ }^{13}$.

\footnotetext{
${ }^{13}$ On the other hand, questions around the regional distribution of Council funds are very prevalent. In testimony before the standing committee on Canadian Heritage in May of 2019, artists and arts administrators from across the country have suggested that funding has been concentrated in urban centres like Toronto, Montreal, and Vancouver. Research by the Toronto Alliance for the Performing Arts, submitted to the committee notes that "Tying 'application success' to 'application numbers' reduces the Canada Council to a national lottery dependent on capacity and ability to churn out applications," (Toronto Alliance for the Performing Arts, 2019) suggesting quite simply that less artists in a certain location should not equate to less funding, and that artistic merit and diversity of regional voices must be a necessary element of Council decision-making.
} 
As artists themselves, jury members are required to exhibit their own presence in the room to advocate for what they see as work that merits the legitimation of support from the national funder. Marisol d'Andrea explains that in composing juries, program officers "looked for artists who are conversant in the field, with a degree of legitimacy, credibility, and multidisciplinary, and who represent regional diversity" (2017a, p. 30). That commitment to regional diversity acknowledges the inherent challenges in locating the art world physically, as the continued importance of "[o]ther characteristics — institutional, regional, and demographic_are also reflected in the composition of peer panels" (Chubin as cited in D'Andrea, 2017a, p. $30)^{14}$.

What is of interest here is the ways in which the institution of the Council gathers artists to itself and recommends dispositions and performances through its program officers seeking to develop the function of legitimation. D'Andrea is interested in aspects of groupthink, artistic excellence, and symbolic power in the jury room. My discussions with Council staff were about policies and concepts of consistency. Policies are meant to be implemented, Bryan told me, even while arguing that Council policies are "open". Though these policies are laid out in emails, operational manuals, and handbooks, Bryan tells me, "they don't tell you how to do it." He is suggesting that the performance of these texts gives program officers some ability to improvise within the structured system that promotes "consistency".

Program officers shared a similar sense of their own agency within this system. In addition to the "leeway" one officer mentioned in the gatekeeping required by the new funding model and its validation criteria, another officer spoke about working to translate the

\footnotetext{
${ }^{14} \mathrm{D}$ 'Andrea has written on the processes of peer assessment at the Council and other funding bodies (2017a), and since I did not interview jury members nor observe deliberations, my research will not delve deeply into this aspect of artist and government relations.
} 
expectations of peer assessors into language the artist could use to strengthen their application. In the case of a question about how their practice would be impacted by the grant, she said, "That's not a question in the application form, but I know from comments for the peers that they want to know. That they didn't see anything in the application." The emotional work of being present with artists in the moment of connecting them with the institution is significant:

We don't say things like 'the jury didn't like your work'. We always focus on things like 'they didn't understand this aspect of...' or 'you wrote this and you showed this...' so they would need to provide more support material because they don't understand where you're going. Feedback should be useful... it's constructive and it shouldn't be about, you're a terrible person.

This kind of work is challenging to perform textually. For example, this officer expressed concerns over emailed feedback:

I would keep the language more technical if I were to write an email about it, or I would say things in a very diplomatic way like, you know, it's not that the jury said the work isn't good. I might say, like this is a very competitive context, just so you have to know that there are $\mathrm{X}$ number of applications, this is a national process.

\section{Reaching out}

Presence is significant for understanding the performative interactions between the institutions of government arts funding and the advocating artists. It is true that the Council chooses not to be physically spread across the country, but their outreach efforts have increased significantly in the last several years. During one such instance, I find myself in the lobby of the 
Montreal Arts Interculturel (MAI) building on Jeanne-Mance street in downtown Montréal ${ }^{15}$. The Council is offering an information session on its Explore and Create program, generally designed for the support and onboarding of emerging artists into a funding relationship with the institution. Explore and Create is a part of the reorganization of the Council's programs that took place in 2015-2016, and targets projects that include components for the creation of new works, research, professional development, along with support for arts organizations. As individuals slowly filter into the space, stopping to shake hands with the two program officers that are presenting here today, I am reminded of any number of opening night theatre events I have attended. The artists enter the room, take a look around to see who else is there, nod and smile at the familiar faces, maybe size up some of the newer people they have yet to encounter. There is a sense of seeing and being seen.

The program officers are pacing the "stage" at the front of the room, checking on technology, asking for more chairs to be added as the room fills up, apparently exceeding the expected turnout. Snatches of bilingual conversation I overhear give the general tenor of the artists' expectations:

“Je cherche des 'subs' [subventions, or grants] pour plus de production".

“How are you doing?" "I'm OK, I'm surviving”.

"Trying to make some dough to make some art."

"I guess they'll explain it".

As in the Kingston session I described earlier, the messages delivered in the presentation are decidedly practical. The Council staff explain the basics of creating an artist profile on their

\footnotetext{
${ }^{15}$ The MAI is a gallery and performance space that houses a number of arts organizations, both English and French, in downtown Montreal. It features a gallery, rehearsal and office spaces, and a small blackbox theatre. It was opened in 1999 and receives funding and support from all three levels of government.
} 
online system, tips and tricks for writing a successful grant, and they try to demystify some of the changes the community has sensed in the Council's programs. Presence and identification are a constant undercurrent to the discussion: When looking around the room, a program officer asks, "How many are we?" implicitly saying what is later offered explicitly, "I come directly from our world." Following a discussion about the technical challenges of the online application portal, the staff members appeal for that human connection: "Just call us, we can advise you." In reference to the support material artists are to provide in an application, an officer says, "It is up to you to tell us how important this is $[\ldots]$ We will transmit that to the jury. That's our work."

The officers' efforts to stand as an intermediary between the artist and the peer assessors happens on this level of human presence. At several points during their presentation at the MAI, the officers make an explicit call for more peer assessors, to draw more artists into the processes of advocacy that the institution needs to maintain its own legitimacy in the art world. This is, in part, a question of trying to humanize the relationship between artists and the Canada Council in a way that is reflective of the practices that artists imagine for themselves. This was evident in several conversations with program officers, including this one:

Another benefit I think of having outreach is that people can make themselves heard to a human at the Canada Council [...] I personally understand how important and crucial it is to be doing this work: the outreach piece, because the feedback from the community is generally quite positive and people are just happy to connect with a human being.

Another program officer told me that the Council's outreach efforts are an attempt, in part, to make up for a trust gap that appeared during the beginnings of the transition to the new funding model. During this time the Council had turned inward to realign its priorities, retrain its staff and rebuild its own processes. It even stopped offering feedback to artists applying for funding, an issue that created animosity in the sector over a perception that the Council was 
abdicating its responsibility to be transparent and open with its clients. The officer told me the Council has "an emotional aspect [...] there that we have to always be aware of whatever we do has a huge impact on people." For her, "our outreach I think is happening, it's making us visible, it's about being visible. We stopped travelling for a little while and now are really trying to get you out there, really more than I can remember." As with the advocates described by Puwar (2004), visibility is a necessity for recognition and for the performance of legitimacy.

This level of human, physical outreach, with officers fanning out across the country to present the Council's programs has become such an important part of their practice. Another officer suggested the gap began even earlier. "In 2012 there was a moratorium on travel for certain, like I don't know why. I don't know. And then and then because all of the work that was going towards a new funding model we didn't have as much capacity to go out and share." We live in a large country and presence in space and time, "being there" is not always a viable advocacy tactic. The mediation of advocacy, generally through the technologies and texts of the "institutional ensemble" that is the state (Jessop as cited in Volkerling, 1996, p. 190), is an aspect that must be addressed in relation to performance and presence, not as its own end. As an officer reminded me, "[t]he thing is that you don't ever try to prioritize people who live nearby. You have to be fair, right. People from Vancouver can't really come and sit in a meeting and chat with us."

\section{The place of performance}

A focus on the places where artists become aware and begin to practice advocacy suggests the setting of these interactions can impact on the kinds of performances advocates engage in when they move between them. I want to shift my focus to these performances now, offering some examples of the presentation of the advocate in these particular spaces as they 
negotiate what Erving Goffman labels as their "appearance" and their "manner" (1959, p. 15). For Goffman, appearance can be an indication of the status of the actor in relation to power and a way to appreciate how they might be demonstrating their current understanding of the moment. Is this an informal social gathering? Is this work? Is this a new relationship, or something longstanding, with the appropriate expectations (1959, p. 15)? This question of appearance can be complicated when some artists are experiencing the tension between expected modes of presentation in the art world, and those of the advocate which might be more formal, certainly in the context of a Parliament Hill gathering. Goffman explains manner as more of the physical performance itself: the attitude, vocal, and gestural choices that can align with the appearance, or sometimes confound it (1959, pp. 15-16). Despite the appearance of power in the smart business suit, the central position in the room, the mixed indications of both a formal meeting and a friendly chat, the Conservative staffer with whom we met proceeded with an aggressive, even vulgar manner, forcing the relationship into unexpected channels, and perhaps giving the performer another, more effective means of persuasion.

For an artist like Guy Rodgers of ELAN, whose everyday work constantly shifts from the creation of artworks to advocacy for the arts, physical presentation also becomes a tool for persuasion, influenced by the place and people with whom he is interacting. When I first met Guy, nearly 8 years ago, he was clean-shaven, with close-cropped hair, and a tendency to wear more formal business attire. As I encountered him on numerous occasions over the past several years, I noted a shift toward what Sarah Thornton describes as a person "coded as an artist" (2012, p. 104): he now wears a beard, the suit has morphed into the blazer and jeans, neckties are generally absent, and the hair is longer. He does not have the obvious ostentatious look of the top-hat wearing, spectacle-sporting gentleman I encountered at the reception desk of the Canada 
Council, but choices are being made here. When we met once again for an interview, I asked him about this transformation. Leaning back in his chair in the little café in the lobby of the office building housing ELAN, Guy mused about the strategic deployment of his artistic persona. "Well, if you look at what I looked like at the beginning, I have deliberately developed an artistic look as I have become the representation of that part of our community" (Rodgers, personal communication, December 19, 2018). I ask him when this realization came to him. He offered up a thoughtful smile and said:

I guess, it became clearer to me, that people were looking upon me as that, that was the role, that I, I guess... part of it is theatrical background, partly playing a role... And, you have to make some choices about how you're going to deal with that. I'm no longer what I was when I was 30, I'm rethinking the way I dress, the way I look. So I was shifting to reflect my age, that, I was also shifting to reflect my métier.

Over time, Guy has adapted his manner as a tactic to align more closely with expected and desired moments of appearance before different social groups. He seems to indicate that it is also a means to cement his own understanding of the development of his professional career. By inhabiting and demonstrating the artistic manner, he is able to tip the power balance in certain interactions with bureaucracies. The people with whom Guy interacts, and the spaces they inhabit, are also part of this presentational equation. In places like the Canada Council, peopled with arts bureaucrats, there is a certain understanding (Rodgers, personal communication, December 19, 2018).

I don't have to do anything for them. I don't have to worry about how I dress for them. Once you get to the Department of Canadian Heritage, now you're dealing with bureaucrats. But really, it's when I meet with the community. Lawyers dress a certain way, educators have a style, so, I just cultivate the arts style. 
As arts advocates like Guy interact with groups that have different relationships to the art world, manner can be a powerful communicative tool. This is evident in Kate Cornell's advocacy work, which can often be more public-facing and political, such as in her speeches and presentations before House of Commons committees. Kate also recognizes the importance of her manner in such interactions (Cornell, personal communication, October 16, 2018).

I start to glow when I think about giving a speech to a standing committee, I know I am such a policy wonk, geek, but I love that opportunity to be recorded in Hansard, to perform as an expert, to stand up and represent dance... it makes me sit up straight, there's a physicality to that performance.

As with the students at JAC and at the Council, we see that there is both a macro movement, drawing advocates toward the centres of power, be they downtown Montréal, Performance Court, or Parliament Hill; and there is a micro-movement, from a student's request to be able to move her body despite the shifting conceptions of what bodies can do in a classroom/studio setting, to Guy's evolving presentational style and Kate's dancer-borne physicality.

We see the importance of performance and of presence, both materially and behaviourally in the sense of an open and flexible responsiveness to the shifting dispositions required for an engaged advocacy. These dispositions are often manifest in choices of language. The profanity of the Conservative staffer in my Arts Day meeting is an example of this. But it is also evident in some of the responses I got from Kate Cornell in the preparations for the event. Kate told me that her work to prepare artists for the performance of advocacy at an event like Arts Day can be frustrating because, "these people have boatloads of passion, but they have no policy knowledge" (Cornell, personal communication, October 16, 2018). This requires that Kate 
perform some translation, adapting the language of the messaging to overcome some of the discomfort with the advocacy process.

Frédéric Julien, co-president of the CAC, explained to me that the creation of messaging for Arts Day can be just as frustrating. Julien is the person in charge of creating the script for Arts Day advocates to use in their meetings. In trying to bridge the language gap between the instrumentalization of art from the government and artists' vision of art's intrinsic value, he spoke of a process of "selling" the hard economic message to fellow artists and then trying to use visual storytelling to help these artists feel more comfortable. In the end, however, advocates needed to "use their [the government's] framework, to speak their language." The "appearance" of this kind of language acknowledges who is the advocate and who holds the purse strings.

Imagining this power relation to be a one-way street is not entirely helpful nor is it an accurate representation of how performative advocacy works. This is evident in the outreach work of program officers at the Council. According to an officer I interviewed:

Applicants or people that I met with on the road that is their words for sure: that they are intimidated by the Canada Council. So going and doing that work [the outreach], I feel like it helps to humanize the organization, to show people that we're practicing artists and that we're human you know. To really humanize the arts administrator.

This humanization is about presence, certainly, but also about language:

I see this [outreach and speaking directly to artists] as how you interpret some of the policy language we have here. You make it, not palatable, but make it understandable for people [...] Second piece to that is when we do do outreach, sometimes we hear back from literary writers who have mentioned that the language is quote unquote "awful". They would know.

As a performative action, language builds the relations that impact the material and the human, the people and places of these advocacy processes. I return to the evidence of that link in 
Kate Cornell's "wonky" quote: "I love that opportunity to be recorded in Hansard, to perform as an expert $[\ldots]$ ". Here we see the value she places on her physical performance, as well as the key conceit, the desire to be recorded in the text that describes the actions of the government.

Hansard is the written transcript of all activities in the House of Commons. It is the textual life of the performance of the machinery of policymaking, and those that appear before it as advocates. As much as performative advocacy acknowledges the centrality of presence, it is informed by IE, an approach that expressly embraces texts as a mechanism that coordinates activity (Smith \& Turner, 2014). The textual record of the proceedings of the House of Commons is most certainly a performative document. When advocates mark their presence in that document, we see a link between presence in spaces of power, and the texts that emerge from that presence. These texts also govern the ways that advocates frame their interventions. It is to those texts and institutions that I will now turn my attention. 


\section{Chapter 7 - Texts and Institutions}

At Arts Day, the advocacy team I am observing are sitting in a cramped booth at D'Arcy McGee's pub on Sparks Street. We have time for a quick lunch before our next meeting, and we are doing a little debrief and enjoying each others' company. I am gathering my thoughts, notes, and reflections following our first, rather surprising "backstage" meeting. I am reflecting on the ways in which the dynamic of the team is solidifying. Although artists can certainly pursue advocacy in any number of ways, the team's role as defined by the leadership of the CAC, the organizers of Arts Day, is to activate the text of the meeting script, to make it work in the room with the political representatives and staffers with whom we have been tasked to communicate.

The roles seem to break down this way: Frédéric, co-chair of the Coalition and one of the primary designers of the messaging for this year's Arts Day, takes the lead and delivers the most scripted of our comments, along with the documents with which we hope to leave an impression. Caroline, an arts presenter from Ottawa, offers her specific experiences and stories of struggling to present artists at the festivals she organizes. John, a veteran arts administrator, having spent time in his career at both the National Arts Centre and at the Canada Council, is the secret weapon, sitting back and waiting for the right moment to ask a pointed question, share a story from his past, or support an argument. In taking on these roles, each of the team members has a particular relationship to the script, the documented agenda for the time they are spending as advocates in that room.

As we wait for our lunch, Frédéric seems to feel very good about the staffers' reaction to the script he helped to develop. He mentions that this approach might be appreciated by economically-minded Conservative MPs. As plates and drinks arrive, I take advantage of a brief 
private moment to ask Frédéric a quiet question about how the Coalition settled on the messages and structure of this Arts Day "script" (Julien, personal communication, October 2, 2018):

Well, it starts off with a bunch of us policy wonks sitting around, right. We come up with the policies we want to target and that comes from what we identify in the community. We put together some initial language... and then it is Arts Day, and the artists show up.

This pronouncement is followed by a pause and a rueful smile. We both giggle a bit uncomfortably. More food arrives and we set down to eat. While this might appear to be an off the cuff remark, it has crystallized a tension that is vital to the research question I am exploring here. What happens when the language of cultural policy advocacy, codified into texts and technologies of interaction with the state, collides with the working artist? How do advocates, and particularly those like Frédéric Julien and Kate Cornell who have committed to a policyoriented approach, translate the language of advocacy on that level to the realities of the working artist?

This chapter will consider these questions of language, text, and translation. What does it mean to activate a text in terms of advocacy? What are the other texts and documents that coordinate the actions and performances of artists acting as advocates? If an enormous amount of the interactions between advocates and the government are textually mediated, why is it important to focus on presence and the performance? To address these issues, I will analyze the moments where texts become present and performed. I will examine the interactions between advocates and these texts, and how they are embodied. I will demonstrate this by describing the activation of the Arts Day script and detailing how the organizers of the event help to inscribe this text into the performance of advocates in preparation and in the moment of Arts Day. I will then revisit the texts that help to inform the formation of the working, emerging artist by looking at three key assignments in the JAC professional management course, all of which have a textual 
output: the artists' CV, the headshot, and the mock grant application. Finally, I will look at the practices of artists and program officers at the Canada Council, with special attention to the grant applicant profile, its validation amidst the "human connection" identified as important by program officers, and the constraints of technology and textual representation.

\section{"And the artists show up": activating the script}

As with the different roles assumed by members of the advocacy team, the CAC itself is structured as a number of different committees, each having responsibility for certain aspects of an event like Arts Day. Among these, there is a general steering committee that works with the government relations firm Global Public Affairs to manage the Arts Day event. There is a "casting" committee that puts together the advocacy teams and tries to match up advocates from various ridings and constituencies with the most appropriate MPs and Senators on the basis of riding affiliations, shared interests, and past relationships. Most significantly, there is a messaging committee, whose job is to come up with the specific policy asks, and the recommended language for advocates to use during their meetings. Along with the support from the CAC's communications and marketing teams, this committee also creates the documents that codify that language, including the meeting script.

The script, delivered to the team a few days before the event, is 11 pages long and heavy with statistics and footnotes like this one, in reference to the Canadian Arts Presentation Fund: "In constant dollars, it is currently $13.4 \%$ below its inception level ${ }^{16}$, yet the demand has been growing steadily. The program is now heavily oversubscribed". We must begin to wonder, as did

\footnotetext{
${ }^{16}$ The program was fully incepted by fiscal year 2003-2004, at which point it received parliamentary appropriation of \$25.7 million. This would be \$33.5 million in current 2018 dollars (using the monthly, not seasonally adjusted Consumer Price Index for April 2003 [102.4] and April 2018 [133.3]). The current parliamentary appropriation of the program is $\$ 29$ million (excluding \$ 3 million from the Fathers of Confederation Trust, which was incorporated in CAPF in 2015).
} 
many of the participants in the preparatory webinar, how are we to relate to this document, to perform it in the room? In brief, the messaging for Arts Day 2018 is based around three policy asks, and is supported by a particular representation of artistic production that Frédéric and his colleagues called the "creative value chain".

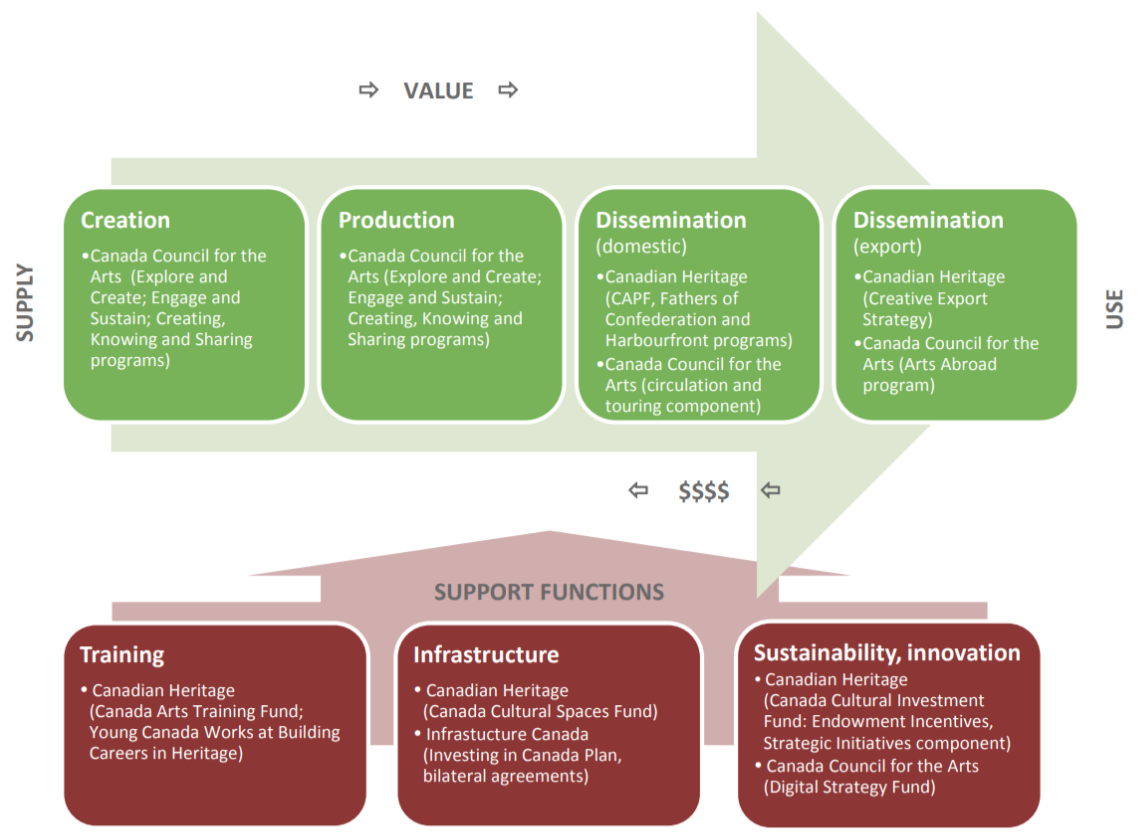

Figure 3 - the creative value chain, provided by the $C A C$

The language for this representation comes from policy frameworks like the Cultural Satellite Account (CSA), and Statistics Canada's Conceptual Framework for Culture Statistics. The CSA is meant to "provide a statistical framework for measuring the economic contribution of culture" (McCaughey et al., 2014, p. 110). Its initial report was tabled in 2012, after several years of testing by the Department of Canadian Heritage and Statistics Canada. The CSA measures things like sales of cultural products, compensation of cultural workers, and the number of those workers and their conditions, all in an effort to "allow the government to assess scenarios of particular interest, such as the impact on culture" and its comparison to other sectors 
of the national economy (McCaughey et al., 2014, p. 115). The Conceptual Framework's stated purpose is to "provide definitions and concepts to support the collection of statistics with the goal of fostering the reporting of uniform and comparable data on the culture sector" ("Canadian Framework for Culture Statistics”, 2011). It defines the various cultural sectors (cultural industries, live performance, music recording, etc.) and attempts to measure their economic impact in similar terms to the CSA. The CSA draws from the framework to produce its data. According to the CAC's documents on the chain, it is a visual representation of "a sequence of activities during which value is added to a new product or service as it makes its way from invention to final distribution". Further, in the same document, we have this phrase: "along with key transversal functions that support the entire creative chain".

While I am not suggesting that this language did not speak to any of the artists who read and brought this document with them into meetings with MPs and political leaders during Arts Day, what is clear from my observations is that the esoteric, economic terms made many artists uncomfortable. The discussion among the "policy wonks" does not necessarily align with the realities when "the artists show up." As Hans Abbing points out, "[a]rtists and economists speak different languages" (2002, p. 13). The language gap is a challenge to reconciling the value propositions in the economic sphere and the artists' sphere, addressing entirely different collective needs and desires from security and material wants on the one hand, to entertainment, reflection, and representation in the media landscape on the other.

I confirmed this not just through the response to my question to Frédéric about the CAC's development of the "creative value chain" and the rest of the messaging documents for Arts Day, but from observations I made during the preparatory web conference about a week before the event. As the leader of the discussion familiarizing these artists with the messaging documents, 
Frédéric makes constant references to finding ways for the participants to be "comfortable". He insists the script that he and the messaging committee have created is not "meant to be read as is", but rather personalized and informed by the artists' own experiences and narratives on the local level. The script's second section is subtitled, "Tell your Story", and includes the following instruction: "Everyday artists in and around your riding are working hard to contribute to the life, vibrancy and economy of their community." Economy is present, but it is after contributions to "life" and "vibrancy", intrinsic terms that seemed to make more sense to many artists participating in the webinar. When one participant suggests an entirely different approach toward a Conservative MP, Frédéric has no trouble with it, if it "makes you more comfortable."

My interpretation of these comments is in alignment with the experiences shared by Kate Cornell. In discussing the question of language, Kate offered this reflection on the 2018 Arts Day message (Cornell, personal communication, October 16, 2018):

I talked about translation... I think in the arts we're not doing a very good job translating and reaching the unusual suspects and getting them to care and to engage... And the messaging document came out... I always think the messaging document should be one page, it was 3 to 5 pages, and Lesley (communications coordinator for the CAC) called me and said, can you please translate this for me! OK, here's the pitch!

The "unusual suspects" to which Kate is referring here are not simply those political staffers and MPs who might never have seen the inside of a theatre, a gallery, or a concert hall, but also those artists themselves whose ability to be advocates might be hampered by discomfort with administrative language like the "creative value chain". To reach these people, Kate relies on a personal connection to the interests of these artists, and to a sense of the collective art world (Cornell, personal communication, October 16, 2018): 
For individual artists I talk a lot about taxation [making sure professional artists have access to the tax exemptions to which they are entitled in the tax code]. We've been working on the taxation file for like two years now. To demonstrate that arts advocacy can have a personal effect on artists. I don't think a lot of people in my community recognize that if we go beyond dance talk in the collective, we're going to have a greater impact and a greater chance of success. They see their world and they stay in their world.

What we have is an example of the ability of documents, created in the meeting rooms of the CAC messaging committee, coordinating, in a rather uncomfortable way, the performances of artists, acting as advocates. Kate is also very aware of the importance of these texts to the advocacy process itself. However, she further acknowledges that these texts need to have specific forms and circulation to be useful, as she offers here (Cornell, personal communication, October 16, 2018):

I'm embarrassed by this, but I tell them [politicians and fellow advocates] to follow me on Twitter because the stuff I share is links to articles, digestible stuff. Because if you're going to be accessible it has to be short and sweet and easy to understand for the uninitiated in that work.

The "leave behind" documents, flyers and one-pagers that advocates deployed during Arts Day, perform these functions. In the concluding reception in the Wellington Building, these documents continued to circulate, as did colourful artists' business cards and other such ephemera. Kate Cornell described a follow-up meeting with a Conservative MP after the 2017 Arts Day. In that interaction, these documents and texts performed specific functions, related to the personal and present relationship she builds with the individual (Cornell, personal communication, October 16, 2018):

At the end of the meeting it was, could you send me XYZ. I'm going to pick which texts I am going to further our conversation with [...] She didn't want the usual stuff, and she was being honest, 'I'm not going to look at that, but 
I will look at this.' That's an important way to consider texts which is to start with the relationship, the face-to-face and then the text comes in. Some of my colleagues do it the other way around. For me, the way I work, it's the most effective way to get their attention.

In order to make it easier to create artworks, advocates must negotiate the texts that circumscribe these relationships, and provide for their access to the corridors of power, just as they must do to access the funding and recognition for their art and practice. Codified into certain texts, and then performed by individuals within specific material spaces, language is a feature of the advocacy processes that comes from the advocacy leaders themselves, as well as from government. The transmitting and sharing of documents are key aspects of many work environments, but the unique nature of some art world documents is evident when we consider how they can act as material representations of dispositions and even bodies themselves. This brings us around to documents like CVs and headshots, and their rigid forms and templates, and their ability to coordinate the activities and perform legitimation within the art world.

\section{"It has to look like you": CVs, headshots, codes and templates}

The Arts Day texts demonstrate advocacy relations on the level of the advocacy group and the direct relation to political power. There are texts that are more demonstrative of the individual emerging artist as they begin to negotiate their dispositions and place as advocates for themselves in the art world. As I proceeded through the eight weeks of classes that I observed at JAC, my fieldnotes would often begin with: "lots of shoes today"; "mostly bare feet"; and in one case, "student wearing 24601 sweatshirt... cute", a reference to the musical Les Misérables. In trying to investigate the performative aspects of artistic work and advocacy, I wanted to pay attention to the physical presence of my participants: how they present themselves, how they use their bodies, voices, choices of clothing, movement and gesture, as well as speech, to negotiate 
their artistic identity and engage in their initial understandings of advocacy. This is especially significant in the context of the JAC professional management class, as I observe student artists begin to navigate their own presentational self as artists while thinking through what it means to be a "professional" in a "creative industry". An IE approach to this investigation draws attention to the texts, codes, and conventions being introduced to these students through their assignments and the ways in which they both facilitate and constrain that presentation.

Returning to the course syllabus, the text that governs the expectations of student and instructor in this course, I consider the opportunities for these students to produce the proper texts to begin to present themselves as working artists. The first assignment to be handed in is the actors' curriculum vitae. What kinds of conventions are constraining the ways life is represented in this form?

Attempting to perform some manner of content analysis of the CVs handed in by the students in the course would have little value. These students do not have extensive experience to represent, most do not have union affiliations, performance history, nor extensive skills to list on a document. I am reminded that it is not the text itself that should be at the centre of the examination, but instead its activation: when, where, and how it is generated across various local situations and individuals, coordinated by convention and institutional reality. The significance of the assignment is in the discussion, the questions around its impact as a coordinating text in the art world, and the highly structured manner in which it is to be presented.

Janna Klostermann discusses how texts such as artist's statements, biographies, and CVs help visual artists to gain access to the art market. "While artists are free to interpret proposal requirements broadly and to write as they see fit, there are conventional ways for writing both artist statements and bio statements" (2016, p. 51). Klostermann employs IE to suggest that texts 
are part of the extra-local structures and institutions that coordinate the work of artists as they negotiate their place in the art world. The importance of the "conventional ways" that these texts are produced is especially relevant in a training situation where artists are transformed into professional practitioners. Producing these texts correctly will have an enormous impact on the legitimation of these artists, the valuation of their work, and on the ways in which the institutions of legitimation will understand their career trajectory. Most artists will comply as conventionally as they are able, and some few will likely try to subvert the model, imagining their resistance to the standard text as a means to differentiate themselves and gain a better standing in the art world.

Zach introduces the assignment by asking how many of the students currently have a CV. Six of the 16 present hold up their hands. These students are in the midst of their final year of schooling, and so I find it surprising that a majority do not have a $\mathrm{CV}$ prepared. Listing it as an assignment in the course suggests it has value in the "professionalization" of these students, and I am reminded that this process has only just begun. Only one student currently has an agent representing her, and Zach asks her how they expect her CV to look. There is a clear template for the actors' CV, just as with the professional CV expected by most employers. Zach has created a template, electronically delivered to the students, and they are asked to alter it to reflect their experience and skills.

The ensuing discussion took place over the following three weeks, during which the students submitted their assignments for evaluation and for in-class discussion. One key theme that emerged was the question of how to categorize certain work. Background or extra work in film, unpaid student films, directing and producing, writing, teaching in summer drama camps, all of these are bandied about in various hierarchies of importance in the document. If you want 
to present yourself as a film and television actor, that work would be first. If your live theatre experience is more impressive, or more expected in a certain situation, then it should take pride of place. If you sing and dance, play an instrument, drive a car, walk on stilts, all these skills are significant and suggest a distinct character that might be beneficial in the casting process. I note the students starting to become confused as they begin to explore and question if perhaps, as actors called upon to represent life on the stage or on film and video, any life experience can be of significance. How are they to choose? Zach does not offer much help: "I'm not going to edit your choices. If you want to put something in, for me, in my path, this is important, or not, then that's OK. You're not making up different truths."

Zach later encourages the students not to "pad" their CV, enhancing their background with fabrications or exaggerations. And yet it seems clear that the formation of the working actor through the $\mathrm{CV}$ is entirely about the forging of one truth over another. This becomes evident when one student asks about a community theatre play she did in high school. Would mentioning that undermine her presentation as a professional? Zach suggests, "If there's something you don't want to talk about, don't put it in." The student responds sheepishly, "Yeah, I was tenyears-old, never mind."

What about our jobs, some ask, like working in a café or a bar where we get to meet and observe people? Is there a space for "other jobs" that are peripheral to the work of an artist? Here we have an express manifestation of the argument made by Alison Bain in her article on the construction of artistic identity (2005). Evoking what she calls a "potent mythology", Bain writes, "[w]hile it might be widely acknowledged that an artist must negotiate other part-time jobs and roles at a distance to earn a living, being an artist is regarded as a full-time commitment to a distinctive way of life" (2005, p. 41). For the visual artists that are of concern in Bain's 
work, it is almost a given that work outside the field must be erased from the life path. This is meant to reproduce the Romantic myth of the artist as singularly devoted to the work of art. For performing artists, other work experiences may not be quite so easily dismissed.

This is especially so for young artists in a training program whose commitment to an artistic career is still forming. The work distinctions are much less clear. One student in the class, who happens to be a little older than most of the others, recounts how he has come to this life from first training as an aircraft pilot. "As a pilot", he explains, "you really have to understand how to perform: perform competence and command, not just for the teachers, but for yourself so that you can actually imagine controlling this enormous and complex machine that defies gravity". It is a reflective moment that reminds us that careers of all sorts require presentational displays of legitimacy.

In the world of artistic production, such performances are a part of the day-to-day work of art. They involve the kinds of representations of symbolic competence referred to by Fine, who writes "[t]he identity of artists is essential in Western art markets in which the conceptions of genius and creativity are so essential. Influential and powerful actors create the creator through the shaping of biography" (2003, p. 175). Fine's conception, like that of Gerber (2017) reminds us that it is not only the pilot's performance of command that allows him to work, but it is the institution of air travel (flight schools, certifications and testing, air travel legislation, and the travelers themselves) that legitimates the individual as "pilot". Cultural labour is no different in that respect. As Gerber writes, artistic work is just one field and there are "multiple pathways to value" (2017, p. 14) that require various kinds of work to communicate and legitimate.

Zach takes the opportunity to remind his students that he would be just as happy to see them succeed as accountants. "Most of us," he offers, "have other careers. You can be a 
professional part-time. It's allowed." Despite the acknowledgement of this reality, the impact of the Romantic artist myth remains a powerful influence on the students' textual presentation. This is a tension that will reproduce itself as these students begin to engage with the art world more widely, when the $\mathrm{CV}$ becomes a marker for legitimacy in relation to institutional forces like the school, the producing community, and the funding apparatus. We must recognize the effects of the delicate negotiation between the arts as a career, perhaps one of a number of careers that will cohabitate in these individuals. Decisions about the document production of the $\mathrm{CV}$ reflect those concerns and the prescriptions that such texts make on the artist.

The experiences of these students and their categorization into a templated document suggest how conventions of text coordinate their activity. Another thread worth noting in the discussion of this assignment is a more visceral and physical manifestation of that process: do these students list their height and weight on their CV? The question has become something of a flashpoint, in light of shifting attitudes about inclusion, diversity, and the aftershocks of the \#metoo movement in the art world. In November of 2017, Emma Davie at the CBC reported on Neptune Theatre in Halifax, where artistic director Jeremy Webb advocated for actors and their agents to remove height and weight from the performer's CV. The report suggests Webb's decision is based on the realities of \#metoo and is meant to start "a more serious conversation about what's acceptable" (Davie, 2017). The implication, according to the report, is that the actor's suitability for a role should be based on their talent and engagement, not their physical characteristics.

Back in Zach's classroom, the ethical questions around including height and weight, and the inherent objectification of the artists' bodies, never really impacted the discussion. While there was some initial acknowledgement that practices are changing, it was quickly subsumed 
under the all-important adherence to the $\mathrm{CV}$ template, in which these numbers were included. It was clear that conformity to the presentation of this text was paramount. Zach argues that these CVs represent not only the actors but the school as a whole. Since the primary use of this CV would be to act as the textual component to the actors' first group audition that was being arranged for them by John Abbott, it was important for the CVs to conform to the school's standard, even including the JAC logo. This redoubles the institutional power of this text to recommend the presentation of the actor.

A few weeks later, Zach holds up a small red book in which he has apparently marked the grades for the $\mathrm{CV}$ assignment. He has concerns, however, and tantalizes the eager class with the announcement that, "your grades can change." Allowing the students to conform fully with the template, Zach proceeds to note several issues in these assignments, including malformed postal addresses, and the fact that we are to use imperial feet and inches, along with pounds, on acting CVs.

It is not much of a shift from focusing on the quantified physical characteristics of the actor represented in the text of the $\mathrm{CV}$, to their visual representation in the headshot. As Scott Frank argues, the headshot is an object that is both aesthetically and socially constructed in specific ways and its primary function is one of commerce (2012, pp. 179-80). As a work of art in itself, it performs a representation of the artist that is meant both to differentiate and to conform to rigidly applied conventions, as much as it instantiates "an entire network of social relations" (2012, p. 179). Frank suggests it is the first step along the road to professionalization (2012, p. 179), and its presence as an assignment in this class at JAC confirms that notion. It is productive here to focus on how Zach presents the headshot as a means of demonstrating 
legitimacy through adherence to these codes, as well as through the display of economic investment, even in light of precarious financial situations with emerging artists.

There is a noticeable tension in the room when the discussion in the class turns to headshots as if the mere mention of the process of capturing these artists' faces on photographic paper forces them to sit up straighter, to tame stray hair, to practice twinkling smiles. While the students have been involved in school productions before and have had headshots displayed on poster boards in front of the school's Casgrain Theatre, those shots are most often taken by instructors at the school itself. Here, we are discussing the first set of shots these students will be required to send out into the professional world, accompanying their CVs as part of the package for their arranged audition before members of the Montreal theatrical art world.

Zach is presenting the headshot as a professional practice. While the school may have taken a photo for promotional purposes, or students may have a friend or a cousin who can take a photo, the headshot is not simply a photo. It is part of a network of associations that construct the presentation of the professional actor. The person who takes the photo can be as significant to the presentation as the photo itself. Casting directors become attuned to the aesthetic qualities of certain photographers, and they can make judgements based on the decision of the actor before them to articulate themselves with a particular photographer. Zach discusses this in class, presenting several options he has personally negotiated on behalf of the students. Each is an established professional, with stylistic differences and different associations. One photographer tends to work with more anglophone performers than francophones. Another tends to work with film and television actors who lean toward a flashier aesthetic, and one more is known to take headshots for the National Theatre School. Zach suggests the kind of work that you want to pursue is at least partly mediated by decisions about your headshot. 
There are significant questions about how to evaluate the headshot in the context of the class. The students recognize this and they express concern over instructors in other classes who have judged their headshots. How does one judge a headshot? The assignment for this professional management class demands that they submit a headshot but there is no rubric to indicate how they will be graded. One student asks, "what do you want our face to look like?", while another wonders “are you grading us on our faces?” Zach responds by suggesting that what is being sought is a perfect balance between the unique individual and the established convention:
You want to present yourself as versatile. I want to see the headshot that says, this is me. You are presenting the version of you that is the good person to work with. It's not a picture from Vanity Fair... It's hard to describe... There's a form, a style, they're different languages. I'm going to grade it on if it's a strong, compelling photo, but also, does it look like you. Does it look like you can take that into the workplace? Does it look like you care?

This is a lot to ask from a photo, but the reality is that a headshot does all of this work, acting as a marker of legitimacy, and as an instantiation of traditional values in the presentation of the performing artist. Frank argues that headshots are artifacts, but they also "become the material expression of the social relations, values, and aspirations of Hollywood", or in this case, of any art world (2012, p. 187). In other words, they are a performative text that is one of the many processes of advocacy, in this case, advocacy for one's own value as contributing to the work of art.

There is another important aspect of the creation of that value and it is an economic one. Headshots cost money, and that investment is yet another example of the ways that emerging artists can demonstrate their legitimacy. Zach has reached out to a few of his own contacts to 
make arrangements for a special group rate for the students to get their shots done. The first offer is presented as "dirt cheap" at $\$ 75$ for a session. This is met by the students with some wide eyes and some shrugs. The second offer is $\$ 200$ for a session, this time eliciting a chorus of gasps, followed by one student who bravely offers, "\$200 is not that bad actually.” As relatively affluent students living in an acknowledged middle-class suburban area, I sense that the shock is not in the actual amounts, but in the recognition that the reality of the career actor is an economic investment as much as it is a commitment to the work of art.

One more discussion that is worth noting here with regards to both CVs and headshots is the increasingly digital circulation and communication of these texts. Zach mentions to the students that when he arrives for an audition, "I don't show up with a CV," suggesting that this process has already happened over email, through an online portal such as his agent's website, or CastingWorkbook.com, a platform that aggregates performers' information for the casting directors in the film, television, and theatre industries. A student shares a story of a casting director being "shocked" when she arrived at an audition with her headshot and CV in hand.

The final class I observed was a workshop with a representative from CastingWorkbook. This company has built a successful online platform for actors' CVs and headshots and connects these documents directly with casting agents. In existence for more than 25 years, they boast connections to all the major studios and streaming content creators and are also in use by theatres, dance, and opera companies. The company is based in Los Angeles, with satellite offices in Montreal, Toronto, Vancouver, London, UK, and in Spain. As part of their aggressive recruitment strategy for emerging actors, representatives from CastingWorkbook will visit all theatre schools and give workshops with professional organizations like ELAN on how to use their services to build a viable career path in the arts and creative industries. 
As an online platform, and one that comes at a cost to emerging artists, the decision to create a profile on the site has many of the same economic and performative dimensions of the $\mathrm{CV}$ and headshot. Here, these documents exist in a digitally integrated, app-based presentation that is seemingly more comfortable to artists that have not known a world before Facebook. The salesman who visited with the students made a strong pitch for his platform as a way to automate, organize, and present the actors' professional identity in the properly coded format that would lead to recognition, work, and ultimately, to legitimacy in the art world, all from your smartphone.

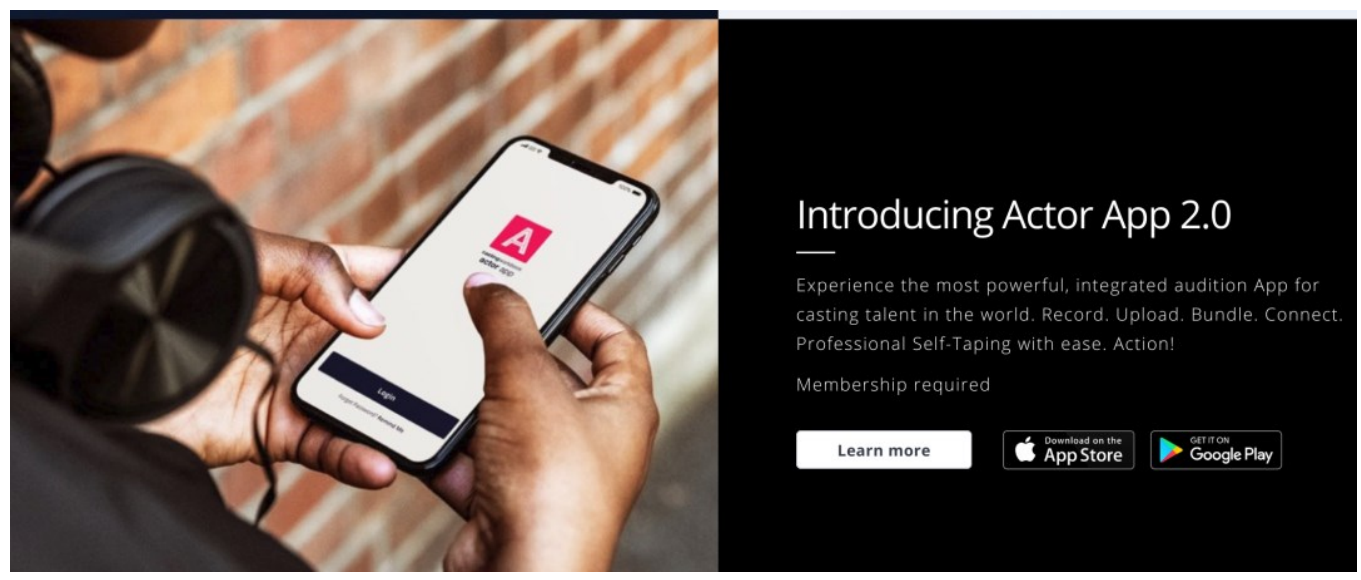

Figure 4 - the 'actor app' from the CastingWorkbook website

The CV and the headshot are textual representations of the life of the artist. They are coded forms of communication that demonstrate legitimacy and commitment through the careful curation of life and work experiences and through the investment of significant funds and attention to bodily display. They are also steps along a narrowly defined path, laid out by mentors like Zach, by the institution of the school, and the larger institutions of the artistic life. A refrain heard throughout my observations of the students in this class was, "I don't want to seem unprofessional". The corollary, of course, is that seeming professional, what I would argue is a prime example of demonstrating legitimacy, is perhaps the main takeaway expected from this 
course. Adherence to the codes and conventions of the professional performing art world requires a series of performances that is more presentational than in other professions simply because the thing being offered is the actors' whole being. These are important considerations for how these artists are going to relate to their peers and to potential employers. The question of those employers, who they are, and how to reach them, allows me to turn my attention to the final assignment that the course demanded of these students: the grant application.

\section{"A legit company": the project grant}

I have shown that the headshot and the CV are textual representations of the actors' body and of their experiences. They are individual to the working artist though they are coordinated by institutions and traditions that are extra-local (Prodinger \& Turner, 2013; Smith, 2001). These documents demonstrate the formation of these emerging artists as advocates relating to peers, to pedagogical requirements, and to notions of artistic career that Zach would often define as becoming "an actor for hire". The advocacy I am suggesting so far is of a more personal nature: where are these artists going to find their community and their career, and what kinds of investments will they be required to make in the texts that demonstrate their legitimacy as participants in this art world? There are, however, many career paths for an artist, and one that is promoted quite heavily in this class is the self-producing artist, the one who does not wait for work to come to them, but rather goes out and creates that work for themselves and others. To pursue this path, putting aside the few cases of artists with independent and unlimited wealth and resources, will require more direct interaction with the funding apparatus and the processes of advocacy as I have been exploring them here. This brings us to the final assignment on Zach's syllabus, the mock project grant application. 
Zach has provided more extensive instructions for this assignment than for many of the others. The assignment sheet is reproduced below (with permission) in the interest of clarity. As with the CV assignment, he has also provided templates for the budget aspect, as arts councils at all levels of government do in their applications. Interestingly, Zach did not require the students to create actual profiles on any of the online funding portals for the Canada Council, the Conseil des arts et des lettres du Quebec, nor the Conseil des arts de Montreal. The "mock" aspect of this application keeps the separation between student and professional firmly in place, while still demonstrating the importance of these texts as the primary demonstration of legitimacy with government funders.

\section{Production Grant Assignment}

The goal of this assignment is to prepare the student for the possible future reality of selfproducing theatre, establishing realistic budgets, and the basics of applying for production grants.

Draw on your personal sensibilities, passion, and creative goals in your choice of production. Create a project that you would love to see realized. This may be a real or imaginary project that you envision. If there is a project you have in mind for the future, this is a perfect opportunity to develop your ideas.

\section{The assignment will consist of 5 parts:}

- Cover page $(10 \%)$

- Template provided

- Detailed Project Description (50\%)

What is the project?

$\circ \quad$ What makes this project unique?

- What aspect of your craft do you intend to explore?

Who is a part of your creative team?

Who is your target audience?

- Do you have a chosen venue?

- What can you tell us about the performance style and design elements?

$\circ \quad$ Anything else you feel you should say about this project?

- Minimum 500 words required.

- Work Schedule (10\%)

- Include rehearsal and performance dates, and some breakdown of the process. You may also include a calendar if you wish.

- $\quad$ The Budget (20\%) 
- A breakdown of expenses and revenues, based on realistic figures as much as possible. (template provided)

- Publicity Plan of Attack (10\%)

O How do you plan to publicize the show? Be creative.

A few specific details:

1. Assignment due in hard copy no later than Friday, November $2^{\text {nd }}, 2018$.

2. This assignment is worth $\mathbf{3 0 \%}$ of your final grade.

Have fun!

(Project grant application instructions, provided by Zach Fraser)

Though this is clearly presented as a school assignment, with its assessment leading to a grade and the passing of the course, students are still asked for a project that draws on "personal sensibilities, passion, and creative goals". Their project should be something "that you would love to see realized", and there is even the suggestion that the project could be "real", or an application that might eventually interact fully with the funding apparatus.

There were only a few very brief discussions of this assignment during the classes that I observed. They often revolved around understanding the nature of questions in the form. In my own work consulting with artists and organizations on grant-writing, I note that the same kinds of questions are often asked. These are also the kinds of questions I heard from participants at the ELAN workshop in Chelsea. For example, if an application demands that you describe what makes your project unique, there is a dual assumption: first that you know enough about the current state of artistic practice to be able to differentiate your own work from all that is around you; and second, that your project rests on that kind of differentiation. The template, as a coordinating text, seems to defy that very idea of differentiation. Students asked several times if they were required to use the template as if that constraint would somehow stifle their creativity.

I reviewed six project grant applications from the students in the course. In studying these texts, I intended to discover if there was a common sense of the language that these kinds 
of applications must deploy. There was very little discussion in class, regarding the language of the grant application, the specific performatives that are often thought to exist as a secret recipe that these emerging artists must learn to have their work validated through government support.

The projects themselves were varied, though heavily weighted toward new works and collective creations. This may be a reflection of the kind of training the students are receiving and a general understanding of the current practices in the theatrical art world in and around Montreal. All but one exhibited some aspect of what I would consider a socially engaged project, a work of art that is explicitly connected to a social goal. One proposed the creation of a feminist theatrical collective to explore issues faced by women in the field. Another was a proposed new play on the topic of climate change. Another was framed as an artistic intervention into mental health discourses. Only one of the projects I reviewed in my representative sample of the assignments was a purely artistic exploration that made no obvious connection to any instrumental objective.

This general move toward instrumental language is interesting because there is no clear instruction in the assignment to suggest students must address their work to some perceived lack in the social world. Again, what I may be witnessing here is students absorbing, through their teachers and the evolving relationships they are building with the artistic community, a construction of language that tends to connect the work of art to political and social engagement. There may be a sense that Zach, having been involved with these students for over two years, would look kindly on work that had these politically interested characteristics. Students are creating texts that are coordinated through the unspoken and diffuse circulation of established forms of art work from institutions like their school, and their part of the art world. 
While my observations clearly showed me that the goals of the students in this assignment ran the gamut from getting a grade, to exploring their creativity, to social justice issues, there was one other noteworthy aspect running through the applications that I reviewed. They all exhibited a commitment to provide opportunities for other emerging professionals to work and gain experience. This idea has appeared in the mandates and applications of just about every emerging, independent theatre company with whom I have worked and consulted for the past 20 years, including my own.

This demonstrates one of the disjunctures I have uncovered in this research. Some artists and art students that have participated in this study, acting as advocates for their work, believe that their efforts are reinforced by the kind of moral authority I have discussed in instrumental terms. Of course, we should provide opportunities for emerging artists, they are the future of our creative sector. Yet they often misunderstand the power of their own claims, and in turn, invite confusion from their colleagues, politicians, and policymakers, even their teachers, as they demonstrate their solidarity with the sector, but fail to justify their claims for the necessity of their work in particular. They exhibit a difficulty in even considering the implicit moral backing of their pleas and seek the more practical and political economic arguments to underpin their efforts.

One of the projects I reviewed was of the student who wanted to create a "legit company" as she imagined her career after JAC. Advocative language was prominent in the assignment and I was not surprised to see the ideas these students are being taught activated in this text. These students are being told, over and over, that theatre (and one might argue, art work in many disciplines) is a job that thrives on human contact, on connection and relationship. The standard to which a successful production is most often held is "bums in seats", how many people can you 
get to participate in consuming your art. For many, that holds true with the production side as well: how many friends, colleagues, and fellow artists can I involve in this project? Can I provide them with a meaningful experience and even a paycheque? And in this class, they are connecting these ideas with the governmental funding apparatus, the pathway to "a second show", and the ability to "pay our actors." There is an explicit relationship here between advocacy for one's own work and that for the community as a whole. This is a feature that is perhaps more specific to artistic disciplines like theatre, dance, and some music, where the work is inherently collective and requires numerous creators along with a host of support personnel (Becker, 1982).

Students in Zach's class begin to realize that despite whatever intrinsic or instrumental connections they attempt to make with these applications, the form remains the primary currency of the interaction with the funding apparatus. For the short application description section of their mock application, they are required to use 15 words or less. A student who asks "Is 18 words OK?" is answered with a resounding, "No!" from around the room, demonstrating the processes of textual discipline already becoming established. The strange notion of balancing their budgets confuses many students who imagine that a successful artwork will make money and perhaps enable them to have enough left over to invest in producing more work. "Don't we want to show them it's going to work, to make money?" It takes them a few minutes of discussion to understand that paying themselves and the artists that they propose to employ is the very definition of the Council's goal of supporting ongoing work. Art work, at least in the Council's estimation, is a subsistence career, one that should provide the basic necessities of living while the artist pursues their core creative activity. What must be acknowledged is that such a living includes the advocacy work of securing those very resources. 
This assignment and the more official processes of funding applications in relation to the Council itself would appear to share a common goal: to build an ongoing relationship of properly formatted, precisely performed, textual mediations where artists demonstrate their legitimacy. This, argues Wagman, is the very nature of the artistic career (2016, p. 203), but it would appear that such a career, imagined in the Romantic vein of the artist in control of their own creative processes, is an illusion. If there is one goal for the course, Zach tells me in our interviews, it is to give these students a sense of their own agency in the art world (Fraser, personal communication, November 13, 2018):

I want them to be empowered... to feel that they have their own voice that they are in charge of their own destiny and that is tied to the class. I don't want them to feel like they are dependent on others to get their work.

It is a lovely thought, expressed by a dedicated teacher, but it is also flawed from the start. Zach is talking about these artists being dependent on agents, artistic directors, casting directors, and those members of the art world that we generally think of as enabling the performer to be hired as a performer. However, navigating an artistic career is just as dependent on advocacy with the structures of funding and legitimation, on the performances required by codes and conventions, project descriptions and budgets, mandates and organizational structures, as it is on the specific texts and images that present the artist as a legitimate professional in the art world. To perform these texts in relation to the legitimating powers in the art world: the state and their fellow artists, these activities constitute the moments when their "actual work is being slotted into, subsumed by, and subjected to extra-local institutional work processes" (Klostermann, 2016, p. 58). If successful in their performance, the reward is the ability to continue making art, and possibly to move from being an advocate for themselves and their own work, to advocating for the wider network and community of artists with whom they identify. 
Gasoi - 238

\section{"I read the applications": validating the artist at the Canada Council}

Zach's project grant assignment may prepare these emerging artists to present a project to the funding apparatus, and this requires them to activate particular scripts and templates, but it presupposes a stage in the interaction with the government that I would like to now examine: that of being validated as an advocate.

Thus far I have argued that advocacy is an act of speaking and being present in the art world that incorporates a relationship with the institutions of arts funding, like the Canada Council. As much as events like Arts Day illustrate the presence of advocates and their bodies in the corridors of power, simply having an invite to participate in that event also presupposes a step in the process of legitimation and professionalization of the artist.

As suggested in my discussions with the program officers at the Council, it is nearly unheard of for artists to simply show up at the offices in Ottawa to have a chat about their work. That relationship begins with creating a profile, a textually, and digitally mediated process requiring artists to perform in specific ways. Like the online CastingWorkbook profiles expected of performers seeking work as "actors for hire", many artists wish to move into a more direct relationship with the funding structures of the government. They wish to advocate for the ability to create their own productions under their own creative control. The Canada Council profile is a key requirement that communicates the artists' disposition within a series of checkboxes, dropdown menus, and forms.

I asked one of the program officers about how she imagines an artist might first encounter the Council:

I would think that first point would be, say they 'Google' Canada Council for the Arts, it leads them to our website and then possibly they get directed to the portal after ideally having read program guidelines reviewing the 
Gasoi - 239

application form. I think that's the intention of how artists can access information.

These responses assume that most or all interactions with the Council occur online. From the initial Google search, to negotiating the website, to beginning the advocacy process, the presence of the advocate is imagined as an individual sitting in front of a computer screen, interacting with texts and hyperlinks. The "ideal" of having read the program guidelines also circumscribes a particular performance expected of the artist, that of reading and understanding a set of texts. If this is the intended path of interaction for the artists, as the program officer suggests, then they are limited in their demonstration of legitimacy. The setting for the interaction is virtual, the props required are a computer and an internet connection, and there is a lack of attention to presence and human connection, of demystifying the Council as an institution.

The "portal" to which this officer is referring is the online form artists are required to fill out before they can apply for any funding programs. The process is akin to the kinds of profile creation we are increasingly used to with the various online identities that we inhabit. As J. Sage Elwell argues, this is just one more instance of the "transmediated self" (2014, p. 242), the shattering of personality across various platforms, within various, often instrumental, moments. Transmediating the artist is a necessary step to integrating with the processes of advocacy at the Council, as suggested by this note on the website:

After your eligibility is confirmed, you may use the profile to apply to programs. You must submit your Applicant Profile for validation. Once your Applicant Profile has been validated, you can apply for grants. Note profile validation can take up to 15 business days. 
The same program officer also admitted that she had heard that "artists find the website very confusing," suggesting that the negotiation of disposition, the transformation into advocate through this particular portal, is a challenging one. Once an artist begins the process of creating an applicant profile, they are immediately faced with a series of choices that have performative force, "as we carefully craft the identities and activities we want to share with others" (Elwell, 2014, p. 244). Elwell is referring to social media profiles that demonstrate certain individual qualities we might want to display to certain audiences. The Canada Council profile is equally performative, in that the choices between "professional artist" and "arts professional" demand that we demonstrate a binary disposition: a profile meant to portray some kind of Romantic vision of the creative artist; or, a professional in the art world, aligning with Becker's vision of the "support personnel" (1982) that enable the work of art and artists.

Despite the Council's new funding model that is meant to eliminate the separation of artistic disciplines, what the profile process seems to have done is simply to alter the language. As an officer already mentioned, disciplines have become "fields of practice", and the profile can only place the artist in one, not multiple fields. Unless an individual chooses the "Inter-Arts" or "Multidisciplinary Activities" options, which would appear to defeat the purpose of having a field of practice at all.

As Portwood-Stacer argues in her essay on the refusal to participate in online social media, the creation, circulation, definition, and especially the abandonment of these digital profiles is a performative act. By refusing to take part in social media platforms like Facebook, she argues "individuals want to intervene in what they identify as large problems, but feel best equipped to make their intervention at a personal level, at the site of their own individual behavior" (2012, p. 1054). From the perspective of the program officer, the digital/textual 
mediation of the profile has further effects, including the tendency to both distance the artist and the representative of the institution, and to circumscribe particular performances. A program officer offered this comment regarding how she tries to connect to the artist, despite the tendency toward "automation" in validating these profiles:

And you know people on the other end, being artists, [they] are waiting for you to validate their profile. Right, you know you've got to do it with a certain urgency. But you also have to take the time and be with them as if you were talking to them and they were telling you about their practice.

The tension between textual mediation and presence is explicit in this comment. The same officer admitted to being concerned about "missing things" when validating profiles. "It's easy to miss a line on the screen." Perhaps the implication is also that you will miss less with an artist present in the room, or engaging through other mediations like physical texts, CVs, artist statements, materially present.

The validation of profiles can also involve the program officer engaging with other texts. "I go down the rabbit hole sometimes when I am validating profiles," one officer told me, describing Google searches, flipping through the pages of arts magazines, looking up exhibitions at artist-run centres in far-flung villages and towns across the country. This kind of detective disposition is another part of the advocacy process, where the job of the officer is to both seek the information that will validate the artist as a professional and to demonstrate the legitimacy of the profile process and, thereby, the institution itself. When that process does hit a snag, the emotional aspect of these relationships between artists and government representatives is once again evident. "I think many of us want to encourage and don't want to dismiss just because we know what it's like being on the other side. And we know it's like getting, like unsuccessful letters or rejection letters." 
Once the process of validation is completed and the interaction with the Council has moved on to the phase of applying for funding from specific programs, these emotional and performative actions continue. The everyday work of the program officer is in both translating the texts that comprise the application process, in activating these texts for a jury, and in trying to ensure their own performance reflects the intention of the artist.

But really to help me with that nitty-gritty, day-to-day, speaking to people... I read the applications, obviously. So I try to give the artists the respect of knowing what I'm talking about when I'm talking about their work... I will look them up on the internet to make sure that I'm getting it right.

Once again in this comment, we have the texts that result from an internet search as a tool for performing a relationship with the work of the artist. Performing the knowledge and understanding of the artist through texts like applications, artists' websites, social media profiles, and online biographies, creates a particular relationship between the artist and the funding apparatus. That relationship is further complicated when the program officer must take into account the different language and dispositions when faced with individual artists and with artistic organizations:

I try to always keep in mind when talking to somebody that you're talking to an individual and they are spending time in the studio working on their project and their very into whatever they're doing, so sometimes to be very careful about seeming critical or judgemental language maybe... you can't really go there. But if you're talking to an organization you're often, you're talking to somebody in a position, so you're talking to a curator or an Executive Director and they are invested, for sure, in the thing that they're doing, because it's their job. But it's a different kind of investment, so the communication is a little bit different for me.

This comment crystallizes the distinction between the artistic disposition and the advocative one, though it couches that distinction in terms of individuals and artistic collectives. 
By assuming that the individual artist has an emotional investment that is different than that exhibited by the arts professional doing "their job", there is both a reinforcement of the Romantic ideal, and a sense of the division of labour and disposition that is inscribed into certain categories of art work.

What we recognize is that the profile, like the $\mathrm{CV}$ and the headshot or the artist statement, is a powerful coordinating text. Texts and documents that circumscribe the activities of artists and relationships among these individuals and the state are activated and performed in the practice of advocacy. Performance gives us the opportunity to think through these actions of "reading and taking up" not just "words, numbers, or images" (Smith, 2001, p. 160), but also performances themselves coming from a complex network of people, policies, and institutional powers. Understanding the working artist and their actions as advocates means investigating the work of these texts as they too perform and construct the communicative encounters in the art world.

Institutions that create these texts and negotiate their access by certain individuals will impact on the actions of program officers, themselves acting as advocates for their "clients", in trying to align the actual work of the artist with the language and topologies of the institution. Despite reforms to the system of disciplines, despite attempts to break down silos both materially and philosophically, these kinds of texts remain central to the relationship between artists and the state. It is not the texts themselves that must ultimately concern us as researchers and as advocates, but their power in coordinating the performances of art world members. 


\section{Conclusion: staying present in the research}

In this dissertation, I have shown that these cases demonstrate the significance of considering "what do you do?" over some vague sense of what it is to "be an artist" (or a program officer, or a political staffer, for that matter). I have shown that a shift in studying the work of art and the work of artists in their relationship with the legitimating structures and government institution of arts funding and support can provide a more nuanced and present exploration of elements of the art world and its communication.

The question of artistic identity has been well documented, but identity does not tell us enough about what it is that artists and cultural bureaucrats $d o$ in the art world. My research suggests we need greater connection between the study of cultural production (and a narrowed focus on artistic production), and the study of policy texts and their results. By changing the question from who the artist is to what the artist does, and where and when they do it, this dissertation has recognized the importance of performance, of place, and of the ways that cultural policies are activated in relation to the legitimating structures and institutions of arts support. The language of advocacy helps us to appreciate these relations as an active process of demonstrating legitimacy.

Sociological understandings of the art world exemplified by Becker imagine the artist as one part of a collective, grudgingly acknowledging the core of the traditional Romantic genius, along with the stretchers of canvas, the riggers of lights, and the movers of amps, as the vital support for the making of art. In this understanding of the art world, when government is acknowledged, the theoretical impetus for its involvement in legitimating and supporting art work and artists is often instrumental: a matter of economics, national display, even health, and social welfare outcomes. 
In another thread of scholarship, the state is imagined as the source of a disciplinary regime of governmentality and new public management that bureaucratizes the work of art and of artists, circumscribing very particular performances of the self through textual mediation and online profile generation. Alongside these discourses, those arts bureaucrats that actually interface with artists have their own misgivings and frustrations as they navigate structural changes in the institution while attempting to build bridges between that institution and the individual.

Scholars that have elucidated the relationship between intrinsic and instrumental values of artistic objects and the cultural policies that enable their creation (Belfiore, 2002; Belfiore and Bennett, 2007; Gibson, 2008; Gray, 2007; Gray, 2008) are often most concerned about whether instrumentalist policies will place pressures upon artists that undermine their ability to creatively reflect society and offer meaningful experiences to audiences. They are further concerned with providing justifications or critiques of the instrumentalist model. Does the study of the institution of artistic creation finally come down to questions about aligning creative impulses with policy priorities? Does the study of legitimation of artists and their practices need to trouble that binary? As Belfiore wonders, does research on art worlds always need to either take a purely critical and humanistic stance, or address specific policy questions usually tied to funding priorities? Or can "the relationship between research, policy-making, and practice development" be "effective and mutually beneficial for the involved parties" (2016, p. 214). This dissertation shows that the questions being asked by cultural policy research are given new life by shifting away from this binary and toward the practices, performances and language of art world members.

As a discursive formation, the art worlds I have looked at are defined not only by the products of their creation, the conditions of their workers, nor the social structures they exhibit. 
They are understood not simply by the meanings assigned to their texts, but by how those texts are enacted and performed. They are studied not just through an examination of their histories, but their evolving and present relations taking place in time and space, at the moments where these individuals appear before one another and both challenge and submit to the ruling relations that govern their collective effort.

The artists gathered by the CAC for Arts Day must negotiate the language of the politician and the economist when they perform their advocacy. They must bridge the gap between art work that is meant to ennoble, inspire, and reflect society, and art that will work to put money into local economies that governments can point to in an instrumental fashion. The pressure to translate this advocacy language comes from inside and outside the organization. Advocates must practice a liveness and presence in these kinds of situations, lest they become locked into performances that are too scripted to acknowledge the constantly changing situation in an advocacy event.

As they are introduced to the structures that will help them to build a career beyond being an artist for hire, students at JAC must overcome physical and symbolic distances to present themselves to these structures, just as they must learn to encode their experiences and their very physical being into the conventional texts of CVs, headshots, and grant applications, required for their own advocacy. Meanwhile, the program officers at the Canada Council itself advocate to increase their presence and agency in the working lives of artists. Struggling against language and classifications imposed during a wholesale transformation of disciplinary and philosophical orientation, their performance as intermediary between the artist and the state is bound by operational outlines and policies. They are encouraged to outreach to communities where they can encounter artists in the moment as they prepare their own advocacy. 
In 2013, De Graaf et al. published their summation of the Seventh International Conference in Interpretive Policy Analysis, an event that heralded "a new dawn" for policy research, informed by "the performative dimension of policy-making" (2013, p. 422). In their account of the keynote from Alletta Norval, the political scholar notes attention needs to be paid to "those moments when democratic demands break through the threshold of visibility and shift the stage on which arguments can be presented and heard" (Norval as cited in de Graaf et al., 2013, p. 423). This is the result that I seek with this research. It is not to advocate for a flood of new money into the arts sector, nor to remove already existing funding. It is not my goal to implement new policies that enshrine instrumental nor intrinsic values on art work. It is to turn the spotlight more clearly on this stage where cultural policies are argued, where advocacy takes place, and where advocacy relationships are built. In other words, it is not the goal here to advocate, it is the goal to make better advocates.

Research in the field contends that cultural policies that attempt to bind the nation into particular narratives expressed through artwork constrain not only artistic practices but entire knowledge environments. For instance, Michael Dorland wonders if the lack of promotion and protection in the nascent film industry in Canada might be a function of our "garrison mentality" (1998, p. 23), a term he borrows from Northrop Frye to indicate that tendency to retreat into ourselves, to avoid conflict, or in other words, to go along to get along. Citing the work of political scholar Mark Neocleous, Ira Wagman goes even further to suggest that the cultural policies in his study, primarily in the realm of Canadian film and broadcast from the late 1920s through to the mid-sixties, demonstrate a reconfiguration of national thought, affecting policies under organizations like the Canadian Radio and Telecommunications Commission, and displaying "the declining influence of cultural nationalists and humanities-based approaches 
within the policymaking process and the rising influence of economic nationalists and specialists drawing upon administrative techniques" (2007, p. 3). This dissertation is a means to begin shifting the conversation and reconfiguring the knowledge environment to re-focus on the humanities and the performative processes of policy impact on legitimation and the artistic career.

I argue for a theatricalization of language in discussions of cultural policy and artistic production. Metaphors of staging, presentation, and visibility are powerful representations of the active work of art world members. Demonstrating the importance of the setting and staging of cultural policy discussions, Stephen Harper used a specific setting when pressing a point about how "ordinary Canadians" felt about what he identified as an artistic elite, whining for their grants while sipping champagne. He did not perform this act of de-legitimation in front of the Parliament buildings, but in a Tim Horton's, the ultimate regular-guy Canadian locale (Benzie et al., 2008). Staging can be a powerful means to reinforce a message.

My research has shown that presence and performance are helpful terms that widen our understanding of the art world and its policy activations. Rosie Anderson repeats this call, insisting "that extending an embodied, performance approach from the analysis of the implementation of policy into the analysis of the making of policy and the forming of policy claims is both productive and challenging" (2014, p. 22). Alison Bain tells us "the complex interplay of absence and presence" is a vital part of artists displaying those identities (2004, p. 424). For Bain, identity as an artist is a matter of successful communication to the art world, and this dissertation responds to her call for attention to the "significant opportunity for scholars to examine the lives of artists in greater detail, to attend to the spaces in which these artists operate, and to emphasise their perceptions and subjective experiences" (2004, p. 424). 
The significance of movement must also be acknowledged. The choreographing of an advocacy event like Arts Day requires the coordination of physical movements, gathering artists in the power-full space of Ottawa's Parliament Hill and its attendant offices and meeting rooms, the movement of artists and government agents within those spaces. Just as students at JAC consider the movement of their bodies on the micro-level (can I stand?) and on the macro-level (do I move to Toronto or LA?), how artists move through spaces of advocacy, and what they might be moving away from, are important aspects of the careful negotiation of their disposition and performance.

Performative advocacy, the concept that I have introduced to demonstrate this complex interplay of performance, locality, presence, and disposition in the relationships between artists and government, generates new avenues of inquiry into artistic production. Understanding how artists speak the discourses of legitimation, and how they are formed into professional beings through work that often falls outside their core creative activity, gives us insight that can be applied to various sectors and pockets of the art world.

Lindsay Stephens demonstrates this process in her discussion of circus arts, legitimated by the Canada Council in 2009, with its own disciplinary category in the funding rubric (2015, pp. 243-244). One of the gaps in this work, particularly that of Stephens, is that it does not delve deeply enough into the processes by which legitimation comes to pass. For Stephens, this is a missed opportunity to strengthen her argument that this legitimation "gave credence to performers' claims that what they do is art" $(2015$, p. 243). How do they make those claims to each other and these governmental bodies? These are the processes uncovered in the cases I have illustrated in this research. 
Art work represents a form of advocacy work even within the production of art itself. Artists can hold the position of political outsider and even critic, all while they are required to engage with political relationships. For instance, in August 2010, the highly acclaimed Summerworks Theatre Festival in Toronto produced a play by Catherine Frid entitled Homegrown. According to some critics, the play took a sympathetic view of a member of the infamous Toronto 18 terrorist cell, accused of plotting attacks against targets in Canada's largest city. In June of 2011, festival organizers were informed that Canadian Heritage had decided to eliminate the subsidy that accounted for $20 \%$ of the festival's operating budget. Artists responded to this decision in several ways, including meetings and press releases. But one of their key interventions were staged readings of the play across the country, performances that used the theatrical form itself to advocate for government to reverse its decision. These "foolish" interventions (Anderson, 2014) were ultimately successful, and funding was restored a few months later. The example of supporters of Summerworks displays a performance of advocacy that specifically targeted a policy decision impacting artists on the ground, while also displaying the performance of art work as advocacy for certain instrumental social issues. The interventions by the supporters of Summerworks are a moment of advocacy in time and space, comprising a range of individuals and organizations large and small.

I have shown that paying closer attention to these particular moments, especially the moments when artists discover the disposition of the advocate, can help to demystify the world of cultural policy and recentre the artist as a key voice in policy discussion. Communicating their individual experiences allows us to understand how those experiences and actions are coordinated by the institution of arts funding, and the instrumental manner that governments often imagine its implementation and evaluation. 
The danger of studying policy is the pull to change it, the desire to advance the agenda of participants, particularly when you identify as a member of the very sector under investigation. In the way I choose to pursue this research, I must acknowledge my identity as an artist while doing everything possible to refuse the call to occupy a position as cheerleader or doomsayer for the arts sector. Moreover, as Paquette and Redaelli point out in their discussion of arts management research, we must be aware of the differing epistemologies that impact these studies as they run the range between the objective and rational that is the supposed hallmark of academic research, and the reflexivity of a practice-based research agenda (2015, p. 15). Acknowledging the need for reflexivity and practical research should not create a binary between academia and the art world, but rather celebrate their diverse perspectives, and allow these visions to do the work required to "reconcile the disputes among practitioners and scholars" (Paquette \& Redaelli, 2015, p. 16), strengthening the communication of advocacy and its understanding by all parties: artists, scholars, government, and the public.

There can be no argument that the environment in which artists and the government are interacting is rapidly changing. Due attention must be paid to the cultural industries, the digital shift, and the increasing precarity and impact assessment culture that now pervades the art world. Technological articulations of the cultural worker and the industrial communications model, with its attendance on ownership, conglomerations, and globalization deserve study.

We must not lose sight of the place of the artist and their practices within the discussion. My study has demonstrated that institutional ethnography is a productive means to connect the experiences of individuals within pockets of the art world with the ruling relations that coordinate their activities over various networks of support and legitimation. From a student actor who wonders whether it is appropriate to move her body in a class on professional 
management, to the political staffer whose surprisingly vulgar performance challenges the expected decorum in an advocacy meeting, to the program officer who must delve into documents and online histories to validate the $\mathrm{CV}$ and profile of a new applicant, these individuals are performing advocacy within the constraints of ruling relations that this study and its methodological approach has helped to uncover. I believe further study along these important lines, including the unique work of program officers at arts councils and ministries of culture at various levels of government will prove informative and vital to maintaining a robust and sustainable art world in Canada.

Now that the Canadian government has seen fit to reinvest public monies into organizations like the Canada Council, the relationship between bodies like it, and the bodies of artists, their presence in the discourse of legitimation must remain central. More research along these lines and in different sectors of the art world and the cultural industries may well uncover new modes of performance and new dispositions that will help to connect the experiences I have illuminated here, with growing concerns over digitization, copyright enforcement, and the intense globalization exemplified by streaming services such as Netflix. By studying how the local experiences of individuals and small organizations that feed into the larger structures of the cultural industries, relate to the texts and technologies of cultural support, we are better placed to build an art world where advocacy is a mutually reinforcing communication process. 
Gasoi - 253

\section{References}

2018-19 Explore and Create Funding Overview. (n.d.). Canada Council for the Arts. Retrieved July 22, 2020, from https://canadacouncil.ca:443/research/stats-and-stories/explore-andcreate

Abbing, H. (2002). Why are artists poor?: The exceptional economy of the arts. Amsterdam University Press.

About | NAC Indigenous Theatre. (n.d.). Retrieved May 26, 2020, from https://naccna.ca/en/indigenoustheatre/about

About MainLine Theatre | Théâtre MainLine Theatre. (n.d.). Retrieved May 23, 2020, from http://www.mainlinetheatre.ca/en/a-propos

About Us | Canadian Arts Coalition. (n.d.). Retrieved February 15, 2020, from https://www.canadianartscoalition.com/about-2/

Acland, C. R. (2006). Harold Innis, Cultural Policy, and Residual Media. International Journal of Cultural Policy, 12(2), 171-185. https://doi.org/10.1080/10286630600813677

Acosta, R. (2012). Advocacy networks through a multidisciplinary lens: Implications for research agendas. Voluntas: International Journal of Voluntary \& Nonprofit Organizations, 23(1), 156-181. https://doi.org/10.1007/s11266-011-9187-3

Ahearne, J. (2009). Cultural policy explicit and implicit: A distinction and some uses. International Journal of Cultural Policy, 15(2), 141-153. https://doi.org/10.1080/10286630902746245

Anderson, B. R. O. (2006). Imagined communities: Reflections on the origin and spread of nationalism (Revised edition). Verso. 
Anderson, R. (2014). Playing the fool: Activists' performances of emotion in policy making spaces. Emotion, Space and Society, 13, 16-23. https://doi.org/10.1016/j.emospa.2014.05.004

Arendt, H. (1998). The Human Condition: Second Edition (2nd edition). University of Chicago Press.

Aronczyk, M., \& Brady, M. J. (2015). Branding History at the Canadian Museum of Civilization. Canadian Journal of Communication, 40(2). https://doi.org/10.22230/cjc.2015v40n2a2812

Arts Management. (n.d.). Sprott School of Business. Retrieved October 23, 2020, from https://sprott.carleton.ca/programs/mba/arts-management/

Ashton, D. (2013). Cultural workers in-the-making. European Journal of Cultural Studies, 16(4), 468-488. https://doi.org/10.1177/1367549413484308

Austin, J. L. (1975). How to Do Things with Words (J. O. Urmson \& M. Sbisà, Eds.). Harvard University Press.

Bain, A. (2005). Constructing an artistic identity. Work, Employment and Society, 19(1), 25-46. https://doi.org/10.1177/0950017005051280

Bain, A. (2013). Creative Margins: Cultural Production in Canadian Suburbs. University of Toronto Press. http://www.jstor.org/stable/10.3138/j.ctt5hjwr7

Bain, A. (2004). In/visible geographies: Absence, emergence, presence, and the fine art of identity construction. Journal of Economic and Social Geography, 95(4), 419-426. https://doi.org/10.1111/j.1467-9663.2004.00318.x

Bain, A., \& McLean, H. (2013). The artistic precariat. Cambridge Journal of Regions, Economy and Society, 6(1), 93-111. https://doi.org/10.1093/cjres/rss020 
Banks, M. (2007). The Politics of Cultural Work. Springer.

Banks, M., Gill, R. \& Taylor, S. (2013). Theorizing Cultural Work: Labour, Continuity and Change in the Cultural and Creative Industries (Mark Banks, R. Gill, \& S. Taylor, Eds.). Routledge.

Banks, M. \& Hesmondhalgh, D. (2009). Looking for work in creative industries policy. International Journal of Cultural Policy, 15(4), 415-430. https://doi.org/10.1080/10286630902923323

Baumann, S. (2007). A general theory of artistic legitimation: How art worlds are like social movements. Poetics, 35(1), 47-65. https://doi.org/10.1016/j.poetic.2006.06.001

Becker, H. \& Pessin, A. (2006). A Dialogue on the Ideas of "World" and "Field." Sociological Forum, 21(2), 275-286.

Becker, H. (1982). Art Worlds. University of California Press.

Belfiore, E. (2004). Auditing culture: The subsidised cultural sector in the New Public Management. International Journal of Cultural Policy, 10(2), 183-202.

Belfiore, E. (2009). On bullshit in cultural policy practice and research: Notes from the British case. International Journal of Cultural Policy, 15(3), 343-359. https://doi.org/10.1080/10286630902806080

Belfiore, E. (2016). Cultural policy research in the real world: Curating "impact", facilitating “enlightenment.” Cultural Trends, 25(3), 205-216. https://doi.org/10.1080/09548963.2016.1204050

Belfiore, E., \& Bennett, O. (2007). Rethinking the social impacts of the arts. International Journal of Cultural Policy, 13(2), 135-151. https://doi.org/10.1080/10286630701342741 Bell, D., \& Oakley, K. (2015). Cultural policy. Routledge/Taylor \& Francis Group. 
Belshaw, D., \& Fancy, D. (2014). Introduction: Why Acting Training? Canadian Theatre Review, 160(1), 5-7.

Benjamin, J. (1976). Performatives as a Rhetorical Construct. Philosophy \& Rhetoric, 9(2), 8495.

Bennett, O. (2004). Review essay. International Journal of Cultural Policy, 10(2), 237-248. https://doi.org/10.1080/1028663042000255844

Bennett, T. (2002). Culture and governmentality. In J. Z. Bratich, J. Packer, \& C. McCarthy (Eds.), Foucault, Cultural Studies, and Governmentality. SUNY Press.

Bennett, T. (2013). The Birth of the Museum: History, Theory, Politics (1st edition). Routledge.

Benzie, R., Campion-Smith, B., \& Whittington, L. (2008). Ordinary folks don't care about arts: Harper. The Toronto Star. https://www.thestar.com/news/politics/federalelection/2008/09/24/ordinary_folks_dont_c are_about_arts_harper.html

Berland, J. (1995). Marginal notes on cultural studies in Canada. University of Toronto Quarterly; North York, 64(4), 514-525.

Bille, T., Grønholm, A., \& Møgelgaard, J. (2016). Why are cultural policy decisions communicated in cool cash? International Journal of Cultural Policy, 22(2), 238-255. https://doi.org/10.1080/10286632.2014.956667

Birkland, T. A. (1998). Focusing Events, Mobilization, and Agenda Setting. Journal of Public Policy, 18(1), 53-74.

Bisaillon, L., \& Rankin, J. (2012). Navigating the Politics of Fieldwork Using Institutional Ethnography: Strategies for Practice. Forum: Qualitative Social Research, 14(1). https://doi.org/10.17169/fqs-14.1.1829 
Born, G. (1995). Rationalizing culture: IRCAM, Boulez, and the institutionalization of the musical avant-garde. University of California Press.

Born, G. (2005). Uncertain Vision: Birt, Dyke and the Reinvention of the BBC. Vintage.

Born, G. (2010). The Social and the Aesthetic: For a Post-Bourdieuian Theory of Cultural Production. Cultural Sociology, 4(2), 171-208. https://doi.org/10.1177/1749975510368471

Bourcheix-Laporte, M. (2019). Creative Canada: A Critical Look at a "New" Cultural Policy Framework. Canada Radio Telecommunications Corporation.

Bourdieu, P. (1983). The field of cultural production, or: The economic world reversed. Poetics, 12(4-5), 311-356. https://doi.org/10.1016/0304-422x(83)90012-8

Bourdieu, P. (1984). Distinction: A Social Critique of the Judgement of Taste. Harvard University Press.

Bourdieu, P. (1992). The Logic of Practice (R. Nice, Trans., 1st edition). Stanford University Press.

Bourdieu, P. (1993). But who created the creators. Sociology in Question, 139-148.

Bradshaw, J. (2008). Harper defends cuts to federal arts programs. The Globe and Mail. https://www.theglobeandmail.com/arts/harper-defends-cuts-to-federal-artsprograms/article1349820/

Brault, S. (n.d.). The arts and culture as new engines of economic and social development. http://policyoptions.irpp.org/magazines/policy-optionsat-25/the-arts-and-culture-as-newengines-of-economic-and-social-development/

Briefs and Reports | Canadian Dance Assembly. (n.d.). Retrieved February 14, 2020, from http://www.cda-acd.ca/en/advocacy/briefs-reports 
Brison, J. (2005). Rockefeller, Carnegie, and Canada: American Philanthropy and the Arts and Letters in Canada. McGill-Queen's Press - MQUP.

Burchell, G., Foucault, M., Gordon, C., \& Miller, P. (Eds.). (1991). The Foucault effect: Studies in governmentality: With two lectures by and an interview with Michel Foucault. University of Chicago Press.

Burke, K. (1969). A Grammar of Motives (Revised edition). University of California Press.

Butler, J. (1997). Excitable speech: A politics of the performative. Routledge.

Butler, J. (2015). Notes toward a performative theory of assembly. Harvard University Press.

Cabantous, L., Gond, J.-P., Harding, N., \& Learmonth, M. (2016). Critical Essay: Reconsidering critical performativity. Human Relations, 69(2), 197-213. https://doi.org/10.1177/0018726715584690

Campbell, M., \& Gregor, F. (2004). Beginning an Institutional Ethnography. In Mapping social relations: A primer in doing institutional ethnography. Altamira Press.

Canada Council for the Arts Act, Pub. L. No. 2001, c. 34, s. 14(E), 2001, c. 34, s. 14(E) (2009). https://laws-lois.justice.gc.ca/eng/acts/c-2/page-1.html

Canada Council Unveils New Funding Model. (n.d.). Canadian Art. Retrieved October 19, 2020, from https://canadianart.ca/news/canada-council-unveils-new-funding-model/

Canadian Artists' Representation v. National Gallery of Canada, No. 35353 (Supreme Court of Canada May 14, 2014). http://canlii.ca/t/g6vmx

Canadian Heritage. (2017). Creative Canada Policy Framework. Canadian Heritage. https://www.canada.ca/en/canadian-heritage/campaigns/creative-canada/framework.html Carroll, N. (1987). Can Government Funding of the Arts Be Justified Theoretically? Journal of Aesthetic Education, 21(1), 21. https://doi.org/10.2307/3332811 
Gasoi - 259

Caust, J. (2003). Putting the "art" back into arts policy making: How arts policy has been "captured" by the economists and the marketers. International Journal of Cultural Policy, 9(1), 51-63. https://doi.org/10.1080/1028663032000089723

CBC News. (2018). Doctors to prescribe museum visits to help patients "escape from their own pain” | CBC News. https://www.cbc.ca/news/canada/montreal/montreal-museum-finearts-medecins-francophone-art-museum-therapy-1.4859936

Chang, W. J. (2010). How “Small” Are Small Arts Organizations? The Journal of Arts Management, Law, and Society, 40(3), 217-234. https://doi.org/10.1080/10632921.2010.504604

Charland, M. (1986). Technological nationalism. Canadian Journal of Political and Social Theory, 10(1-2), 196-220.

Cluley, R. (2012). Art Words and Art Worlds: The Methodological Importance of Language Use in Howard S. Becker's Sociology of Art and Cultural Production. Cultural Sociology, 6(2), 201-216. https://doi.org/10.1177/1749975512440223

Cohen, N. S. (2015). Cultural Work as a Site of Struggle: Freelancers and Exploitation. In Marx and the Political Economy of the Media (pp. 36-64). Brill.

Coles, A., MacNeill, K., Vincent, J., \& Vincent, C. (2018). The Status of Women in the Canadian Arts and Cultural Industries-Research Review 2010-2018. Ontario Arts Council. https://www.arts.on.ca/oac/media/oac/Publications/Research\%20Reports\%20ENFR/Arts\%20Funding\%20and\%20Support/OAC-Women-the-ArtsReport_Final_EN_Oct5.pdf

Course List | Professional Theatre. (n.d.). Retrieved January 11, 2020, from https://www.dawsoncollege.qc.ca/professional-theatre/course-list/ 
Dabrusin, J. (2019). Gender Parity in Canadian Artistic and Cultural Organizations. Canadian House of Commons. https://www.ourcommons.ca/Content/Committee/421/CHPC/Reports/RP10279196/chpcr p16/chpcrp16-e.pdf

D’Andrea, M. J. (2017). Symbolic Power: Impact of Government Priorities for Arts Funding in Canada. The Journal of Arts Management, Law, and Society, 47(4), 245-258. https://doi.org/10.1080/10632921.2017.1340209

Davie, E. (2017). Stop including weight, height and chest size on resume, Halifax director urges | CBC News. https://www.cbc.ca/news/canada/nova-scotia/actor-resume-halifax-theatredirector-weight-height-chest-waist-measurements-1.4408299

Davies, S. (2008). Intellectual and political landscape: The instrumentalism debate. Cultural Trends, 17(4), 259-265. https://doi.org/10.1080/09548960802615398

de Graaf, L., Metze, T., \& van Hulst, M. (2013). Understanding the drama of democracy: Looking back at the Seventh International Conference in Interpretive Policy Analysis. Critical Policy Studies, 7(4), 422-424. https://doi.org/10.1080/19460171.2013.851150 de la Fuente, E. (2007). The 'New Sociology of Art': Putting Art Back into Social Science Approaches to the Arts. Cultural Sociology, 1(3), 409-425. https://doi.org/10.1177/1749975507084601 de Peuter, G. (2014a). Confronting Precarity in the Warhol Economy. Journal of Cultural Economy, 7(1), 31-47. https://doi.org/10.1080/17530350.2013.856337 de Peuter, G. (2014b). Beyond the Model Worker: Surveying a Creative Precariat. Culture Unbound: Journal of Current Cultural Research, 6(1), 263-284. https://doi.org/10.3384/cu.2000.1525.146263 
Denis, A. B. (1975). Some Social Characteristics of CEGEP Graduates'. 1, 5(2), 39-56.

Denis, A., \& Lipkin, J. (1972). Quebec's CEGEP: Promise and reality. McGill Journal of Education/Revue Des Sciences de l'éducation de McGill, 7(002). https://mje.mcgill.ca/article/view/6875

Denzin, N. K. (1995). Messy Methods for Communication Research. Journal of Communication, 45(2), 177-184. https://doi.org/10.1111/j.1460-2466.1995.tb00735.x

Denzin, N. K. (2003). The Call to Performance. Symbolic Interaction, 26(1), 187-207. https://doi.org/10.1525/si.2003.26.1.187

Deveau, J. L. (2009). Examining the institutional ethnographer's toolkit. Socialist Studies/Études Socialistes, 4(2).

Dewing, M. (2010). Current Publications: Arts, culture and entertainment: Federal Government Policy on Arts and Culture. https://lop.parl.ca/Content/LOP/ResearchPublications/200841-e.htm?cat=arts

Dick, B., Jeannotte, S., \& Hill, K. (2019). Positioning Culture within Canadian Municipalities. Culture and Local Governance, 6(1), 1-22. https://doi.org/10.18192/clg-cgl.v6i1.4550

Dobson, S. (2001). Introduction to Institutional Ethnography as Method. Studies in Cultures, Organizations and Societies, 7(2), 147-158. https://doi.org/10.1080/10245280108523556

Donald, J. (1997). Higher Education in Quebec: 1945-1995. In G. A. Jones (Ed.), Higher Education in Canada: Different Systems, Different Perspectives (pp. 161-188). Taylor \& Francis.

Dorland, M. (1998). The Canadian State and the Problem of Knowledge Formation. In M. Dorland (Ed.), So Close to the State/s: The Emergence of Canadian Feature Film Policy. University of Toronto Press. 
Dorland, M. (2000). Policying culture: Canada, State Rationality, and the Governmentalization of Communication. In J. Berland \& S. Hornstein (Eds.), Capital Culture: A Reader on Modernist Legacies, State Institutions, and the Value(s) of Art (pp. 141-152). McGillQueen's Press - MQUP.

Druick, Z. (2007a). Projecting Canada: Government Policy and Documentary Film at the National Film Board. McGill-Queen's Press - MQUP.

Druick, Z. (2007b). Remedy and Remediation: The Cultural Theory of the Massey Commission. Review of Education, Pedagogy, and Cultural Studies, 29(2-3), 159-174. https://doi.org/10.1080/10714410701196468

Dubois, V. (2011). Cultural capital theory vs. Cultural policy beliefs: How Pierre Bourdieu could have become a cultural policy advisor and why he did not. Poetics, 39(6), 491-506. https://doi.org/10.1016/j.poetic.2011.09.003

Duncan, C., \& Wallach, A. (1980). The Universal Survey Museum. Art History, 3(4), 448-469. https://doi.org/10.1111/j.1467-8365.1980.tb00089.x

Edwardson, R. (2003). The Many Lives of Captain Canuck: Nationalism, Culture, and the Creation of a Canadian Comic Book Superhero. Journal of Popular Culture, 37(2), 184201. https://doi.org/10.1111/1540-5931.00063

Elwell, J. S. (2014). The transmediated self: Life between the digital and the analog. Convergence, 20(2), 233-249. https://doi.org/10.1177/1354856513501423

Everett-Green, R. (2017). Mélanie Joly to reset 'symbols of progressiveness' as heritage minister. https://www.theglobeandmail.com/arts/melanie-joly-to-reset-symbols-ofprogressiveness-as-heritage-minister/article27156035/ 
Gasoi - 263

Filewod, A. (2011). Committing Theatre: Theatre Radicalism and Political Intervention in Canada. Between the Lines.

Finances of Performing Arts Organizations. (n.d.). Hill Strategies Research Inc. Retrieved October 19, 2020, from https://hillstrategies.com/resource/finances-of-performing-artsorganizations-2/

Fine, G. A. (2003). Crafting authenticity: The validation of identity in self-taught art. Theory and Society, 32(2), 153-180. https://doi.org/10.1023/A:1023943503531

Florida, R. (2002). The Rise of the Creative Class. Basic Boks.

Fougère, M., \& Solitander, N. (2007). The Rise of Creative Governmentality-And how it's transgressing working hours, job security, politics and everyday strife. Critical Management Studies 2007 Proceedings: Electronic Journal of Radical Organization Theory, 20. http://www.mngt.waikato.ac.nz/ejrot/cmsconference/2007/proceedings.asp

Frank, S. (2012). Ready for Your Close-Up? Polyvalent Identity and the Hollywood Headshot. Visual Anthropology Review, 28(2), 179-188. https://doi.org/10.1111/j.15487458.2012.01123.x

Friend, D. (2019). National Arts Centre’s Indigenous Theatre will not receive \$3.5M in requested federal funding | CBC News. CBC. https://www.cbc.ca/news/canada/nationalarts-centre-indigenous-theatre-lower-funding-1.5081973

Funding Principles. (n.d.). Retrieved September 29, 2019, from https://canadacouncil.ca/funding/funding-decisions/principles

Gamble, A. (1994). The Free Economy and the Strong State: The Politics of Thatcherism. Macmillan International Higher Education. 
Gattinger, M. (2017). The Roots of Culture, the Power of Art: The First Sixty Years of the Canada Council for the Arts. McGill-Queen's Press - MQUP.

Gattinger, M., \& Saint-Pierre, D. (2008). Toward Subnational Comparative Cultural Policy Analysis: The Case of Provincial Cultural Policy and Administration in Canada. Journal of Arts Management, Law, and Society; Washington, 38(3), 167-186.

Gerber, A. (2017). The Work of Art: Value in Creative Careers (1 edition). Stanford University Press.

Geertz, C. (1998). Deep Hanging Out.www.nybooks.com, https:/www.nybooks.com/articles/1998/10/22/deep-hanging-out/.

Gibson, L. (2008). In defence of instrumentality. Cultural Trends, 17(4), 247-257. https://doi.org/10.1080/09548960802615380

Goetze, C. (2017). Pierre Bourdieu's Toolbox: Fields, Power, Practices, and Habitus in the Analysis of Peacebuilding. In The Distinction of Peace (pp. 15-39). University of Michigan Press. https://www.jstor.org/stable/pdf/j.ctt1qv5nd6.6.pdf

Goffman, E. (1959). The Presentation of Self in Everyday Life (1st ed.). Anchor. https://www.amazon.ca/Presentation-Self-Everyday-Life/dp/0385094027

Goffman, E. (1968). Asylums: Essays on the Social Situation of Mental Patients and Other Inmates. Aldine Transaction.

Government of Canada, S. C. (2019). The Daily-Provincial and Territorial Culture Indicators, 2017. https://www150.statcan.gc.ca/n1/daily-quotidien/190425/dq190425b-eng.htm

Granatstein, J. L. (1984). Culture and Scholarship: The First Ten Years of the Canada Council. Canadian Historical Review, 65(4), 441-474. https://doi.org/10.3138/CHR-065-04-01 
Gray, C. (2002). Local Government and the Arts. Local Government Studies, 28(1), 77-90. https://doi.org/10.1080/714004133

Gray, C. (2007). Commodification and instrumentality in cultural policy. International Journal of Cultural Policy, 13(2), 203-215. https://doi.org/10.1080/10286630701342899

Green, B. (2018). To Advocate for Theatre, or Not to Advocate for Theatre? https://pact.ca/toadvocate-for-theatre-or-not-to-advocate-for-theatre/

Hajer, M. A. (2005). Setting the stage: A dramaturgy of policy deliberation. Administration \& Society, 36(6), 624-647.

Hall, J. Y. (2005). Lobbying for Arts and Culture: From the Culture Wars to the Rise of New Issues. The Journal of Arts Management, Law, and Society, 35(3), 227-238. https://doi.org/10.3200/JAML.35.3.227-238

Hanson, N. (2016). Funding: More Than Just Money. Canadian Theatre Review, 167, 5-6. https://doi.org/10.3138/ctr.167.001

Hardt, M., \& Negri, A. (2017). Assembly. Oxford University Press.

Hariman, R. (1995). Political Style: The Artistry of Power. University of Chicago Press.

Hawkins, J. (2012). Leveraging the Power of Individuals for Arts Advocacy. The Journal of Arts Management, Law, and Society, 42(3), 128-140. https://doi.org/10.1080/10632921.2012.729497

Hesmondhalgh, D., \& Baker, S. (2008). Creative Work and Emotional Labour in the Television Industry. Theory, Culture \& Society, 25(7-8), 97-118. https://doi.org/10.1177/0263276408097798

Hesmondhalgh, D., \& Pratt, A. C. (2005). Cultural industries and cultural policy. International Journal of Cultural Policy, 11(1), 1-13. https://doi.org/10.1080/10286630500067598 
Higham, R. (2002). Arts and Culture as Profit Centre?: A Martial Arts Lesson for Canada’s Cultural Policy Warriors. Canadian Journal of Communication, 27(2). https://doi.org/10.22230/cjc.2002v27n2a1307

Hill, K. (2019, November 27). A Statistical Profile of Artists in Canada in 2016 (With Summary Information about Cultural Workers) | Hill Strategies Research Inc. Hill Strategies Research Inc. https://hillstrategies.com/resource/statistical-profile-of-artists-in-canada-in$2016 /$

History. (2011). http://ccarts.ca/about-the-cca/history/

History - Canadian Arts Coalition. (n.d.). Retrieved July 29, 2020, from https://www.canadianartscoalition.com/history/

Hracs, B. J. (2015). Cultural Intermediaries in the Digital Age: The Case of Independent Musicians and Managers in Toronto. Regional Studies, 49(3), 461-475. https://doi.org/10.1080/00343404.2012.750425

International Centre of Art for Social Change. (n.d.). ART / DIALOGUE / ACTION. Retrieved October 29, 2020, from https://icasc.ca/

Jennings, S. (2009). Art and politics: The history of the National Arts Centre. Dundurn.

Klages, G. (2008). “Will the establishment finance the revolution?”: Canadian arts advocacy groups, the federal government, and development of arts policies, 1963-1972 [Doctoral dissertation, York University]. https://search-proquestcom.proxy.library.carleton.ca/docview/304424052/abstract/284E2C376AA74F72PQ/1 Klamer, A., \& Petrova, L. (2007). Financing the Arts: The Consequences of Interaction among Artists, Financial Support, and Creativity Motivation. The Journal of Arts Management, Law, and Society, 37(3), 245-256. https://doi.org/10.3200/JAML.37.3.245-256 
Klostermann, J. (2016). Write Like a Visual Artist: Tracing artists' work in Canada's textually mediated art world. Literacy \& Numeracy Studies, 24(2), 43-63. https://doi.org/10.5130/lns.v2482.5060

Knecht, B. M. (2011). Performing under pressure: Understanding the relationship between government and the performing arts. [Doctoral dissertation, University of Calgary] Library and Archives Canada - Bibliothèque et Archives Canada.

Lahire, B. (2003). From the habitus to an individual heritage of dispositions. Towards a sociology at the level of the individual. Poetics, 31(5-6), 329-355.

Léger, M. J. (2010). The Non-Productive Role of the Artist: The Creative Industries in Canada. Third Text, 24(5), 557-570. https://doi.org/10.1080/09528822.2010.502774

Lewis, J., \& Miller, T. (Eds.). (2002). Critical Cultural Policy Studies: A Reader. WileyBlackwell.

Lingo, E. L., \& Tepper, S. J. (2013). Looking Back, Looking Forward: Arts-Based Careers and Creative Work. Work and Occupations, 40(4), 337-363. https://doi.org/10.1177/0730888413505229

Maguire, J. S., \& Matthews, J. (2012). Are we all cultural intermediaries now? An introduction to cultural intermediaries in context: European Journal of Cultural Studies. https://doi.org/10.1177/1367549412445762

Mass Culture • Mobilisation culturelle. (n.d.). Retrieved February 14, 2020, from https://massculture.ca/

McCaughey, C., Duxbury, N., \& Meisner, A. (2014). Measuring cultural value in Canada: From national commissions to a culture satellite account. Cultural Trends, 23(2), 109-119. https://doi.org/10.1080/09548963.2014.897452 
McCormack, T. (1984). Culture and the State. Canadian Public Policy / Analyse de Politiques, 10(3), 267-277. https://doi.org/10.2307/3550320

McGuigan, J. (2004). Rethinking cultural policy. Open University.

McHendry, G. F., Jr. (2016). Thank You for Participating in Security: Engaging Airport Security Checkpoints via Participatory Critical Rhetoric. Cultural Studies ++ Critical Methodologies, 16(6), 548-559.

Michel de la Chenelière International Atelier for Education and Art Therapy |MMFA. (n.d.).

Retrieved October 19, 2020, from https://www.mbam.qc.ca/en/education-wellness/aboutthe-michel-de-la-cheneliere-international-atelier-for-education-and-art-therapy/

Morgan-Feir, C. (2016). Canada Council's New Funding: 5 Knowns and Unknowns. Canadian Art. https://canadianart.ca/news/5-knowns-and-unknowns-about-canada-councils-newfunding-model/

Mulcahy, K. (2006). Cultural Policy: Definitions and Theoretical Approaches. The Journal of Arts Management, Law, and Society, 35(4), 319-330. https://doi.org/10.3200/JAML.35.4.319-330

Mulcahy, K. (1995). Public Culture and Political Culture: La Politique Culturelle du Quebec Changing Arts Policies. Journal of Arts Management, Law and Society, 25(3), 225-249.

Negus, K. (2002). The work of cultural intermediaries and the enduring distance between production and consumption. Cultural Studies, 16(4), 501-515. https://doi.org/10.1080/09502380210139089

Newman, M. Z., \& Levine, E. (2011). Legitimating Television: Media Convergence and Cultural Status (1st edition). Routledge.

Paquette, J., \& Redaelli, E. (2015). Arts Management and Cultural Policy Research. Springer. 
Parviainen, J. (2010). Choreographing Resistances: Spatial-Kinaesthetic Intelligence and Bodily Knowledge as Political Tools in Activist Work. Mobilities, 5(3), 311-329. https://doi.org/10.1080/17450101.2010.494838

Peterson, R. A. (2007). Culture, Production of. The Blackwell Encyclopedia of Sociology. https://doi.org/10.1002/9781405165518.wbeosc191

Peterson, R. A., \& Anand, N. (2004). The Production of Culture Perspective. Annual Review of Sociology, 30(1), 311-334. https://doi.org/10.1146/annurev.soc.30.012703.110557

Pinsent-Johnson, C., \& Thompson, T. L. (2011). Institutional Ethnography and Actor Network Theory: The Possibilities and Challenges of Exploring the Relational in Adult Education Research, New Prairie Press.

Portwood-Stacer, L. (2012). Media refusal and conspicuous non-consumption: The performative and political dimensions of Facebook abstention: New Media \& Society. https://doi.org/10.1177/1461444812465139

Prodinger, B., \& Turner, S. M. (2013). Using Institutional Ethnography to Explore how Social Policies Infiltrate into Daily Life. Journal of Occupational Science, 20(4), 357-369. https://doi.org/10.1080/14427591.2013.808728

Puwar, N. (2004). Space Invaders: Race, Gender and Bodies Out of Place (1st edition). Bloomsbury Academic.

Rankin, J. (2017). Conducting Analysis in Institutional Ethnography: Analytical Work Prior to Commencing Data Collection. International Journal of Qualitative Methods, 16(1), 160940691773448. https://doi.org/10.1177/1609406917734484 
Reid, J. (2017). Standpoint: Using Bourdieu to Understand IE and the Researcher's Relation with Knowledge Generation. In Perspectives on and from Institutional Ethnography (pp. 7190). Emerald Publishing Limited.

Robertson, C. (2004). Movement + apparatus: A cultural policy study of artist-run culture in Canada (1976-1994) [Doctoral dissertation, Concordia University]. In Communication Studies: Vol. PhD. https://spectrum.library.concordia.ca/8199/1/NQ96943.pdf

Robertson, C. (2006). Policy matters: Administrations of art and culture. YYZ Books.

Rowe, M. S. (2019). Boundary Work and Early Careers in Design and Media. Poetics, 72, 7080. https://doi.org/10.1016/j.poetic.2018.09.005

Rushton, M. (2002). Political oversight of arts councils: A comparison of Canada and the United States. International Journal of Cultural Policy, 8(2), 153-165. https://doi.org/10.1080/1028663022000009597

Rusted, B. (2006). Performing Visual Discourse: Cowboy Art and Institutional Practice. Text and Performance Quarterly, 26(2), 115-137. https://doi.org/10.1080/10462930500519481

Sabatier, P. A. (1988). An Advocacy Coalition Framework of Policy Change and the Role of Policy-Oriented Learning Therein. Policy Sciences, 21(2/3), 129-168.

Schon, D. A., \& Rein, M. (1995). Frame Reflection: Toward the Resolution of Intractable Policy Controversies. Basic Books.

Scott, S. (2010). Revisiting the Total Institution: Performative Regulation in the Reinventive Institution. Sociology, 44(2), 213-231. https://doi.org/10.1177/0038038509357198 Scullion, A., \& García, B. (2005). What is cultural policy research? International Journal of Cultural Policy, 11(2), 113-127. https://doi.org/10.1080/10286630500198104 
Searle, J. (1965). What is a speech act?. M. Black, ed. In M. Black (Ed.), Philosophy in America (pp. 221-239). Cornell University Press.

Shtern, J. (2012). Beyond Policy Analysis: Methods for Qualitative Investigation. In I. Wagman \& P. Urquhart (Eds.), Cultural Industries.ca: Making Sense of Canadian Media in the Digital Age (pp. 166-182). Lorimer.

Sirois, G. (2018). Entre confrontation et coopération: La représentation des intérêts des artistes et des travailleurs culturels de la francophonie canadienne. Minorités Linguistiques et Société, 10, 176. https://doi.org/10.7202/1054101ar

Smith, D. E. (1987). The Everyday World as Problematic: A Feminist Sociology. University of Toronto Press.

Smith, D. E. (1990). Texts, Facts and Femininity: Exploring the Relations of Ruling. Routledge UK.

Smith, D. E. (2001). Texts and the ontology of organizations and institutions. Studies in Cultures, Organizations and Societies, 7(2), 159-198. https://doi.org/10.1080/10245280108523557

Smith, D. E. (2005). Institutional Ethnography: A Sociology for People. Rowman Altamira.

Smith, D. E., \& Turner, S. M. (2014). Incorporating texts into institutional ethnographies, University of Toronto Press.

Smith, G. W. (1990). Political Activist as Ethnographer. Social Problems, 37(4), 629-648. https://doi.org/10.2307/800586

Soussloff, C. M. (1997). The Absolute Artist: The Historiography of a Concept. U of Minnesota Press. 
Staff Directory-About Us $\mid$ Canadian Dance Assembly. (n.d.). Retrieved February 14, 2020, from http://www.cda-acd.ca/en/about-us/staff-directory

Staten, H. (2012). The Origin of the Work of Art in Material Practice. New Literary History, 43(1), 43-64. https://doi.org/10.1353/nlh.2012.0001

Statistics Canada. (2011, October 24). Canadian Framework for Culture Statistics. https://www150.statcan.gc.ca/n1/en/catalogue/87-542-X

Status of the Artist Act/Loi sur le statut de l'artiste, S.C. 1992, c. 33 (1992).

Stephens, L. K. (2015). The Economic Lives of Circus "Artists": Canadian Circus Performers and the New Economy. Canadian Journal of Communication, 40(2), 243-260.

Sterne, J. (2002). Cultural Policy Studies and the Problem of Political Representation. The Communication Review, 5(1), 59-89. https://doi.org/10.1080/10714420212351

Stevens, L. (2016). The Théâtre du Soleil's Le Dernier Caravansérail. In L. Stevens, Anti-War Theatre After Brecht (pp. 91-124). Palgrave Macmillan UK. https://doi.org/10.1057/978$1-137-53888-8 \_5$

Taber, J. (2011). Actors union talks up Canadian culture with MPs. Globe and Mail. https://www.theglobeandmail.com/news/politics/ottawa-notebook/actors-union-talks-upcanadian-culture-with-mps/article618861/

Taber, N. (2010). Institutional ethnography, autoethnography, and narrative: An argument for incorporating multiple methodologies. Qualitative Research, 10(1), 5-25. https://doi.org/10.1177/1468794109348680

Taylor, S., \& Littleton, K. (2008). Art work or money: Conflicts in the construction of a creative identity. The Sociological Review, 56(2), 275-292. https://doi.org/10.1111/j.1467954X.2008.00788.x 
Teghtsoonian, K. (2016). Methods, discourse, activism: Comparing institutional ethnography and governmentality. Critical Policy Studies, 10(3), 330-347. https://doi.org/10.1080/19460171.2015.1050426

Teitel, D. (2016). New Pie and More Pie—Funding for Canada Council for the Arts: An Interview with Guylaine Normandin and Geneviève Vallerand. Canadian Theatre Review, 167(1), 12-15.

The Canadian Conference of the Arts to Close Doors after 67 Years. (2012). http://ccarts.ca/inthe-news/press-releases/the-canadian-conference-of-the-arts-to-close-doors-after-67years/

Thornton, S. (2012). Seven days in the art world. Granta Books.

Throsby, D. (1999). Cultural Capital. Journal of Cultural Economics, 23(1-2), 3-12. https://doi.org/10.1023/A:1007543313370

Timofeeva, E. (2008). Socially Shaping Discourse: Making CDA Work for Cultural Policy. The International Journal of Diversity in Organizations, Communities, and Nations: Annual Review, 8(3), 241-248. https://doi.org/10.18848/1447-9532/CGP/v08i03/39609

Toronto Alliance for the Performing Arts. (2019). Regional and cultural equity issues vis-à-vis the Canada Council for the Arts. Toronto Alliance for the Performing Arts.

Tummons, J. (2017). Institutional Ethnography, Theory, Methodology, and Research: Some Concerns and Some Comments. In J. Reid \& L. Russell (Eds.), Studies in Qualitative Methodology (Vol. 15, pp. 147-162). Emerald Publishing Limited. http://www.emeraldinsight.com/doi/10.1108/S1042-319220170000015003

Upchurch, A. R. (2016). The Origins of the Arts Council Movement: Philanthropy and Policy. Palgrave Macmillan UK. 
Van den Bulck, H., Puppis, M., Donders, K., \& Van Audenhove, L. (Eds.). (2019). The Palgrave Handbook of Methods for Media Policy Research. Palgrave Macmillan. https://doi.org/10.1007/978-3-030-16065-4

Vestheim, G. (1994). Instrumental Cultural Policy in Scandinavian Countries: A Critical Historical Perspective. The European Journal of Cultural Policy, 1(1), 57-71. https://doi.org/10.1080/10286639409357969

Volkerling, M. (1996). Deconstructing the difference-engine: A theory of cultural policy. International Journal of Cultural Policy, 2(2), 189-212.

Wagman, I. (2007). From spiritual matters to economic facts: Recounting problems of knowledge in the history of Canadian audiovisual policy, 1928-61. [Doctoral dissertation, McGill University]. Library and Archives Canada - Bibliothèque et Archives Canada.

Wagman, I. (2016). Bureaucratic Celebrity. In L. York \& K. Lee (Eds.), Celebrity Cultures in Canada (pp. 201-218). Wilfrid Laurier University Press.

Wagman, I. (2010). On the Policy Reflex in Canadian Communication Studies. Canadian Journal of Communication, 35(4). https://cjconline.ca/index.php/journal/article/view/2422/2208

Walby, K. (2007). On the Social Relations of Research: A Critical Assessment of Institutional Ethnography. Qualitative Inquiry, 13(7), 1008-1030. https://doi.org/10.1177/1077800407305809

Walby, K. (2013). Institutional ethnography and data analysis: Making sense of data dialogues. International Journal of Social Research Methodology, 16(2), 141-154. https://doi.org/10.1080/13645579.2012.661207 
Walmsley, B. (2018). Deep hanging out in the arts: An anthropological approach to capturing cultural value. International Journal of Cultural Policy, 24(2), 272-291. https://doi.org/10.1080/10286632.2016.1153081

Warren, L. D. (2001). Organizing creation: The role of musical text. Studies in Cultures, Organizations and Societies, 7(2), 327-353. https://doi.org/10.1080/10245280108523563

Woddis, J. (2014). Arts practitioners in the cultural policy process: Spear-carriers or speaking parts? International Journal of Cultural Policy, 20(4), 496-512. https://doi.org/10.1080/10286632.2013.818672

Wolff, J. (1993). The social production of art (2nd ed). New York University Press. Young, L., \& Everitt, J. M. (2005). Talking to governments. In Advocacy Groups (1st edition). UBC Press. 